\title{
Case Studies of Riparian and Watershed Restoration in the Southwestern United States-Principles, Challenges, and Successes
}

By Barbara E. Ralston, and Daniel A. Sarr, editors

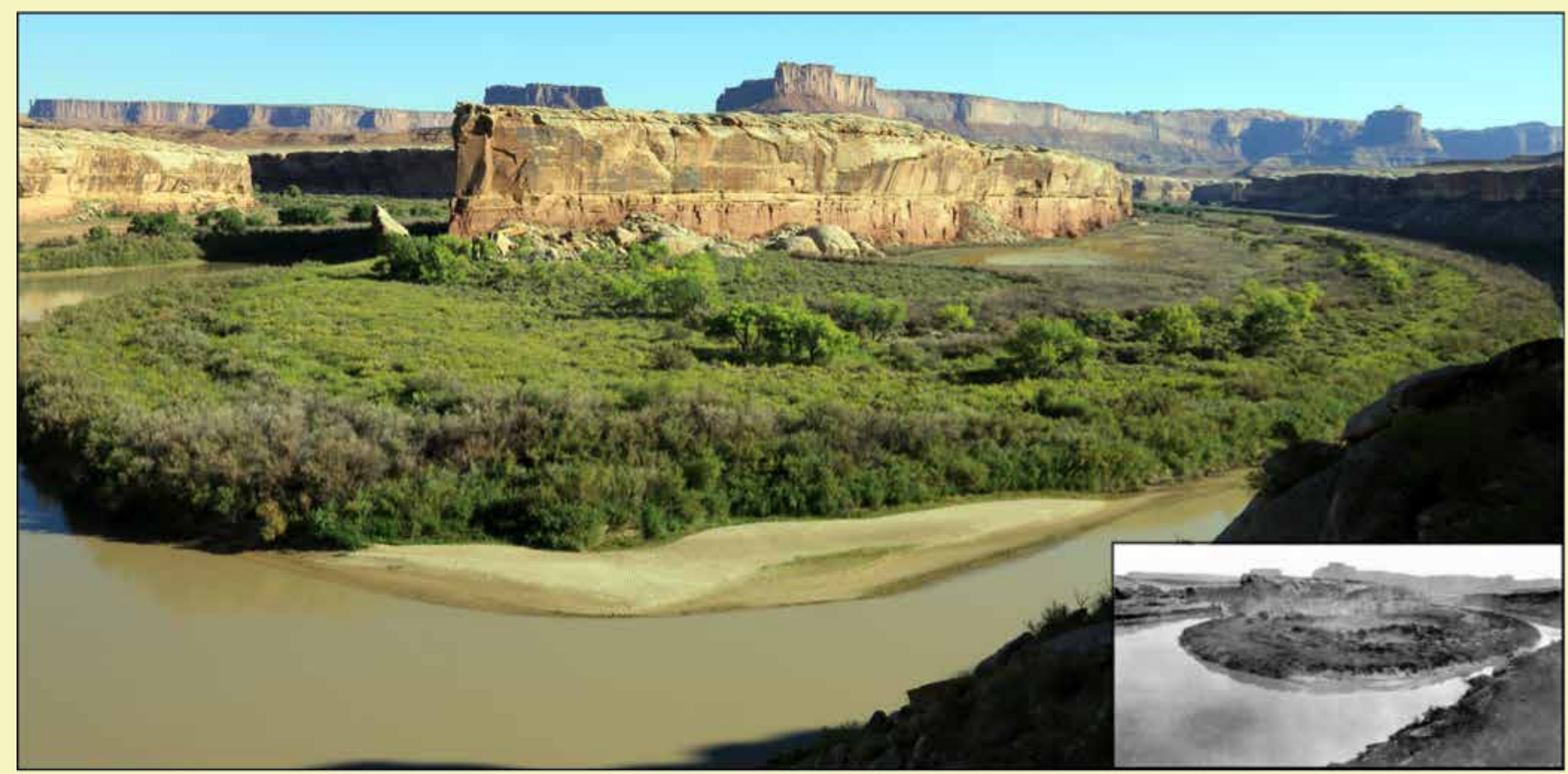

Open-File Report 2017-1091 
Cover: Repeat photographs of Bonita Bend in Stillwater Canyon of the Green River in Utah. The inset photograph was taken in 1871 by E.O. Beaman (USGS) and the larger photograph was taken by Robert Webb (USGS) in 2012. The channel has narrowed over time. Riparian vegetation includes a mixture of saltcedar (Tamarix sp.) in the foreground and cottonwoods (Populus sp.) farther inland. 


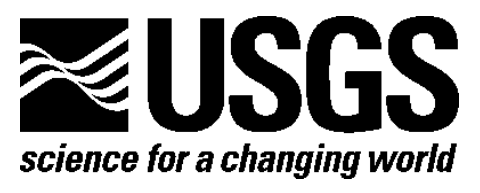

\section{Case Studies of Riparian and Watershed Restoration in the Southwestern United States-Principles, Challenges, and Successes}

By Barbara E. Ralston, and Daniel A. Sarr, editors

Open-File Report 2017-1091

U.S. Department of the Interior

U.S. Geological Survey 


\section{U.S. Department of the Interior \\ RYAN K. ZINKE, Secretary}

\section{U.S. Geological Survey \\ William H. Werkheiser, Acting Director}

U.S. Geological Survey, Reston, Virginia: 2017

For more information on the USGS—-the Federal source for science about the Earth, its natural and living resources, natural hazards, and the environment-visit https://www.usgs.gov or call 1-888-ASK-USGS (1-888-275-8747)

For an overview of USGS information products, including maps, imagery, and publications, visit https://store.usgs.gov.

Any use of trade, firm, or product names is for descriptive purposes only and does not imply endorsement by the U.S. Government.

Although this information product, for the most part, is in the public domain, it also may contain copyrighted materials as noted in the text. Permission to reproduce copyrighted items must be secured from the copyright owner. The contributions by non-U.S. Geological Survey (USGS) authors in this volume are published as they were submitted. Contributions authored entirely by non-USGS authors do not represent the views or position of the USGS or the U.S. Government and are published solely as part of this volume.

Suggested citation:

Ralston, B.E., and Sarr, D.A., 2017, Case studies of riparian and watershed restoration in the southwestern United States-Principles, challenges, and successes: U.S. Geological Survey Open-File Report 2017-1091, 116 p., https://doi.org/10.3133/20171091.

ISSN 2331-1258 (online) 


\section{Acknowledgments}

Funds from the WaterSMART program within the Ecosystems Mission Area of the U.S. Geological Survey supported both the workshop and the publication of this report. 


\section{Contents}

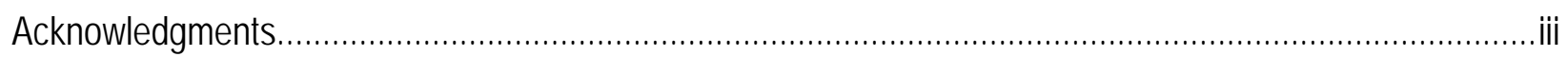

Introduction

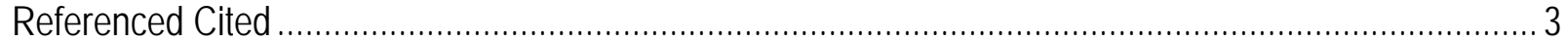

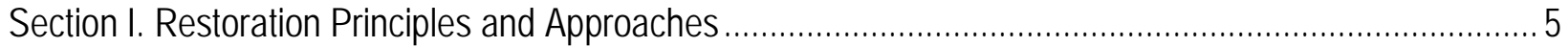

Restoration Principles for Riparian Ecosystem Resilience ............................................................. 5

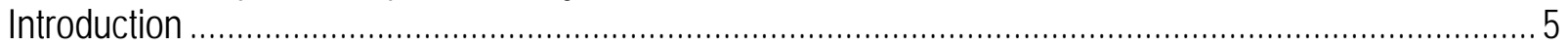

Landscape and Watershed Context............................................................................................

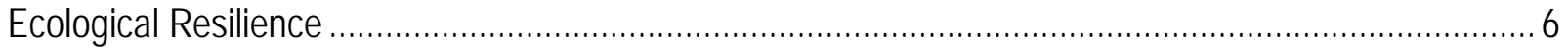

Restoration Principles - Protect, Reconnect, Restore (processes first) ............................................... 6

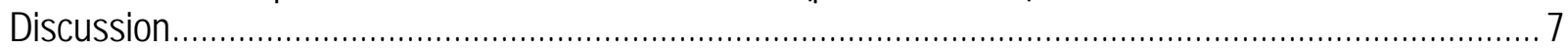

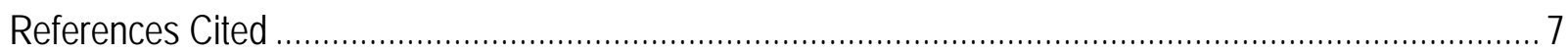

Section II. Local Scale Revegetation Projects .......................................................................... 10

Use of the Biophysical Template for Riparian Restoration and Revegetation in the Southwest .................. 10

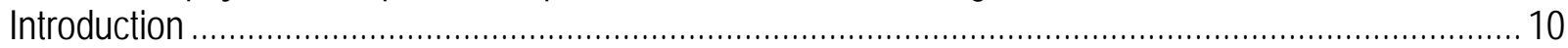

Landscape and Watershed Context........................................................................................... 10

Understanding the Biophysical Site Template........................................................................... 11

Using the Biophysical Site Template: Site Design and Implementation .............................................. 12

Dealing with Changing and Challenging Conditions: Adaptive Management and Monitoring .................. 12

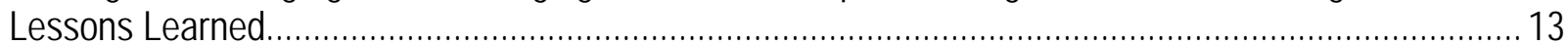

References Cited ................................................................................................................. 13

Riparian Restoration in the Context of 21st Century Hydrology ........................................................ 18

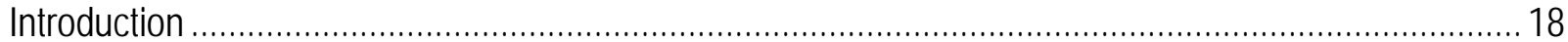

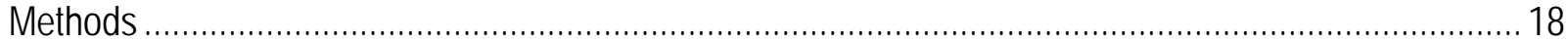

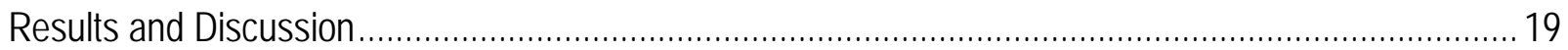

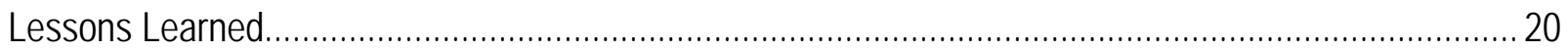

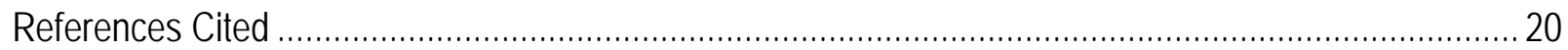

The Reality of Climate Change and the Need for Genetics Approaches in Riparian, River and Watershed

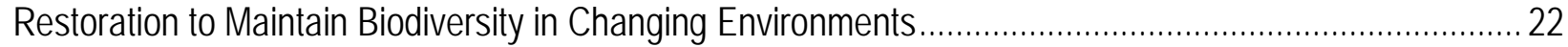

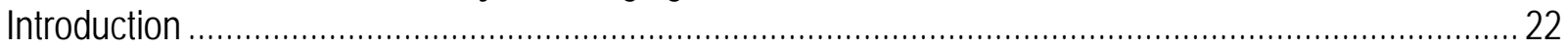

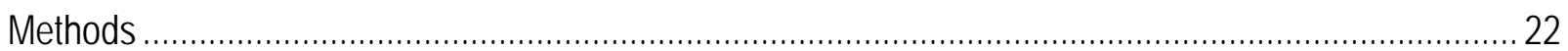

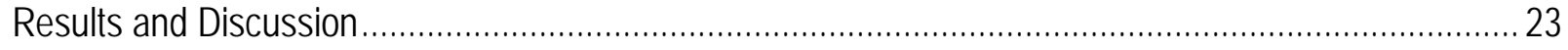

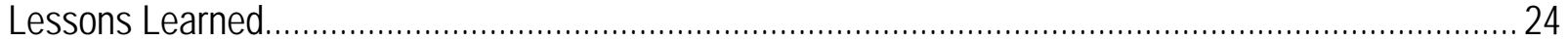

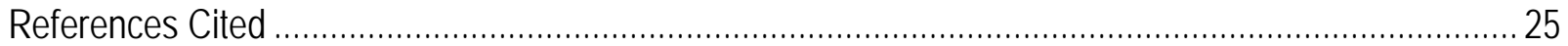

Riparian Rehabilitation along the Colorado River: Successes and Challenges of a Pilot Project ............... 28

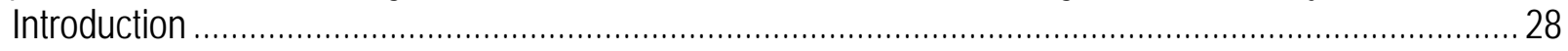

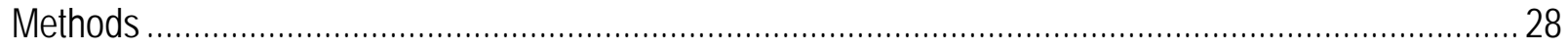

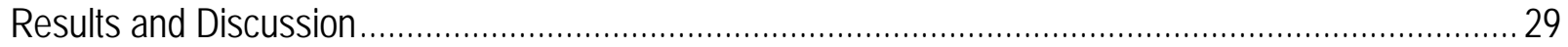

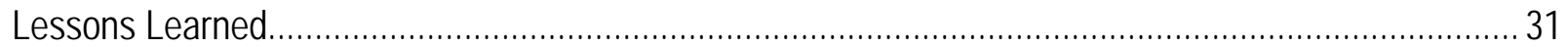

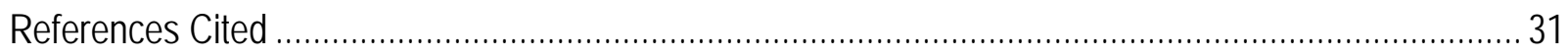

Riparian restoration following tamarisk and Russian olive control in Canyon de Chelly National Monument,

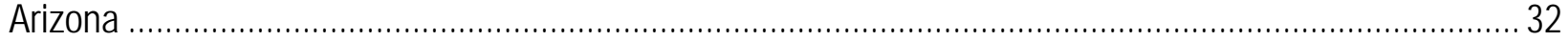

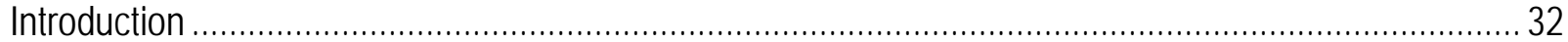

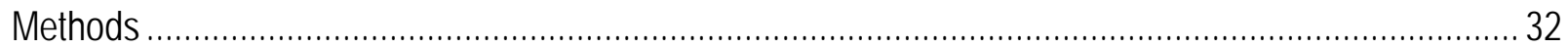




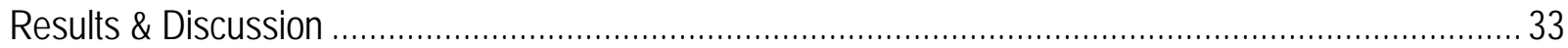

Lessons Learned.

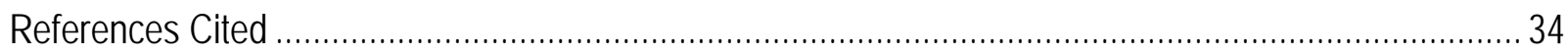

Riparian and Wetland Restoration Effects on Bird and Butterfly Communities on the Colorado River .........37

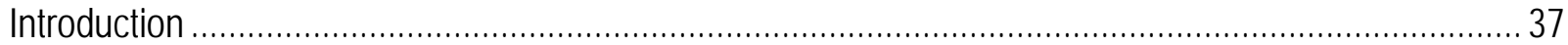

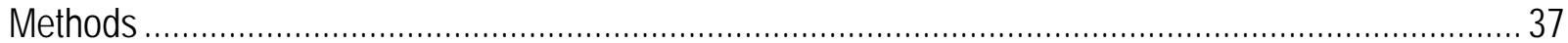

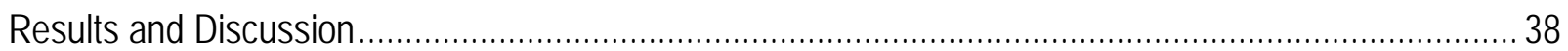

Lessons Learned- Implications for Riparian Restoration .................................................................. 39

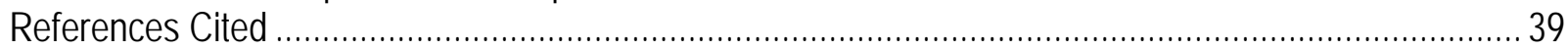

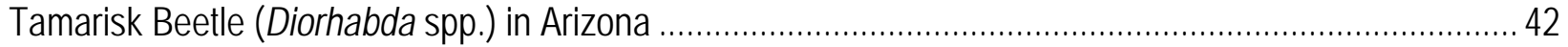

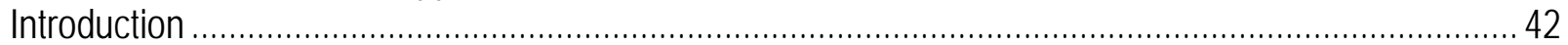

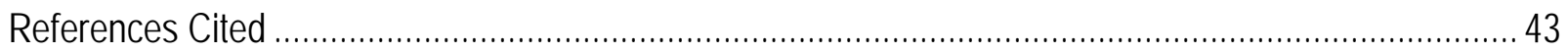

Colorado River Riparian Ecosystem Rehabilitation in Glen Canyon National Recreation Area, Arizona ..... 46

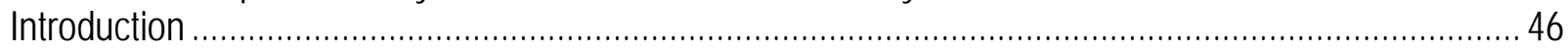

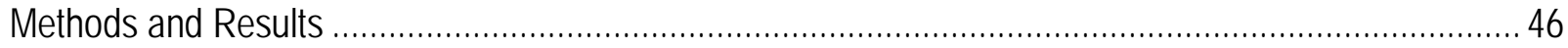

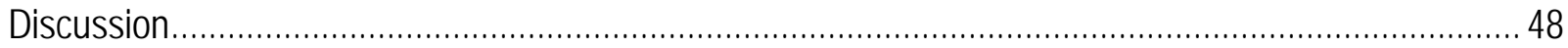

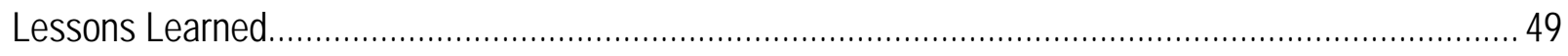

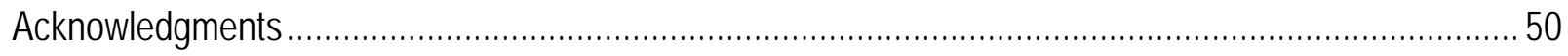

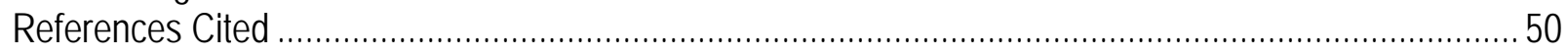

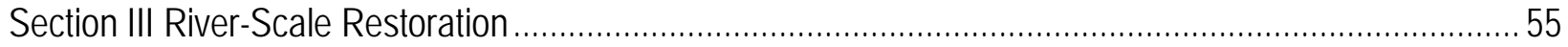

Channel Form and Riparian Vegetation: Relevant Temporal and Spatial Scales ..................................... 55

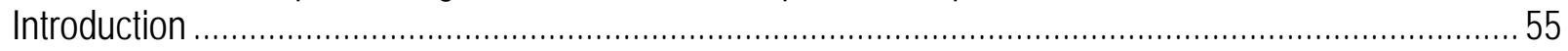

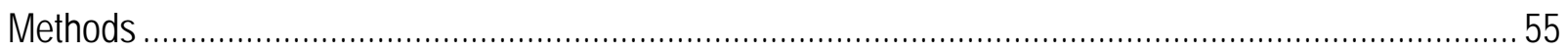

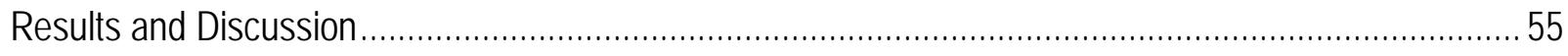

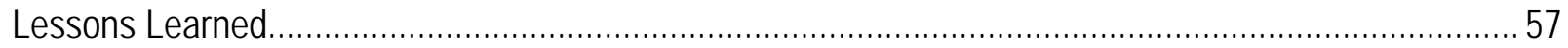

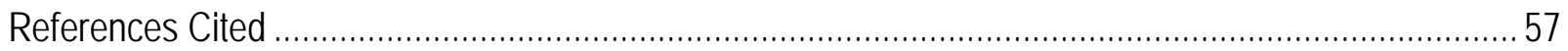

Parsing Out the Effects of Non-native Vegetation Management on Channel Form and Riparian and Aquatic

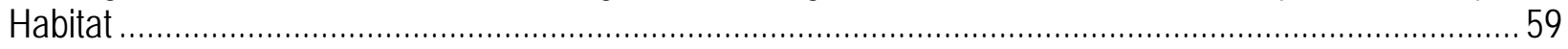

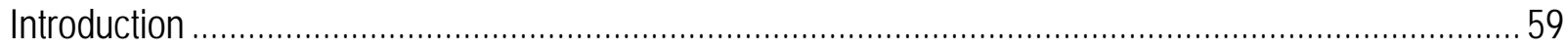

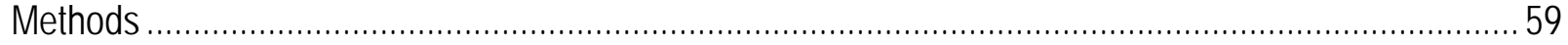

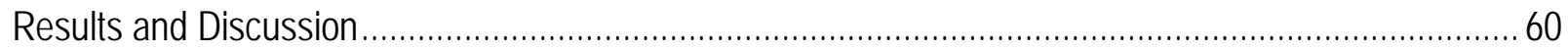

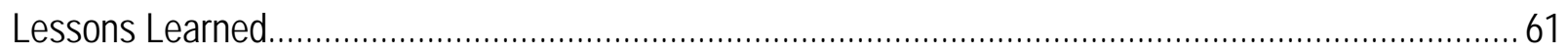

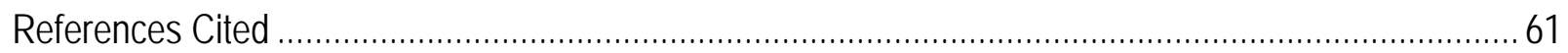

Riparian Conservation and Restoration Planning on the Colorado River in Utah ....................................64

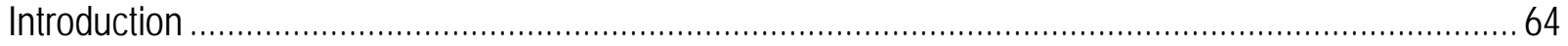

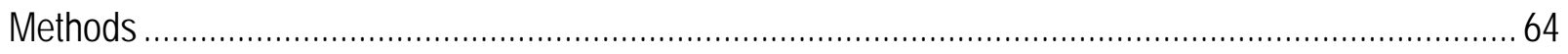

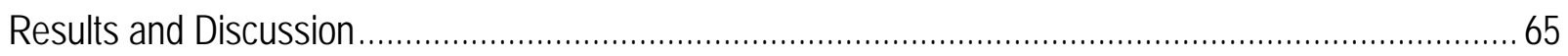

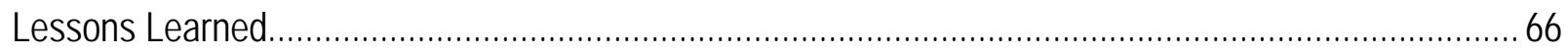

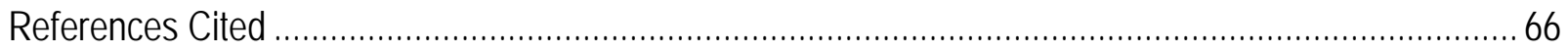

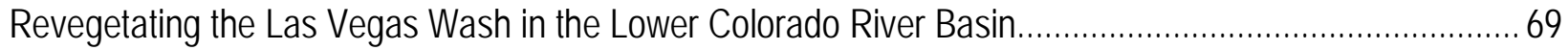

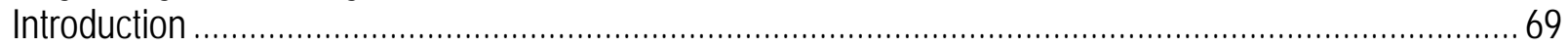

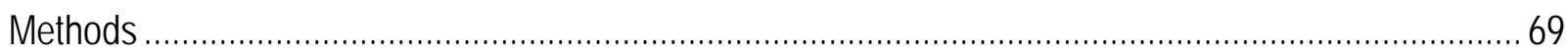

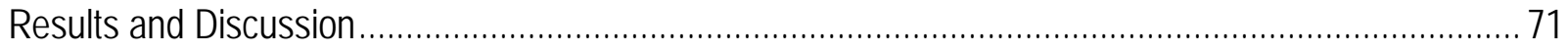




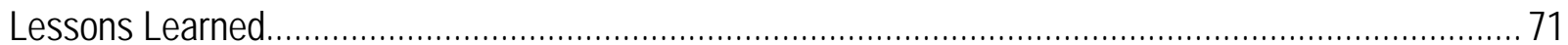

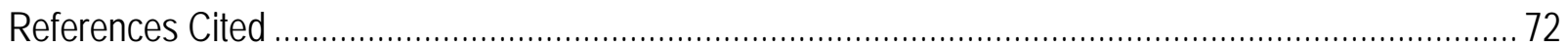

Riparian Restoration in the Colorado River Basin........................................................................... 73

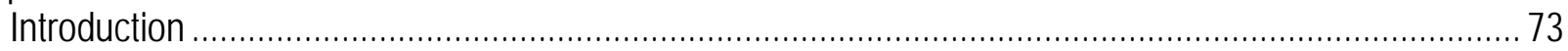

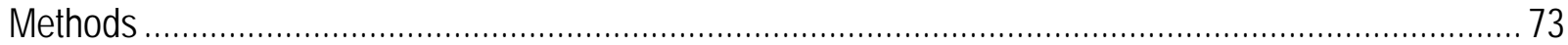

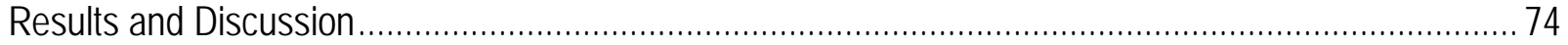

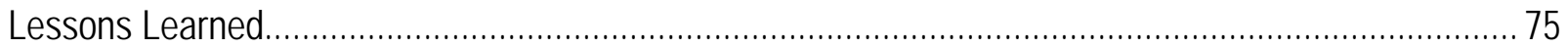

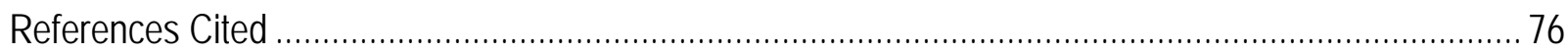

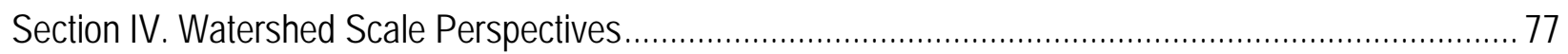

Multi-scale Riparian Restoration Planning and Implementation on the Virgin and Gila Rivers ....................77

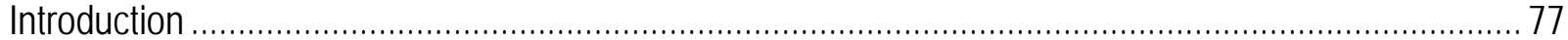

Southwestern Willow Flycatcher, Tamarisk, \& Tamarisk Beetle Background........................................ 78

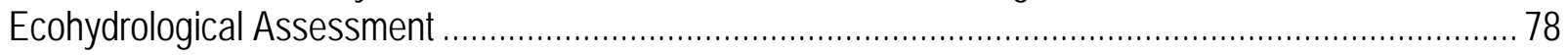

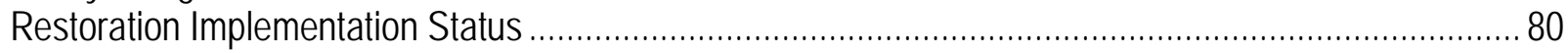

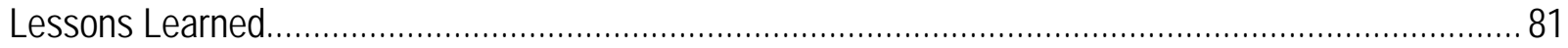

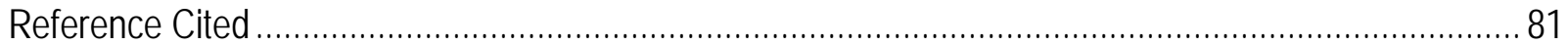

Linking Forest Landscape Management and Climate Change to the Conservation of Riparian Habitat in the

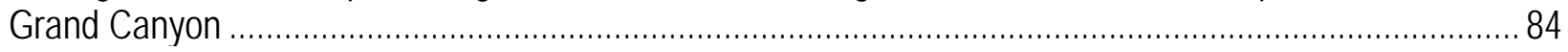

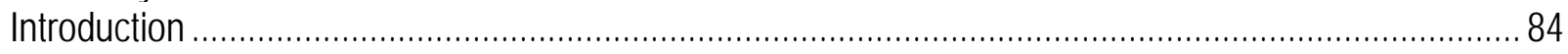

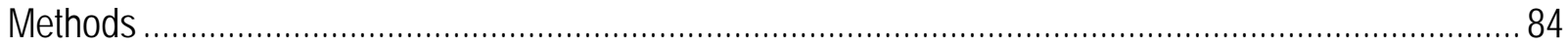

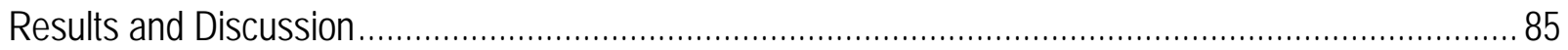

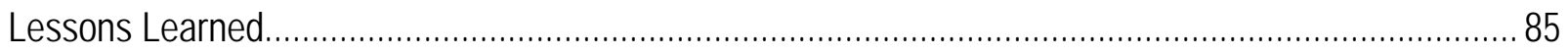

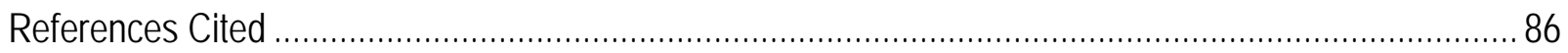

Conducting Monitoring for a Public-Private Collaborative: Lessons from the Dolores River Restoration

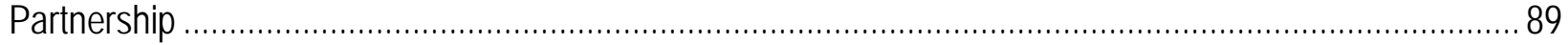

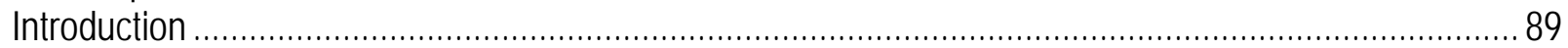

Methods - Building on Collaborative Lessons............................................................................ 90

Results and Discussion - Building on Collaborative Lessons .......................................................... 90

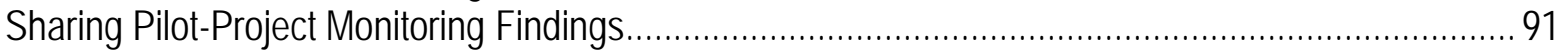

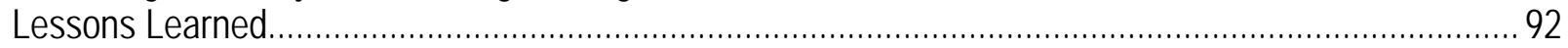

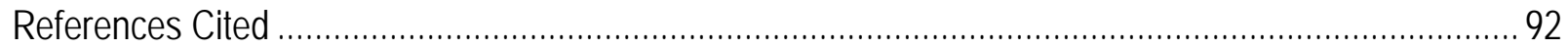

Developing a Monitoring Plan for the Verde River Cooperative Invasive Plant Management Plan.............. 94

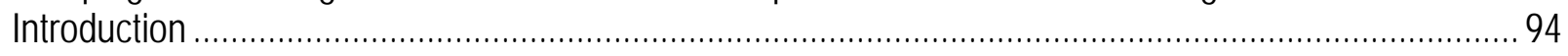

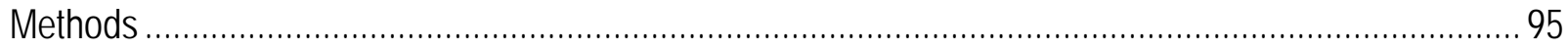

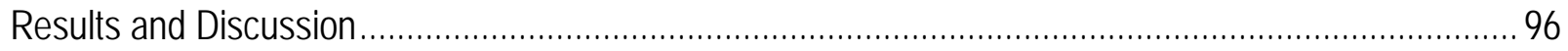

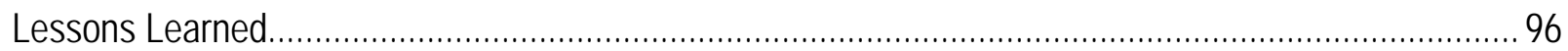

Section V. Monitoring following revegetation ............................................................................... 97

Monitoring Wetland Restoration Projects in Arizona within the Arizona Game and Fish Department's In-Lieu

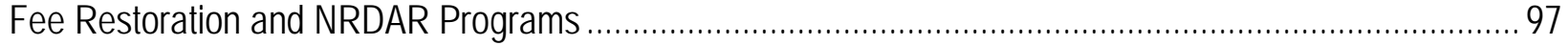

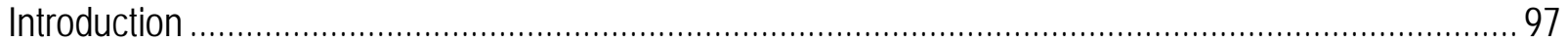

Citizen Science along the Middle Rio Grande - Collecting Data on Ecosystem Change.......................... 100

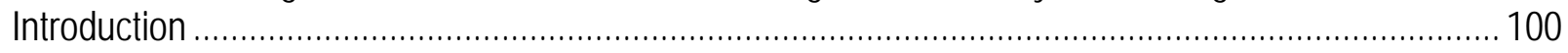

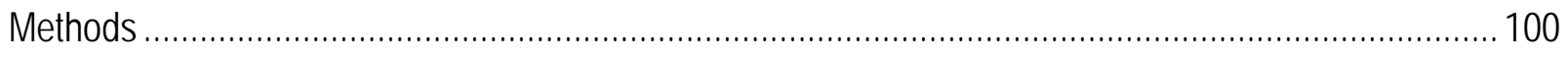

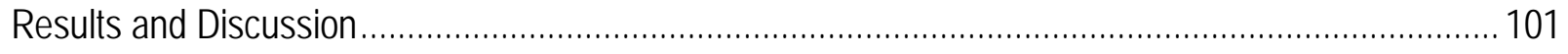

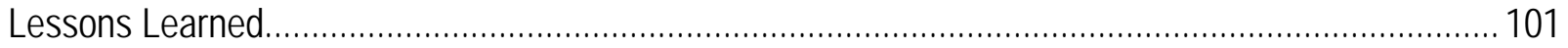




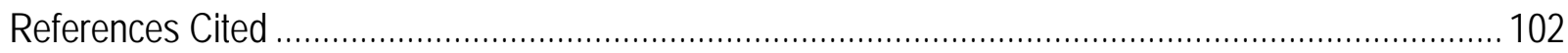

Lessons Learned from Revegetation of Aggregate-Mined Areas Along a Large Western River................ 106

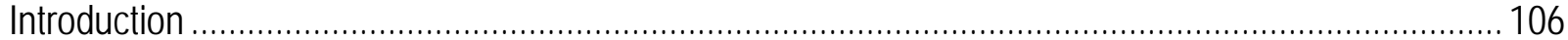

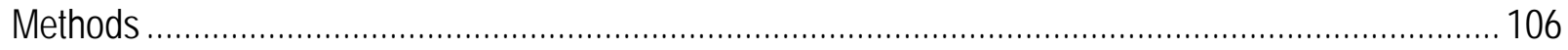

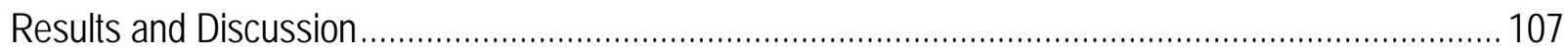

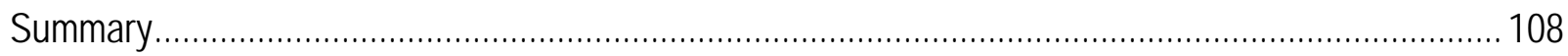

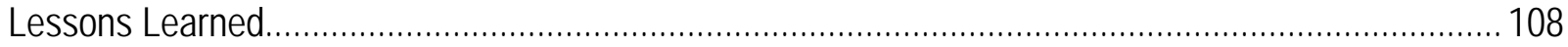

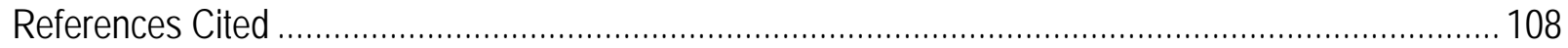

Section VI. Results of breakout group discussion and research needs ranking by workshop participants 112 


\section{Conversion Factors}

Inch/Pound to International System of Units

\begin{tabular}{|c|c|c|}
\hline Multiply & By & To obtain \\
\hline \multicolumn{3}{|c|}{ Length } \\
\hline inch (in.) & 2.54 & centimeter $(\mathrm{cm})$ \\
\hline inch (in.) & 25.4 & millimeter (mm) \\
\hline foot $(\mathrm{ft})$ & 0.3048 & meter (m) \\
\hline mile (mi) & 1.609 & kilometer (km) \\
\hline \multicolumn{3}{|c|}{ Area } \\
\hline acre & 4,047 & square meter $\left(\mathrm{m}^{2}\right)$ \\
\hline acre & 0.4047 & hectare (ha) \\
\hline acre & 0.004047 & square kilometer $\left(\mathrm{km}^{2}\right)$ \\
\hline square foot $\left(\mathrm{ft}^{2}\right)$ & 0.09290 & square meter $\left(\mathrm{m}^{2}\right)$ \\
\hline square inch $\left(\right.$ in $\left.^{2}\right)$ & 6.452 & square centimeter $\left(\mathrm{cm}^{2}\right)$ \\
\hline square mile $\left(\mathrm{mi}^{2}\right)$ & 259.0 & hectare (ha) \\
\hline square mile $\left(\mathrm{mi}^{2}\right)$ & 2.590 & square kilometer $\left(\mathrm{km}^{2}\right)$ \\
\hline \multicolumn{3}{|c|}{ Volume } \\
\hline gallon (gal) & 3.785 & liter (L) \\
\hline cubic inch $\left(\mathrm{in}^{3}\right)$ & 0.01639 & liter (L) \\
\hline cubic foot $\left(\mathrm{ft}^{3}\right)$ & 0.02832 & cubic meter $\left(\mathrm{m}^{3}\right)$ \\
\hline acre-foot (acre-ft) & 1,233 & cubic meter $\left(\mathrm{m}^{3}\right)$ \\
\hline \multicolumn{3}{|c|}{ Flow rate } \\
\hline cubic foot per second $\left(\mathrm{ft}^{3} / \mathrm{s}\right)$ & 0.02832 & cubic meter per second $\left(\mathrm{m}^{3} / \mathrm{s}\right)$ \\
\hline
\end{tabular}

Temperature in degrees Celsius $\left({ }^{\circ} \mathrm{C}\right)$ may be converted to degrees Fahrenheit $\left({ }^{\circ} \mathrm{F}\right)$ as ${ }^{\circ} \mathrm{F}=\left(1.8 \times{ }^{\circ} \mathrm{C}\right)+32$. Temperature in degrees Fahrenheit $\left({ }^{\circ} \mathrm{F}\right)$ may be converted to degrees Celsius $\left({ }^{\circ} \mathrm{C}\right)$ as ${ }^{\circ} \mathrm{C}=\left({ }^{\circ} \mathrm{F}-32\right) / 1.8$. 


\section{Datum}

Vertical coordinate information is referenced to the [insert datum name (and abbreviation) here, for example, North American Vertical Datum of 1988 (NAVD 88)].

Horizontal coordinate information is referenced to the [insert datum name (and abbreviation) here for example, North American Datum of 1983 (NAD 83)].

Altitude, as used in this report, refers to distance above the vertical datum.

Note to USGS users: Use of hectare (ha) as an alternative name for square hectometer ( $\mathrm{hm}$ 2) is restricted to the measurement of small land or water areas. Use of liter $(\mathrm{L})$ as a special name for cubic decimeter $\left(\mathrm{dm}^{3}\right)$ is restricted to the measurement of liquids and gases. No prefix other than milli should be used with liter. Metric ton (t) as a name for megagram (Mg) should be restricted to commercial usage, and no prefixes should be used with it.

\section{Abbreviations}

$\begin{array}{ll}\text { DOD } & \text { U.S. Department of Defense } \\ \text { EPA } & \text { U.S. Environmental Protection Agency } \\ \text { ppm } & \text { parts per million } \\ \text { USGS } & \text { U.S. Geological Survey } \\ \text { BOR } & \text { Bureau of Reclamation } \\ \text { BLM } & \text { Bureau of Land Management } \\ \text { USFS } & \text { U.S. Forest Service } \\ \text { USFWS } & \text { U.S. Fish and Wildlife Service }\end{array}$




\title{
Case Studies of Riparian and Watershed Restoration in the Southwestern United States-Principles, Challenges, and Successes
}

\author{
By Barbara E. Ralston ${ }^{1}$, and Daniel A. Sarr ${ }^{1}$, editors
}

\section{Introduction}

Globally, rivers and streams are highly altered by impoundments, diversions, and stream channelization associated with agricultural and water delivery needs (Nilsson and others, 2005). Climate change imposes additional challenges by further reducing discharge, introducing variability in seasonal precipitation patterns, and increasing temperatures (Palmer and others, 2008; Seager and others, 2012). Collectively, these changes in a river or stream's annual hydrology affects surface and groundwater dynamics, fluvial processes, and the linked aquatic and riparian responses, particularly in arid regions (Palmer and others, 1997; Webb and Leake, 2006; Osterkamp and Hupp, 2010; Perry and others, 2012). Recognizing the inherent ecosystem services that riparian and aquatic habitats provide, society increasingly supports restoring the functionality of riparian and aquatic ecosystems (National Research Council, 1992).

Given the wide range in types and scales of riparian impacts, approaches to riparian restoration can range from tactical, short-term, and site-specific efforts to strategic projects and long-term collaborations best pursued at the watershed scale. A 1997 special supplement in Restoration Ecology highlighted riparian restoration within the watersheds of the western United States and emphasized the watershed or basin scale and multi-disciplinary approaches to restore ecosystem function (Kentula, 1997). The review recognized the complexity of riparian ecosystems and suggested that future research required the incorporation of multi-scale and multi-temporal research to advance the field of restoration science (Landers, 1997). Most recently, a global review of the scientific literature regarding riparian restoration projects identified spatio-temporal limitations in implementation and evaluations (Gonzalez and others, 2015): assessments typically occurred at the local scale and often ignored the multi-scale and multi-dimensional aspects of rivers. Additionally, they found a systematic publication bias; published papers describing failures in restoration occurred less frequently than successes, even though failures can be as equally informative in the field of restoration science.

In the spirit of sharing information, the U.S. Geological Survey’s Grand Canyon Monitoring and Research Center convened a workshop June 23-25, 2015, in Flagstaff, Ariz. for practitioners in restoration science to share general principles, successful restoration practices, and discuss the challenges that face those practicing riparian restoration in the southwestern United States. Presenters from the Colorado River and the Rio Grande basins, offered their perspectives and experiences in

\footnotetext{
${ }^{1}$ U.S. Geological Survey
} 
restoration at the local, reach and watershed scale. Outcomes of the workshop include this Proceedings volume, which is composed of extended abstracts of most of the presentations given at the workshop, and recommendations or information needs identified by participants. The organization of the Proceedings follows a general progression from local scale restoration to river and watershed scale approaches, and finishes with restoration assessments and monitoring.

A presentation was given at the beginning of each session that outlined general principles and challenges involved with each scale of restoration. First among these presentations, Rasmussen and Orr (Section I) outlined general principles for redefining resilience in southwest river systems, which are increasingly challenged by diminishing annual discharge, variability in seasonal precipitation, and changing fluvial dynamics. Section II focused on site-specific revegetation and restoration principles and experiences, with an overview of approaches and considerations provided by Orr and others. Grabau and others provided perspective about how to determine what restoration is possible in the face of a highly altered and largely dewatered channel as is found along the lower Colorado River. With regard to climate change and in evolutionary terms, Whitham provided principles for incorporating plant genetics and common garden experiments to identify plant material suitable for successful restoration in the face of a warmer and drier climate. The Las Vegas Wash study (though in a later section, has applications at the local scale) used multiple data sources to identify plant species tolerances and the planting locations on the restoration site where plants would be most likely to succeed (for example, salinity tolerance and water availability) for a constructed restoration project.

Schmidt (Section III), addressed river scale restoration, and emphasized the need for interdisciplinary approaches and time-series analysis to understand the historical, current, and potentially future hydrologic and geomorphic context for local and river wide restoration approaches. The Rio Grande project (Dean and others, Section III) and the Canyon de Chelly project (Reynolds and Cooper, Section II) incorporated time-series research of geomorphic change to understand and develop the most successful approach to exotic species removal and native plant revegetation. Skidmore (Section III) introduced the idea of a spectrum of restoration approaches, which consider the level of resilience of a river, or the river segment, to determine if passive or more active approaches are necessary to meet restoration goals.

Orr and others (Section IV) discussed general ecological and geomorphic principles for watershed restoration in the Southwest. In several of the abstracts that precede and follow this contribution, the emergent importance of multi-partner communication and collaborative structures for sharing information among restoration practitioners is discussed. The Dolores River restoration partnership discussed by Oppenheimer and others (Section IV) highlights these approaches. Specific case studies applied these general principles to varying degrees. The Gila, Dolores and Colorado River restoration efforts utilize multiple, linked local site restoration efforts for ongoing river-scale restoration (Orr and others, Oppenheimer and others, and Rasmussen and others). At the constructed riparian sites, the extreme end of the spectrum as identified by Skidmore, it is important to recognize that constructed wetlands and riparian areas that are irrigated are of value, but require greater investment and long-term maintenance (Grabau and others, Section II). Lastly, the topic of measuring success through monitoring (Section V), including citizen science efforts, completed the presentations that were applicable to all restoration efforts (Ingraldi and others, Schuetz and others; Pabst and others). Summary tables from breakout groups intended to identify key points associated with successes, challenges and collaborative opportunities and research needs follow the extended abstracts (table 1). A list of ranked prioritized research needs developed from scores (1-5, lowest to highest need) assigned by individual workshop participants and averaged for each research category is summarized in table 2. 
Although they describe an impressive array of activities across the region, these abstracts represent a small amount of restoration work taking place in the Southwest. Hopefully, by including them in an online volume, others can benefit from the lessons learned and shared, and identify contacts that may be able to help answer questions, which may arise as restoration projects are developed. A list of meeting participants is included (table 3).

\section{Referenced Cited}

Gonzalez, E., Sher, A.A., Tabacchi, E., Masip, A., and Poulin, M., 2015, Restoration of riparian vegetation-A global review of implementation and evaluation approaches in the international, peerreviewed literature: Journal of Environmental Management, v. 158, p. 85-94, doi: 10.1016/j.jenvman.2015.04.033.

Goodwin, C.N., Hawkins, C.P., and Kershner, J.L., 1997, Riparian restoration in the western United States-Overview and perspective: Restoration Ecology, v. 5, no. 4S, p. 4-14, accessed on April 28, 2017, at http://dx.doi.org/10.1111/j.1526-100X.1997.00004.x.

Kentula, M.E., 1997, A step toward a landscape approach in riparian restoration: Restoration Ecology, v. 5, no. 4S, p. 2-3, accessed on April 28, 2017, at http://dx.doi.org/10.1111/j.1526100X.1997.00002.X.

Landers, D.H., 1997, Riparian restoration-Current status and the reach to the future: Restoration Ecology, v. 5, no. 4S, p. 113-121, accessed on April 28, 2017, at http://dx.doi.org/10.1111/j.1526100X.1997.00113.x.

National Research Council, 1992, Restoration of aquatic ecosystems-Science, technology, and public policy: Washington, DC, The National Academies Press, 576 p., accessed on April 28, 2017, at http://www.nap.edu/catalog/1807/restoration-of-aquatic-ecosystems-science-technology-and-publicpolicy.

Nilsson, C., Reidy, C.A., Dynesius, M., and Revenga, C., 2005, Fragmentation and flow regulation of the world's large river systems: Science, v. 308, no. 5720, p. 405-408, accessed on April 28, 2017, at http://www.sciencemag.org/content/308/5720/405.short.

Osterkamp, W.R., and Hupp, C.R., 2010, Fluvial processes and vegetation-Glimpses of the past, the present, and perhaps the future: Geomorphology, v. 116, no. 3-4, p. 274-285, accessed on April 28, 2017, at http://dx.doi.org/10.1016/j.geomorph.2009.11.018.

Palmer, M.A., Hakenkamp, C.C., and Nelson-Baker, K., 1997, Ecological heterogeneity in streamsWhy variance matters: Journal of the North American Benthological Society, v. 16, no. 1, p. 189-202, accessed on April 28, 2017, at http://www.jstor.org/stable/1468251.

Palmer, M.A., Liermann, C.A.R., Nilsson, C., Flörke, M., Alcamo, J., Lake, P.S., and Bond, N., 2008, Climate change and the world's river basins-Anticipating management options: Frontiers in Ecology and the Environment, v. 6, no. 2, p. 81-89, accessed on April 28, 2017, at http://www.esajournals.org/doi/full/10.1890/060148.

Perry, L.G., Andersen, D.C., Reynolds, L.V., Nelson, S.M., and Shafroth, P.B., 2012, Vulnerability of riparian ecosystems to elevated $\mathrm{CO}_{2}$ and climate change in arid and semiarid western North America: Global Change Biology, v. 18, no. 3, dop. 821-842, accessed on April 28, 2017, at http://dx.doi.org/10.1111/j.1365-2486.2011.02588.x.

Seager, R., Ting, M., Li, C., Naik, N., Cook, B., Nakamura, J., and Liu, H., 2012, Projections of declining surface-water availability for the southwestern United States: Nature Climate Change v. 3, p. 482-486, accessed on April 28, 2017, at http://dx.doi.org/10.1038/nclimate1787. 
Webb, R.H., and Leake, S.A., 2006, Ground-water surface-water interactions and long-term change in riverine riparian vegetation in the southwestern United States: Journal of Hydrology, v. 320, no. 3-4, p. 301-323, accessed on April 28, 2017, at http://dx.doi.org/10.1016/j.jhydrol.2005.07.022. 


\title{
Section I. Restoration Principles and Approaches
}

\section{Restoration Principles for Riparian Ecosystem Resilience}

\author{
By Christine G. Rasmussen ${ }^{1}$, and Bruce K. Orr ${ }^{2}$
}

\section{Introduction}

Riverine ecosystems are naturally dynamic systems subject to high spatial and temporal variability. This creates a lot of uncertainty in determining when and how natural resource managers should intervene to restore or enhance riparian ecosystems to maintain or recover desired ecosystem benefits. These systems are generally predicted to become even more variable due to climate change coupled with other stressors related to human land and water management practices, or the introduction of biological control agents (such as the tamarisk leaf beetle, Diorhabda spp.) in the western United States. Within this context of uncertainty, we describe the importance of landscape and watershed context, ecological resilience, current restoration principles, and trends in restoration practices, and we suggest ways to incorporate resilience-building strategies into restoration planning.

\section{Landscape and Watershed Context}

River-riparian ecosystems are interactive and deeply linked products of their landscape context (fig. 1). At broad scales in the landscape, there are several key factors that affect the fluvial and geomorphic processes and attributes that shape the structure and composition of riparian zones in alluvial river systems. These factors include climate (precipitation and temperature patterns), parent material (lithology), topography (slope, aspect, upslope drainage patterns), and inputs rates of water, sediment, nutrients, energy, woody debris, and chemical constituents from the watershed into the river. At finer scales within the watershed, key fluvial and geomorphic processes and attributes then shape riverine and riparian habitats, which in turn affect the biotic responses of aquatic and terrestrial populations and communities (fig.1). Natural and anthropogenic disturbances (e.g., floods, fire, landslides, human land and water use, climate change) influence the system at all levels, from climate, watershed inputs, fluvial and geomorphic attributes and processes, to habitat (structure, complexity, connectivity), and biotic responses (Downs and others, 2011). Recognizing how broad-scale process differences interact with drivers and stressors (such as natural disturbance and human land use and flow regulation) is an important first step in assessing riparian condition and planning trajectories for functional recovery or enhancement of resilient riparian ecosystems (fig. 2).

\footnotetext{
${ }^{1}$ Eco Mainstream Contracting, Mancos, Colorado

${ }^{2}$ Stillwater Sciences, Berkeley, California
} 


\section{Ecological Resilience}

Ecosystem resilience can be defined as "the ability of ecological systems to persist despite changing conditions" and measured "by the amount of disturbance a system can absorb without shifting to an alternative state” (White and Stromberg, 2011), and as used here, applies to the general character of a riverine system, under both desirable and undesirable conditions. Concepts of resilience can be applied at all levels of ecosystem processes and functions, providing a unifying framework for developing more effective restoration strategies.

Ecosystem resilience can be visualized using the classic ball-and-cup model (fig. 2), with the cups showing attraction basins into which the ball (ecosystem) is drawn (Standish and others, 2014). Shallow attraction basins represent limited resilience where even small disturbances may shift the ecosystem beyond a threshold and into a new attraction basin and an alternative state. Helpful resilience keeps the system in a desired state (dark grey ball, fig. 2, example: an intact meadow); unhelpful resilience fights the recovery process and keeps the system in an undesirable state (grey ball, example: an over-widened meadow channel; and white ball, example: an incised channel or gully). The differentiation of helpful and unhelpful resilience can clarify applications of the concept for management interventions, and help identify what types of actions may be required to return to the predisturbance state (Standish and others, 2014). Ecosystems may transition into several states over time, some fully supporting desired species and functions, while in others many desirable species and functions may be lost. In the most extreme case, after abiotic conditions and processes are highly altered, essentially all original species and functions are lost.

\section{Restoration Principles - Protect, Reconnect, Restore (processes first)}

As a practical restoration approach, the concept of protect, reconnect, and then restore (beginning with processes first (Roni and others, 2008)) fits well with the resilience concept. Actions designed to protect intact ecosystems, processes, and features should be prioritized as they are typically the most cost-effective way to maintain desirable species and ecosystem services. Reconnection of flows of material through a watershed or ecosystem through such means as retro-fitting fish passage barriers or maintaining seed sources, as well as connecting functioning portions of river corridors as habitat nodes that can serve as refuges for aquatic and riparian species. Restoration, still focusing on processes first, is a bit more complex, and is often applied where we are compelled to implement projects or efforts. Processes are those things 'that happen' in ecosystems (for example, floods, drought, germination, erosion, deposition, vegetation destruction, etc.), which create, change and maintain ecosystem features, desirable and undesirable. Processes govern the slopes of the ball-and-cup model, with the time and/or intensity of the process determining the steepness and length of the slope. Essentially, the ball doesn't move without processes; the challenge is to enable natural processes, as much as possible, in order to create or maintain desired habitat features. Restoration of processes for sustainable effects (Beechie and others, 2010), requires addressing the root causes of degradation at the scale of the problem, matching the action with the potential of the site, plus articulating expected outcomes. Restoration of natural processes does not typically include site-based, feature-focused actions such as bank stabilization, vegetation removal, or channel reconfiguration, though these actions may be part of broader process restoration efforts and, in some cases, may be the only options available for enhancing ecosystem functions. In other cases, loss of function is so great that restoring or even maintaining past or current function is impossible, and the best set of actions will be those that assist transition to a new, more desirable state. 


\section{Discussion}

Trends in river restoration (Palmer and others, 2014) are bending toward a resilience-centered approach, preserving or enhancing the ability of an ecosystem to adjust to new conditions, while maintaining its general character and functions. Projects are increasingly ecologically focused rather than engineering focused, with project goals defining channel functions instead of channel form or morphology, leaving room for the river to respond to whatever changes come with altered climate. More and more, project managers are recognizing a range of possible outcomes for restoration efforts, similar to the multiple stable states of the resilience concept, rather than assuming a single reference condition that may no longer be attainable. Desired outcomes are increasingly described in terms of processes and improvement of limiting factors for many species rather than simply constructing specific habitat features for a single species. Broad-based changes in restoration practice include employing a structured, transparent way to identify and prioritize sites, adding ecological 'insurance' to projects (such as no-regrets strategies, increased diversity) in an effort to avoid big-money blow-outs, and directly incorporating social and political realities (Palmer and others, 2014).

Without question, we are in a period of great change in the natural resources upon which we depend. Human population growth and resource use, climate change (e.g., amount, type, and intensity of precipitation), and expansion of invasive species, all have potential to modify and degrade our natural ecosystems. As restoration practitioners, and as a society, we will benefit from increased adoption of more flexible, processed-based approaches, allowing ecosystems to adapt to what may come. Above all, we should strive to 'do no harm' with our efforts, focus more on what an ecosystem does rather than what it looks like, and implement monitoring to identify and implement additional actions as necessary to keep ecosystems on desired trajectories and prevent them from progressing toward undesired states.

\section{References Cited}

Beechie, T.J., Sear, D.A., Olden, J.D., Pess, G.R., Buffington, J.M., Moir, H., Roni, P., and Pollock, M.M., 2010, Process-based principles for restoring river ecosystems: BioScience, v. 60, no. 3, p. 209222, accessed April 28, 2017, at http://www.bioone.org/doi/abs/10.1525/bio.2010.60.3.7.

Downs, P.W., Singer, M.S., Orr, B.K., Diggory, Z.E., and Church, T.C., 2011, Restoring ecological integrity in highly regulated rivers-The role of baseline data and analytical references:

Environmental Management, v. 48, no. 4, p. 847-864, accessed April 28, 2017, at. https://link.springer.com/article/10.1007/s00267-011-9736-y.

Palmer, M.A., Hondula, K.L., and Koch, B.J., 2014, Ecological restoration of streams and riversShifting strategies and shifting goals: Annual Review of Ecology, Evolution, and Systematics, v. 45, no. 1, p. 247-269, accessed April 28, 2017, at http://dx.doi.org/10.1146/annurev-ecolsys-120213091935.

Roni, P., Hanson, K., and Beechie, T., 2008, Global review of the physical and biological effectiveness of stream habitat rehabilitation techniques: North American Journal of Fisheries Management, v. 28, no. 3, p. 856-890, accessed April 28, 2017, at http://dx.doi.org/10.1577/M06-169.1.

Standish, R.J., Hobbs, R.J., Mayfield, M.M., Bestelmeyer, B.T., Suding, K.N., Battaglia, L.L., Eviner, V., Hawkes, C.V., Temperton, V.M., Cramer, V.A., Harris, J.A., Funk, J.L., and Thomas, P.A., 2014, Resilience in ecology-Abstraction, distraction, or where the action is?: Biological Conservation, $\mathrm{v}$. 177, p. 43-51, accessed April 28, 2017, at http://www.sciencedirect.com/science/article/pii/S0006320714002353.

White, J.M., and Stromberg, J.C., 2011, Resilience, restoration, and riparian ecosystems_Case study of a dryland, urban river: Restoration Ecology, v. 19, no. 1, p. 101-111, accessed April 28, 2017, at 
http://onlinelibrary.wiley.com/doi/10.1111/j.1526-

100X.2009.00531.x/abstract;jsessionid=7BAA730965943B1C3FCA80299D6DDFAE.f04t01.

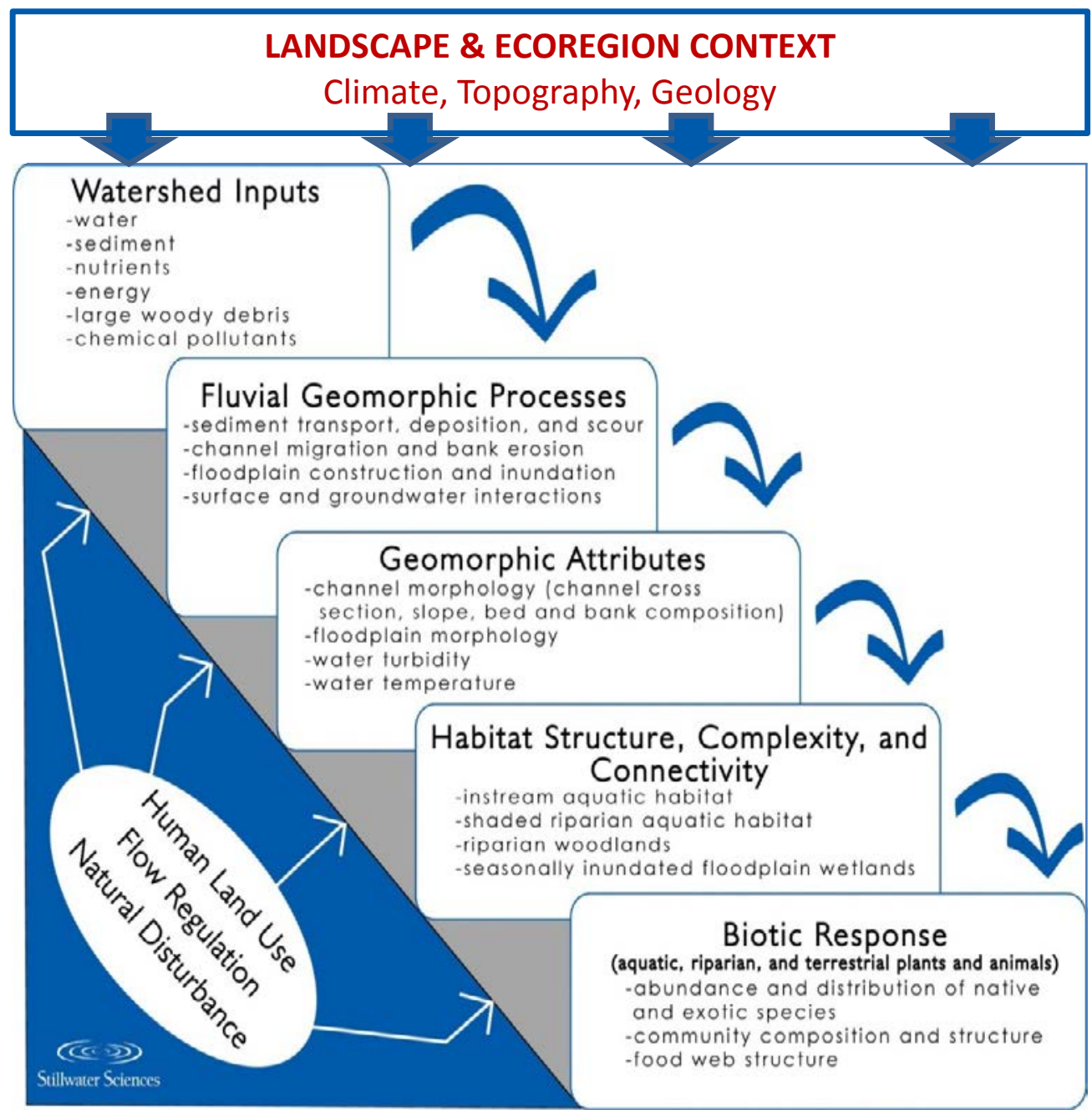

Figure 1. Ecosystem process linkages between climate and broad-scale context and biological features. Figure courtesy of Stillwater Sciences. 


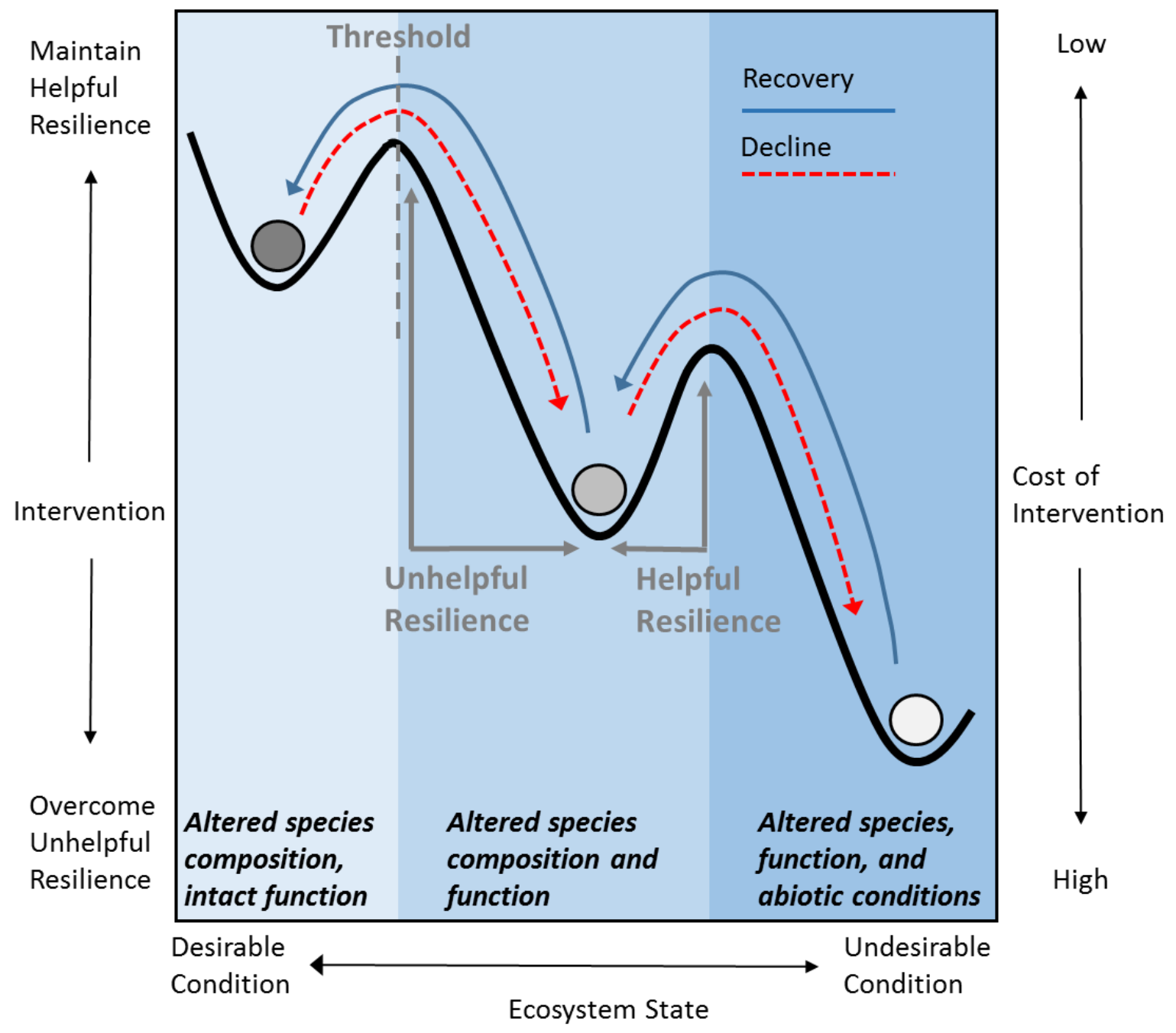

Figure 2. Ball-and-cup figure representing ecological resilience and changes in ecosystem characteristics Modified from Standish and others, 2014. 


\title{
Section II. Local Scale Revegetation Projects
}

\section{Use of the Biophysical Template for Riparian Restoration and Revegetation in the Southwest}

\author{
By Bruce K. Orr ${ }^{1}$, Amy G. Merrill ${ }^{1}$, Zooey E. Diggory ${ }^{1}$, and John C. Stella ${ }^{2}$
}

\section{Introduction}

The goals for riparian restoration projects vary and increasingly have many objectives including, creating or improving wildlife habitat, increasing native plant diversity, suppressing invasive non-native species, reducing flood risk, and mitigating for environmental impacts. Regardless of the specific goals, there are fundamental concepts and lessons that facilitate project success. Many of these concepts and lessons emphasize an awareness of riverine processes and disturbance regimes, as well as ecological interactions, while others are practical matters such as the importance of implementation monitoring and oversight. The typically limited funding available for restoration work, the effort that is invested in a project up until the point of implementation, and the uncertainties of weather patterns, land uses, and climate change all underscore the importance of applying planning and implementation concepts that contribute to sustainable and successful projects. We build upon experiences from California and elsewhere in the Southwestern United States (Southwest) to illustrate a scaled conceptual framework with lessons learned and proposed hypotheses for restoring riparian corridors in the Southwest. Working from coarser to finer scales within this framework, we use specific examples to illustrate approaches and to describe lessons learned from various case studies. Explicit integration of natural ecosystem processes operating at appropriate scales is a fundamental part of planning, implementation, and adaptive management. We also describe examples in which feedbacks between these processes and major stressors are integrated into the restoration design process. Practical but often critical matters of sequencing, funding, site selection, stakeholder interactions, and permitting are also recognized as equally important aspects of restoring or enhancing riparian corridors of the Southwest.

\section{Landscape and Watershed Context}

Alluvial rivers are dynamic systems that are affected by complex interactions between numerous inputs and processes. Factors that vary at broad landscape scales, such as climate, topography and lithology, shape processes and attributes that affect the riparian community structure and composition through a hierarchy of interaction (Merrill and others 2006). A simplified conceptual model illustrating these interactions is shown in figure 1. In the model, landscape context (climate, topography, and lithology) and natural watershed inputs (such as water, sediment, and nutrients) drive physical processes (such as sediment transport and channel migration) that, in turn, determine geomorphic attributes and physical habitat structure of the river-floodplain system. The geomorphic attributes and habitat structure drive biological responses and are important determinants of plant and animal species abundance,

\footnotetext{
${ }^{1}$ Stillwater Sciences, Berkeley, California

${ }^{2}$ State University of New York, College of Environmental Science and Forestry
} 
distribution, and composition. Modification of any of the key inputs or processes will influence channel and floodplain geomorphic attributes and, subsequently, affect riparian plant communities and fish and wildlife populations. For example, reduction in peak flows (a watershed input) can alter fluvial processes such as the timing, frequency, extent, and duration of floodplain inundation. This alteration in inundation patterns can result in changes in riparian plant species composition and age-class structure, which can alter habitat suitability for native birds and thus result in a shift in bird community species composition. In turn, riparian vegetation can feed back to hydraulic and geomorphic processes. For example, increased hydraulic roughness provided by newly established vegetation can increase sediment deposition and floodplain accretion, and encroachment of vegetation into the active channel following flow regulation commonly contributes to channel deepening. Natural and anthropogenic disturbances can occur at different scales, ranging from global climate change effects on regional temperatures, precipitation, and evapotranspiration rates, to a 20,000 ha wildfire in the watershed headwaters, to landslides or flood scour and deposition along a single alluvial reach, to vegetation removal and soil disturbance by invasive turkey or wild boar populations within a single floodplain site. The effects of these disturbances also can occur at multiple scales, including the scale of the original disturbance event, to finer scale processes and structures within a watershed, including habitat structure, complexity, connectivity, and biotic responses (Stillwater Sciences, 2001; Vaghti and Greco, 2007; Downs and others, 2011). Restoration ecologists need to understand how these landscape- and watershed-scale processes in and around their restoration area respond to abrupt and/or long-term (e.g., punctuated vs. press) sources of disturbance and stress in order to chart a path towards functional recovery or enhancement of resilient riparian ecosystems within the targeted restoration area (see Rasmussen and Orr, Section I).

An important part of prioritizing restoration and enhancement actions in a watershed or broader landscape is to clearly articulate and match restoration goals and objectives to specific river reaches. It is important to remember that priority restoration reaches and targets can be identified based on landscape differences in ecosystem functions and services currently provided (vs. needed for full restoration), and the distribution of stressors and process domains that affect sensitivity and/or recovery.

Thus, landscape and watershed context matters. For example, the restoration of cottonwood and willow riparian forests on the Santa Clara River in southern California is appropriate only in gaining reaches (i.e, where groundwater rises towards the surface and feeds into the river channel) with reliable shallow groundwater, while more xeric types of riparian vegetation (for example, alluvial scrub) are more appropriate restoration targets in losing reaches (i.e., where river water is being lost downward to the water table)(Orr and others, 2011). Variations in the structure and location of underlying bedrock creates groundwater basins filled with alluvial sediments. Groundwater is typically forced to the surface at the downstream end of such a basin where bedrock and the water table are near the surface, while groundwater is often lost to a deeper water table where the river enters the upstream end of the basin. These physical geological controls can create patterns of intermittent and perennial flow that are consistent over decades or centuries, which in turn can create patterns of vegetation (such as large areas of cottonwood-willow forests and wetlands in gaining reaches and alluvial scrub in losing reaches) which are also persistent over those same temporal scales (Beller and others, 2015).

\section{Understanding the Biophysical Site Template}

Once a site has been selected, restoration or enhancement plans must incorporate the existing biophysical template and dominant ecosystem processes. Understanding if and how the site's physical structure might limit processes required for full recovery is an important part of restoration planning. Important site-scale processes include floodplain hydrologic connectivity (extent, duration, depth, and 
timing of inundation), groundwater-surface water interactions, sediment scour and deposition, net primary production, and loss through grazing, fire, or other disturbances. Human land uses and management actions or needs must also be considered at this scale. These include flood control, water use (withdrawals and return flows), public access or use, infrastructure that must be avoided or protected, and legacies of past use (for example, toxins, or altered floodplain topography).

Understanding of these factors will help determine the appropriate restoration approach for each site. The appropriate strategy should consider whether to employ passive (process-based) or active (for example, horticultural revegetation, regrading or recontouring of channel or floodplain) restoration approaches, or a combination of both. For example, if the site does not currently possess the features necessary to support the desired target habitats, can such features be efficiently and sustainably created? If so, is it worth the cost and effort, or should the restoration target be reassessed?

\section{Using the Biophysical Site Template: Site Design and Implementation}

Key components of the biophysical template are the finer scale patterns of micro-topography, soils (texture, salinity, nutrients), water availability (flood pulse patterns of surface water, depth to groundwater), existing patches of desirable native vegetation, and presence of non-native, invasive species. Typically, a site plan will include defining and mapping restoration or management units based on the above factors. It should include vegetation and habitat targets and a revegetation strategy (natural recruitment versus replanting using horticultural techniques) selected for each unit. Next a palette of appropriate native plant species is selected to match conditions found within each unit targeted. Once the dominant or characteristic species have been determined, additional species may be added to increase biodiversity, support native pollinators, or add functional redundancy using species with a range of responses to temperature or moisture gradient in hopes of creating a more ecologically resilient community. Specifying operational guidelines for the planting plan is also an important step. This typically includes specifying the source of material. The existing paradigm of only using locally collected seed or cuttings is now being challenged by those who promote the use of at least some nonlocal ecotypes that might be better adapted to the predicted future climate conditions (Whitham, Section II). The type of stock (seed, container, cutting), size or vigor of cuttings and seedlings, and need for irrigation and weed control are important operational considerations that can affect the success of horticultural restoration efforts. A schedule for implementation should also be included in the plan. This should include any timing constraints indicated by ecological issues (for example, plant dormancy, seasonal rains and soil moisture) or permitting requirements (for example, work windows to avoid impacts to nesting birds or other listed species). A key lesson learned from past projects is that oversight of restoration implementation by an experienced practitioner is critical.

\section{Dealing with Changing and Challenging Conditions: Adaptive Management and Monitoring}

The complexity of conditions and water uses in many western rivers, combined with uncertainty about climate change effects, pose serious challenges for restoration practitioners. The long-term success of riparian restoration will be controlled by both abiotic and biotic factors and can be maximized by incorporating lessons from other riparian restorations in the region (Stella and others, 2013). Pilot experiments and adaptive management approaches may be critical in restoration efforts with high uncertainty. For example, Downs and others (2011) conducted an experiment on a floodplain along the Merced River that was degraded by historical gold mining dredge spoils. The river was slated for restorative recontouring and we aimed to test a variety of factors on seedling survival of four dominant native tree species including: the influence of distance to groundwater, irrigation (two abiotic factors), initial plant size, and weed competition (two biotic factors). The results of this relatively small- 
scale experiment provided practical information to improve the success of the larger-scale floodplain restoration as well as inform other revegetation efforts in degraded areas of the Southwest. The most important factor controlling tree survival shifted over time since planting, from initial plant size in the first year, to irrigation duration in the second year, and finally to distance to groundwater in the third year (fig. 2). The initial experiment and funding only ran for three years, but valuable additional information on longer term restoration trajectories and success can be gained by revisiting demonstration or experimental sites after many year (for example, 10 years in this case, figs. 2, 3). Implementation and effectiveness monitoring, which are often required as part of permitting, can be coupled with other types of monitoring to create an effective adaptive management approach. For example, monitoring key underlying physical processes and conditions, such as floodplain inundation or groundwater levels, in conjunction with more routine implementation and effectiveness metrics, can provide yet another efficient mechanism for teasing apart the ecological and site constraints on restoration performance and providing the information necessary for adaptive management and ultimate success.

\section{Lessons Learned}

- The biophysical template concepts can be applied at multiple scales: from landscapes and watershed scales, through river corridor and reach scales, down to the individual site scale.

- Upstream conditions and events can strongly influence the success of your project - landscape and watershed context matters.

- Bad decisions during implementation can undermine the best of plans - effective oversight of crews during implementation is essential.

- Well-designed monitoring and adaptive management approaches, including pilot and demonstration projects or experiments, can be used to address key management uncertainties and identify cost-effective solutions. This is especially important in planning and implementing larger and more expensive restoration projects.

\section{References Cited}

Beller, E.E., Downs, P.W., Grossinger, R.M., Orr, B.K., and Salomon, M.N., 2016, From past patterns to future potential-Using historical ecology to inform river restoration on an intermittent California river: Landscape Ecology, v. 31, no. 3, p. 581-600, accessed April 28, 2017, at https://link.springer.com/article/10.1007\%2Fs10980-015-0264-7.

Downs, P.W., Singer, M.S., Orr, B.K., Diggory, Z.E., and Church, T.C., 2011, Restoring ecological integrity in highly regulated rivers-The role of baseline data and analytical references:

Environmental Management, v. 48, no. 4, p. 847-864, accessed April 28, 2017, at http://dx.doi.org/10.1007/s00267-011-9736-y.

Merrill, A.G., Benning, T.L., and Fites, J.A., 2006, Factors controlling structural and floristic variation of riparian zones in a mountainous landscape of the western United States: Western North American Naturalist, v. 66, no. 2, p. 137-154, accessed April 28, 2017, at http://dx.doi.org/10.3398/15270904(2006)66[137:FCSAFV]2.0.CO;2.

Orr, B.K., Diggory, Z.E., Coffman, G.C., Sears, W.A., Dudley, T.L., and Merrill, A.G., 2011, Riparian vegetation classification and mapping-Important tools for large-scale river corridor restoration in a semi-arid landscape, in Willoughby, J., Orr, B., Schierenbeck, K., and Jensen, N., eds., Proceedings of the CNPS Conservation Conference-Strategies and solutions, 17-19 Jan 2009: California Native Plant Society, Sacramento, CA, p. 212-232. 
Stella, J.C., Rodríguez-González, P.M., Dufour, S., and Bendix, J., 2013, Riparian vegetation research in Mediterranean-climate regions-Common patterns, ecological processes, and considerations for management: Hydrobiologia, v. 719, no. 1, p. 291-315, accessed April 28, 2017, at https://link.springer.com/article/10.1007\%2Fs10750-012-1304-9http://dx.doi.org/10.1007/s10750012-1304-9.

Stillwater Sciences, 2001, Merced River baseline studies-Volume II - Geomorphic and vegetation investigations report: Stillwater Sciences, Berkeley, Calif.

Vaghti, M.G., and Greco, S.E., 2007, Riparian vegetation of the Great Valley, in Barbour, M.G., KeelerWolf, T., and Schoenherr, A.A., eds., Terrestrial vegetation of California, third edition: University of California Press, Berkeley and Los Angeles, p. 425-455. 


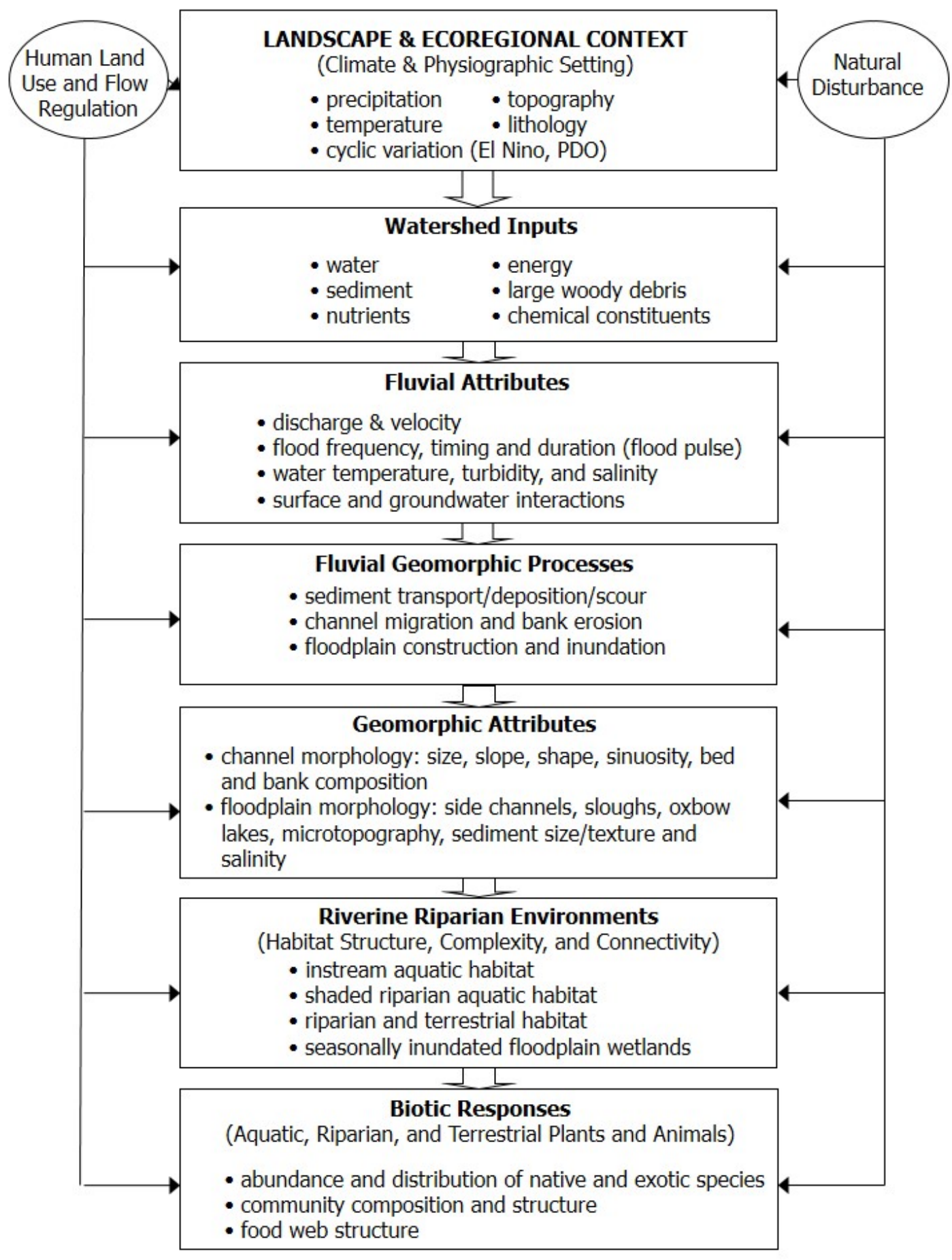

Figure 1. Conceptual physical and biological framework for alluvial river systems. Adapted and modified from Stillwater Sciences (2001) and Vaghti and Greco (2007). Pacific Decadal Oscillation is abbreviated at PDO in the Landscape and Ecoregional Context panel. 

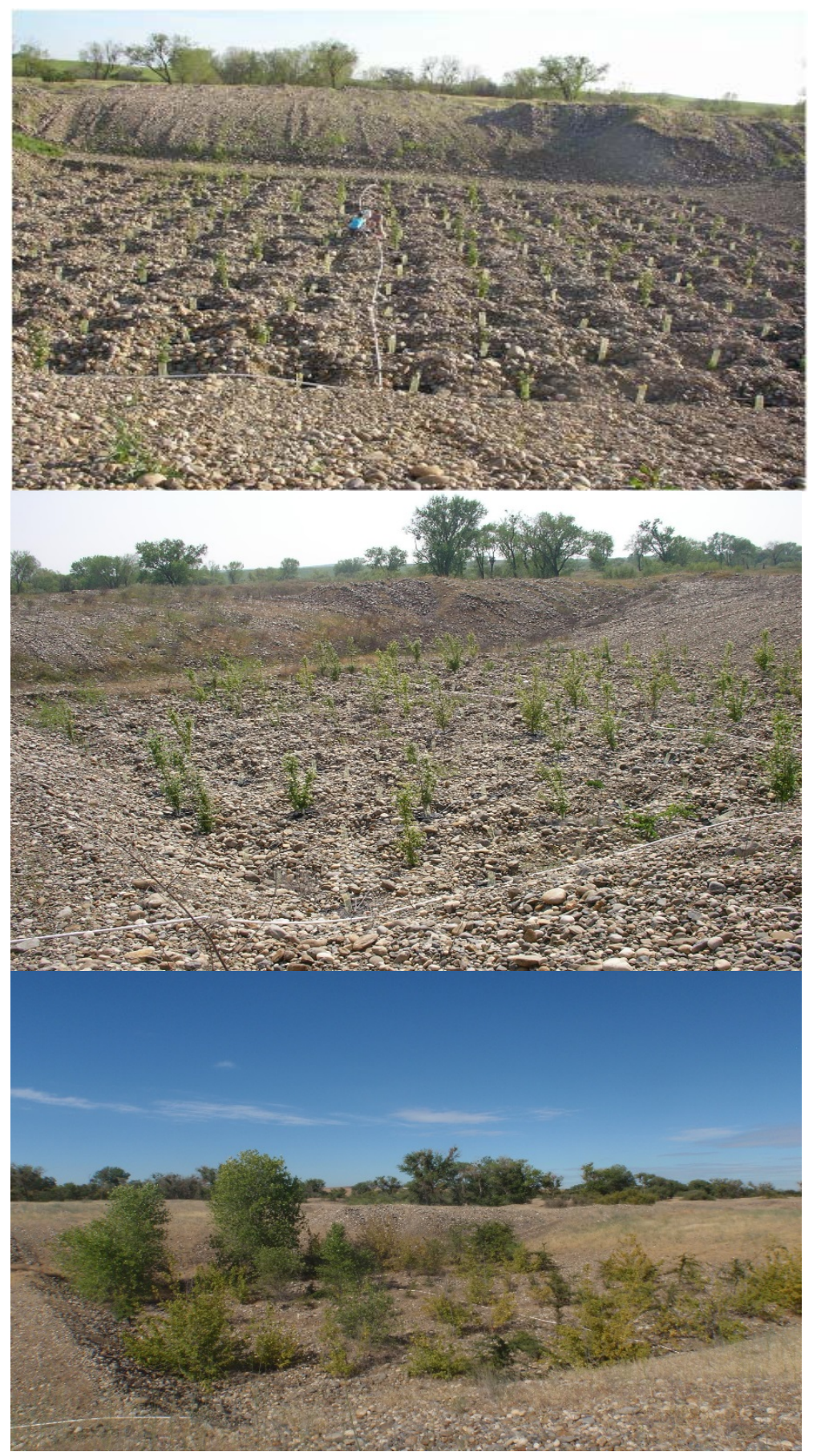

Figure 2. Time series of three photos from top to bottom of the floodplain dredger mining tailings revegetation experiment site on the lower Merced River, CA showing variation in plant survival and growth with species and irrigation and weed cover treatment within the 2-m depth to groundwater experimental block. Top: Year 1 (April 2004). Middle: Year 2 (April 2006). Bottom: Year 10 (June 2014)(photos, Stillwater Science). 


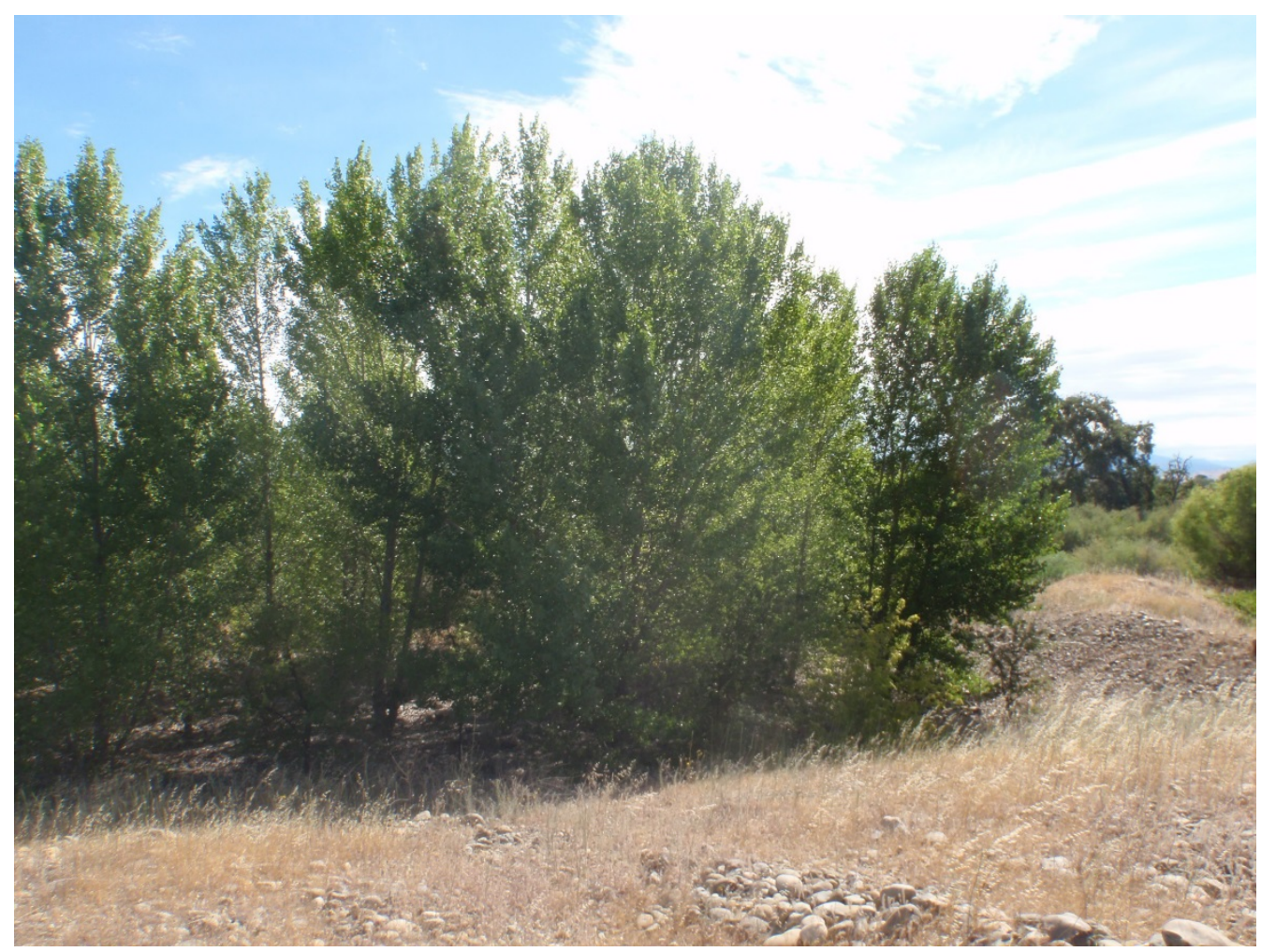

Figure 3. View of plants in the 1-m depth to groundwater experimental block in Year 10 (June 2014). Greater survival and growth were apparent in Year 10 in this block compared to the 2-m depth to groundwater block (See fig. 2, bottom photo)(photos, Stillwater Science). 


\title{
Riparian Restoration in the Context of 21st Century Hydrology
}

\author{
By Matthew R. Grabau ${ }^{1}$, Todd Caplann ${ }^{1}$, Karen Schlatter ${ }^{2}$, and Chad McKenna ${ }^{1}$
}

\section{Introduction}

Riparian areas worldwide have been severely impacted by land use changes and flow regulation. Floodplains have been disconnected, preventing disturbance necessary for native plant establishment. Non-native species have become dominant due to altered hydrology and positive feedbacks-non-native species promote conditions that increase their competitive advantage over native riparian species (Busch and Smith, 1995). Riparian restoration is highly desirable due the ecological importance and degree of degradation of these areas. "Restoration" should in theory restore fluvial processes that support diverse native plant communities with some level of resilience (ability to withstand stress without returning to a degraded state). However, hydroelectric power and water diversions will likely continue in perpetuity. Thus, restoration is typically limited to mitigation of stressors by optimizing use of limited water resources, floodplain excavation, and active revegetation. Success of future projects can be improved through science-based monitoring of existing projects to better understand hydrologic effects on key biological and physical variables during various water years. This monitoring can help improve future designs and site selection. Additionally, adaptive management is increasingly important. Managers might need to implement innovative actions to see if they can maintain desired ecosystem services within constraints of new climates.

We present two case studies that demonstrate how restoration practitioners and scientists are teaming together to design, construct, and monitor large-scale riparian restoration projects under an uncertain hydrologic regime. Both projects use undesirable species (non-natives and/or natives with low habitat value) removal, floodplain reconnection, and planting to maximize benefits despite water limitations. Long-term monitoring and adaptive management programs are also in development, and will inform management decisions at existing sites as well as future restoration projects. The first case study is the Middle Rio Grande (MRG) restoration project in Albuquerque, New Mexico. The second study is from the Colorado River Delta in Baja California, Mexico.

\section{Methods}

Along the MRG, primary limitations for native riparian plant recruitment are river channelization, flood flow diversions, declining groundwater, and non-native plant species. The US Army Corps of Engineers has completed a series of restoration projects in the MRG with an emphasis on improving river-floodplain connectivity and constructing willow wetlands ("willow swales"). The design aimed to create shallow groundwater and hydric soil conditions to promote willow growth. Floodplain terraces were excavated to achieve maximum groundwater depth of three feet. Bankline openings were created at some sites to inundate swales at the two-year flow rate (approximately 70 - 85 $\mathrm{m}^{3} / \mathrm{s}$ ) historically common during snowmelt runoff and moderate monsoon rain events. Fourteen willow

\footnotetext{
${ }^{1}$ GeoSystems Analysis, Inc., Tucson, Arizona

${ }^{2}$ Sonoran Institute, Tucson, Arizona
} 
swales between 0.7 and 3.7 ha were excavated during fall 2011 and winter 2012, prior to planting with dormant willow (Salix exigua, S. gooddingii) and cottonwood (Populus fremontii wislizeni) cuttings harvested from the MRG valley. Piezometers were installed in swales after planting to monitor groundwater depth. In late summer 2014, we recorded willow height, root-sprout density, percent canopy dieback and sediment deposition thickness on a 25-m grid at all fourteen swales.

The Colorado River Delta historically received approximately 14 million acre-feet $\left(17.3 \times 10^{9}\right.$ $\mathrm{m}^{3}$ ) of water annually, supporting a vast expanse of riparian, marsh, and estuarine habitat. However, upstream diversions have reduced surface flows and extensively degraded the riparian corridor over the past 70 years-groundwater levels have declined, salinity has increased, and non-native Tamarix spp. has become dominant. However, native tree communities have been periodically rejuvenated (e.g. floods in the 1980s and 90s, Nagler and others, 2005). Today, native vegetation is supported by incidental flows from the Morelos Dam near the US-Mexico border and agricultural return flows. However, large sections of the river are too extensively desiccated to support native phreatophytes (i.e., plants that to survive must have their roots constantly in touch with moisture from groundwater).

Minute 319 of the 1944 US-Mexico Water Treaty, among other objectives, dedicated ecological flows to the Colorado River in Mexico. A one-time pulse flow of 105,400 acre-feet $\left(130 \times 10^{6} \mathrm{~m}^{3}\right)$ was delivered during 2014, and 52,700 acre-feet $\left(65 \times 10^{6} \mathrm{~m}^{3}\right)$ of "base flows" will be delivered between 2012 and 2017. Among other goals, the pulse flow was intended to promote establishment of native trees, primarily cottonwood and willows. Most of the riparian corridor was left unaltered prior to the pulse flow and thus depended on the pulse to remove non-native species and create bare, moist soils. However, the flow magnitude (designed peak flow rate of $120 \mathrm{~m}^{3} / \mathrm{s}$, or 4,200 cfs) was much lower than historic floods. Furthermore, the flow had to traverse nearly $80 \mathrm{~km}$ down a largely dry river channel to reach a target restoration area (Laguna Grande). To encourage floodplain reconnection and native tree establishment in Laguna Grande, approximately 80 hectares of vegetation were cleared along historic channel meanders, and flow impediments were breached. Near-surface soil salinity was mapped along cleared channel Meanders of Laguna Grande Restoration Area before (March 2014) and after (October 2014) 2014 environmental flows using an electromagnetic induction survey (methods following Lesch and others, 1995), and vegetation establishment was quantified along cleared channel meanders using 1$\mathrm{m}$ or 4-m wide belt transects placed at regular intervals perpendicular to the meanders.

\section{Results and Discussion}

Monitoring data from the MRG project verify that the design target groundwater depths and inundation goals were achieved. However, riparian plant growth and canopy development in the first three years following construction were widely variable (fig. 1). Preliminary analysis indicates that variability may be in part due to differences in soil texture and record low snowmelt in the three years after construction. Flow records from the USGS Gage at Albuquerque (USGS 08330000) indicate mean daily flows exceeded 2,000 cfs $\left(57 \mathrm{~m}^{3} / \mathrm{s}\right)$ eight times since project construction. However, seven of these events were rapidly attenuating flood pulses associated with monsoon rain events. Monsoon flows can provide enhanced soil moisture and deposit fine-grained sediment in swales, which can enhance the growth of planted willows (Caplan and other,s 2013). Unlike longer soil hydration periods associated with snowmelt runoff, monsoonal events provide less opportunity for willow root development and corresponding foliar canopy development. We hypothesize that swales with more vigorous early willow growth have relatively finer textured alluvium and correspondingly greater soil moisture retention.

Willow growth during this period might have been improved if swales had been designed to inundate at lower flow rates. However, lower design flows would require more excavation and higher costs while potentially accelerating sedimentation, drowning plant material, or creating difficult planting 
conditions (i.e., saturated soils) if higher flows occurred. Thus hydrologic uncertainty remains a primary design limitation. Further understanding of the effects of soil texture and stratigraphy on groundwater and soil moisture dynamics on willow growth in water-limited conditions will allow practitioners to increase success by enhancing site selection criteria.

Minute 319 environmental flows inundated cleared areas at Laguna Grande Restoration Area and at least temporarily increased groundwater levels between $50 \mathrm{~cm}$ and $2 \mathrm{~m}$ above baseline conditions. Additionally, large-scale soil salinity reductions were observed near reconnected meanders (fig. 2). Based on a generalized $12 \mathrm{dS} / \mathrm{m}$ soil salinity tolerance (i.e. with mortality of mature native trees occurring at higher electrical conductivity (EC) values, following GeoSystems Analysis, Inc. 2011), over 50 percent of the surveyed area became suitable for native trees. Cottonwood and/or willow established in approximately 70 percent (22 of 32) of established belt transects. Lack of establishment in some cleared areas was likely due to limited soil moisture, high salinity, and/or a lack of nearby seed sources. Outside of cleared areas, establishment was limited because flow rates did not provide widespread scour of existing vegetation. Assessment of Minute 319 flow effects on the Colorado Delta is ongoing by numerous organizations. Monitoring will continue in Laguna Grande to determine the longevity of soil salinity reductions and survival of seedlings.

These projects highlight the need for active management to enhance habitat conditions supported by $21^{\text {st }}$ century hydrology along regulated rivers. Firstly, flow is constrained by anthropogenic water demand, infrastructure, and management. Second, the future amount and timing of in-stream flow is uncertain due climate change effects. While floodplain reconnection enhances riparian areas, resilience of "restored" ecosystems along regulated rivers cannot be guaranteed because of existing stressors are not being removed, and future stressors are uncertain. Instead, long-term maintenance, monitoring and adaptive management are the tools required to maintain restoration areas.

\section{Lessons Learned}

- Riparian restoration on regulated rivers requires effective use of limited flows.

- Undesirable species clearing and floodplain reconnection enhance benefits of environmental flows.

- Environmental flows to the Colorado River in Mexico, even orders of magnitude below historic levels, can reduce salinity limitations, improve water availability, and promote native species regeneration.

- Effective monitoring is critical for guiding adaptive management, extending the lifespan of restoration projects, and informing future restoration designs.

\section{References Cited}

Busch, D.E., and Smith, S.D., 1995, Mechanisms associated with decline of woody species in riparian ecosystems of the southwestern U.S.: Ecological Monographs, v. 65, no. 3, p. 347-370, accessed on April 28, 2017, at http://www.jstor.org/stable/pdfplus/2937064.pdf.

Caplan, T.R., Cothern, K., Landers, C., and Hummel, O.C., 2013, Growth response of Coyote Willow (Salix exigua) cuttings in relation to alluvial soil texture and water availability: Restoration Ecology, v. 21, no. 5, p. 627-638, accessed on April 28, 2017, at http://dx.doi.org/10.1111/j.1526100X.2012.00928.x.

GeoSystems Analysis, Inc., 2011, Review of salinity and sodicity, monitoring, and remediation for riparian restoration areas: Prepared for Bureau of Reclamation, Lower Colorado Region, Boulder City, Nevada. 
Lesch, S.M., Rhoades, J.D., Strauss, D.J., Lin, K., and Co, M.A.A., 1995, The ESAP user manual and tutorial guide version 1.0: USSL Research Report No. 138, Agricultural Research Service, U.S.

Department of Agriculture, April 1995. 114 p.

Nagler, P.L., Hinojosa-Huerta, O., Glenn, E.P., Garcia-Hernandez, J., Romo, R., Curtis, C., Huete, A.R., and Nelson, S.G., 2005, Regeneration of native trees in the presence of invasive Saltcedar in the Colorado River Delta, Mexico: Conservation Biology, v. 19, no. 6, p. 1842-1852, accessed on April 28, 2017, at http://dx.doi.org/10.1111/j.1523-1739.2005.00234.x.

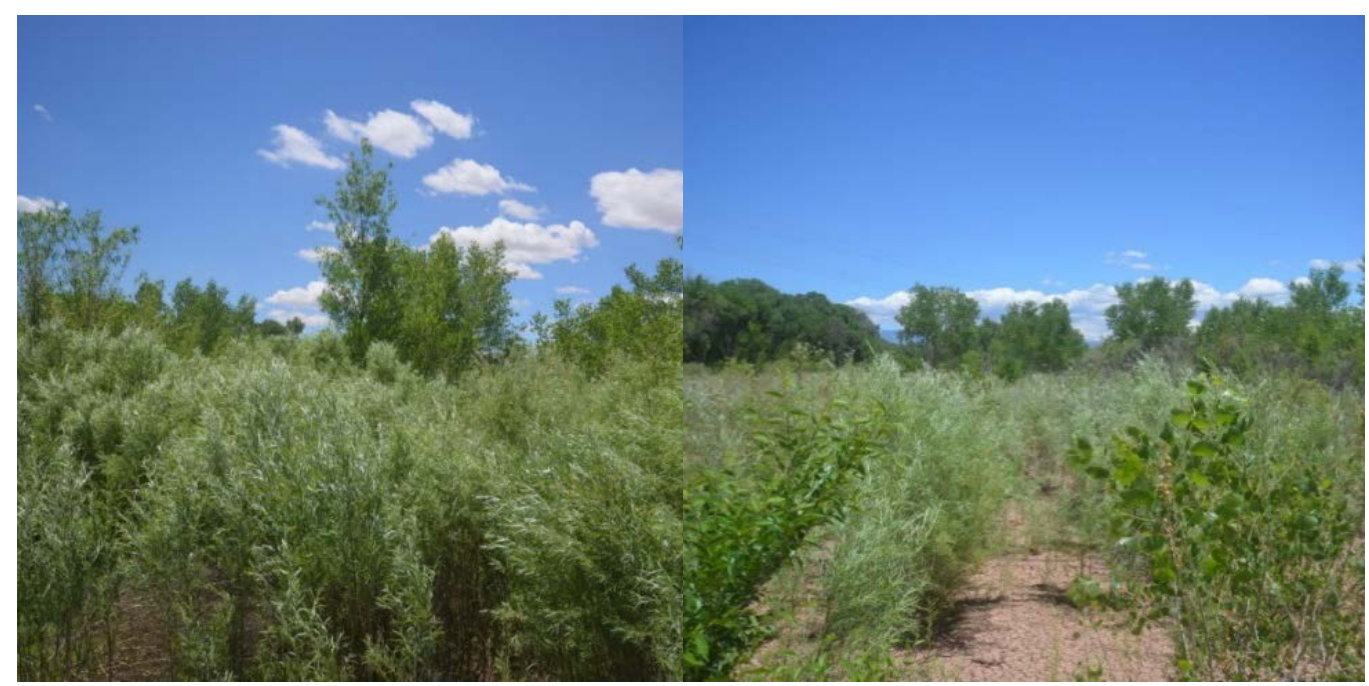

Figure 1. Variable coyote willow (Salix exigua) growth in constructed willow swales at the Middle Rio Grande site after three years of growth, with dense, high-quality habitat in some swales (left), and lesser growth and rootsprouts in others (right). Photos from June 12, 2015, M. Grabau, GeoSystems Analysis, Inc.

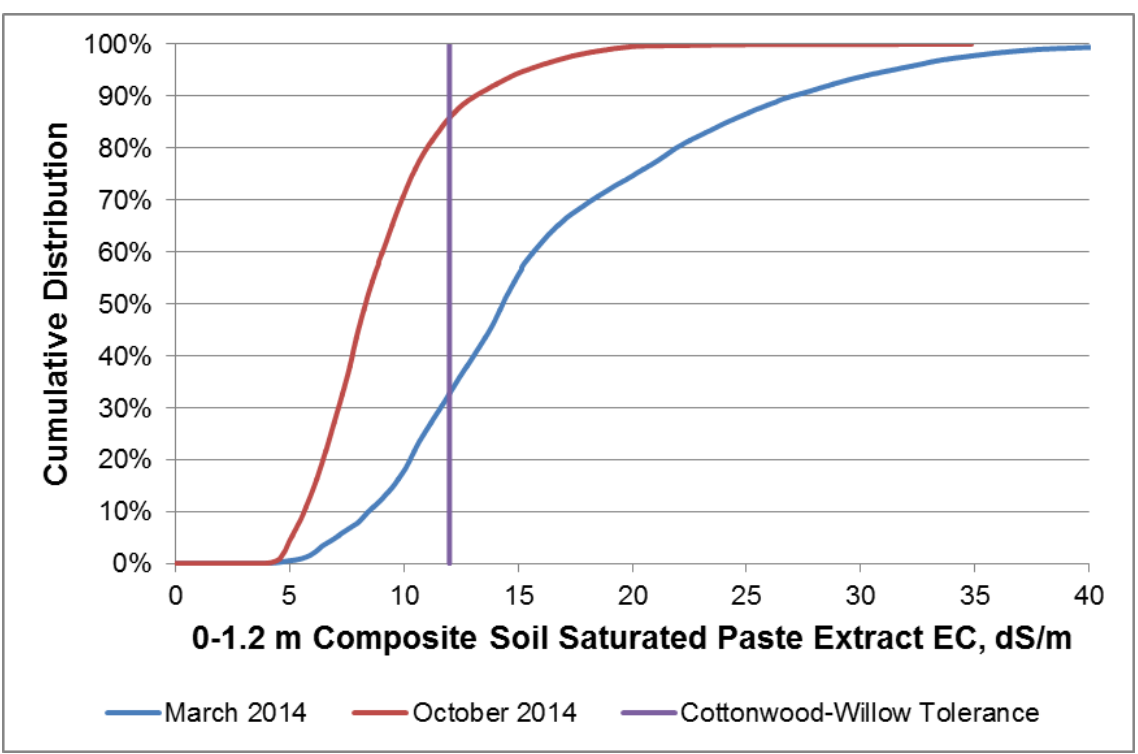

Figure 2. Cumulative distribution functions of estimated 0-1.2 m composite soil saturated paste extract electrical conductivity for 60 hectares along cleared meanders before (March 2014) and after (October 2014) the 2014 Minute 319 pulse and base flow deliveries. 


\title{
The Reality of Climate Change and the Need for Genetics Approaches in Riparian, River and Watershed Restoration to Maintain Biodiversity in Changing Environments
}

\author{
By Thomas G. Whitham ${ }^{1}$
}

\section{Introduction}

The role of genetics in restoration has largely revolved around the mantra of restoring with local genotypes. Other than this largely accepted policy, the use of genetics in restoration has been minimal. However, anthropogenic impacts on the planet have largely rendered this policy as inadequate at best and damaging at worst. Climate change and other global challenges represent grave risks for all ecosystems of the world. Because of rapid environmental change, plants that are locally adapted today are likely to be locally maladapted to tomorrow's environments. Thus, in regions of especially rapid change such as the American Southwest, local populations are likely to lack sufficient genetic variation to adapt to these new environments. Similarly, with rapid change and a fragmented landscape, many species cannot migrate fast enough to reach favorable environments. Ignoring this new climate change reality will likely result in restoration failure, high biodiversity loss, and the loss of restoration funding. With foundation species that support 1000s of other species (for example, Fremont cottonwood, (Populus fremontii), coyote willow (Salix exigua)), it is crucial to identify the individual plant genotypes and populations that can survive future environmental conditions. By focusing on these foundation species that are community and ecosystem drivers, we can save many of the species that are dependent upon them for their survival. To achieve this goal, new experimental approaches are required that identify the genetic components of local adaptation to future conditions, biodiversity, community stability, and ecosystem processes. Key to this approach is the use of common gardens embedded in lands to be restored such as the Southwest Experimental Garden Array (http://www.sega.nau.edu). Based on the findings from these common gardens, restoration biologists can then deploy genetically appropriate genotypes and populations that are most likely to survive future environmental conditions.

\section{Methods}

A crucial tool to partition genetic and environmental components of plant phenotypes (for example, growth, phenology, and resistance to disease) is the use of a common garden (also referred to as provenance trials and experimental forests). When researchers observe differences among individual plants in nature, two hypotheses could account for the differences in morphology, resistance to disease, drought tolerance, community differences in biodiversity, and other traits of interest to restoration biologists and land managers. The differences could be due to the environmental or microsite differences where the plants are growing. Alternatively, they could be due to genetic differences among plants or a combination of both factors. By growing individual plant genotypes in a common garden that have been collected from diverse sites that vary in soils, climate, interactions with other species, and other gradients of interest, the common growing environment allows researchers to be confident that any differences in the traits among plants are genetically based. Researchers and land managers can then

\footnotetext{
${ }^{1}$ Merriam-Powell Center for Environmental Research and Department of Biological Sciences, Northern Arizona University, Flagstaff, Arizona
} 
use this genetic variation to address important management issues such as climate change just as agricultural scientists have used genetic variation to increase crop yield. Although common gardens have been used by the U.S. Forest Service for a long time to identify superior genotypes and populations that would have high growth rates and productivity for economic reasons, more complex field trials are needed that will allow us to quantify other traits such as tolerance to invasive species and drought, biodiversity, nutrient cycling, interactions with mycorrhizal mutualists and many other traits important for restoration and land management. Thus, while the metrics have changed, the basic tool of the common garden remains much the same.

Our studies have benefited tremendously by using this approach, which is exemplified in a new research facility, the Southwest Experimental Garden Array (SEGA). Building on the common garden approach, Northern Arizona University (NAU) has undertaken a long-term program to develop SEGA as a research platform to study and develop solutions that utilize genetics approaches to mitigate climate change, invasive species and other global challenges. Because this research platform (fig. 1) is embedded in federal, state, and private lands (for example, USFS, BLM, BOR, Arizona Game \& Fish Department, The Nature Conservancy, Grand Canyon Trust, Babbitt Ranches, The Arboretum at Flagstaff) these collaborating agencies are interested in how our findings can be used for better land management. This facility is open to scientists from throughout the region and around the world to quantify the ecological and evolutionary responses of species to changing climatic conditions using emerging technologies. SEGA was initiated in 2012 with \$4.5 million in funding from the National Science Foundation (NSF) and NAU to create a system of 10 common gardens along the steep elevation gradient in northern Arizona. Additional gardens are being added to this network and as the size of the garden array increases so will the resolution of its findings. Because temperature and moisture predictably change with elevation, these gardens reflect climatic differences from desert to alpine forests that mimic the effects of climate change. By using experimental manipulations of moisture within a site and by planting at multiple sites including more extreme low elevation sites, researchers can identify the genotypes, populations, and communities that can best tolerate these hotter, drier environments. SEGA enables a new generation of genetics-based climate change research that allows researchers from diverse disciplines to quantify the ecological and evolutionary impacts of climate change on (1) foundation plant species; (2) their associated communities; (3) native-exotic species interactions; and (4) the ecosystem processes that emerge from these interactions. In short, SEGA and other similar common garden facilities allow unprecedented opportunities to address riparian issues that can enhance restoration success for future climates and other challenges.

\section{Results and Discussion}

Numerous findings have emerged from these common garden experiments that are important for riparian restoration and land management. Based on these findings, larger landscape-level restoration on the surrounding lands can be undertaken with greater chances of success. For example, a recent review (Whitham and others, 2012) shows that different plant genotypes within individual species support different communities and these patterns are common to diverse ecosystems worldwide. Similarly, in cottonwoods different genotypes support different communities of soil microbes, mycorrhizae, arthropods, vertebrates, understory plants, lichens, and pathogens (Lamit and others, 2015 and references therein). For example, figure 2 shows how the arthropod communities found on individual trees are genotype dependent (Shuster and others, 2006). Each circle encompasses the clonal replicates of individual tree genotypes of narrowleaf cottonwood, Populus angustifolia. Each genotype was replicated (cloned) 2-8 times and randomly planted in a common garden. The arthropod communities on these different genotypes and their replicate clones were quantified and the results are graphed using the 
ordination method of NMDS. Because the variation among clones within a genotype are far less than the variation among genotypes, we can statistically say that there is a strong genetic component to the composition of the arthropod community.

Importantly, arthropod community composition is a heritable trait (in the broad sense $\mathrm{H}^{2}{ }_{\mathrm{C}}=0.60$ \pm 0.47 ; Shuster and others, 2006). In other words, genetic variation among individual tree genotypes accounts for about 60 percent of the variation in the composition of the arthropod community. Analyses of ecosystem processes such as nitrogen mineralization and decomposition yield similar results (Fischer and others, 2014). For example, the composition of the microbial decomposer community was found to feed back to affect nitrogen mineralization and tree performance (for example, Schweitzer and others, 2008). Thus, plant genetic diversity and the choice of individual genotypes used in restoration have important biodiversity and ecosystem consequences.

Another important finding is that genetics-based approaches can provide important solutions to help mitigate climate change impacts on wildlands. For example, Grady and others (2011) showed that different genotypes and populations of Fremont cottonwood predictably varied in their performance when grown at the edge of their distribution in southwestern Arizona. Figure 3 shows how restoration biologists and managers can use field trials to select the tree genotypes that will perform best under future conditions.

Trees were collected from 16 source populations of Fremont cottonwood and grown at a BOR riparian restoration site. We found that annual aboveground net primary productivity (ANPP, an important predictor of biodiversity), declined with increasing mean annual maximum transfer distance. A transfer distance of $6.5^{\circ} \mathrm{C}$ means that a high-elevation, cool-site population was transferred to the warmer, low-elevation experimental forest.

Three major findings are shown. 1) The slope of the regression line shows the sensitivity of cottonwood to a warmer climate. Foundation species characterized by high sensitivity are key candidates for conservation/restoration strategies, while less sensitive species might receive lower priority. 2) We can select source populations for a predicted level of climate change (for example, if temperature increases $4^{\circ} \mathrm{C}$, the regression line shows the populations that are best adapted to a future, hotter environment). 3) The trait-based variation in a population response shows its potential to adapt to climate change (see vertical bars). If the predicted change in climate is less than the variation, then the population has the potential to adapt (evolve) to predicted changes. In combination, these findings provide a powerful tool to assist managers in the selection of genotypes and source populations that maximize biodiversity and survive climate change.

\section{Lessons Learned} ecosystems.

Four major findings emerged from our SEGA trials that can affect the restoration of riparian

- In regions of high climate/global change impacts, plants locally adapted today, will become locally maladapted tomorrow rendering restoration practices based on the use of local stock a poor practice both ecologically and financially.

- Since there is a major genetic contribution to biodiversity, community stability, carbon storage, nutrient cycling and other ecosystem processes, by using the standing genetic variation in native populations, genetic approaches can help mitigate global challenges.

- Since our common garden arrays are embedded in lands of diverse collaborators (e.g., BOR, BLM, NPS, USFS, The Nature Conservancy, Babbitt Ranches, AZ Game \& Fish Department, Grand Canyon Trust, The Arboretum at Flagstaff), these agencies are ideally positioned to utilize our genetics findings to manage their adjacent lands. 
- Just as in agriculture, these field trials allow researchers to identify specific genotypes, levels of genetic diversity, populations and species mixes that work best under a given level of projected future conditions. Although agriculture is focused on yield, here our metrics of success are biodiversity, trophic structure, long-term survival, or any of the other genetics-based traits that ecologists/conservationists/managers deem most important.

\section{References Cited}

Fischer, D.G., Chapman, S.K., Classen, A.T., Gehring, C.A., Grady, K.C., Schweitzer, J.A., and Whitham, T.G., 2014, Plant genetic effects on soils under climate change: Plant and Soil, v. 379, no. 1, p. 1-19, accessed on April 28, 2017, at http://dx.doi.org/10.1007/s11104-013-1972-x.

Grady, K.C., Ferrier, S.M., Kolb, T.E., Hart, S.C., Allan, G.J., and Whitham, T.G., 2011, Genetic variation in productivity of foundation riparian species at the edge of their distribution: implications for restoration and assisted migration in a warming climate: Global Change Biology, v. 17, no. 12, p. 3724-3735, accessed on April 28, 2017, at http://dx.doi.org/10.1111/j.1365-2486.2011.02524.x.

Lamit, L.J., Busby, P.E., Lau, M.K., Compson, Z.G., Wojtowicz, T., Keith, A.R., Zinkgraf, M.S., Schweitzer, J.A., Shuster, S.M., Gehring, C.A., and Whitham, T.G., 2015, Tree genotype mediates covariance among communities from microbes to lichens and arthropods: Journal of Ecology, v. 103, no. 4, p. 840-850, accessed on April 28, 2017, at http://dx.doi.org/10.1111/1365-2745.12416.

Shuster, S.M., Lonsdorf, E.V., Wimp, G.M., Bailey, J.K., Whitham, T.G., and Kalisz, S., 2006, Community heritability measures the evolutionary consequences of indirect genetic effects on community structure: Evolution, v. 60, no. 5, p. 991-1003, accessed on April 28, 2017, at http://dx.doi.org/10.1554/05-121.1.

Whitham, T.G., Gehring, C.A., Evans, L.M., LeRoy, C.J., Bangert, R.K., Schweitzer, J.A., Allan, G.J., Barbour, R.C., Fischer, D.G., Potts, B.M., and Bailey, J.K., 2010, A community and ecosystem genetics approach to conservation biology and management, in DeWoody, A., Bickham, J., Michler, C., Nichols, K., Rhodes, G., and Woeste, K., eds., Molecular approaches in natural resource conservation and management: Cambridge University Press, p. 50-73.

Whitham, T.G., Gehring, C.A., Lamit, L.J., Wojtowicz, T., Evans, L.M., Keith, A.R., and Smith, D.S., 2012, Community specificity_Life and afterlife effects of genes: Trends in Plant Science, v. 17, no. 5, p. 271-281, accessed on April 28, 2017, at http://www.sciencedirect.com/science/article/pii/S1360138512000064. 


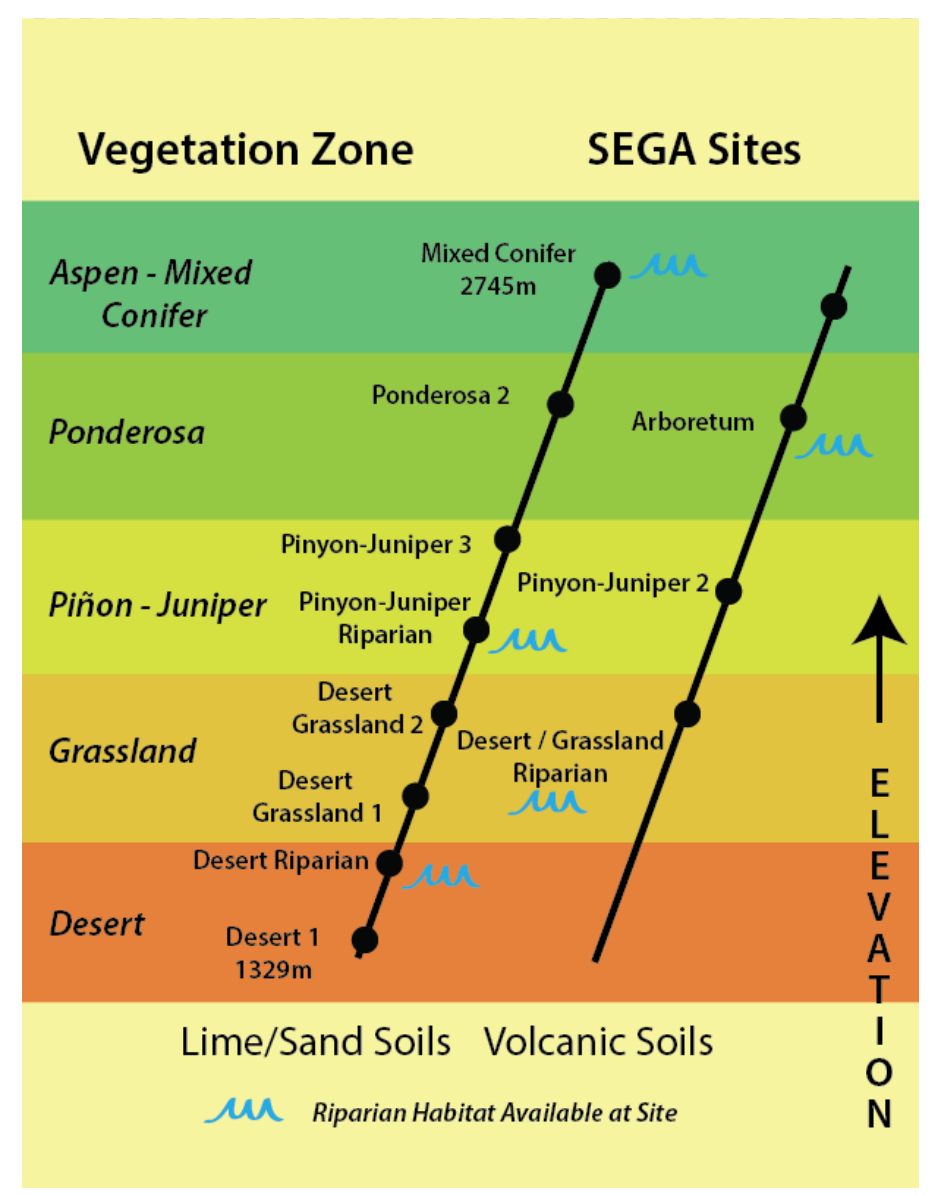

Figure 1. The NSF/NAU funded Experimental Garden Array (SEGA) is designed to integrate genetics approaches into climate change, invasive species and other global change issues.

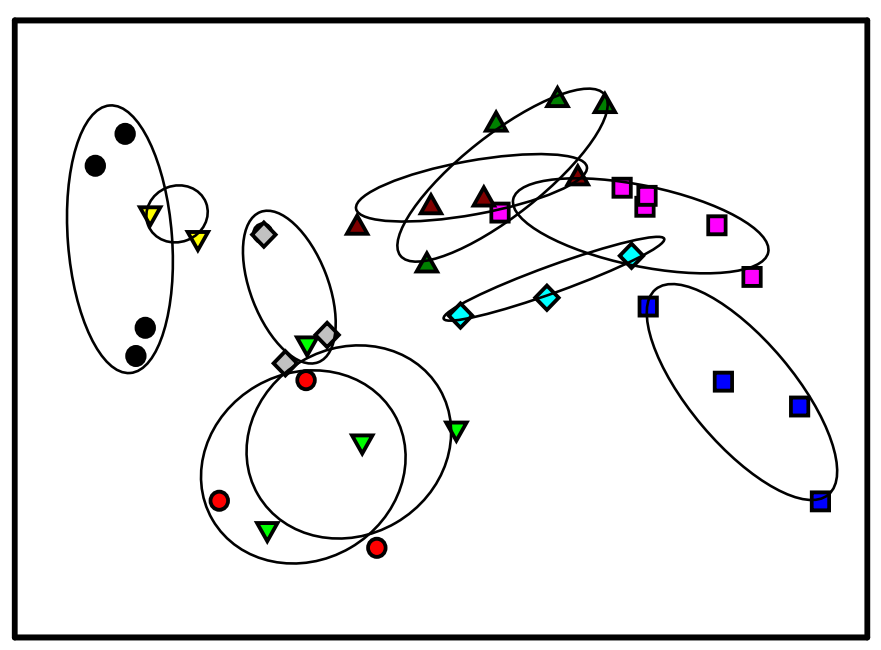

Figure 2. Ordination using nonmetric multidimensional scaling (NMDS) shows that different tree genotypes (e.g., each distinct symbol and its replicate clones) support different arthropod communities. 


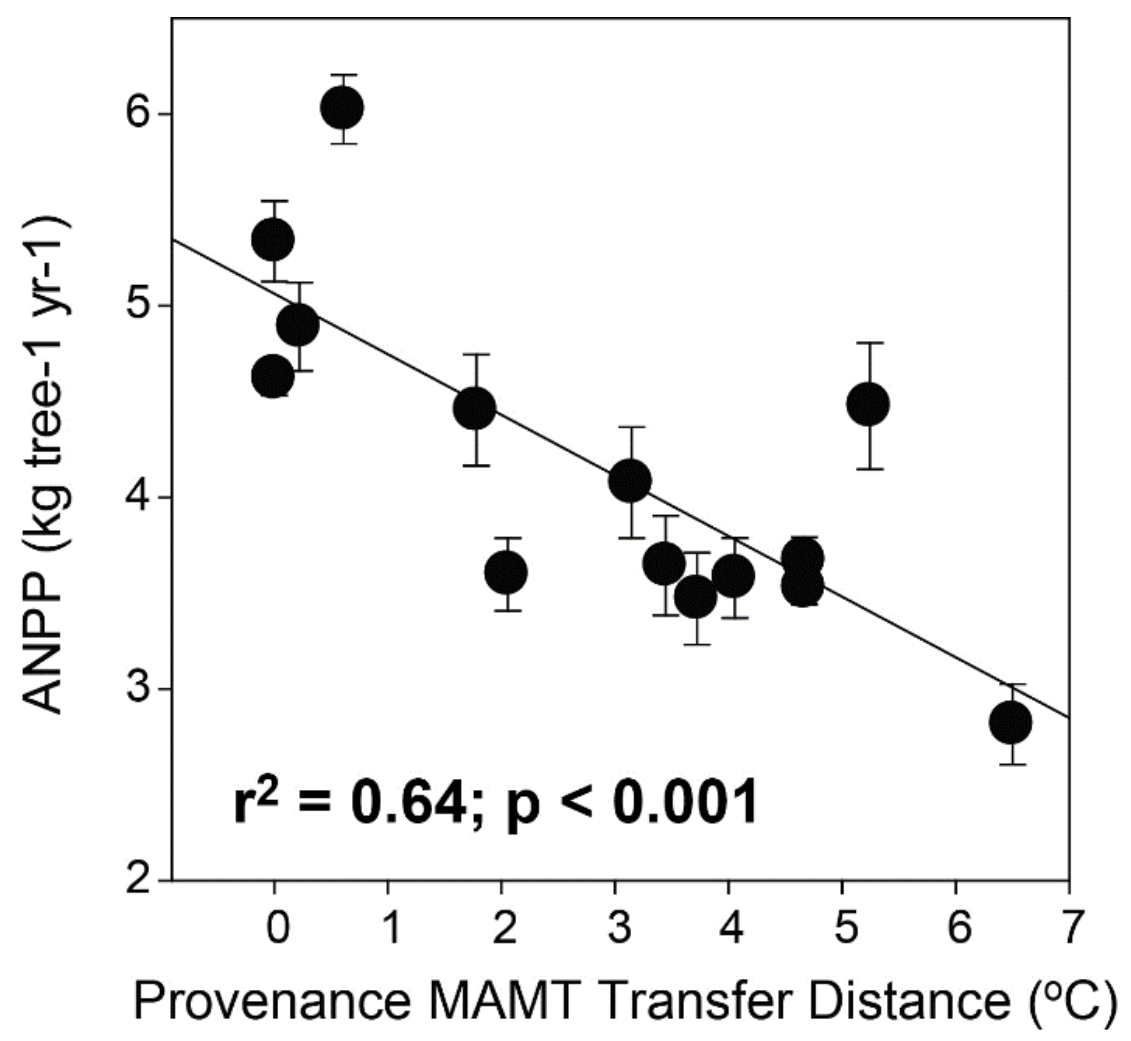

Figure 3. When grown at a low elevation common garden, different populations of Fremont cottonwood exhibit different productivities (ANPP) that are correlated with their mean annual maximum temperature (MAMT) transfer distances. 


\title{
Riparian Rehabilitation along the Colorado River: Successes and Challenges of a Pilot Project
}

\author{
By Melissa A. McMaster ${ }^{1}$, and Todd A. Chaudhry ${ }^{2}$
}

\section{Introduction}

In 2012, Grand Canyon National Park (GRCA) conducted a pilot riparian rehabilitation project along the Colorado River. This project took place at Granite Camp, which can only be accessed by a 12mile backcountry hike or by rafting 93 miles $(149.6 \mathrm{~km})$ of whitewater through Grand Canyon. Despite its remoteness, Granite Camp is a popular river and backpacking campsite, and like many areas along the Colorado River corridor has been adversely impacted by the operations of Glen Canyon Dam, high recreational use, and the introduction of non-native plant species, particularly tamarisk (Tamarix spp.) (Zachmann and others, 2012; Sankey and others, 2015). These factors have created a novel riparian ecosystem with no historical analogue in terms of floristic composition, structure and function (Mortenson and others, 2012). The unexpected arrival of the tamarisk leaf beetle (Diorhabda carinulata) in the park will likely lead to variable mortality of tamarisk, which will have unknown and possibly adverse effects on the riparian ecosystem and visitor experience. Partially in light of such potential effects, this pilot project was initiated to assess the feasibility of proactively planting native species along the river corridor. The goals of this pilot project were to: 1 ) rehabilitate the native riparian plant community and wildlife habitat; 2) assess various methods of tamarisk removal and native revegetation for a remote location in proposed wilderness; and 3) enrich the overall visitor experience.

\section{Methods}

This project was initiated through a partnership with Grand Canyon Association with funding from the Nina Mason Pulliam Charitable Trust and the National Park Service (NPS). The project was implemented in phases, beginning with project scoping to identify objectives, site assessment, and consultation with Fred Phillips Consulting LLC to develop a comprehensive invasive plant control and native species planting plan. During the site assessment, we collected data on soils, depth to ground water and the existing plant community composition and structure. These data informed the decisions on which native species were best suited for revegetation in different microhabitats of the site.

Our rehabilitation plan consisted of specific clearing and planting prescriptions that were based on microhabitat attributes. The plan included the following prescriptions: 1) selective tamarisk removal with minimal to no native vegetation planting, 2) selective tamarisk removal with active planting, 3) complete tamarisk removal with minimal to no planting, and 4) complete tamarisk removal with active planting. We made the decision to leave some of the tamarisk on site, particularly at the upriver end of the camp, as it provided wildlife habitat, shade for recreationists and boat anchors.

We also developed a monitoring plan that included plot-based vegetation sampling, planting maps, mortality counts and photo monitoring. Data acquired through pre- and post-treatment monitoring will be used to quantify changes in vegetation floristics and structure to determine if our treatments are successful in shifting the balance from a tamarisk- to native-dominated riparian area over the long term.

\footnotetext{
${ }^{1}$ Mariposa Ecological and Botanical Consulting LLC, Flagstaff, Arizona

${ }^{2}$ National Park Service
} 
The first step of active rehabilitation was the removal of tamarisk from the site. The majority of GRCA is Proposed Wilderness and is therefore managed as Wilderness as per NPS policy (National Park Service, 2006). Accordingly, the minimal tool must be used to preserve Wilderness character, so we limbed and cut down all trees with handsaws to minimize noise disturbance. This challenging work was done through the hard labor of dedicated volunteers during fall and spring of 2012-13. The process of removal consisted of: 1) cutting back the branches, leaving only large stumps, 2) cutting branches into pieces less than $1.5 \mathrm{~m}$ and disposing them in the river, 3) digging around and cutting the stumps approximately $0.5 \mathrm{~m}$ below the ground surface, 4) treating stumps with herbicide (Habitat), and 5) burying stumps 24-48 hours post herbicide application and recontouring the treatment areas to mimic the natural topography.

The timeline for project completion was short, so we had to work quickly to gather and grow plant materials to be used at the site. We began collection of live plants and seeds in the summer of 2012 and installed them in the spring of 2013. We collected seeds and cuttings from within the park and generally from within a few kilometers of the site to ensure local provenance. We started plant materials at the nursery on the South Rim of GRCA and transferred some plants to Phoenix for the winter to allow for additional growing time before planting. We collected poles of coyote willow (Salix exigua), Goodding's willow (Salix gooddingii) and cottonwood (Populus fremontii) in February 2013. Using pole cuttings is generally a fast, easy and cost-effective way to obtain plant material. We collected poles during dormancy, clipped the stems to the main branch or pole, submerged them in water for 7-10 days and then planted them into the capillary fringe of the water table (F. Phillips, pers. comm.).

Over the course of 2 days in April 2013, we planted 85 upland trees, 137 shrubs, 10 forbs, 155 sedge plugs and 140 grass plugs on site. The plants were flown in via helicopter and volunteers completed the planting. We strategically placed the potted plants based on the planting plan, and crews dug holes, mulched and watered each individual plant. We also experimented with planting some forbs and grasses along the banks of Monument Creek near the confluence with the Colorado River. The numbers of individual plants of select species are listed in Table 1. In November 2013, we did a second planting to replace some key species that did not survive or to augment areas that needed additional vegetation.

\section{Results and Discussion}

Over five months, crews removed a total of 1,667 tamarisk trees and reduced the canopy cover from an average of 72 percent across the site to 30 percent. We also took advantage of a previously scheduled High Flow Event (HFE) in November 2012 in that we removed all tamarisk from below the high water line during the first removal trip. The HFE benefitted the site by depositing a fresh layer of sand where tamarisk removal occurred and effectively transporting the tamarisk cuttings downriver while minimizing the accumulation of plant debris in eddies (fig. 1). 
Table 1. Survival of tree and shrub species planted on site from April 2013 through June 2014. The first number under the Survival (\%) for coyote willow and Goodding's willow represents survival of pole plantings while the second number represents potted plants.

\begin{tabular}{|c|c|c|c|c|c|}
\hline Common name & Scientific name & $\begin{array}{c}\text { February } \\
2013 \\
\text { planting }\end{array}$ & $\begin{array}{l}\text { April } 2013 \\
\text { planting }\end{array}$ & $\begin{array}{c}\text { November } \\
2013 \\
\text { planting }\end{array}$ & Survival (\%) \\
\hline & & $\begin{array}{c}\text { Number } \\
\text { planted } \\
\text { (all poles) }\end{array}$ & $\begin{array}{c}\text { Number } \\
\text { planted } \\
\text { (all pots) }\end{array}$ & $\begin{array}{c}\text { Number } \\
\text { planted } \\
\text { (all pots) }\end{array}$ & \\
\hline Coyote willow & Salix exigua & 118 & - & - & 50 (Feb) 100 (Nov) \\
\hline Goodding's willow & Salix gooddingii & 15 & - & 8 & 40 (Feb) 100 (Nov) \\
\hline Fremont's cottonwood & Populus fremontii & 23 & - & 2 & 20 \\
\hline Mesquite & Prosopis glandulosa & - & 45 & - & 91 \\
\hline Catclaw acacia & Acacia greggii & - & 35 & - & 88 \\
\hline Hackberry & Celtis laevigata & - & 5 & - & 100 \\
\hline Sacred datura & Datura wrightii & - & 61 & 10 & 75 \\
\hline Brittlebush & Encelia farinosa & - & 26 & 4 & 62 \\
\hline Mormon tea & Ephedra spp. & - & 7 & 10 & 52 \\
\hline Poreleaf & Porophyllum gracile & - & 11 & 4 & 45 \\
\hline Wolfberry & Lycium andersonii & - & 4 & - & 25 \\
\hline Chuckwalla's delight & Bebbia juncea & - & 17 & 2 & 30 \\
\hline Box elder & Acer negundo & - & - & 4 & 75 \\
\hline
\end{tabular}

Survival of plantings was variable due to a range of factors (table 1). Coyote willow survival was surprisingly low with only a 50 percent success rate. The high mortality can be attributed to the loss of shoreline due to fluctuating river flows and because we planted many of the poles singly instead of in groups. Based on results from work done by others and the mortality rates we observed, coyote willow poles planted in groups of three often have higher survival rates (F. Phillips, pers. comm.). We also had limited success with the Goodding's willow and cottonwood poles (table 1). Currently, there is very limited natural regeneration of Goodding's willows due to changes in the flow regime and the presence of beaver throughout the river corridor. Because of this, most of the poles we collected were from senescent trees, which may have contributed to high plant mortality. The cottonwood poles also had high mortality but the reason for this in unclear. We continued to grow out Goodding's willows and cottonwoods in the greenhouse and replaced some of the poles with tall, vigorous trees in $7.57 \mathrm{~L}$ pots in November 2013, which resulted in much higher survival rates (table 1). Very few of the plants that were installed on the creek bank survived, as there was a small flood during monsoon season. Additionally, many of the sedges planted along the shoreline of the river were washed away during the fluctuating flows of summer water releases. Despite these issues, we were able to meet our overall project objectives in the short-term and are optimistic that with sufficient maintenance that the site will continue to be dominated by native riparian vegetation and function well from both ecological and recreational perspectives. 


\section{Lessons Learned}

- Clear project objectives must be identified upfront which is a challenge in novel ecosystems.

- Conducting restoration in a backcountry setting is particularly difficult and efforts should be made to plan ahead and prepare for unforeseen impediments as much as possible.

- Working in restoration sites with open public access can be particularly challenging and appropriate limits to access need to be carefully considered.

- Planting potted and well-developed Goodding's willow's and cottonwoods is more successful but should be weighed against the ease and low cost of planting poles.

- Ensure adequate resources are secured for long-term site maintenance and monitoring.

\section{References Cited}

Mortenson, S.G., Weisberg, P.J., and Stevens, L.E., 2012, The influence of floods and precipitation on Tamarix establishment in Grand Canyon, Arizona-Consequences for flow regime restoration: Biological Invasions, v. 14, no. 5, p. 1061-1076, accessed on April 28, 2017, at http://dx.doi.org/10.1007/s10530-011-0139-z.

National Park Service, 2006, Management policies—The guide to managing the National Park System: National Park Service, Department of Interior, Washington, D.C., 274 p.

Sankey, J.B., Ralston, B.E., Grams, P.E., Schmidt, J.C., and Cagney, L.E., 2015, Riparian vegetation, Colorado River, and climate-Five decades of spatiotemporal dynamics in the Grand Canyon with river regulation: Journal of Geophysical Research—Biogeosciences, v. 120, no. 8, p. 1532-1547, accessed April 28, 2017, at http://dx.doi.org/10.1002/2015JG002991.

Zachmann, L.J., Horncastle, V., and Dickson, B.G., 2012, Colorado River management plan-

Research, monitoring, and mitigation program data analyses: The Lab of Landscape Ecology and Conservation Biology, School of Earth Sciences and Environmental Sustainability, Northern Arizona University, Flagstaff, Arizona. 68 p.
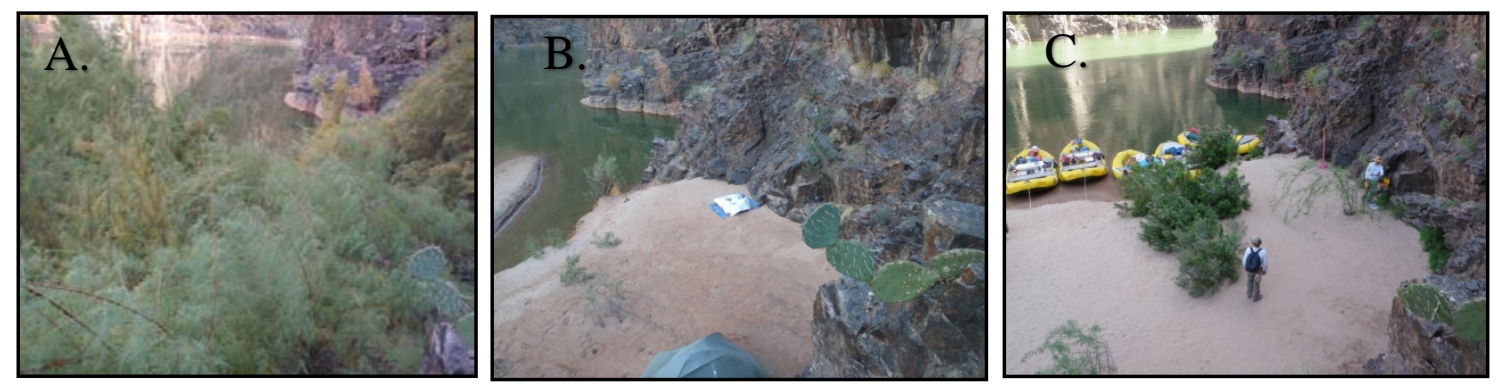

Figure 1. View of the most upriver portion of the site. A) October 2012; prior to tamarisk removal. The vegetation in the foreground is dominated by tamarisk. B) December 2012; after tamarisk removal and the High Flow Event. Note the native plants that were retained in the sandy area near the river. C) April 2015, 2.5 years post-removal. Note the rapid growth of retained native plants shown in photo b), including mesquite (Prosopis glandulosa) and seep willow (Baccharis emoryi)(photos M. McMaster, National Park Service). 


\title{
Riparian restoration following tamarisk and Russian olive control in Canyon de Chelly National Monument, Arizona
}

\author{
By Lindsay V. Reynolds ${ }^{1,2}$, and David Cooper ${ }^{3}$,
}

\section{Introduction}

Historically, riparian areas in the southwestern United States were populated by stands of native cottonwood and willows. Throughout the last century however, southwestern riparian areas have been transformed by the invasion of the exotic trees tamarisk (Tamarix ramosissima, T. chinensis, and their hybrids) and Russian olive (Elaeagnus angustifolia) (Friedman and others, 2005). Riparian areas throughout Canyon de Chelly National Monument in northeastern Arizona were invaded early in the 20th century and by 2005 tamarisk and Russian olive dominated the floodplains (fig. 1). Streams in Canyon de Chelly were historically wide, shallow and braided, with native cottonwood and willows along the margins (Webb and Leake, 2006; Cadol and others, 2011). Some of the most downstream reaches still remain wide and shallow however, the tributary canyon streams have narrowed and downcut 1 to 5 meters (m) over the last 50 years. Both the invasion of exotic trees and the downcutting of stream channels throughout Canyon de Chelly have created challenges for land managers and residents. Lowered water tables and a lack of flooding associated with stream downcutting have hampered farming in the canyon. In an effort to restore native vegetation and an active floodplain throughout the canyons, the National Park Service in collaboration with the Navajo Nation began clearing tamarisk and Russian olive throughout the canyon system in 2005. To date, approximately 800 acres of invaded area have been cleared, representing about half of the total invaded area in Canyon de Chelly. We analyzed patterns and process of exotic plant invasion into Canyon de Chelly and response of plant communities to removal methods of tamarisk and Russian olive.

\section{Methods}

Plant removals occurred in six, one kilometer-long study reaches. The upstream $300 \mathrm{~m}$ of each reach was an untreated control, and directly downstream was a $300 \mathrm{~m}$ cut-stump-herbicide treatment. Downstream of the cut-stump was a $200 \mathrm{~m}$ buffer zone with no treatment followed by a $300 \mathrm{~m}$ wholeplant treatment where tamarisk and Russian olive stems and roots were removed using a backhoe (fig. 2). Exotic plant removals were conducted from winter of 2005 through fall of 2006. Wood produced by the treatments was piled and burned on site.

To understand the history of invasion in Canyon de Chelly, we aged tamarisk and Russian olive plants in four study sites along transects perpendicular to the stream channel (Reynolds and others, 2014). Elevation of each plant was determined by topographic surveying and extracted plants were cross-sectioned and sanded. Plant cross sections were analyzed using a microscope to count annual growth rings (Reynolds and others, 2014).

To understand the role of the seed bank and plant community response to tamarisk and Russian olive removal, the soil seed bank was analyzed using samples collected in June 2007 from 12 random

\footnotetext{
${ }^{1}$ U.S. Geological Survey

${ }^{2}$ Colorado State University, Department of Biology

${ }^{3}$ Colorado State University, Department of Forest \& Rangeland Stewardship
} 
points in Canyon de Chelly, outside of our removal study sites. Four-to-six squares of topsoil were extracted at each sample location. Samples were spread onto trays in a greenhouse and watered daily. Seedlings were identified and removed through one year of study (Reynolds and Cooper, 2011). Vegetation in the removal treatment sites was analyzed in plots along transects in the six sites. Three transects were aligned perpendicular to the canyon wash in each control and treatment, spaced $100 \mathrm{~m}$ apart, yielding nine transects in each study site. Each transect spanned the riparian area width. Percent cover of woody and herbaceous species was estimated in each of the plots and Wetland Indicator Scores were calculated for all species in plots and in the soil seed bank samples (Reynolds and Cooper, 2011).

To understand abiotic response to exotic plant removal, we analyzed water table and soil nitrogen in our sites. Water table depth was measured weekly during the summers of 2005-2007 using ground water monitoring wells along transects in each site (Reynolds and Cooper, 2011). Soil nitrogen (N) availability was analyzed using ion exchange resin bags, which absorbed available nitrate and ammonium from the soil and provide an estimate of plant-available soil N. Following removal treatments, soil $\mathrm{N}$ was analyzed near cut-stump Russian olives and in adjacent meadows that lacked Russian olives. Resin bags were installed in September of 2006 and 2007 and collected in March of 2007 and 2008 (Reynolds and Cooper, 2011).

\section{Results \& Discussion}

Following the removal of the exotic shrubs tamarisk and Russian olive, a shift occurred in our study sites toward plant communities that are drier and support more upland species than occurred in the past (fig. 3). This shift began with a dramatic reduction in overbank flooding and lowering of the ground water table over the last thirty years as the stream downcut through many reaches of Canyon de Chelly (Cadol and others, 2011; Reynolds and others, 2014). Stream downcutting was concurrent with major invasion of tamarisk and Russian olive in the 1980s and 90s, and then followed by a transition of the understory vegetation to more upland plant species (Reynolds and Cooper, 2011; Reynolds and others, 2014). Historic vegetation, as reflected by the soil seed bank, contained more wetland species, more native species, and fewer exotic species (Reynolds and Cooper, 2011; fig. 3). Because cottonwood and willow seeds are short-lived they are not represented in the seed bank, so we measured their historical presence through our aging analysis and a previously published aerial photo analyses (Cadol and others, 2011; Reynolds and others, 2014). A viable soil seed bank dominated by native species has persisted for many decades, including twice as many riparian species as the extant vegetation (Reynolds and Cooper, 2011).

Exotic shrub removal effectively reduced seed inputs from tamarisk and Russian olive into treatment plots and lowered the likelihood of reinvasion (Reynolds and Cooper, 2011). However, tamarisk and Russian olive removal did not affect ground water dynamics. The water table at our sites was deep, varying from 1 to $6 \mathrm{~m}$ below the floodplain, but did provide perennially available water to deep-rooted plants (Reynolds and Cooper, 2011). Ecosystem nutrient levels were impacted by shrub removal, but the change had no effect on the plant community. The decomposing roots of Russian olive trees killed by the cut-stump method provided a short-term increase in available soil nitrogen. However, increased nitrogen near Russian olive stumps did not influence the cover of exotic or native species in our herbaceous vegetation plots (Reynolds and Cooper, 2011).

Whole-plant removal of exotic shrubs provided complete removal of target shrubs, including their roots, but was costly, labor-intensive, and provided no increased benefit to native vegetation establishment over the cut-stump method (fig. 3). Both shrub removal methods resulted in similar decreases in exotic species cover, increases in native cover, and had little effect on species richness or wetland species (fig. 3; Reynolds and Cooper, 2011). 
Further, grazing by horses, cows and sheep is a persistent challenge in the Canyon de Chelly ecosystem, which we did not address. The installation of grazing exclosures in tamarisk and Russian olive removal areas after our study was finished, suggests native plant recovery can be enhanced by excluding grazers for a period of time (B. Wolk, oral comm., 2015).

There is great potential for native riparian species colonization of treatment sites from the soil seed bank. However, because of downcutting and lack of flooding on the old floodplains, riparian and wetland plants can no longer persist in these sites. Following the removal of tamarisk and Russian olive, our study sites are transitioning to dry grasslands, as indicated by an increased abundance of native upland species (Reynolds and Cooper, 2011). Many rivers in western North America have experienced floodplain abandonment due to downcutting, river regulation by dams, or both (Tockner and Stanford, 2002). Our results are applicable to sites across western North America where tamarisk and Russian olive stands rarely or infrequently flood and where establishment following exotic plant removal is likely to be upland, not riparian species. Restoration of historic riparian communities along rivers that have incised may not be possible, therefore land managers should consider strategies for facilitating native upland species in exotic riparian removal sites.

\section{Lessons Learned}

- Hydrology should be considered when restoring riparian sites. Where sites have dried due to stream downcutting and lack of flooding, target species should be native, upland plants.

- Cut-stump removal is more cost effective at removing exotic shrubs and results in equally species-rich native plant communities as whole-plant removal.

- Continued monitoring is needed in all restoration areas.

- Seed additions of native plants may be beneficial to recovery of native plant communities.

- Management of grazing is needed in addition to monitoring recovering plant communities.

\section{References Cited}

Cadol, D.D., Rathburn, S.L., and Cooper, D.J., 2011, Aerial photographic analysis of channel narrowing and vegetation expansion in Canyon De Chelly National Monument, Arizona, USA, 1935-2004: River Research and Applications, v. 27, no. 7, p. 841-856, doi: 10.1002/rra.1399.

Friedman, J.M., Auble, G.T., Shafroth, P.B., Scott, M.L., Merigliano, M.F., Freehling, M.D., and Griffin, E.K., 2005, Dominance of non-native riparian trees in western USA: Biological Invasions, v. 7, no. 4, p. 747-751, doi: 10.1007/s10530-004-5849-z.

Reynolds, L.V, and Cooper, D.J., 2011, Ecosystem response to removal of exotic riparian shrubs and a transition to upland vegetation: Plant Ecology, v. 212, no. 8, p. 1243-1261, doi: 10.1007/s11258-0119901-7.

Reynolds, L.V, Cooper, D.J., and Hobbs, N.T., 2014, Drivers of exotic riparian tree invasion on a desert stream: River Research and Applications, v. 30, no. 1, p. 60-70, doi: 10.1002/rra.2619.

Tockner, K., and Stanford, J.A., 2002, Riverine flood plains-Present state and future trends: Environmental Conservation, v. 29, no. 3, p. 308-330, doi: 10.1017/S037689290200022X.

Webb, R. H., and Leake, S. A., 2006, Ground-water surface-water interactions and long-term change in riverine riparian vegetation in the southwestern United States: Journal of Hydrology, v. 320, no. 3-4, p. 302-323, doi: 10.1016/j.jhydrol.2005.07.022. 


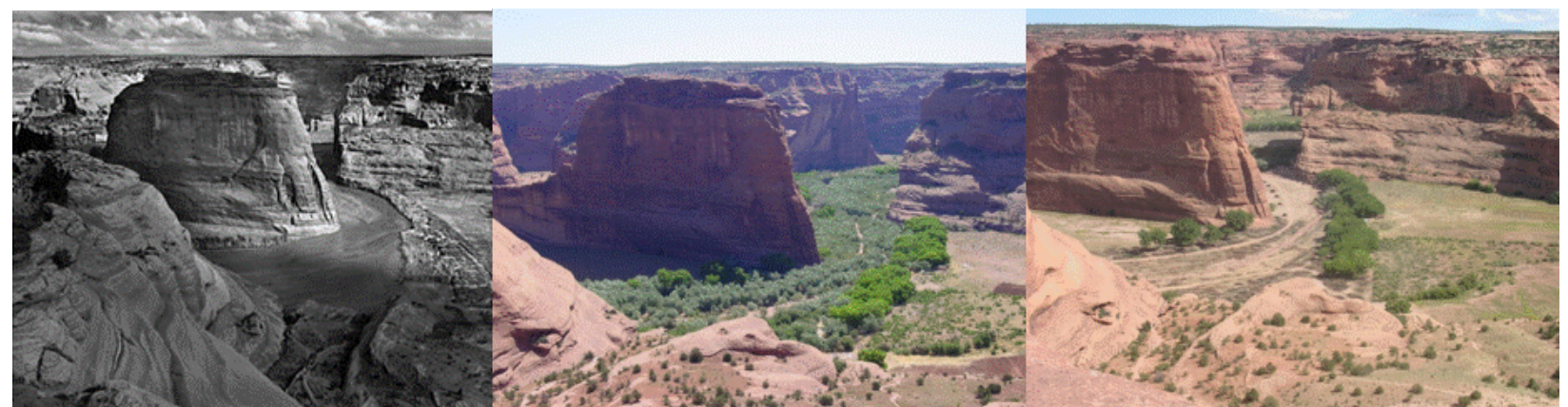

Figure 1. Photographs of Chinle Wash at White House Ruins overlook facing northeast, Canyon de Chelly National Monument, Arizona. Left photo was taken in 1942 by Ansel Adams (National Archives), middle photo was taken in 2005 by D. Cooper, right photo was taken in 2006 by L. Reynolds following removal of tamarisk and Russian olive at the site.

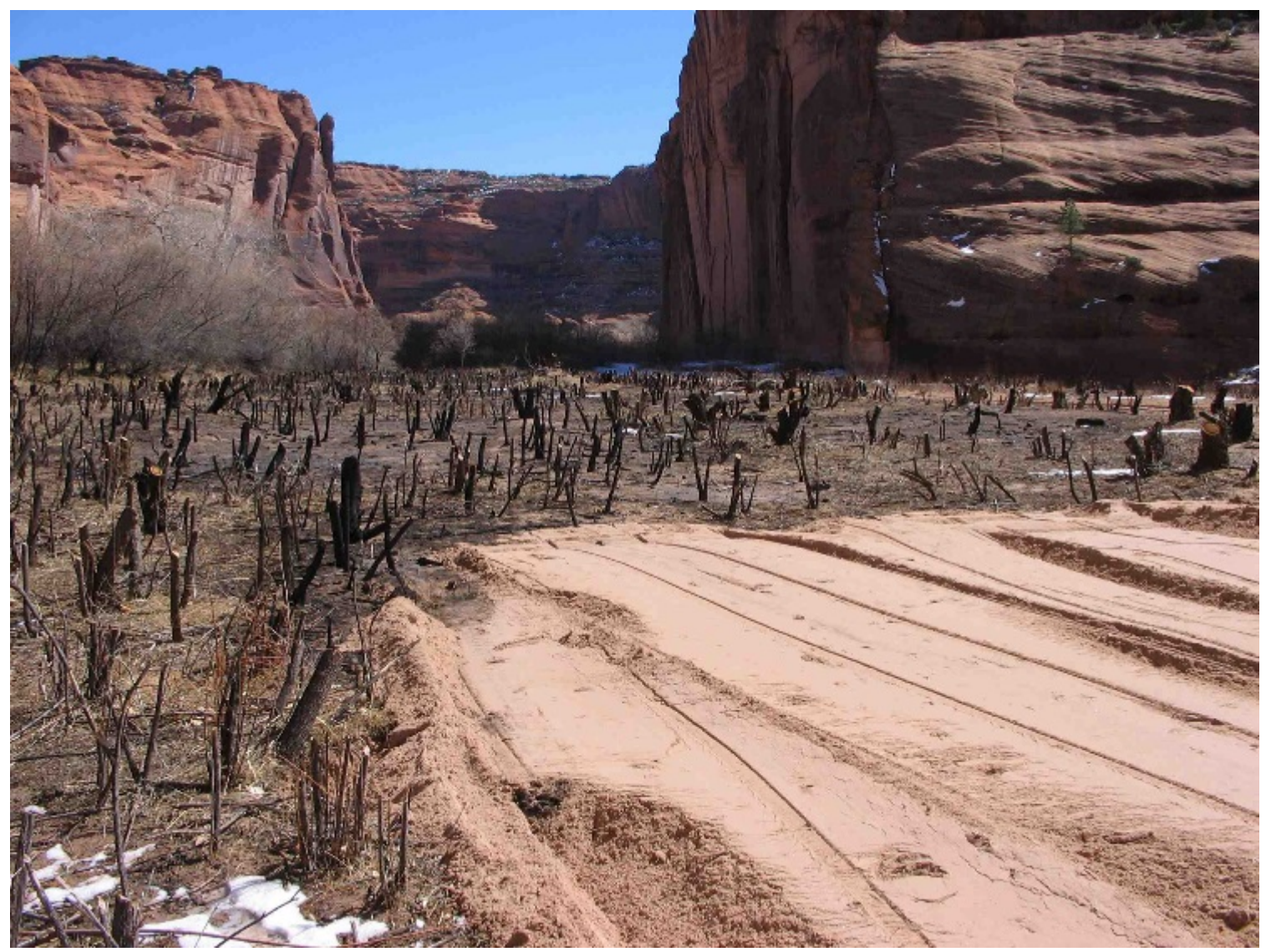

Figure 2. Photograph of tamarisk and Russian olive removal treatment: cut-stump shown on the left and wholeplant removal on the right (photo L. Reynolds, Colorado State University). 


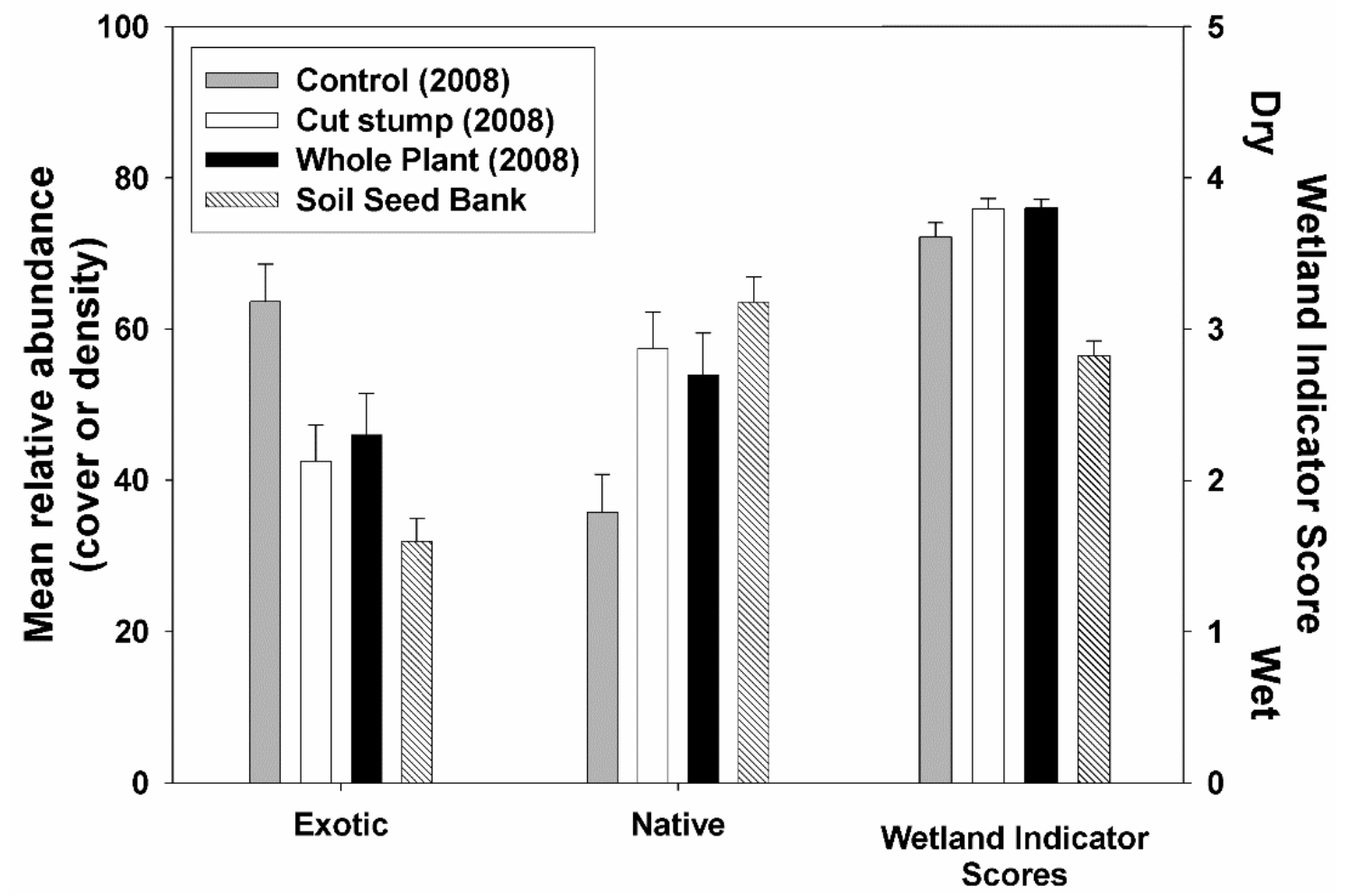

Figure 3. Graph of relative abundance (+standard error (SE) bars) (cover for treatments and density for seed bank: left axis) of exotic and native species and mean wetland indicator scores (right axis) for herbaceous plants in 2008 in treatment and seed bank sites: control (gray), cut-stump (white), whole-plant (black), and seed bank (hatched). See Reynolds and Cooper (2011) for more details. 


\title{
Riparian and Wetland Restoration Effects on Bird and Butterfly Communities on the Colorado River
}

\author{
By Heidi Trathnigg ${ }^{1}$, and Fred Phillips ${ }^{1}$
}

\section{Introduction}

The riparian and wetland habitats of the lower Colorado River through Yuma, Arizona, have been degraded by flow regulation, water development projects, agricultural development, timber harvesting, and non-native species invasion. This degradation has caused a decline in wildlife communities, including birds and butterflies. To improve habitat, restoration efforts including removal of non-native species; re-contouring riparian habitat; creation of wetlands and a mile-long backwater channel; and planting native riparian and wetland plants have occurred at the Yuma East Wetlands (YEW), Yuma County, Arizona.

Butterflies can serve as a good indicator of ecological health because larvae often have specific host plants (Nelson, 2007), adults are nectar generalists, some species can quickly respond to environmental change (Erhardt, 1985; Scoble, 1992), and they occupy a broad range of ecological niches (Scoble, 1992). Bird communities may quickly re-colonize areas that have experienced improvements in habitat quality, particularly in restored habitats. The structure and composition of vegetation often strongly influences the distribution of birds and successful breeding strategies.

We evaluated the effect of on-going riparian and wetland restoration on the richness and density of breeding birds, richness and abundance of butterflies, vegetation cover, nectar resources, and host plant abundance in restored and control riparian and wetland sites at the YEW. Evaluating the effects of habitat restoration on the recovery of wildlife communities can help establish success criteria for riparian and wetland restoration, determine if restoration techniques sufficiently address the needs of the wildlife community, and redefine restoration strategies.

\section{Methods}

In 2001, the Yuma Crossing National Heritage Area initiated the YEW Restoration Project as a multi-stakeholder effort to restore native riparian and wetland habitats (Phillips and others, 2009). They have currently restored over 142 hectares (ha) of native riparian and wetland habitats. Restoration activities included excavating a series of backwater channels (a total of $2.4 \mathrm{~km}$ ) along contours of historic channels connected to the Colorado River. A series of stop-log structures, mimicking historic pulse flows, flood the channels and allow for flood irrigation to surrounding riparian and wetland habitats. Site alterations created approximately, 60.7 ha of native wetlands dominated by California bulrush (Schoenoplectus californicus), threesquare bulrush (Schoenoplectus pungens), and cattail (Typha sp.) connected to the backwater channels. In areas where salinity exceeded the tolerance of other native riparian species, the Heritage Area planted salt-tolerant species such as: inland saltgrass (Distichlis spicata), alkali sacaton (Sporobolus airoides), western sea purslane (Sesuvium verrucosum) and salt heliotrope (Heliotropium curassavicum). Finally, the Heritage Area planted riparian areas dominated by cottonwood, willow, and mesquite (Prosopis spp.) with an understory of native grasses and flowering plants.

\footnotetext{
${ }^{1}$ Fred Phillips Consulting, LLC
} 
We surveyed riparian birds using the intensive area search method (Great Basin Bird Observatory, 2010) in ten plots systematically located in restored and control riparian habitats. We placed five restored plots in areas dominated by cottonwood and willow with an understory of native herbaceous and grass species. We then placed five control plots in saltcedar and arrowweed (Pluchea sericea) areas. Plots ranged in size from 1-3 ha to include several breeding territories of land birds. We conducted area searches during the time period of the highest breeding activity for most riparian birds: early April- June 2011. We considered birds detected in the plot three times or with observed nesting evidence as residents.

We conducted marsh bird surveys three times over the typical marsh bird breeding season: March 15-May 31, 2008 and 2011 in eight restored wetland and eight control wetland areas. Points were located 200m apart to prevent double counting. We used a combination of methods to detect nesting activities of birds that breed in wetlands, which included 1) the National Marsh Bird Monitoring Program protocol developed by USFWS, and 2) variable circular plots to detect other nesting birds. We recorded all birds visually and audibly detected in $10 \mathrm{~m}$ increment bands around the center of the plot up to $100 \mathrm{~m}$ for a total of 5 minutes per point.

We sampled butterflies during May, June, July and September 2011 in restored and control riparian habitats. We established five transects of $100 \mathrm{~m}$ in length in each of the control and restored riparian plots discussed above. We identified butterfly species encountered along each transect and recorded their location along the transect (in meters) during timed searches. One minute per every $20 \mathrm{~m}$ was spent searching for butterflies. In addition to the location, we recorded behavior for the butterfly, including basking, flying, nectaring, etc. If a butterfly was nectaring, we identified the plant species. If we detected multiple individuals of one species in the same location and conducting the same behavior, we recorded the number of individuals.

To determine if habitat characteristics and host plant frequency differed between restored and control plots, we measured total vegetation volume (TVV) at 30 randomly selected points in the riparian habitats and 20 points in the wetland habitats after completing the breeding bird surveys. At each TVV point, we measured a three-meter radius circle for riparian areas and two-meter radius circle for wetland areas around each point to estimate vegetation species cover. We used the Daubenmire Cover Scale to estimate percent cover for each vegetation species in the plot using the following vegetation strata classes, including: herb ( $<0.5 \mathrm{~m}$ ), shrub (woody stems, $0-4 \mathrm{~m}$ ), medium canopy (4- $6 \mathrm{~m})$ and tall canopy $(>6 \mathrm{~m})$. To estimate the availability of nectar plants and blooms for butterflies, we established $3 \mathrm{~m}$ diameter plots every $10 \mathrm{~m}$ along the butterfly transects. At each plot, we tallied the plants with blooming flowers by species and the number of inflorescences counted.

\section{Results and Discussion}

The restored riparian habitats had a four-fold higher total resident bird density than the control riparian habitats (Independent sample T-test; $t=1.729, p=0.018$, fig. 1 ). Mourning doves (3 individuals/hectare) and verdins (4 individuals/hectare) had the highest densities in the restored riparian habitats. We identified a total of 15 species as residents in the restored habitats and only 9 species as resident species in the control habitats; however this difference was not significant $(t=1.283, p=0.386)$.

The study also found butterfly richness correlated $(\alpha=0.10)$ to percent herbaceous vegetation $(p=0.055)$ and flowering species richness $(p=0.061)$ and abundance $(p=0.047)$.

In wetland sites, we found bird richness and abundance significantly higher in restored sites compared to control sites. We detected six endangered Yuma clapper rails (Rallus longirostris yumanensis) in the restored wetlands with evidence of breeding. We observed other marsh birds, such as 
least bitterns (Ixobrychus exilis) and soras (Porzana carolina) in both the restored and control wetland habitats.

The results of this study indicate that restoring structural complexity to native plant communities in riparian and wetland habitats on the Lower Colorado River can have a positive effect on bird and butterfly density, richness, and abundance. A diverse native understory comprised of grasses and flowering forbs and shrubs was a particularly important component to structural and species diversity in restored riparian and wetland sites. The understory contributed to the higher plant species diversity and percent herbaceous cover detected in restored riparian sites and percent herbaceous cover in restored wetland sites than their control equivalents.

Studies have shown the importance of understory nectar plants in structuring butterfly assemblages (Nelson and Andersen, 1999; Fleishman and others, 2005). However, many riparian restoration projects, particularly on the lower Colorado River, do not plant native understory forbs (Nelson and Andersen, 1999). Although not tested, regular flood irrigation in the riparian sites at the YEW may provide other required resources for butterflies, including: increased nectar production, increased host plant production, and a drinking water source. A diverse native understory provides competition to recolonizing invasive species, beneficial nectar resources and host plants for butterflies, and habitat complexity for bird and other wildlife species.

\section{Lessons Learned- Implications for Riparian Restoration}

- Plant riparian and wetland restoration projects with diverse native understory plants to enhance structural complexity, provide wildlife and butterfly habitat, butterfly host and nectar plants, and suppress invasive plant recolonization.

- Regular irrigation may increase nectar production, host plant density, and provide a drinking water source to butterflies and bird communities.

- Suitable habitat corridors may be necessary to recover riparian obligate butterfly species.

- The riparian obligate bird community will begin to recover once a site is planted, but some species require more mature sites.

\section{References Cited}

Erhardt, A., 1985, Diurnal Lepidoptera-Sensitive indicators of cultivated and abandoned grassland: Journal of Applied Ecology, v. 22, no. 3, p. 849-861, accessed on April 28, 2017, at http://www.jstor.org/stable/2403234.

Fleishman, E., Mac Nally, R., and Murphy, D.D., 2005, Relationships among non-native plants, diversity of plants and butterflies, and adequacy of spatial sampling: Biological Journal of the Linnean Society, v. 85, no. 2, p. 157-166, accessed on April 28, 2017, at http://dx.doi.org/10.1111/j.10958312.2005.00479.x.

Great Basin Bird Observatory, 2010, Nevada bird count-Intensive area searches and spot mapping: Great Basin Bird Observatory’s Protocol for Conducting Bird Surveys using Intensive Area Search and Spot Mapping Methods, 37 p.

Nelson, S.M., and Andersen, D.C., 1999, Butterfly (Papilionoidea and Hesperioidea) assemblages associated with natural, exotic, and restored riparian habitats along the lower Colorado River, USA: Regulated Rivers-Research \& Management, v. 15, no. 6, p. 485-504, accessed on April 28, 2017, at http://dx.doi.org/10.1002/(SICI)1099-1646(199911/12)15:6<485::AID-RRR550>3.0.CO;2-Z 
Nelson, S.M., 2007, Butterflies (Papilionoidea and Hesperioidea) as potential ecological indicators of riparian quality in the semi-arid western United States: Ecological Indicators, v. 7, no. 2, p. 469-480, accessed on April 28, 2017, at http://www.sciencedirect.com/science/article/pii/S1470160X06000513. Phillips, F., Flynn, C., and Kloeppel, H., 2009, At the end of the line-Restoring Yuma east wetlands, Arizona: Ecological Restoration, v. 27, no. 4, p. 398-406, doi: 10.3368/er.27.4.398.

Scoble, M.J., 1992, The Lepidoptera-Form, function and diversity: Oxford University Press, Oxford, 404 p.

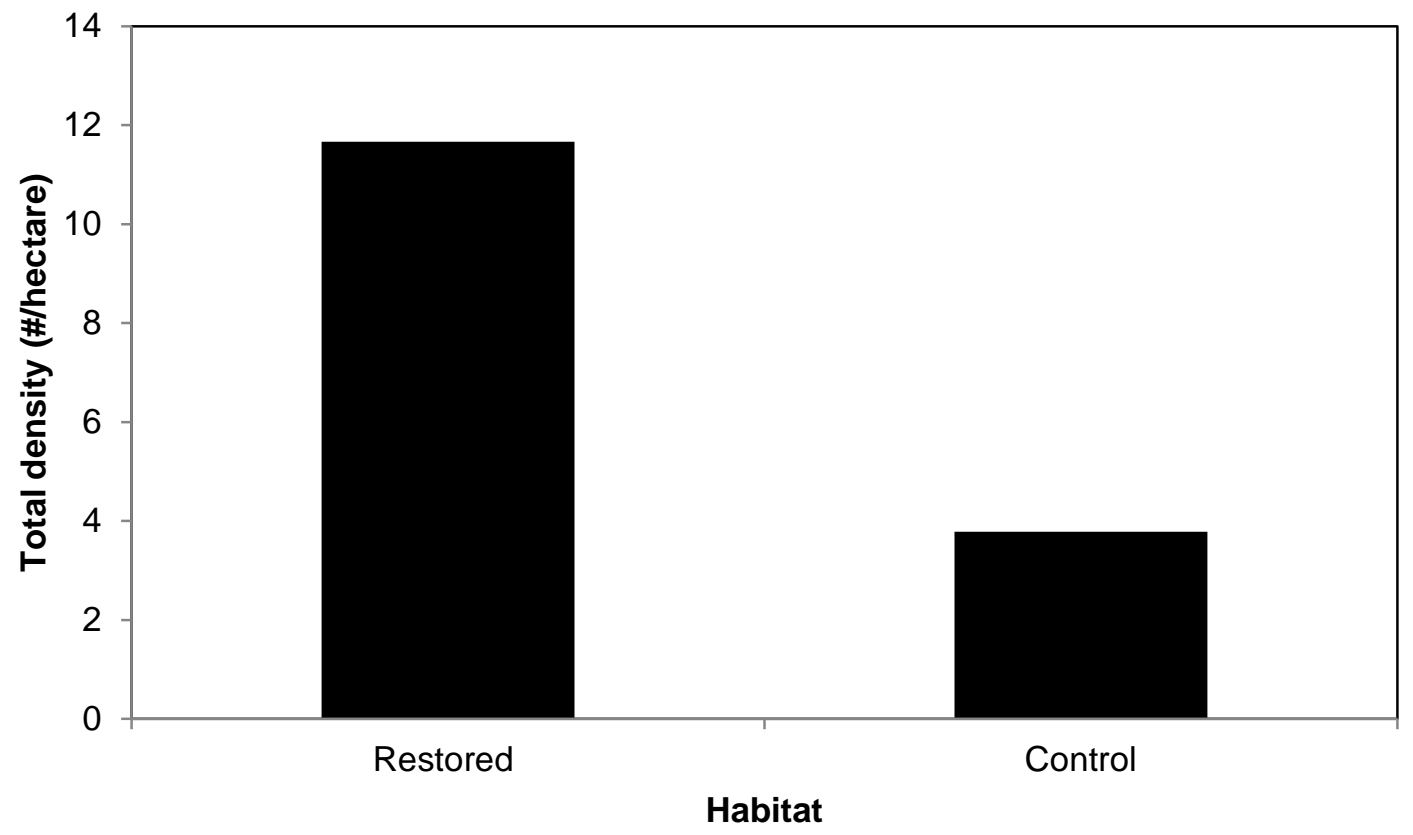

Figure 1. Total resident bird density (\#/hectare) in restored versus control riparian habitats in the YEW, Yuma County, AZ (t=1.729, $p=0.018, n=5)$ for 2011. 


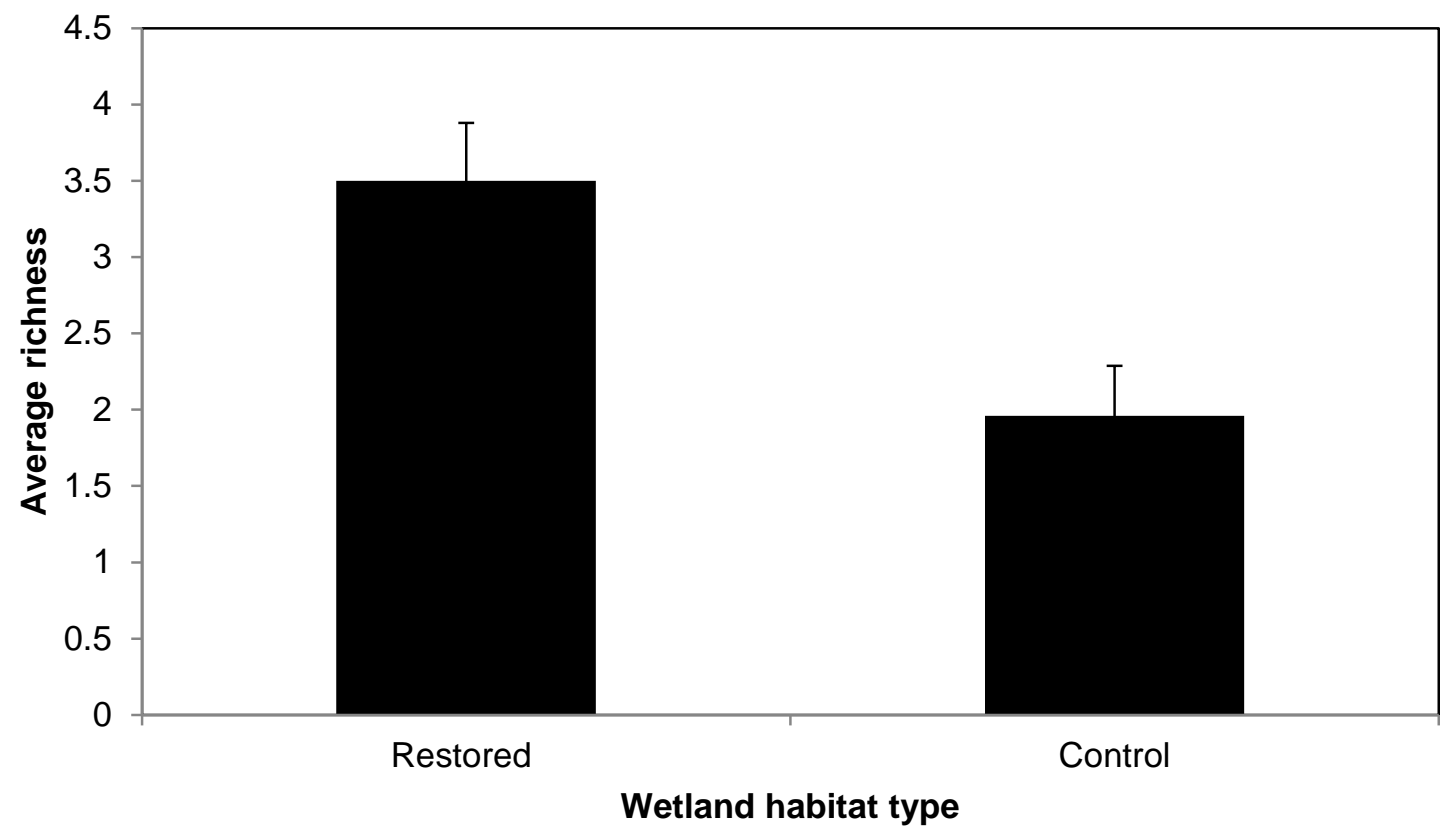

Figure 2. Average marsh bird richness in restored versus control wetland sites within the YEW, Yuma County, $A Z(T=3.073, p=0.004)$. Error bars indicate standard error. 


\title{
Tamarisk Beetle (Diorhabda spp.) in Arizona
}

\author{
By Benjamin R. Bloodworth ${ }^{1}$, and Jamie Nielsen ${ }^{1}$
}

\section{Introduction}

The tamarisk beetle (Diorhabda spp.) is a small leaf beetle that specializes on vegetation within the Tamarix genus (fig.1). It was studied as a biocontrol agent for tamarisk (Tamarix spp.) by the U.S. Department of Agriculture for more than a decade before it was approved for limited release in 2001 (DeLoach et al, 2004). There are five different beetle species in the Old World, four of which are currently present in North America, each with its own physiological drivers and physical limitations for population expansion and range (Tracy and Robbins, 2009). One of these drivers is related to critical day length (CDL), the photoperiod trigger which dictates the date a specific population of beetles enters diapause, the hibernation-like state in which adult beetles over-winter (Lewis and others, 2003). It was originally thought that the long CDL for the northern tamarisk beetle (D. carinulata) meant that this species would enter diapause too early in the season at more southern latitudes where summer day lengths are relatively short, and not survive below $38^{\circ} \mathrm{N}$ latitude, or roughly the Utah/Arizona state line (Bean and others, 2007).

The first major releases in the Colorado River Basin (CRB) were of the northern tamarisk beetle along the Colorado River near Moab, Utah in 2004. The beetle quickly expanded its range moving up and down the Colorado River, into Colorado and Arizona. As the beetles moved into Arizona the populations had enough genetic variety to quickly evolve a shorter CDL, enabling southward expansion (Bean and others, 2012). Northern tamarisk beetles continued to colonize southward in the CRB, moving as far as Davis Dam, below Lake Mojave, and south of I-40 along the Little Colorado River, by 2012. This southern progression "stalled" and these populations have remained at roughly the same latitude (around $34^{\circ} \mathrm{N}$ ) for the past couple of seasons

(http://www.tamariskcoalition.org/sites/default/files/images/2014_Diorhabda_Distribution_Map_Final_ v2.jpg). This is likely due to populations reaching a point where further CDL evolution will be a slow process. While the populations will continue to evolve, it is expected that further southward movement will be slow and incremental (Bean, pers comm 2015; Tracy, pers comm 2015).

In the time frame from 2003 to 2009, three other species of beetle were released in Texas. One of these, the subtropical tamarisk beetle (D. sublineata), does well at lower latitudes and was released along the Rio Grande downstream of El Paso, TX. This species has since moved up both the Rio Grande and Pecos River drainages into New Mexico

(http://www.tamariskcoalition.org/sites/default/files/images/2014_Diorhabda_Distribution_Map_Final_ v2.jpg). The subtropical tamarisk beetle moved swiftly north along the Rio Grande until it reached Las Cruces, NM, in late 2013. At this point the advance slowed and population expansion during 2014 was minimal. According to James Tracy (pers comm 2015), out of Texas A\&M, who develops models of tamarisk beetle movement, this slowing of spread is likely the result of high chemical usage in the Las Cruces valley, as tamarisk beetles are very sensitive to pesticide/herbicide applications.

Due to a paucity of tamarisk cover in areas along the Rio Grande, and chemical usage in the river valleys, the predictions of beetle arrival in the Gila River watershed (in southern AZ) according to the original models developed by James have been delayed. His original models showed an arrival in

\footnotetext{
${ }^{1}$ Tamarisk Coalition, Grand Junction, Colorado
} 
the middle Gila of early to mid-2017 (Tracy and others, 2013). In discussion with him, he expects that tamarisk beetle arrival will be delayed by at least $1.5-2$ years and will be determined by the density of the tamarisk canopy and the amount of chemical usage for agricultural purposes along the expected arrival pathway (Tracy, pers comm 2015). This new expected initial arrival of tamarisk beetles in the Gila (2019 to 2020) may provide a larger window of opportunity to establish vegetation and structure for wildlife that currently rely on fully foliated tamarisk. However, one must also consider the possibility of human intervention and illegal beetle movement/release and realize that beetles may be active in the river systems of Southern Arizona earlier than natural dispersal would predict.

Tamarisk beetles will eventually populate every riparian area and river reach in Southern Arizona, including the Delta. The species moving into these areas will likely not be the northern tamarisk beetle currently occupying the Upper Colorado River Basin, but will most likely be the subtropical tamarisk beetle (or some hybrid from that assemblage) moving into the area from New Mexico. The natural expansion of these populations into the Gila River drainage will depend on the tamarisk canopy cover and agricultural chemical use along the way. It is predicted that the earliest naturally dispersed arrival of the tamarisk beetle in Southern Arizona will likely be in 2019 or 2020.

Once the beetles are in an area, tamarisk will experience cycles of defoliation, refoliation, dieback, and eventual mortality, though the timing and frequency of these events are highly variable and may be dependent on site conditions, Tamarix species, or individual plant genetics (Bean and others, 2013; Hultine and others, 2013; Jamison and others, 2015). As a classical biological control agent, the beetle will never eradicate tamarisk but will instead reach equilibrium as in its native lands. With beetles in the system, tamarisk canopies will continue to be reduced, flowering will greatly diminish or cease altogether, and plant densities will decrease over time. However, beetle populations move in response to available green foliage and periods of defoliation may occur at different times in subsequent years, or may skip a year altogether (fig. 2, Jamison and others, 2015). More research is needed to ascertain longterm trends in defoliation and mortality as tamarisk beetles and their hosts move toward a new ecological balance.

\section{References Cited}

Bean, D.W., Dalin, P., and Dudley, T.L., 2012, Evolution of critical day length for diapause induction enables range expansion of Diorhabda carinulata, a biological control agent against tamarisk (Tamarix spp.): Evolutionary applications, v. 5, no. 5, p. 511-523, accessed April 28, 2017, at http://onlinelibrary.wiley.com/doi/10.1111/j.1752-4571.2012.00262.x/full.

Bean, D.W., Dudley, T.L., and Hultine, K.R., 2013, Chap. 22 Bring on the beetles-The history and impact of tamarisk biological control, in Sher, A., and Quigley, M., eds., Tamarix: A case study of ecological change in the American West: Oxford University Press, Oxford, UK, p. 377-403.

Bean, D.W., Dudley, T.L., and Keller, J.C., 2007, Seasonal timing of diapause induction limits the effective range of Diorhabda elongata deserticola (Coleoptera: Chrysomelidae) as a biological control agent for Tamarisk (Tamarix spp.): Environmental Entomology, v. 36, no. 1, p. 15-25, accessed April 28, 2017, at http://dx.doi.org/10.1603/0046-225X(2007)36[15:STODIL]2.0.CO;2.

DeLoach, C.J., Carruthers, R., Dudley, T., Eberts, D., Kazmer, D., Knutson, A.E., Bean, D.W., Knight, J., Lewis, P.A., Milbrath, L.R., Tracey, J.L., Tomic-Carruthers, N., Herr, J.C., Abbott, G., Preswich, S., Harruff, G., Everitt, J.H., Thompson, D.C., Mityaev, I, Jashenko, R., Li, Baoping, Sobhian, R., Kirk, A., Robbins, T.O., and Delfosse, E.S., 2004, First results for control of saltcedar (Tamarix spp.) in the open field in the western United States, in Cullen, J.M., Briese, D.T., Kriticos, D.J., Lonsdale, W.M., Morin, L., and Scott, J.K. eds., Proceedings of the XI International Symposium on Biological Control of Weeds: CSIRO Entomology, Canberra, Australia, p. 505-513. 
Hultine, K.R., Dudley, T.L., and Leavitt, S.W., 2013, Herbivory-induced mortality increases with radial growth in an invasive riparian phreatophyte: Annals of Botany, v. 111, no. 6, p. 1197-1206, accessed April 28, 2017, at http://dx.doi.org/10.1093/aob/mct077.

Jamison, L., van Riper III, C., and Bean, D., 2015, Chapter 13, The influence of Tamarix ramosissima defoliation on population movements of the northern tamarisk beetle (Diorhabda carinulata) within the Colorado Plateau, in Huenneke, L.F., van Riper, C., III, and Hays-Gilpin, K.A., eds., The Colorado Plateau VI—Science and management at the landscape scale: University of Arizona Press, Tucson, AZ, p. 281-291.

Lewis, P.A., DeLoach, C.J., Knutson, A.E., Tracy, J.L., and Robbins, T.O., 2003, Biology of Diorhabda elongata deserticola (Coleoptera: Chrysomelidae), an asian leaf beetle for biological control of saltcedars (Tamarix spp.) in the United States: Biological Control, v. 27, no. 2, p. 101-116, accessed April 29, 2017, at http://www.sciencedirect.com/science/article/pii/S1049964403000021.

Tracy J.T., Coulson, R., and Knutson, A.E., 2013, Projecting distribution and dispersal of subtropical tamarisk beetles, Diorhabda sublineata, towards habitat of the endangered southwestern willow flycatcher: Entomological Society of America Annual Meeting 2013, Austin, Texas, accessed July 7, 2017 at https://esa.confex.com/esa/2013/webprogram/Paper78321.html.

Tracy J.T., and Robbins, T.O., 2009, Taxonomic revision and biogeography of the Tamarix-feeding Diorhabda elongata (Brullé, 1832) species group (Coleoptera: Chrysomelidae: Galerucinae: Galerucini) and analysis of their potential in biological control of Tamarisk: Magnolia Press, p. 1152.

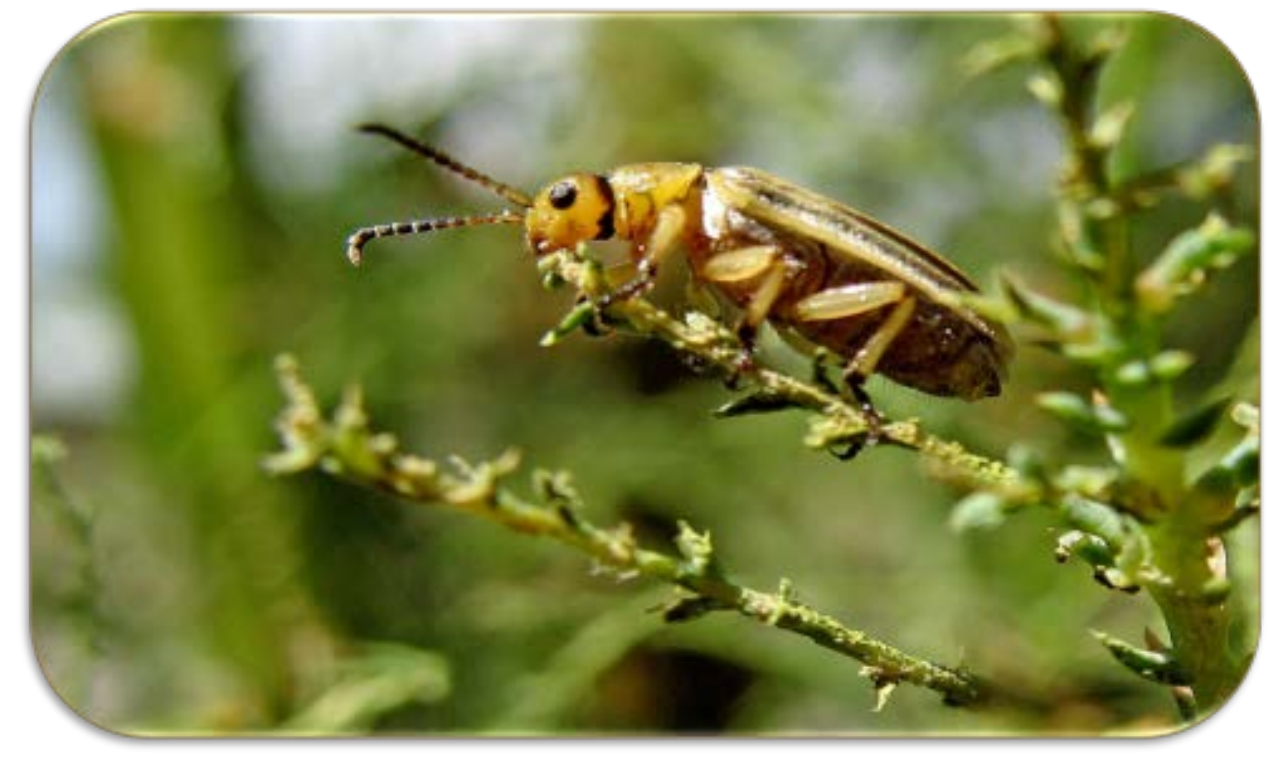

Figure 1. Adult tamarisk beetle (Diorhabda sp.) from Tamarisk Coalition. 


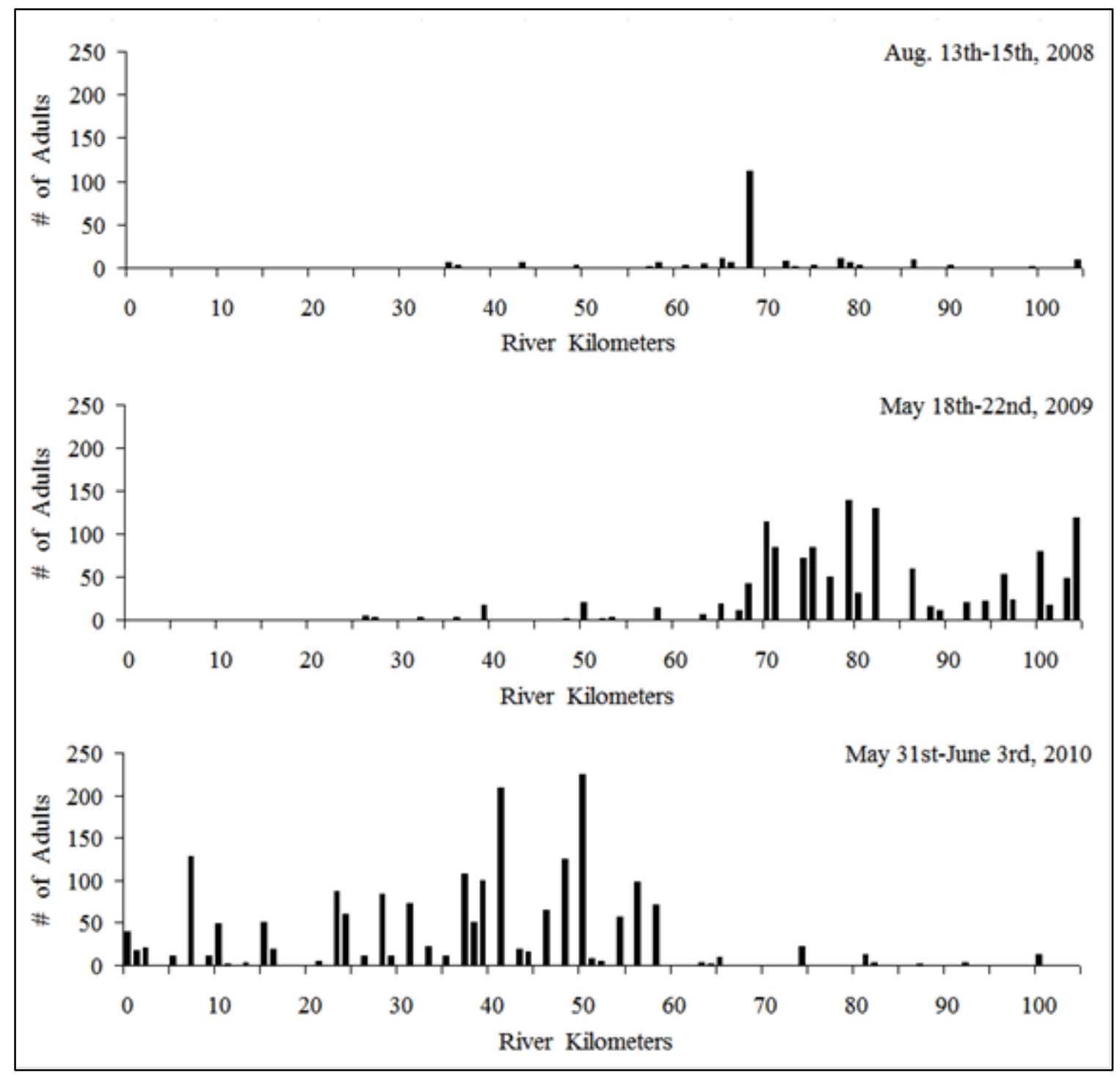

Figure 2. Adult tamarisk beetle presence along the Dolores River, Colorado, by year (from Jamison and others, 2015). 


\title{
Colorado River Riparian Ecosystem Rehabilitation in Glen Canyon National Recreation Area, Arizona
}

\author{
By Lawrence E. Stevens ${ }^{1}$, Kelly J. Burke², and Lonnie Pilkington ${ }^{3}$
}

\section{Introduction}

The riparian zone of the Colorado River ecosystem in Glen Canyon National Recreation Area has been highly altered by the construction and operations of Glen Canyon Dam since 1963, particularly through: reduced flood frequency; reduced sediment transport; the loss of focal species, such as northern leopard frog [NLF; Lithobates (Rana) pipiens], Southwestern Willow Flycatcher (Empidonax trailii extimus), and several native fish species; and colonization by nonnative tamarisk (Tamarix spp.) and other plant and fish species (Stevens, 2014). Riparian rehabilitation requires clearly defined goals, objectives, existing, and desired future riparian ecosystem conditions; a good understanding of causality in relation to flow regulation impacts; and support for practical, site-specific application of stewardship options in relation to National Park Service (NPS) mission and public interests. Through collaboration between Grand Canyon Wildlands Council, Inc. (GCWC), the U.S. National Park Service (NPS), and collaborating organizations and agencies since 2001, we planned and implemented rehabilitation and monitoring of three 1-4 ha riparian study sites and a 2 ha control site in lower Glen Canyon National Recreation Area (NRA: fig. 1). Here, we augment and update information presented in Stevens and others, (2015), and report that riparian rehabilitation efforts in lower Glen Canyon NRA have improved native plant and animal populations and habitat in accord with the National Park Service mission and ecosystem goals.

\section{Methods and Results}

Lees Ferry. The 4 ha Lees Ferry (LF) site was collaboratively selected as the highest priority for riparian rehabilitation. Photographs from 1923 (Turner and Karpiscak, 1980) showed that native Fremont cottonwood (Populus fremontii) and Goodding's willow (Salix gooddingii) phreatophyte trees existed there but were subsequently replaced by nonnative tamarisk (Tamarix spp.). After planning and compliance, tamarisk was removed at LF using large land-moving equipment in 2001-2002, and the site was revegetated with native riparian phreatophytes. Vegetation, invertebrates, and terrestrial vertebrates were monitored before treatment through 2014. Native vegetation cover increased to more than 80 percent within 3 years by 2005, and native phreatophyte tree height had exceeded $10 \mathrm{~m}$ within 6 years after treatment (Stevens and others, 2015). Post-treatment avian and herpetofaunal densities approached or exceeded those of the pre-treatment tamarisk stand and the 2 ha Paria Beach control site within three years. However, the assemblage of small rodent taxa at LF has remained a monoculture of cactus mouse (Peromyscus eremicus), and is lower in diversity than that of the control site or some other rehabilitation sites. This early project also included removal of tamarisk from 63 tributaries throughout Grand Canyon National Park (GRCA), an effort that facilitated development of GRCA's now-robust vegetation

\footnotetext{
${ }^{1}$ Museum of Northern Arizona, Biology Department, Flagstaff, Arizona

${ }^{2}$ Grand Canyon Wildlands Council, Inc., Flagstaff, Arizona

${ }^{3}$ National Park Service, Glen Canyon National Recreation Area, Resource Management Division
} 
management program. We regarded LF as a pilot rehabilitation site, one at which we were able to learn about and better plan other restoration projects, particularly those in more remote sites upstream.

Hidden Slough (Colorado River Mile -6.5R). The second highest priority NPS rehabilitation site was Hidden Slough (HS), which is remote and is only accessible by boat (figs. 1, 2). Treatment there included the following: 1) manual removal of 2.5 ha of tamarisk in November 2008, which involved 14 staff for 14 days of cutting and stacking tamarisk; 2) burning the slash by the NPS in March 2009; 3) installation of an irrigation system; 4) revegetation using native phreatophytes (primarily Goodding's willow) and seeding xeroriparian species from 2009-2012; 5) monitoring vegetation survival and growth through 2015 (Stevens and others, 2015); and 6) construction and monitoring of a 5 X 10 m, 1.5 mdeep pond in 2014 for potential translocation of NLF. Vegetation, invertebrate and vertebrate assemblage development results were similar but slower than those at LF, in part because the solar radiation budget at HS is limited by steep adjacent cliffs.

Pond construction at HS (fig. 3) was undertaken in part because the site had been used intensively studied for geohydrology and seepage erosion research in the early 1990s (e.g. Budhu and Gobin, 1994, 1995), and also because NLF had been briefly translocated there in the mid-1990's. However, monitoring of the pond and slough in 2014 - 2015 demonstrated that higher than expected groundwater electrical conductivity and temperature may limit NLF success (table 1).

Table 1. Flow and water quality summary at Hidden Slough (Colorado River Mile -6.5R) and Leopard Frog Marsh (Mile -9R) riparian restoration study sites in 2014-2015.

\begin{tabular}{|c|c|c|c|c|c|c|c|c|}
\hline Location - Site & $\begin{array}{l}\text { Flow } \\
\text { (L/sec) }\end{array}$ & $\begin{array}{l}\text { Water Temp } \\
\left({ }^{\circ} \mathrm{C}\right)\end{array}$ & $\mathrm{pH}$ & $\mathrm{EC}(\mu \mathrm{S})$ & $\begin{array}{l}\text { Salinity } \\
\text { (ppm) }\end{array}$ & $\begin{array}{c}\mathrm{DO} \\
(\mathrm{mg} / \mathrm{L})\end{array}$ & $\begin{array}{c}\text { Total } \\
\text { Alkalinity } \\
\text { (ppm) }\end{array}$ & $\begin{array}{l}\text { Depth } \\
\text { Range } \\
\text { (m) }\end{array}$ \\
\hline HS - Pond & --- & $\begin{array}{c}19.9 \\
(9.79,6)\end{array}$ & $\begin{array}{c}7.8 \\
(0.24,6)\end{array}$ & $\begin{array}{l}1824 \\
(1639,6)\end{array}$ & $\begin{array}{c}915 \\
(815,6)\end{array}$ & $\begin{array}{c}5.4 \\
(1.1,6)\end{array}$ & $\begin{array}{c}447 \\
(468,6)\end{array}$ & $0.3-0.8$ \\
\hline HS - Slough & --- & $\begin{array}{c}16.8 \\
(4.88,6)\end{array}$ & $\begin{array}{c}8.1 \\
(0.65,6)\end{array}$ & $\begin{array}{c}767 \\
(74,6)\end{array}$ & $\begin{array}{c}383 \\
(37.8,6)\end{array}$ & $\begin{array}{c}4.8 \\
(0.1,6)\end{array}$ & $\begin{array}{c}187 \\
(40,6)\end{array}$ & $0.5-1.0$ \\
\hline $\begin{array}{l}\text { LFM - Lower } \\
\text { Pond }\end{array}$ & --- & $\begin{array}{c}19.0 \\
(8.61,3)\end{array}$ & $\begin{array}{c}7.9 \\
(0.36,3) \\
\end{array}$ & $\begin{array}{c}261 \\
(18,3)\end{array}$ & $\begin{array}{c}130 \\
(9.4,3)\end{array}$ & $\begin{array}{c}4.5 \\
(4.0,3)\end{array}$ & $\begin{array}{c}127 \\
(13,3) \\
\end{array}$ & $0.6-1.2$ \\
\hline $\begin{array}{l}\text { LFM - Middle } \\
\text { Pond }\end{array}$ & --- & $\begin{array}{c}19.9 \\
(8.84,3)\end{array}$ & $\begin{array}{c}7.6 \\
(0.18,3) \\
\end{array}$ & $\begin{array}{c}354 \\
(141,3)\end{array}$ & $\begin{array}{c}177 \\
(70.6,3)\end{array}$ & $\begin{array}{c}4.3 \\
(1.5,3)\end{array}$ & $\begin{array}{c}165 \\
(110,3)\end{array}$ & $1.0-1.3$ \\
\hline LFM - Spring & $\begin{array}{c}3.7 \\
(0.8,10)\end{array}$ & $\begin{array}{c}20.9 \\
(0.59,10)\end{array}$ & $\begin{array}{c}8.4 \\
(0.14,10)\end{array}$ & $\begin{array}{c}178 \\
(17,10)\end{array}$ & $\begin{array}{c}90 \\
(7.9,10)\end{array}$ & $\begin{array}{c}5.1 \\
(0.6,10)\end{array}$ & $\begin{array}{c}88 \\
(8,8)\end{array}$ & $0.1-0.2$ \\
\hline $\begin{array}{l}\text { LFM - Upper } \\
\text { Pond }\end{array}$ & --- & $\begin{array}{c}17.5 \\
(6.65,6) \\
\end{array}$ & $\begin{array}{c}7.7 \\
(0.27,6) \\
\end{array}$ & $\begin{array}{c}439 \\
(73,6) \\
\end{array}$ & $\begin{array}{c}220 \\
(36.6,6) \\
\end{array}$ & $\begin{array}{c}4.5 \\
(1.4,6) \\
\end{array}$ & $\begin{array}{c}166 \\
(76,6) \\
\end{array}$ & $0.8-1.5$ \\
\hline $\begin{array}{l}\text { CR - } \\
\text { Mainstream }\end{array}$ & --- & $\begin{array}{c}11.5 \\
(1.78,8)\end{array}$ & $\begin{array}{c}8.1 \\
(0.21,7) \\
\end{array}$ & $\begin{array}{c}738 \\
(58,6)\end{array}$ & $\begin{array}{c}369 \\
(28.2,8)\end{array}$ & $\begin{array}{c}5.8 \\
(1.5,7)\end{array}$ & $\begin{array}{c}131 \\
(9,8)\end{array}$ & --- \\
\hline
\end{tabular}

Leopard Frog Marsh (Colorado River Mile -9L). Activities at LFM have focused on NLF pond habitat construction and water quality monitoring for potential reintroduction NLF, as well as protection of wetland Niobrara ambersnail (Oxyloma h. haydeni) and two relatively rare native plant populations (figs 1,4). This north-facing debris fan is presently strongly dominated by native common reed (Phragmites australis), which overgrew the site after adoption of the Glen Canyon Dam moderate-low fluctuating flows in 1991, a dam-release pattern designed to conserve sediment and native fishes downstream from the dam (Stevens, 2014). LFM contains a post-dam springs ecosystem (LFM 
Springs), through which the groundwater and outfow pass through the riparian zone into the mainstream. Following 2009-2011 monitoring of biota there, the partnership of the NPS, U.S. Fish and Wildlife Service, Arizona Game and Fish Department, and Grand Canyon Wildlands Council collaboratively planned and implemented NLF habitat rehabilitation, with construction overseen by GCWC since May 2014. This effort included construction of three 5 X 10 m, 1-1.5 m-deep ponds, which were excavated by hand to limit potential construction noise impacts to endangered bird species. The cooperating agencies directed GCWC to monitor flow and water and habitat quality at LFM for two years after pond construction to ensure the long-term suitability and low cost of maintenance of the NLF habitat there.

The ponds were constructed in the middle of the dense, nearly monocultural Phragmites stand, which does not support Niobrara ambersnail. We anticipated that these ponds would be inundated by high flow experimental floods (HFEs) of 1050-1275 m3/s from Glen Canyon Dam, which are conducted nearly every year to rejuvenate camping beaches and shoreline habitats downstream. The great density of Phragmites stems effectively stalls high flows, eliminating flow velocity and sedimentation impacts. Thus, construction of the ponds within the Phragmites stand protects the ponds from scouring HFE flows and sedimentation, a pattern verified during the November 2014 HFE of $1062 \mathrm{~m}^{3} / \mathrm{s}$ (Stevens, pers obs.). While the potential exists for introduction of non-native fish into the ponds during HFEs, none did so in 2014 and such populations can readily be removed by seining.

Monitoring of water quality and geomorphology at LFM reveals that the constructed ponds appear to be highly suitable for NLF translocation (table 1). There is a marked transition in water quality from the relatively warm, low-EC springs, through the ponds (which vary in water temperature seasonally), to the cold, high-EC mainstream. By virtue of the through-flowing groundwater at the site, the ponds are not subject to anoxic soils, and therefore are well-protected SHA. Our observations over the 2014-2015 growing season demonstrated that the ponds have been abundantly colonized by native aquatic invertebrates, including two species of Ephemeroptera, five species of Odonata, four species of aquatic predaceous nepomorph Hemiptera, two species of predaceous diving beetles, copepods, and other aquatic invertebrates. None of the above aquatic invertebrates are regularly or ever detected in the adjacent mainstream (Blinn and Cole, 1991; Stevens and others, 1997; Cross and others, 2011), perhaps in part due to uniform post-dam water temperatures, flow fluctuations, and SHA. In addition to invertebrate colonists, a pond survey in March 2015 revealed the first and only known tiger salamander (Ambystoma mavortium ssp.) reported from the Colorado River corridor downstream from the confluence with the San Juan River (Tanner 1958; Woodbury, 1959; Brennon and Holycross, 2006). Likely, this individual was an escaped bait animal from the 1990s which colonized and survived in the LFM spring area; however, that specimen was not collected at the time of detection due to uncertainty on the part of the collaborating agencies about its nativity. It subsequently left the pond in springtime 2015 and has not been detected since. In summary, the LFM constructed ponds appear to provide suitable NLF habitat, and may be useful for NLF translocation and restoration into the Glen Canyon reach, as well as research insights into post-dam aquatic foodbase processes. Translocation of NLF to these ponds is the purview of the NPS and the collaborating agencies.

\section{Discussion}

Overall, we demonstrate that strong partnerships can produce effective, mission-supportive rehabilitation of CRE riparian habitat. Vegetation rehabilitation resulted in little regrowth and new recruitment of non-native tamarisk at Lees Ferry and at Hidden Slough. Survivorship and growth rates of planted native phreatophyte trees was high but varied in relation to the solar radiation budget of study 
sites, with slower responses in canyon-bound areas. However, not all target animal populations respond at equivalent rates.

\section{Lessons Learned}

Several lessons learned over the past 15 years may facilitate future riparian rehabilitation efforts in the Glen Canyon reach and elsewhere in the Colorado River ecosystem:

- Robust partnership is needed to successfully accomplish mission-supportive riparian habitat rehabilitation. NGOs can provide expertise, volunteer labor, and assistance with compliance and reporting requirements to agencies that may not have sufficient financial or staff resources to undertake such projects.

- National Environmental Policy Act, Endangered Species Act, Antiquities Act, and Tribal, construction, and other legal requirements require compliance and involve considerable up-front planning, along with funding and staff time.

- Nonnative vegetation removal is labor intensive, particularly at remote sites. Disposal of slash by burning of slash is easier than chipping, piling, or transporting it off-site.

- Irrigation installation and maintenance requires much effort, with 2-3 site visits/week needed during the growing season; gravity-supported irrigation is preferable to forced flow irrigation.

- The availability and use of local, native stock is a necessity for revegetation. Soil auguring breaks up soil crusts that limit root growth. Successful revegetation techniques included planting both rooted and unrooted cuttings, and manual scattering of xeroriparian species seeds. Avoid planting invasive native species, such as cattail (Typha domingensis) and arrowweed (Pluchea sericea).

- All planted Salicaceae require protection from beaver. We used $1 \mathrm{~m}$-tall hog-wire fencing, and that fencing needs to be inspected at least semi-annually, and repaired, expanded, or replaced as needed. These exclosures around planted trees can be overtopped by HFEs, necessitating painting of trunks with sand-impregnated latex deck paint to deter beaver predation during high flows.

- Monitoring should include pre-treatment, as well as long-term post-treatment measurement of survival and growth of planted vegetation, and documentation of changing wildlife use of rehabilitated versus control sites.

- Signage, information flyers, and on-line resources help inform the public, recreational guides, and managers about restoration details and project success. Scientific publication of results provides additional outreach to the scientific community, and lends credibility to management recommendations and future actions.

- Colonization by tamarisk leaf beetle (Diorhabda carinulata) now influences riparian rehabilitation in Glen Canyon and throughout the Colorado River Basin (Hultine and others, 2010). The beetle has rapidly defoliated tamarisk, which is a dominant riparian species below $1600 \mathrm{~m}$ elevation throughout the basin. While the beetle may eventually eradicate most tamarisk in the region, north-facing sites (e.g., LFM) may be less strongly affected, and thus patches of tamarisk may persist for decades in shaded microsites along the river.

Among remaining uncertainties in the Glen Canyon reach is the impact of shallow hyporheic anoxia (SHA), which may affect groundwater quality and NFL habitat quality at the HS rehabilitation site. SHA does not appear to affect the LFM site, due to groundwater throughflow from LFM Springs. However, SHA may mobilize pollutants that may affect trophic structure in the Colorado River 
ecosystem downstream (Walters and others, 2015). Determination of how SHA is influenced by the operations of Glen Canyon Dam remain to be determined.

The choices as to which future management and research options best help the NPS achieve its stewardship goals in the Glen Canyon reach, and those about riparian rehabilitation in particular, lie principally with that agency. The results presented here demonstrate that collaborative engagement among federal and NGO partners can result in successful riparian rehabilitation, and that such actions are compatible with, and support the NPS resource management mission.

\section{Acknowledgments}

We thank the Arizona Water Protection Fund for financial and administrative support. We thank the staff of Glen Canyon National Recreation Area, the U.S. Fish and Wildlife Service, and the Arizona Game and Fish Department for collaborative partnering, particularly C. Hughes, W. Austin, P. Sponholtz, S. Hedwall, and S. McVean. We thank the Museum of Northern Arizona, for supporting Dr. Stevens' research. Coconino County Youth Conservation Corps and Wilderness River Adventures provided logistical and staff support for Hidden Slough field work. The following GCWC employees and volunteers were essential to the success of this project: R. and K. Andress, K. Burnett, R. Clark, K. Crumbo, H. Griego, M. Kaplinski and his NamTech staff, J. Ledbetter, E. Omana, and M. Tillinghast, and particularly T. Stephenson, who maintained the HS site irrigation system. We thank each of them for their enthusiastic commitment to these projects.

\section{References Cited}

Blinn, D.W., and Cole, G.A., 1991, Algal and invertebrate biota in the Colorado River-comparison of pre- and post-dam conditions, in Committee to review the Glen Canyon environmental studies water and technology board, ed., Colorado River ecology and dam management, Santa Fe, New Mexico, May 24-25, 1990, Proceedings: National Academy of Science Press, p. 102-123.

Brennon, T.C., and Holycross, A.T., 2006, A field guide to the amphibians and reptiles in Arizona: Airzona Game and Fish Department, Phoenix, Arizona, 150 p.

Budhu, M., and Gobin, R., 1994, Instability of sandbars in Grand Canyon: Journal of Hydraulic Engineering, v. 120, no. 8, p. 919-933, accessed April 28, 2017, at http://dx.doi.org/10.1061/(ASCE)0733-9429(1994)120:8(919).

Budhu, M., and Gobin, R., 1995, Seepage-induced slope failures on sandbars in Grand Canyon: Journal of Geotechnical Engineering, v. 121, no. 8, p. 601-609, accessed April 28, 2017, at http://dx.doi.org/10.1061/(ASCE)0733-9410(1995)121:8(601).

Cross, W.F., Baxter, C.V., Donner, K.C., Rosi-Marshall, E.J., Kennedy, T.A., Hall, R.O., Jr., WellardKelly, H.A., and Rogers, R.S., 2011, Ecosystem ecology meets adaptive management-Food web response to a controlled flood on the Colorado River, Glen Canyon: Ecological Applications, v. 21, no. 6, p. 2016-2033, accessed April 28, 2017, at http://dx.doi.org/10.1890/10-1719.1.

Stevens, L., 2014, The Colorado River in Grand Canyon: Grand Canyon Wildlands Council, Inc., Flagstaff, AZ, 144 p.

Stevens, L.E., Shannon, J.P., and Blinn, D.W., 1997, Colorado River benthic ecology in Grand Canyon, Arizona, USA — dam, tributary, and geomorphological influences: Regulated Rivers-Research and Management, v. 13, no. 2, p. 129-149, http://dx.doi.org/10.1002/(SICI)10991646(199703)13:2<129::AID-RRR431>3.0.CO;2-S.

Stevens, L.E., Burke, K.J., Spence, J.R., Pilkington, L., and Hughes, C., 2015, Colorado River riparian ecosystem rehabilitation in Glen and Grand Canyons, Arizona, in Huenneke, L.F., van Riper, C., III, 
and Hays-Gilpin, K.A., eds., The Colorado Plateau VI-Science and management at the landscape scale: University of Arizona Press, Tucson, AZ, p. 353-376.

Tanner, W.W., 1958, Herpetology of Glen Canyon of the ipper Colorado River Basin: Herpetologica, v. 14, no. 4, p. 193-195, http://www.jstor.org/stable/3890482.

Turner, R.M., and Karpiscak, M.M., 1980, Recent vegetation changes along the Colorado River between Glen Canyon Dam and Lake Mead, Arizona: U.S. Geological Survey Professional Paper 1132, 125 p., http://pubs.usgs.gov/pp/1132/report.pdf.

Walters, D.M., Rosi-Marshall, E., Kennedy, T.A., Cross, W.F., and Baxter, C.V., 2015, Mercury and selenium accumulation in the Colorado River food web, Grand Canyon, USA: Environmental Toxicology and Chemistry, v. 34, no. 10, p. 2385-2394, accessed April 28, 2017, at http://dx.doi.org/10.1002/etc.3077.

Woodbury, A.M., 1959, Amphibians and reptiles of Glen Canyon: University of Utah Anthropological Papers, no. 40, p. 135-148. 


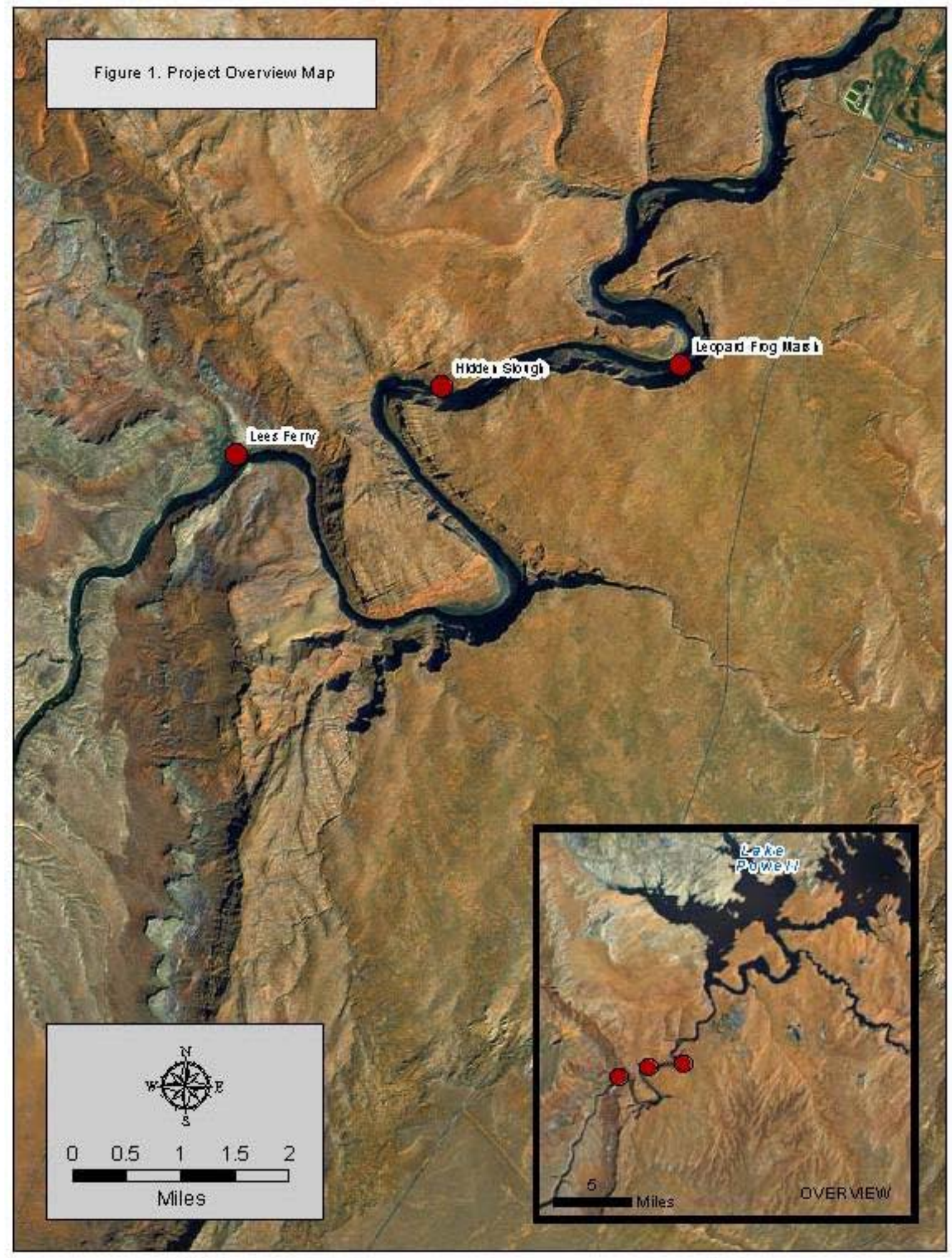

Figure 1. Map of the Glen Canyon reach showing the study sites (from Stevens and others, 2015). 


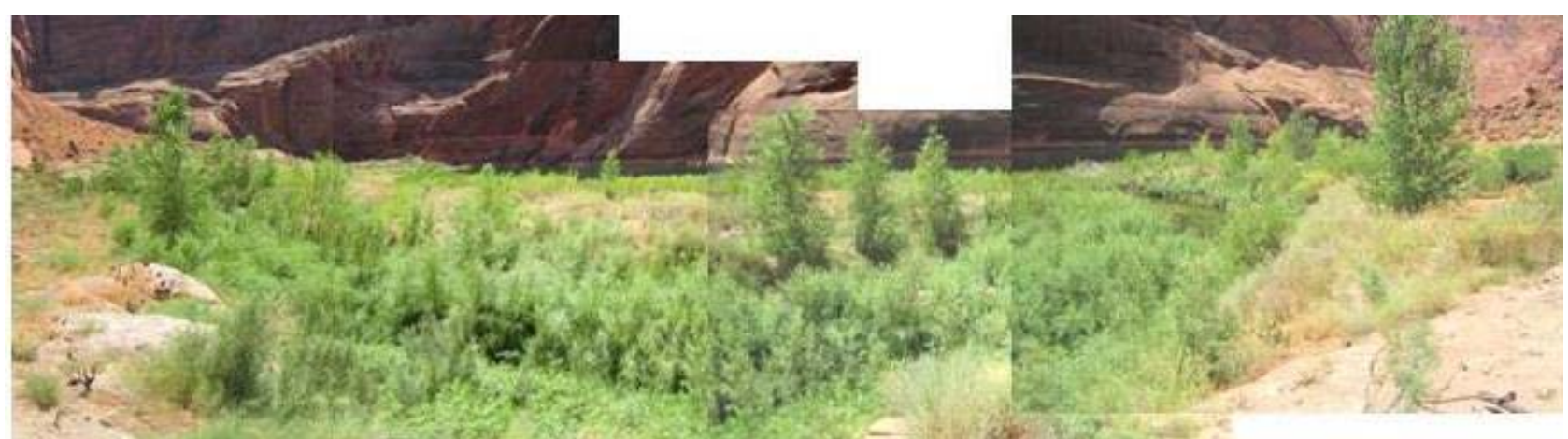

Figure 2. Panorama of Hidden Slough (Colorado River Mile -6.5R) in July 2014 (photo L. Stevens, GCWC).

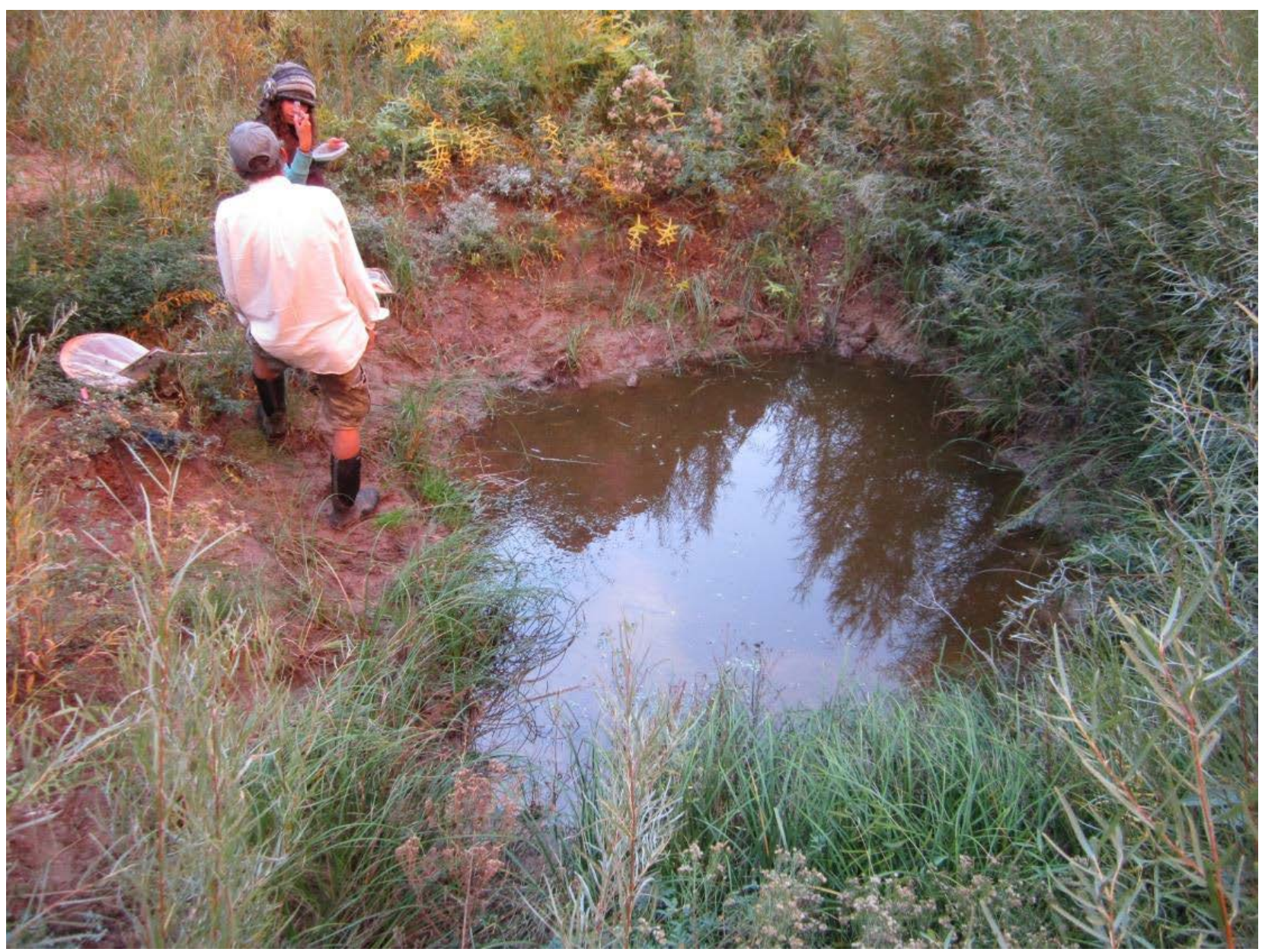

Figure 3. The Hidden Slough pond (photo L. Stevens, GCWC). 


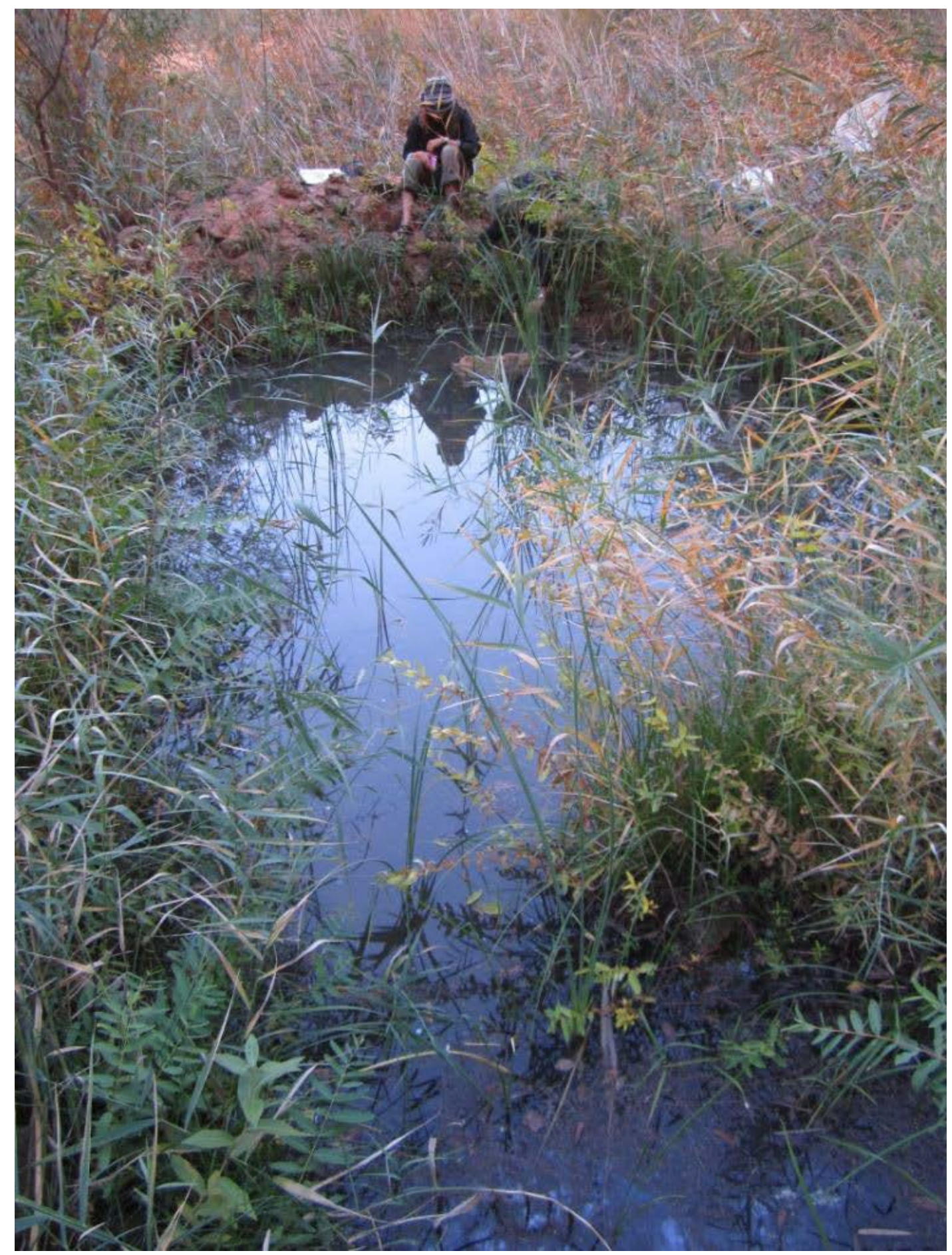

Figure 4. The Leopard Frog Marsh ponds (photo L. Stevens, GCWC). 


\title{
Section III River-Scale Restoration
}

\section{Channel Form and Riparian Vegetation: Relevant Temporal and Spatial Scales}

\author{
By John C. Schmidt ${ }^{1}$
}

\section{Introduction}

The characteristics of riparian ecosystems are directly and indirectly determined by the streamflow regime, and changes in flow regime directly and indirectly affect those ecosystems. Stream flow directly affects riparian vegetation by the magnitude, duration, and hydraulics of inundation during floods and the magnitude and duration of droughts that affect water availability to plants during dry periods of the year. Stream flow indirectly affects riparian vegetation, because stream flows transport sediment and the associated alluvial deposits are the substrate for riparian vegetation. The characteristics and patterns of riparian ecosystem response to stream-flow changes are strongly affected by the characteristics of sediment transport, planform attributes and sediment mass balance of different rivers. There is a growing body of research on the nature of these interactions.

The management objectives for riparian vegetation along rivers of the southwestern United States vary greatly from place to place. In some places, managers typically focus on finding ways to increase the area of native riparian vegetation. In many upland settings, for example, riparian vegetation communities are affected by over-grazing, and management objectives are focused on restoring and recovering those ecosystems. In the Colorado River delta and in other dewatered reaches, restoration of base flows is being used to increase the area of riparian vegetation by providing needed water during dry periods. Elsewhere, native riparian ecosystems have been invaded by non-native vegetation, and mechanical and biological control is being pursued. For example, flood control and elevated base flows along some large rivers have caused large expansion of riparian vegetation zones and have accelerated rates of channel narrowing. Management actions on these rivers are focused on reducing the area of vegetation and increasing the area of the active channel.

\section{Methods}

The field studies on which these findings are based involve a rigorous mix of temporally robust studies of channel change at the cross-section scale and spatially robust determination of channel change over long channel segments. Temporally robust studies include detailed stratigraphic interpretation of floodplain deposits that take advantage of recent advances in interpretation of tree-ring chronologies.

\section{Results and Discussion}

There are many attributes of sediment transport and geomorphology that affect riparian communities. For example, streams differ in the proportion of transported bed load and suspended load, and these differences typically lead to different degrees of lateral channel instability, processes of

\footnotetext{
${ }^{1}$ Utah State University
} 
floodplain construction, and processes of floodplain disturbance. In turn, these differences lead to different floodplain vegetation communities that are adapted to frequent, or infrequent, inundation, burial or exposure of substrate, and availability of newly deposited substrate that is either fine-grained or coarse-grained.

Riparian communities also differ along streams with different geomorphic organization, because the mechanisms of floodplain formation and lateral instability differ among multi-thread channels, confined single thread channels, debris fan-affected channels, and in deltas. The Colorado River system is organized into three different channel settings that are determined by the width of the alluvial valley and by the occurrence, or absence, of debris flows in tributary valleys (fig. 1). Nanson and Croke (1992) provided a geomorphic classification of floodplains that serves as a useful template for anticipating differences in riparian vegetation from place to place.

Where affected by construction and operations of large dams and diversions, riparian vegetation communities can be affected by the indirect effects of stream systems being perturbed into mass balance deficit or surplus that in turn leads to channel incision or sediment accumulation (Schmidt and Wilcock, 2008). Where a river has been perturbed into deficit and bed incision ensues, pre-dam floodplain ecosystems sometimes become disconnected from the post-dam flow regime due to the combination of a lower elevation post-dam channel and a reduced stage of floods. For example, this has occurred in Glen Canyon downstream from Glen Canyon Dam (Grams and others, 2007). Further downstream from Glen Canyon Dam, bed incision has not occurred, but sand bar erosion has been ubiquitous. Flood control has dominated the patterns and characteristics of riparian vegetation change (Sankey and others, 2015), and expanding vegetation has caused a 45 percent decrease in riverside campsite area and has reduced the total area of active sandbars that in turn has reduced the area of sand available as a source for aeolian sand transport (Draut, 2012). Sankey and others (2015) also showed that short-duration controlled floods released from Glen Canyon Dam since 1996 have been ineffective at removing vegetation near the channel, because these floods are of very short duration.

Where the post-dam sediment mass balance has been perturbed into surplus, floodplaininundating stream flows may interact with riparian plants and sometimes enhance the accumulation of fine sediment, as has occurred on those parts of the Rio Grande and Colorado River where suspended fine-sediment loads are large. Sediment accumulation patterns differ depending on the geomorphic organization of different stream segments. Narrowing and planform simplification have occurred throughout the region by vertical accretion of stagnating alternate bars in meandering river segments, colonization of eddy bars in debris fan-affected canyons, and by abandonment of secondary channels where the channels are multi-threaded. Dean and Schmidt (2011) described a cycle of positive feedback on the Rio Grande in the Big Bend region where invasive vegetation reduced channel capacity during periods of low flow, forcing subsequent flood water onto the floodplain, leading to continued vertical aggradation of the floodplain. Allred and Schmidt (1999) demonstrated that channel form has simplified in the Gunnison Valley of the Green River, a reach also perturbed into sediment surplus, due to abandonment of secondary channels, In some cases, the mass balance of rivers has not been perturbed but riparian vegetation has nevertheless invaded the active channel and caused channel narrowing. For example, Manners and others (2014) showed that subtle changes in the distribution of wet and dry years allowed expansion of riparian vegetation into secondary channels and onto active bars of the Yampa River.

There is a widespread assumption that mechanical removal of tamarisk (Tamarix sp.) and tamarisk defoliation by the tamarisk leaf beetle (Diorhabda elongata) have the potential to destabilize vegetated banks and floodplains. Such channel changes potentially will increase aquatic habitat complexity and allow reestablishment of channels with large width-to-depth ratios. However, field 
experiments conducted in Dinosaur National Monument involving removal of tamarisk with the intention of rejuvenating channel instability have had limited success. Tamarisk was removed from the entire length of 2 fan-eddy complexes, with removal efforts primarily focused on eddy sandbars, channel margin deposits, and channel expansion gravel bars. There was little difference between the channel cross-section response in removal and control reaches, primarily because the magnitude of flow regulation is so great that significant hydraulic stresses were never imparted on the banks (Mueller and others, 2014). These findings demonstrate the importance of understanding local hydraulic environments in predicting where vegetation removal will effectively encourage subsequent bank erosion.

\section{Lessons Learned}

The patterns and characteristics of vegetation differ from place to place. Additionally, the patterns and characteristics of modern water development differ between (a) the Southwest's largest rivers where flood control and elevated base flows have altered the flow regime of most of the Upper Colorado River basin and (b) the region's smaller, regional rivers that are typically extensively diverted to support nearby agriculture and municipal areas. In the former case, parts of the region's large rivers have been perturbed into sediment mass balance deficit and in the former case, those rivers have been perturbed into sediment surplus. The differences in sediment transport and geomorphic characteristics among southwestern streams suggest that riparian vegetation management should not proceed without understanding the geomorphic context of the river system in question. Future research concerning the effectiveness of non-native vegetation removal or the success of riparian vegetation re-establishment should differentiate among the many styles of geomorphic organization and characteristic geomorphic processes of different types of rivers.

\section{References Cited}

Dean, D.J., and Schmidt, J.C., 2011, The role of feedback mechanisms in historic channel changes of the lower Rio Grande in the Big Bend region: Geomorphology, v. 126, no. 3-4, p. 333-349, accessed April 28, 2017, at http://dx.doi.org/10.1016/j.geomorph.2010.03.009.

Grams, P.E., Schmidt, J.C., and Topping, D.J., 2007, The rate and pattern of bed incision and bank adjustment on the Colorado River in Glen Canyon downstream from Glen Canyon Dam, 1956-2000: Geological Society of America Bulletin, v. 119, no. 5-6, p. 556-575, accessed April 28, 2017, at http://gsabulletin.gsapubs.org/content/119/5-6/556.

Manners, R.B., Schmidt, J.C., and Scott, M.L., 2014, Mechanisms of vegetation-induced channel narrowing of an unregulated canyon river-Results from a natural field-scale experiment: Geomorphology, v. 211, p. 100-115, http://dx.doi.org/10.1016/j.geomorph.2013.12.033.

Mueller, E.R., Grams, P.E., Schmidt, J.C., Hazel, J.E., Jr., Alexander, J.S., and Kaplinski, M., 2014, The influence of controlled floods on fine sediment storage in debris fan-affected canyons of the Colorado River basin: Geomorphology, v. 226, p. 65-75, http://dx.doi.org/10.1016/j.geomorph.2014.07.029.

Nanson, G.C., and Croke, J.C., 1992, A genetic classification of floodplains: Geomorphology, v. 4, no. 6, p. 459-486, accessed April 28, 2017, at http://www.sciencedirect.com/science/article/pii/0169555X9290039Q.

Sankey, J.B., Ralston, B.E., Grams, P.E., Schmidt, J.C., and Cagney, L.E., 2015, Riparian vegetation, Colorado River, and climate-Five decades of spatiotemporal dynamics in the Grand Canyon with river regulation: Journal of Geophysical Research-Biogeosciences, v. 120, no. 8, p. 1532-1547, accessed April 28, 2017, at http://dx.doi.org/10.1002/2015JG002991. 
Schmidt, J.C., and Wilcock, P.R., 2008, Metrics for assessing the downstream effects of dams: Water Resources Research, v. 44, no. 4, p. 1-19, http://dx.doi.org/10.1029/2006WR005092.

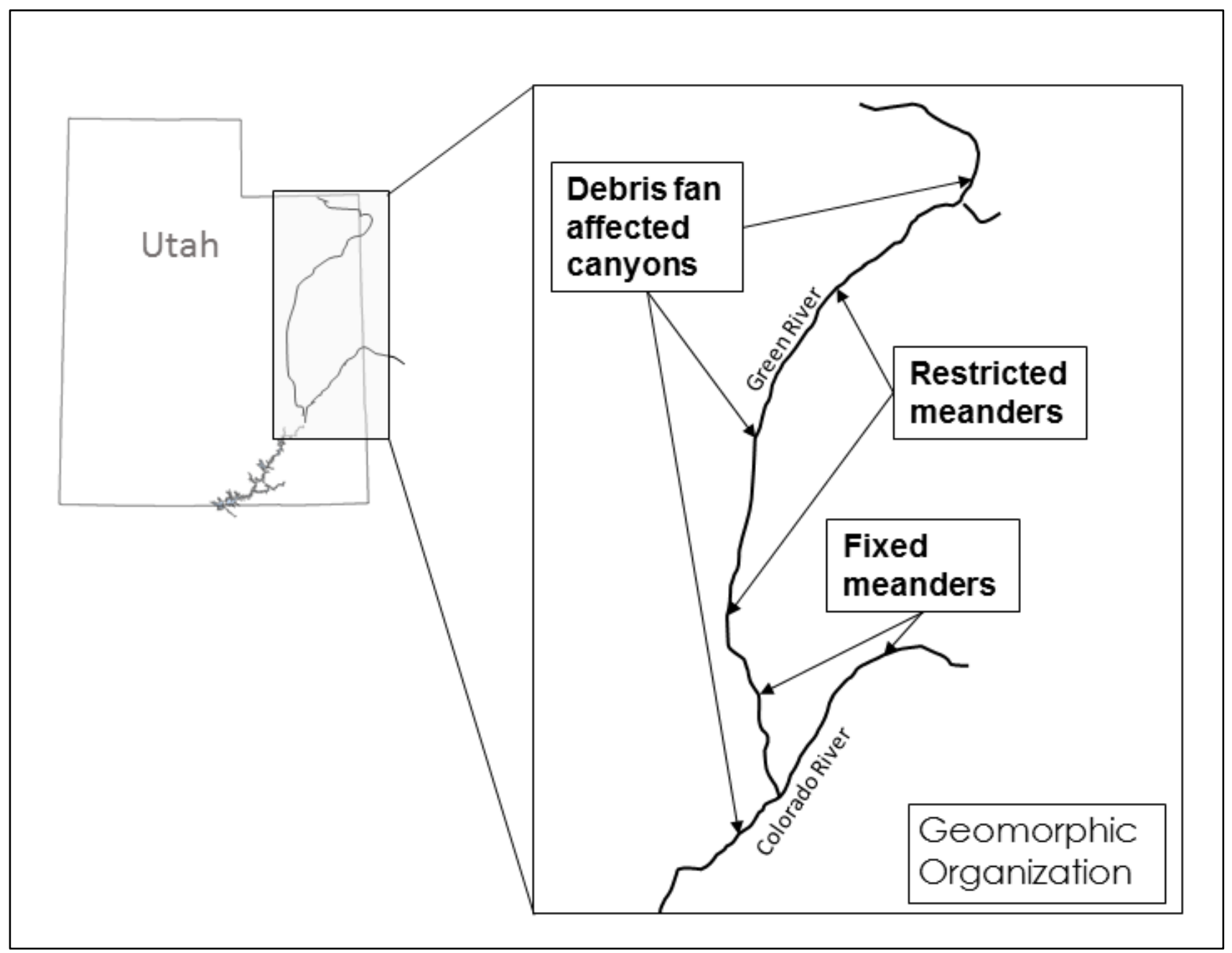

Figure 1. Geomorphic organization of different parts of the Green and Colorado Rivers in Utah. 


\title{
Parsing Out the Effects of Non-native Vegetation Management on Channel Form and Riparian and Aquatic Habitat
}

\author{
By David J. Dean ${ }^{1}$, Jeffery Bennett ${ }^{2}$, and Joe Sirotnak²
}

\section{Introduction}

Rivers throughout the desert southwestern United States have undergone substantial geomorphic change over the past few centuries. These changes have primarily consisted of channel narrowing, and floodplain accretion, which have been driven by dramatic reductions in both mean and peak stream flow caused by water development and water management activities.

The Rio Grande/Rio Bravo in the Big Bend region of far west Texas, Chihuahua, and Coahuila, is one of these rivers (fig. 1). The Big Bend reach of the Rio Grande/Bravo is 318 kilometers (km) long and extends from the confluence with the Rio Conchos downstream to Amistad Reservoir. This river undergoes repeated cycles of channel narrowing and widening, and historical accounts indicate that the Rio Grande/Bravo was a wide meandering river with a thin, patchy and discontinuous riparian zone. However, since the 1940s, channel narrowing has been greater than widening, and channel widths measured in 2008 were more than 50 percent narrower than in the 1940s. Narrowing has primarily been a result of dramatic reductions in the magnitude and duration of flood flow sourced in the upper portion of the basin, while flash floods from ephemeral tributaries continue to deliver large amounts of sediment to the river channel. During periods of low flow, vegetation (both native and non-native) establishes on low elevation surfaces, which stabilizes these deposits and reduces channel-margin flow velocities, which thereby induces additional deposition. These processes create a positive feedback, which leads to further channel narrowing and floodplain accretion (Dean and Schmidt, 2011). Channel narrowing is believed to have a negative effect on the quantity and quality of instream aquatic habitat. Therefore, channel narrowing, combined with the proliferation of non-native vegetation on channel deposits is a significant ecological concern.

Contemporaneous with binational discussions on the feasibility of an environmental flow program, a large-scale vegetation management program began in 2008. Two exotic species are the primary targets: saltcedar (Tamarix spp.) and giant cane (Arundo donax). Both are dominant throughout the riparian corridor. However, biocontrol of saltcedar (Diorhabda spp.) has led to substantial declines of that species. Giant cane exists in dense stands (fig. 2) that are of low ecologic value (Herrera and Dudley, 2003). The goals of cane removal are two-fold: 1) to destabilize banks and reduce the sedimenttrapping efficiency along the channel margins such that wider channel conditions and important aquatic habitats are maintained over time, and (2) reduce the extent of dense stands of giant cane to allow establishment of a riparian community comprised of native plants.

\section{Methods}

Management of saltcedar along the Big Bend reach of the Rio Grande began in 2002 when the Comisión Nacional de Áreas Naturales Protegidas (CONANP) began a saltcedar removal program along a $53 \mathrm{~km}$ reach in Boquillas Canyon (fig. 1). Crews from the community of Boquillas, Mexico used a

\footnotetext{
${ }^{1}$ U.S. Geological Survey

${ }^{2}$ National Park Service
} 
method that involved wounding the tree with machetes, stuffing the wound with gauze, and then applying Triclopyr to the gauze. This method resulted in 85-90 percent effectiveness as measured in the following year. With a follow up treatment, effectiveness was 100 percent. Big Bend National Park staff, along with non-federal partners implemented a companion project in 2005-2006. In 2008, a biocontrol beetle, Diorhabda spp., was released at three sites in the park and at multiple sites upstream. In 2009, additional beetles were released downstream at Black Gap Wildlife Management Area. By 2010, the saltcedar beetle was well established and widespread.

Beginning in 2008, vegetation management actions expanded to include the removal of giant cane from the Texas bank within Hot Springs Canyon. In 2010, and in subsequent years, United States and Mexican managers and bi-national partners implemented cane treatments on both sides of the river within Hot Springs and Boquillas Canyons. Cane removal consists of burning the cane breaks, and treating postfire resprouts with an aquatic-approved herbicide (Imazapyr; fig. 2). Treatment sites are monitored and retreatments occur episodically to limit the extent of resprouting.

Initial vegetation surveys were designed to determine effectiveness of control efforts, rather than detect changes in the plant community. In 2014, vegetation survey methods similar to those used on rivers of the Colorado Plateau were initiated (Ralston, 2010). The objectives of this new design are to determine the effects of the current flow regime and the past vegetation control efforts on the new and regrowing vegetation community. Total plant species richness, nonnative species richness, and percent plant cover will be determined for the entire riparian zone at selected sites. Study sites will include treated and control reaches.

Linking vegetation management to geomorphic processes has been for the purpose at hand. Recent cane removal actions have expanded into areas where channel cross sections are measured annually, and thus a pre- and post-treatment geomorphic dataset exists in those areas. Additional surveying with terrestrial light detection and ranging (LiDAR) began in February 2015 within some vegetation-management areas to begin to quantify geomorphic change in those reaches. Terrestrial LiDAR surveys are used to build high-resolution digital elevation models so geomorphic change in the removal areas, and in control reaches, can be calculated over time (fig. 3). These surveys are conducted annually.

\section{Results and Discussion}

By January of 2015, giant cane had been removed along a total length of $48 \mathrm{~km}$ of river corridor. Within saltcedar and giant cane monitoring plots, the target plants decreased in cover from 40 percent and 90 percent to less than 5 percent respectively. Bare ground increased from zero percent to greater than 60 percent and 40 percent respectively. Some fire and herbicide damage has occurred in adjacent riparian communities. These results show that vegetation management actions have been effective at reducing the abundance of these non-native riparian species, with some negative effects on adjacent areas. Measurement and analyses of the post-removal response of native plants is underway, however, these analyses are not available for inclusion in this extended abstract.

Linking geomorphic process has been challenging. In most areas, physical surveys of channel morphology were not conducted prior to vegetation treatments. A series of high flows before and during cane removal have also eroded large amounts of sediment from near-channel geomorphic surfaces. Since cane removal and high flows occurred concurrently, the geomorphic effects of each are confounded. Geomorphic surveys will continue, and it is hoped that long-term monitoring paired with vegetation management will yield insights independent of other confounding factors. 


\section{Lessons Learned}

- Identify the long-term desired conditions for plant communities prior to initiation of treatments

- Monitoring programs with clear objectives should be outlined and conducted prior to vegetation treatments. Identify funding sources and seek funding prior to initiation of treatments.

- Develop implementation plans and include clearly described roles and responsibilities of all parties prior to project initiation.

- Plan for and expect unintended fire and herbicide damage to adjacent plant communities.

- The methods of removal have proven to be successful.

- Long-term effects of treatments need to be assessed.

\section{References Cited}

Dean, D.J., and Schmidt, J.C., 2011, The role of feedback mechanisms in historic channel changes of the lower Rio Grande in the Big Bend region: Geomorphology, v. 126, no. 3-4, p. 333-349, accessed April 28, 2017, at http://dx.doi.org/10.1016/j.geomorph.2010.03.009.

Herrera, A.M., and Dudley, T.L., 2003, Reduction of riparian arthropod abundance and diversity as a consequence of giant reed (Arundo donax) invasion: Biological Invasions, v. 5, no. 3, p. 167-177, accessed April 28, 2017, at http://dx.doi.org/10.1023/A:1026190115521

Ralston, B.E., 2010, Riparian vegetation response to the March 2008 short-duration, high-flow experiment-Implications of timing and frequency of flood disturbance on nonnative plant establishment along the Colorado River below Glen Canyon Dam: U.S. Geological Survey Open-File Report 2010-1022, 30 p., http://pubs.usgs.gov/of/2010/1022/.

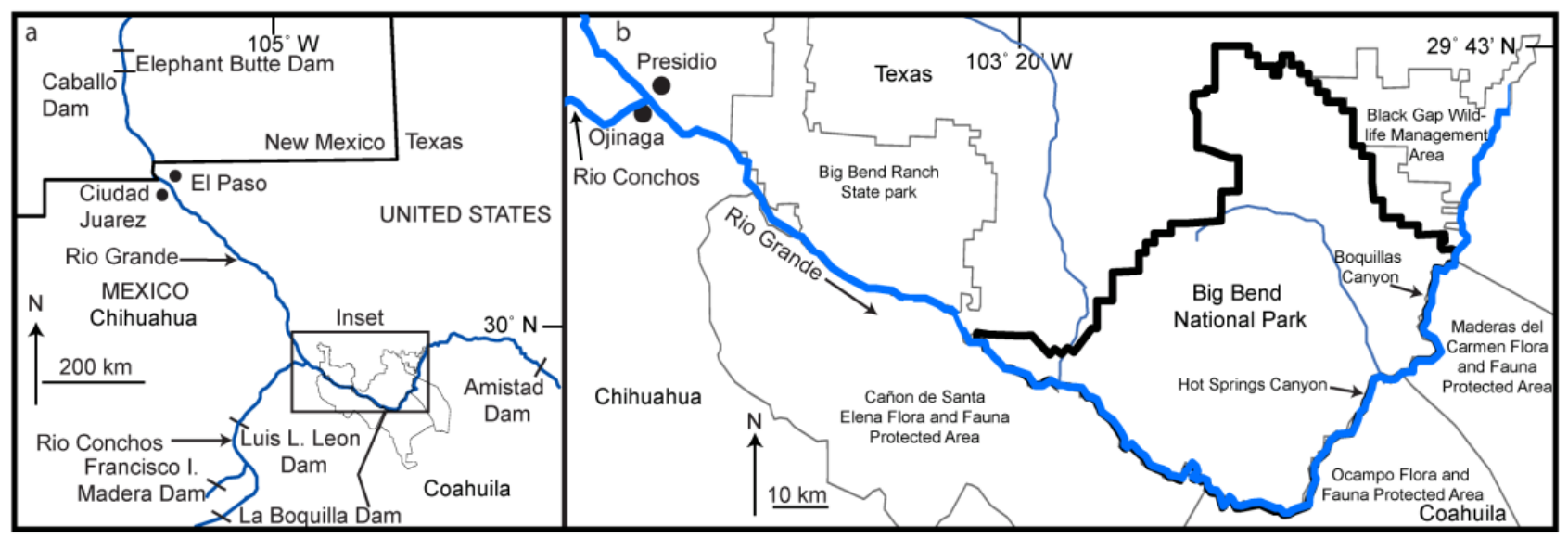

Figure 1. Regional map of the Big Bend region (a). Map of the Big Bend region depicting study areas (b). 

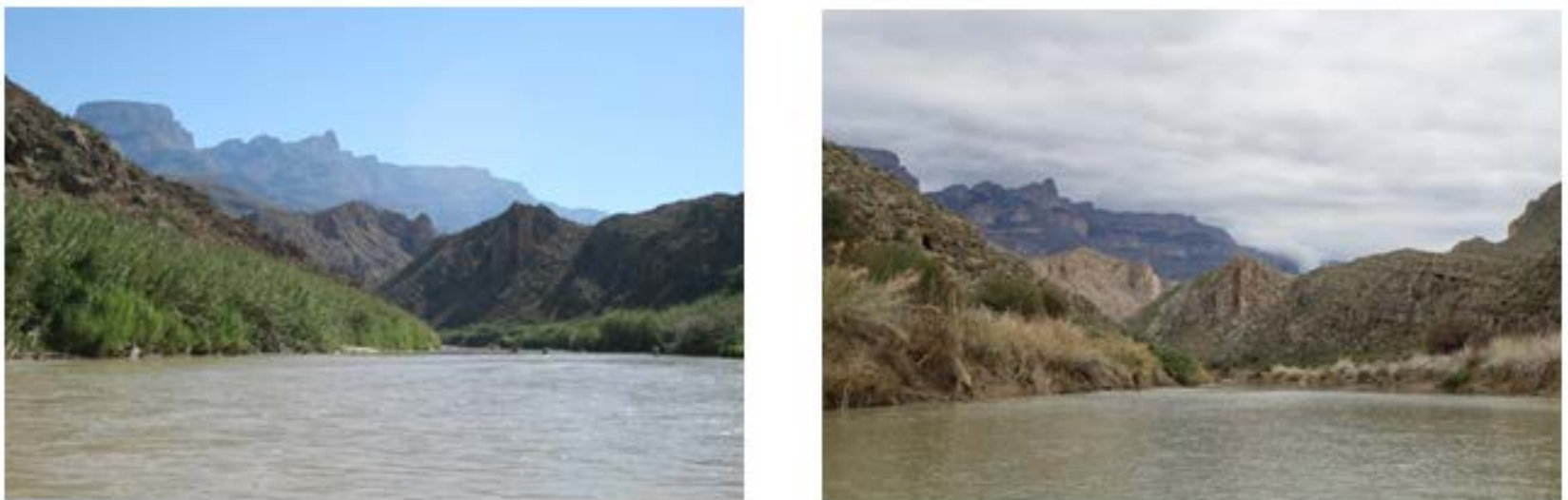

Figure 2. Photograph depicting healthy stand of giant cane (left), and the same stand post-treatment (right) (photos J. Bennett, NPS). 


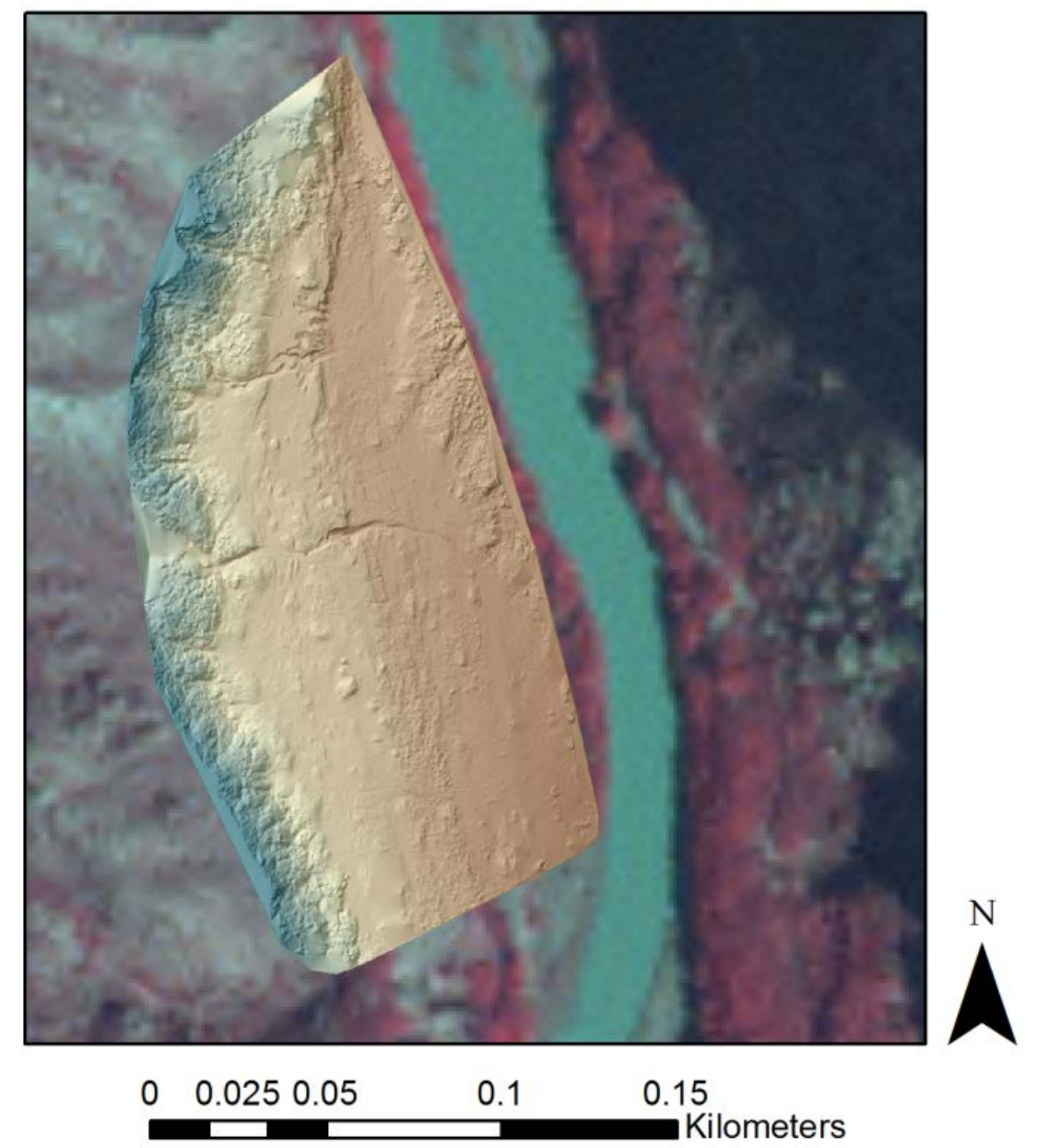

Figure 3. Example of a digital elevation model collected with terrestrial light detection and ranging (LiDAR). Dark brown colors depict low elevations, and light brown and blue colors depict higher elevations. Background image is a color infrared image taken in 2004 (National Agriculture Imagery Program, USDA). Note the dark bands of cane (red vegetation) along the channel margins in 2004. These stands have been removed. Note the overflow flood channel shown in the area of the darkest brown color. Flow is from bottom to top. 


\section{Riparian Conservation and Restoration Planning on the Colorado River in Utah}

By Christine Rasmussen ${ }^{1}$, Patrick B. Shafroth ${ }^{2}$, Sue Bellagamba ${ }^{3}$, Mark Miller ${ }^{4}$, Ann Marie Aubry ${ }^{5}$, and Jason Johnson 6

\section{Introduction}

Strategic planning is increasingly recognized as necessary for providing the greatest possible conservation benefits for restoration efforts. Rigorous, science-based resource assessment, combined with acknowledgement of broader basin trends, provides a solid foundation for scoping and implementing effective projects. It is equally important that methods used to prioritize conservation investments are simple and practical enough that they can be implemented in a timely manner and by a variety of resource managers. With the help of local and regional natural resource professionals, we have developed a broad-scale, spatially-explicit assessment of 146 miles ( 20,000 acres) of the Colorado River mainstem in Grand and San Juan Counties, Utah, that will function as the basis for a systematic, practical approach to conservation planning and riparian restoration prioritization. For the assessment we have: 1) acquired, modified or created spatial datasets of Colorado River bottomland conditions; 2) synthesized those datasets into habitat suitability models and estimates of natural recovery potential, fire risk and relative cost; 3) investigated and described dominant ecosystem trends and human uses, and; 4) suggested site selection and prioritization approaches. Partner organizations (The Nature Conservancy, National Park Service, Bureau of Land Management and Utah Forestry Fire and State Lands) are using the assessment and datasets to identify and prioritize a suite of restoration actions to increase ecosystem resilience and improve habitat for bottomland species. Primary datasets include maps of bottomland cover types, bottomland extent, maps of areas inundated during high and low flow events, as well as locations of campgrounds, roads, fires, invasive vegetation treatment areas and other features. The assessment is available in Rasmussen and Shafroth (2016) detailing ecosystem trends, methods, findings and recommendations.

\section{Methods}

Assessment of conditions and trends in the project area entailed: 1) assemblage of existing data on geology, changes in stream flow, and predictions of future conditions; 2) identification of fish and wildlife species present and grouping species into Conservation Elements (CEs) based on habitat needs; and, 3) acquisition, review and creation of spatial datasets characterizing vegetation, fluvial geomorphic and human features within the bottomland.

Interpretation of aerial imagery and assimilation of pre-existing spatial data were central to our efforts in characterizing resources conditions. Detailed maps of vegetation and channel habitat features in the project area were generated from true color, high resolution $(0.3 \mathrm{~m})$ imagery flown September 16 , 2010. We also mapped channel habitat features at high flow on 1.0-m resolution, publically available,

\footnotetext{
${ }^{1}$ Eco Mainstream Contracting, Mancos, Colorado

${ }^{2}$ U.S. Geological Survey

${ }^{3}$ The Nature Conservancy

${ }^{4}$ National Park Service

${ }^{5}$ Bureau of Land Management

${ }^{6}$ Utah Forestry, Fire and State Lands, Moab, Utah
} 
true color imagery. We obtained additional layers such as land ownership, roads, fire history, non-native vegetation treatment areas, and recreational use features from public sources and project partners.

Habitat suitability models were created for groups of terrestrial species by combining spatial datasets with the habitat needs of conservation elements, guided by literature, where available, and extensive use of expert knowledge. Conservation elements for endangered fish species life stages were identified but not modeled. Terrestrial CE's included:

Riparian Overstory -yellow-billed cuckoo, Bullock’s oriole, black-headed grosbeak, blue grosbeak, warbling vireo, Cooper's hawk, screech owl, saw-whet owl, and bald eagle, (best: tall trees, dense canopy, diverse shrub understory, no tamarisk);

Riparian Understory - southwest willow flycatcher, common yellowthroat, yellow warbler, yellow-breasted chat, beaver, northern river otter, black-necked garter snake, (best: dense mesic shrubs near still water, no tamarisk);

Bat Feeding - Allen's big-eared bat, Townsend's big-eared bat, fringed myotis, Yuma myotis, big free-tailed bat, spotted bat (best: diverse vegetation, close to still water);

Bat Watering - big free-tailed and spotted bats (best: still water with no tall vegetation);

General Diversity - no target species (best: diverse cover types and structure);

Other models - Grassland Species, and Rocky Fringe Snakes (best: low woody cover).

In addition to relative habitat quality and distribution, we created supplemental models intended to assist reach and site-based planning (fig. 1). The Relative Cost of Restoration model includes ease of access to bottomland areas (e.g., by vehicle, on foot, or raft/camp), and presence and relative abundance of both woody and herbaceous non-native species. The Recovery Potential model is based on the presence of native species, absence of non-native species, and access to water from high stream flow. Two fire models, All Fire and Natural Fire models, highlight different aspects of fire risks. The Natural Fire Model reflects only the relative density of tamarisk and native trees, with ratings of 'high' showing where both are prevalent. The All Fire Model shows greater risks associated with human traffic (i.e. roads and campgrounds).

\section{Results and Discussion}

Watershed-wide trends in bottomland conditions (channel narrowing, loss of secondary channel habitats) are likely driven by extraction and impoundment of water in the Colorado mainstem and major tributaries and by expansion of native and non-native vegetation. Areas of high quality habitat are very limited for most CEs, in part due to the preponderance of simplified vegetation cover (e.g. tamarisk), and in part due to the rarity of particular habitat features such as tall trees or still-water channel types. For areas with moderate quality habitats, component layers of each model show the factor or factors lowering habitat quality, allowing identification of actions possible. Multiple habitat models can be overlain, showing reaches and locations where restoration activities may benefit more than one CE, or where activities benefitting one CE may decrease habitat quality for another. Mapping of rare or highly desirable habitats (e.g., still, warm water for young, endangered fish), can be evaluated for proximity to other habitat features and hazards (e.g., spawning areas or locations of potential fish stranding sites). Comparing habitat suitability models with supplemental models allows identification, for example, of

high quality habitats that may be threatened by fire, moderate quality habitats that have high potential to recover without intervention, or areas that are so remote and weed infested that restoration would be cost prohibitive (fig. 2).

Data are available in a summarized form (Rasmussen and Shafroth, 2016). Efforts here were intended to be a 'coarse first cut' at habitat characterization, rating of habitat quality, and identification of factors associated with restoration planning. Many opportunities exist for comparing relative 
suitability with species occurrence data, performing sensitivity analysis on model components, updating layers with current conditions, and improving model representations with higher quality data such as high resolution topography provided by LiDAR.

\section{Lessons Learned}

- GIS habitat modeling, even at coarse scale, can be very useful for extensive project areas, allowing detailed spatial prescriptions for habitat conservation and improvement.

- Data of this extent and detail represents a snapshot of resource conditions, but allows initial planning of 'where to start' and prioritization of efforts.

- Use of expert knowledge is necessary for areas and species with little published data, and can offer refinement of habitat usage by species in unstudied river reaches.

\section{References Cited}

Rasmussen, C., and Shafroth, P.B., 2016, Conservation planning for the Colorado River in Utah: Colorado Mesa University Report, 94 p., accessed April 28, 2017, at http://pubs.er.usgs.gov/publication/70180405. 


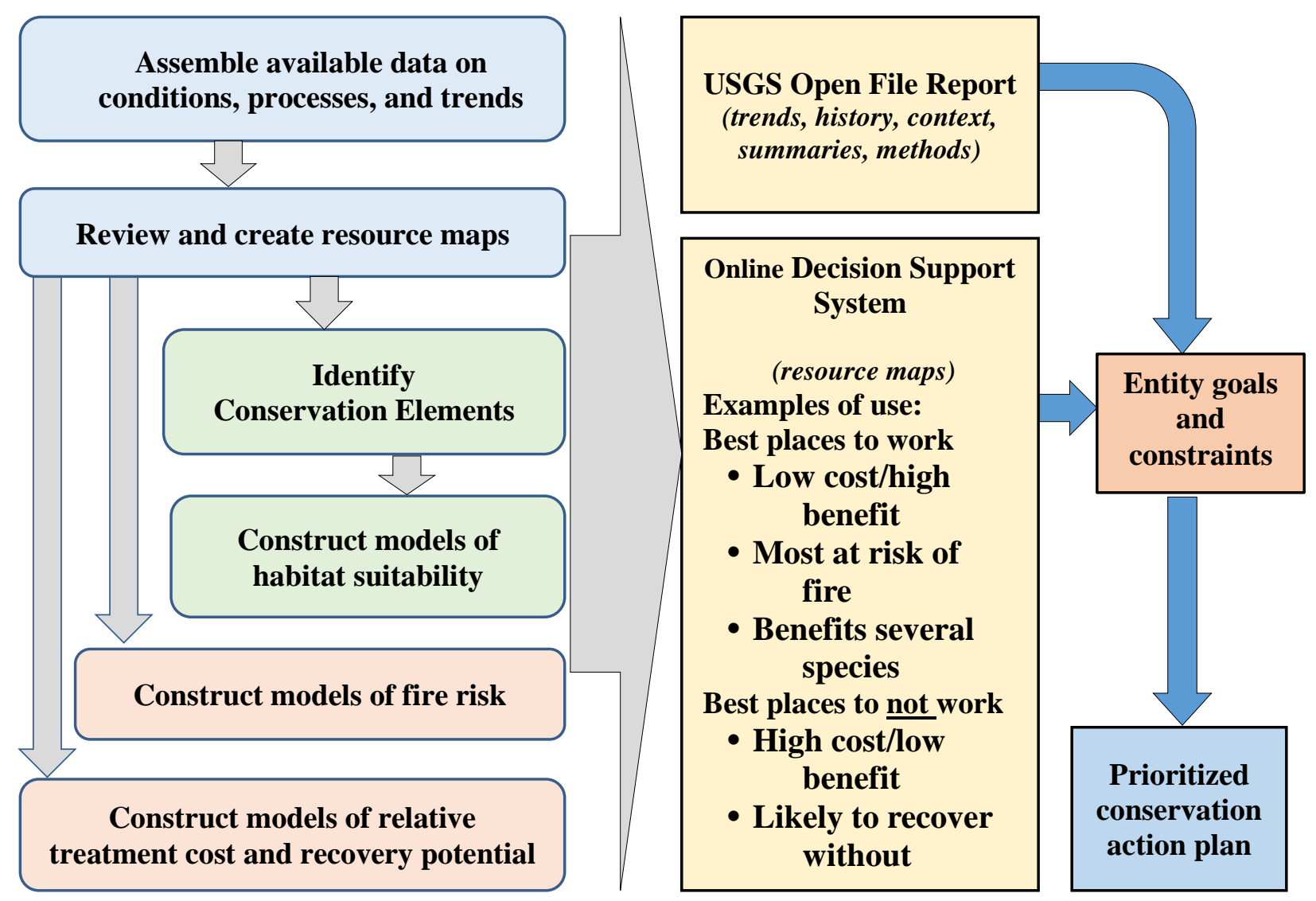

Figure 1. Illustration of steps, resources, and outcomes associated with the Colorado River Conservation Planning Project. All parts of the project involve extensive input from local and regional resource experts, published and unpublished information, and interpretation of new information generated through the effort. Findings are presented in Rasmussen and Shafroth (2016). 

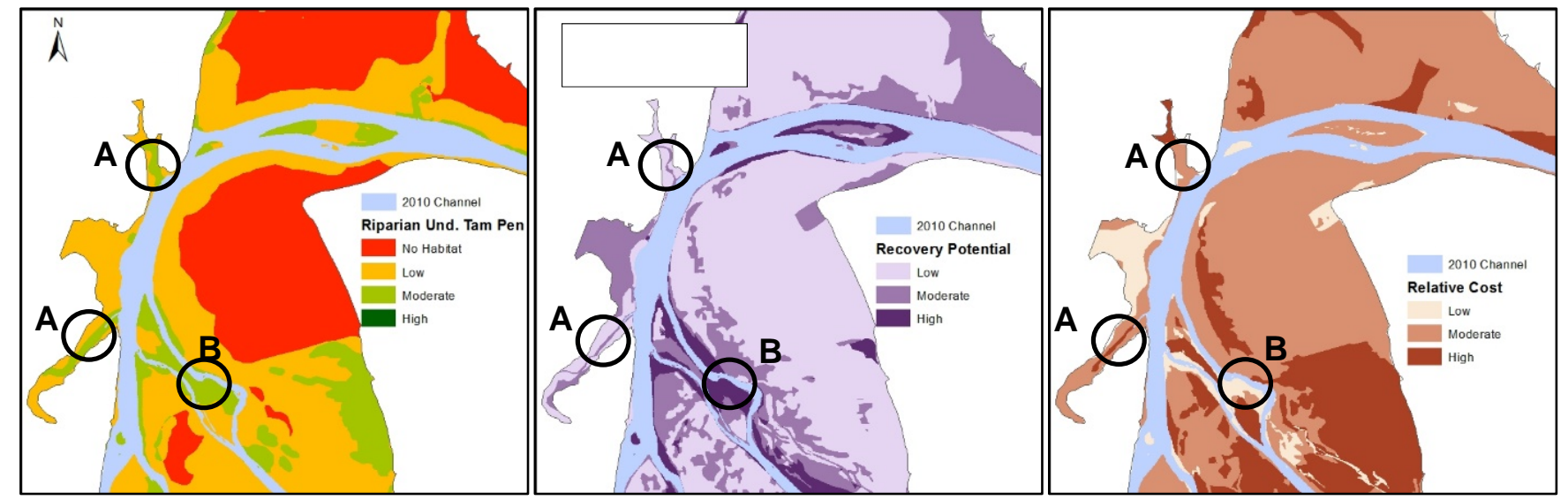

Figure 2. Examples of combinations of habitat and supplemental models. Areas marked with ' $A$ ' indicate where habitats of moderate value for riparian understory species could be improved, where habitats are unlikely to recover without intervention, and costs are moderate. Areas marked with 'B' show habitat of moderate quality where work is not recommended, because recovery potential is high, even without intervention (from Rasmusen and Shafroth, 2016). 


\title{
Revegetating the Las Vegas Wash in the Lower Colorado River Basin
}

\author{
By Seth A. Shanahan ${ }^{1}$, and Jason R. Eckberg²
}

\section{Introduction}

The Las Vegas Wash is a small, historically ephemeral stream in the Lower Colorado River Basin, draining the 1,600 square-mile Las Vegas Valley watershed in southern Nevada and now contributing about 200,000 acre-feet per year of return flow water to Lake Mead. Base flows range diurnally between about 200 and 300 cubic feet per second (cfs) mostly because of highly treated wastewater contributions resulting from municipal and industrial water uses. Urban runoff into upstream tributaries and shallow groundwater drainage contribute lesser amounts of base flow to the Las Vegas Wash, while stormwater has historically swollen flows above 10,000 cfs. By the late 1990's, increasing base flows and episodic storm flows eroded more than 8,000,000 cubic yards of sediment from the channel (Buckingham and others, 2004), nearly eliminating more than 2,000 acres of wetland and riparian habitat that had been created since the 1950's and degrading the ecosystem services they provided. The Southern Nevada Water Authority (SNWA) established a citizen advisory committee in 1997 to obtain recommendations on how to prevent further degradation to the Las Vegas Wash. By 1998, the multi-stakeholder Las Vegas Wash Coordination Committee was formed and SNWA was tasked with leading the effort to stabilize the Las Vegas Wash through an adaptive management process. More than \$125,000,000 has been spent on stabilizing the Las Vegas Wash by designing and constructing erosion control structures (also referred to as "weirs") with improvements inuring to the benefit of various ecosystem services. The weirs are constructed to widen the wetted stream channel, decrease its depth, and reconnect the channel to the floodplain (fig. 1). These conditions support the reestablishment of wetland and riparian vegetation which further armors the channel from erosion in addition to the ecosystem benefits provided (i.e. improvements to water quality and wildlife habitat).

\section{Methods}

Revegetation activities were performed in a generally stepwise fashion which included the following: developing goals and creating a budget; selecting sites and obtaining approvals; assessing site conditions; developing a revegetation plan; preparing for revegetation; establishing and maintaining vegetation; and monitoring and reporting.

The primary goal for revegetation activities along the Las Vegas Wash was to develop ecologically functioning wetland, riparian, and upland areas that are self-sustaining in the long-term. Through the Clean Water Act permitting process, this goal was interpreted quantitatively to mean that established plants should have a survival rate greater than 80 percent, exotic species should represent less than 20 percent of total plant canopy cover, and revegetation plant cover should be at least 70 percent of pre-revegetation total plant cover. In recent years, the goal has been interpreted within a functional assessment framework. The budgeted cost to implement revegetation activities was originally $\$ 12,000$ per acre but was later increased to $\$ 17,500$ per acre. Site selection was straightforward since most revegetation activities were implemented at sites that were disturbed through the weir construction

\footnotetext{
${ }^{1}$ Southern Nevada Water Authority, Colorado River Team, Las Vegas, Nevada

${ }^{2}$ Southern Nevada Water Authority, Las Vegas Wash Team, Las Vegas, Nevada
} 
process. In some circumstances, sites were expanded, or new sites were selected to support complimentary invasive species management goals. Other sites were selected using a prioritization schema which favored sites that had desirable soil conditions (e.g., low soil salinity and high depth to groundwater), a minimal irrigation need, vegetation that could be easily removed, easy access, low expected costs, and easily acquired authorizations. Lands along the Las Vegas Wash are mostly owned by Clark County or the federal government (for example, Bureau of Reclamation withdrawn lands). Revegetation activities were included in early programmatic environmental planning efforts, but site specific activities required approvals from the land owners, the U.S. Army Corps of Engineers, and the Nevada Division of Environmental Protection. Substantial investigations for the presence of threatened and endangered species and archaeological sites were needed.

Site conditions were investigated from the office and the field to inform the revegetation design. Various data sources were reviewed, including but not limited to: aerial and satellite images; U.S. Geological Survey quadrangle maps; U.S. Department of Agriculture soil surveys; land cover maps; stream gage data; flood insurance rate maps; and information from local individuals and experts. Field investigations focused on verifying conditions from the data sources and collecting site-scale information on soils and depth to water. Up to two randomly placed boreholes per acre were augered (hollow stem auger from AMS, Inc. fitted with an EA-400 earth auger powerhead from Echo, Inc.) or excavated to a maximum depth of 10 feet below ground surface to measure groundwater depth and obtain soil samples. Samples were collected from the top two feet of the soil column and analyzed for texture-by-feel (Thien, 1979) and salinity. When feasible, laboratory expenses were minimized by using the soil to water method for quantifying electrical conductivities which could then be converted to saturated paste salinities.

Site-specific revegetation planting plans were drafted following a template established by Kloeppel and others (2006). Salinity and depth to water polygons were created with ArcGIS tools and then the polygons were spatially cut into one acre grid cells, when necessary. Plants were selected for each polygon from a master plant list containing salinity and depth to water tolerance information. The master plant list was generated from on-site investigations and investigations of reference sites. Targeted densities were about 300 plants per acre for non-wetland containerized plantings and about 1,500 plants per acre for wetland plantings. When rapid vegetation cover was necessary for soil stabilization purposes, perennial forb and shrub seed additions were included in the planting plan. Four pounds of pure live seed per acre was the targeted application density. Irrigation systems were designed for non-wetland sites and they usually consisted of 30 foot by 40 foot grids of Certa-SetTM (North American Specialty Products, LLC) above-ground, ultraviolet resistant poly vinyl chloride pipe fitted with R2000WF Rotator ${ }^{\circledR}$ (Nelson Irrigation Corp.) sprinkler heads which flow between 0.9 and 5.7 gallons per minute depending on pressure or 2.0 gallons per minute drip emitters per plant. Most sites used both irrigation delivery methods for some or all of the establishment period. Irrigation water was delivered from the Las Vegas Wash.

Mechanical techniques were mostly used to clear undesirable vegetation or other debris. Large Cat ${ }^{\circledR}$ D8-type dozers fitted with rippers knocked down undesirable vegetation, ripped roots from the soil, and stock piled the slash debris for later burial, burning, or grinding. In some circumstances, crews used hand tools and herbicide to clear sites. Planting was completed through a combination of contracted and volunteer labor. On-site pole cuttings, transplanted clumps of wetland plants, and containerized nursery stock grown from mostly locally harvested seeds or cuttings were used. Sites were intensively managed for a period of two years focusing on irrigation delivery and removing undesirable species. Site inspections were routinely conducted but performance monitoring was annually conducted from late Summer to early Fall and reporting followed. 


\section{Results and Discussion}

More than 1,400 acres of tamarisk (Tamarix ramosissima) were removed from planting sites and adjacent areas. Debris piles were most often hauled to a landfill and controlled burns were sometimes used to reduce debris volume. Controlled burns were often difficult and costly to implement because of concerns with air quality, visual impairment along an airport flight path, and proximity to urban areas. The use of fire as a wetland management tool has been ruled out because of these concerns.

More than 420 acres were actively planted along the Las Vegas Wash with about 30 percent of those areas meeting the regulatory definition of a wetland. Wetland areas had Wetland Prevalence Index scores typically below 2.5. Wetland sites were planted with emergent macrophytes such as bulrushes (Schoenoplectus acutus, S. americanus, and S. californicus) and woody phreatophytes such as cottonwoods (Populus fremontii) and willows (Salix goodingii and S. exigua). Following a gradient of decreasing soil water availability, non-wetland sites were mostly planted with mesquites (Prosopis glandulosa var. torreyana and P. pubescens), saltbush (Atriplex canescens, A. confertifolia, and A. polycarpa), and creosote bush (Larrea tridentata). Quailbush (Atriplex lentiformis) readily established itself without assistance. Since 2001, nearly 10,000 volunteers planted more than half of the total acres during 26 semi-annual outreach events known as “Green Ups.” Event sites were about eight acres and each volunteer planted about nine plants per event under the supervision of an experienced volunteer. Lunch was provided to elicit greater participation, but the proportion of volunteers who signed up but did not show up for the event was rather high at about 33 percent.

During the growing season, sites were intensively irrigated immediately following a planting event (for example, once or twice a week for three hours) and then transitioned to less frequent irrigation (for example, once or twice a month for three hours) so that by the end of two years, irrigation was typically no longer applied. After an initial purchase of irrigation equipment in 2006 for a 60 acre site, minimal new irrigation equipment was necessary since it was reused at subsequent sites. About 40 acres were irrigated per year and water use was about 120 acre-feet per year.

Annual monitoring data were informative for management decision making but less so than routine field investigations. About 250 areas were monitored in 2014 representing nearly 400 acres of revegetation. Noxious species were a small component of vegetation canopy cover, representing on average less than 2.5 percent cover per monitoring area and more than 90 percent of the areas were below 7 percent cover per monitoring area. There was not a positive correlation between site age and noxious species cover which indicates that older sites were generally resilient to noxious species invasions. Wetland sites had slightly higher noxious species cover than non-wetland sites. Wetland sites exhibited the quickest vegetation growth, such that by the end of the first growing season, total cover exceeded 70 percent. In contrast, most non-wetland sites exceeded 70 percent cover after 10 growing seasons. Species richness was highest for wetland sites, but richness declined with site age for all site types.

\section{Lessons Learned}

- Soil salinity and depth to groundwater data were critical for developing suitable revegetation designs.

- Revegetation sites should be designed to be resilient to flooding, exotic species encroachment, herbivory, and mortality.

- Supplemental irrigation needs were more art than science. Routine inspections were necessary to fine-tune irrigation needs. 
- Experimentation was reasonable within limits but it was important to be mindful of the primary purpose of the revegetation plan and execute based on that plan.

- Successful revegetation required an expert-like understanding of multiple disciplines including, but not limited to: plant physiology; soil science; engineering; landscape design; horticulture; and project management.

- Common management practices used in wildland settings (e.g., burning) were not suitable for exurban settings.

\section{References Cited}

Buckingham, S., Whitney, J. Glancy, P.A., and Ehrenberg, A., 2004, Accelerated modern erosion in Las Vegas wash, Clark County, Nevada: Poster presented at the Geological Society of America Annual Meeting, Denver, CO.

Kloeppel, H., Hadley, A., Phillips, F., and Shanahan, S., 2006, Las Vegas wash revegetation master plan: Southern Nevada Water Authority, Las Vegas, Nevada, 58 p., accessed April 28, 2017, at http://www.lvwash.org/assets/pdf/resources_reveg_master.pdf

Thien, S.J., 1979, A flow diagram for teaching texture-by-feel analysis: Journal of Agronomic

Education, v. 8, p. 54-55.

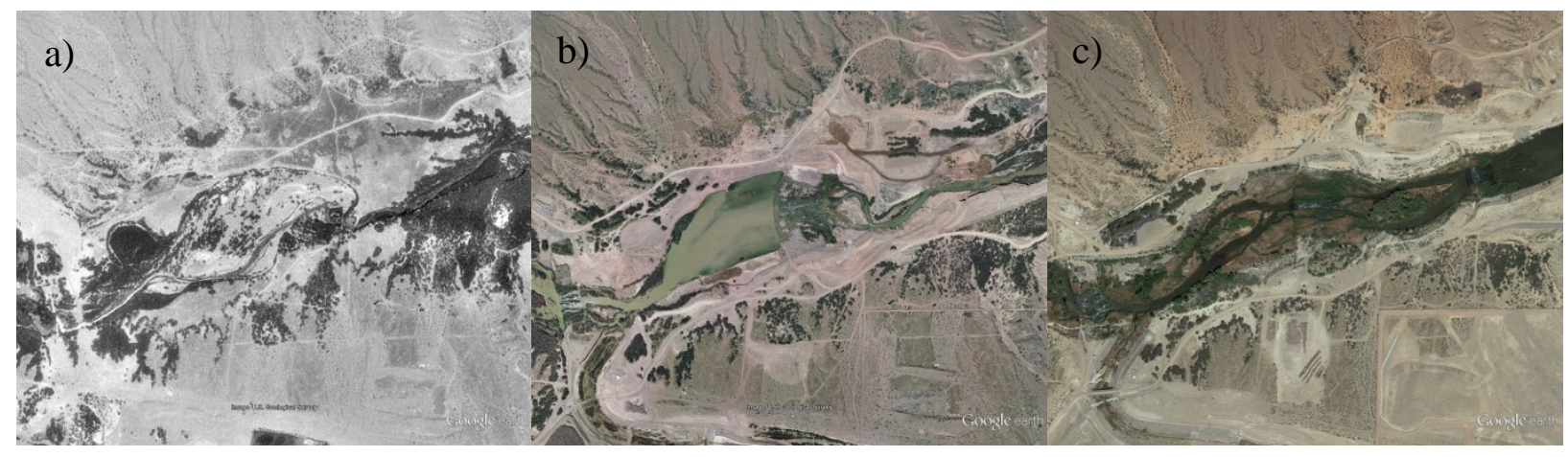

Figure 1. Time-series of aerial photographs evidencing stream channel changes as a result of installing a weir in Las Vegas Wash: a) May 1990 image showing a narrow stream channel surrounded almost entirely by exotic tamarisk (Tamarix ramossisima); b) March 2004 image showing a large water impoundment created by the weir; and c) March 2014 image showing the establishment of native wetland and riparian vegetation (imagery, Bureau of Reclamation). 


\title{
Riparian Restoration in the Colorado River Basin
}

\author{
By Peter B. Skidmore ${ }^{1}$
}

\section{Introduction}

Riparian ecosystems once provided vital habitat, recreational opportunity, and myriad ecosystem services in the Colorado River basin (CRB), but have been substantially reduced and degraded to varying degrees by flow regulation, livestock grazing, and intrusion of invasive woody plant species (Poff, 2011). As part of its Colorado River Initiative, the Walton Family Foundation (WFF) is supporting watershed-scale riparian restoration in select tributary watersheds. Watershed-scale restoration involves assessment, planning and treatment throughout the entire watershed affected by invasive woody plants. This work is primarily focused in watersheds where invasive woody plants have invaded relatively natural and otherwise minimally disturbed systems, where flow regulation and livestock grazing are either not a dominant stressor or where other conservation efforts were expected to address these. This strategy is based on the hypothesis that restoration of native plant communities is more likely to be successful in locations where flows are not greatly perturbed and grazing is effectively managed. During the past five years, the Foundation has provided varying levels of support to watershed partnerships in the Virgin River, Dolores River, Escalante River, Gila River, Verde River, and Colorado River Delta, each of which are implementing riparian restoration programs. Restoration of riparian systems in these basins is planned and implemented by partnerships consisting of conservation organizations, public resource agencies, and private interests.

\section{Methods}

Restoration strategies can be plotted on a "restoration spectrum" (Gillilan, 2005; Skidmore, 2011) that represents a range of ecological constraints, restoration opportunities and goals (fig. 1). The spectrum is bounded on one end by relatively healthy ecological processes and conditions, where the primary goal can be expressed as conservation or protection. The spectrum is bounded on the other end by significant constraints on ecosystem processes and conditions resulting in limited opportunity for or greater challenge to achieve ecological restoration. At this end of the spectrum, restoration goals are often more specific or limited, and actions may be better characterized as "creation" of desired conditions where natural processes that support riparian communities are significantly constrained. Ecological outcomes are commonly narrow, and long-term stewardship and maintenance is expected to be necessary to maintain desired conditions. The middle ground of the spectrum represents the range of ecological conditions, constraints, and goals typically characterized as "restoration".

The following three examples illustrate the spectrum of restoration constraints, opportunities, and goals, as well as differing hypotheses from which restoration plans are developed for tributaries in the CRB.

Escalante River. Near the conservation end of the spectrum, the Escalante River in southern Utah is a relatively intact and healthy riverine ecosystem. The hydrologic regime is only minimally regulated in the uppermost basin, livestock grazing is largely restricted, and the primary stressor to the system is the

\footnotetext{
${ }^{1}$ The Walton Family Foundation, Bentonville, Arkansas
} 
widespread and prolific invasion of Russian olive (Elaeagnus angustifolia) that has choked out native riparian plants and limits recreational opportunities. Because Russian olive (RO) occurs primarily along the river bank, it exerts strong control on bank strength and floodplain roughness, often causing reductions in channel width:depth ratios. While tamarisk (Tamarix spp.) is present throughout the Escalante River system, it is not pervasive, because natural processes promote native plant competition in most of system, and because the tamarisk leaf beetle (Diorabda spp.) is exercising some degree of control. The goal of the local restoration partnership in the Escalante River system is to restore full ecological health as well as recreational opportunity important to the local economy. Restoration strategies in the Escalante are based on the hypothesis that removal of 100 percent of RO from the basin will allow natural processes to restore natural channel and riparian habitat health through primarily passive recruitment and with only limited active planting or future management.

Upper Gila River. The Upper Gila River in eastern Arizona is moderately impacted by flow reductions but has been significantly impacted by grazing and agricultural conversion within the floodplain and riparian corridor that has enabled tamarisk to outcompete native species. Tamarisk is now pervasive. Restoration work is geared toward testing the hypothesis that pockets of native riparian vegetation will provide a source of propagules for natural recruitment and expansion of native woody species as the tamarisk leaf beetle (Diorabda spp.) eventually arrives and reduces the extent of live tamarisk in the future. These restored pockets range from 3 to 15 acres and are created by removing tamarisk and planting native woody species. These pockets are also intended to serve as refuge for federally listed southwest willow flycatcher (Empidonax trailii extimus) (SWFL) because the beetle may eventually denude tamarisk that SWFL presently use for nesting. The Upper Gila River represents a middle ground in the spectrum of impacts and constraints, restoration potential, and expected ecological outcomes and is designed to test a model for restoration at a scale where tamarisk is pervasive and the tamarisk leaf beetle is present or is expected to be.

Colorado River Delta. Restoration within the Colorado River Delta (Delta) in Mexico falls on the "creation" end of the spectrum. Regular flow to the Delta has been entirely cut off since the closing of major upstream dams in the CRB. Riverine habitat is substantially reduced, and riparian vegetation, where it exists, is dominated by tamarisk or other invasive species. Restoration opportunity in the Delta is severely constrained by limited surface and ground water, though some water for restoration has been secured by the Delta Water Trust. Recognizing both hydrologic constraints as well as the significance of the Delta for migratory birds, the primary restoration goal of local organizations is to create pockets of riparian habitat. These sites will be largely dependent on irrigation water for establishment and may be needed for long-term support at some sites. A secondary goal of larger scale, passive restoration is based on the hypothesis that a pulse of flow (implemented for the first time in 2014) timed to coincide with native cottonwood seed production and germination will result in successful natural recruitment and survival of native species where ground-water depths can support their growth without the need for future river flow or irrigation.

\section{Results and Discussion}

Ecological restoration is an inherently experimental endeavor with uncertain outcomes. To test hypotheses and assumptions and to benefit and inform future restoration, restoration actions supported by WFF are currently (2015) being monitored in six CRB tributary systems. Monitoring to date has been primarily structured to evaluate implementation progress (i.e., acres of invasives cleared, natives planted) and to manage secondary weed infestations. The WFF and local restoration partnership 
grantees are also seeking to evaluate the assumption that once established, native plants will outcompete non-native plants over the long term and that natural recruitment will sustain this balance in the future. Watershed partnerships are now defining indicators for passive recruitment of native woody species to test this hypothesis and evaluate long-term or durable success. Because recruitment of native woody riparian species is often dependent on stochastic and infrequent events, even simple indicators of recruitment may require long-term monitoring to evaluate trends.

\section{Lessons Learned}

Full restoration plan implementation is expected to require five or more years for most basins and is not yet complete in any of the basins. However, with coordination and involvement across all basins, some early lessons have been learned.

- Existing monitoring protocols are useful to evaluate implementation progress and to evaluate long-term ecological trends in some basins. However, because the experimental nature of restoration is not expressly acknowledged, monitoring is often not set up to test hypotheses and assumptions about restoration that can inform future planning and implementation. And, durable restoration success may take many years to decades to evaluate.

- Riparian restoration costs within the CRB have ranged from \$575 - \$3,370 per acre, and restoration is implemented with limited public funding. Cost comparisons among watersheds provide little constructive insight to management, because cost/acre analyses are complicated by cost variables such as density and distribution of invasives, proliferation of secondary (herbaceous) invasives, equipment and personnel access, biomass management strategies, field crew requirements, and land ownership and management.

- Active revegetation can jumpstart recovery of native plant cover, but substantially increases the cost of restoration, ranging from $\$ 490$ - \$1,334 per acre, and can be cost prohibitive at scale. Active planting of areas cleared of invasive plants has generally been implemented only where geomorphic or hydrologic conditions limit or prevent scour, deposition, and flooding conducive to natural recruitment, where there is significant soil disturbance created by clearing activities, and where invasive plant seed sources are in close proximity or native seed sources are limited or distant.

- Geographic Information System (GIS) is an underutilized planning and communication tool. Inadequate resources devoted to GIS are limiting effective communication about implementation progress and outcomes, and complicate comparison of management strategies and costs among watersheds.

- The tamarisk leaf beetle has spread rapidly in the upper CRB, but its effectiveness at reducing tamarisk will require time to fully understand. Consequently, pilot restoration projects developed with an emphasis on a learning paradigm and experimental design may be the most prudent approach to restoration in the near-term.

- Watershed partnerships are critical to long-term success of basin-scale restoration. A focus on invasive plants has provided a common interest among traditionally disparate parties, has been effective as a catalyst for collaboration, and may provide a foundation from which future more controversial interests can be addressed. Common themes among effective partnerships include a relatively non-controversial goal, professional facilitation of partnership entities, and dedicated local leadership. 


\section{References Cited}

Gillilan, S., Boyd, K., Hoitsma, T., and Kauffman, M., 2005, Challenges in developing and implementing ecological standards for geomorphic river restoration projects-A practitioner's response to Palmer and others (2005): Journal of Applied Ecology, v. 42, no. 2, p. 223-227, http://dx.doi.org/10.1111/j.1365-2664.2005.01021.x.

Poff, B., Koestner, K.A., Neary, D.G., and Henderson, V., 2011, Threats to riparian ecosystems in western North America: An analysis of existing literature: Journal of the American Water Resources Association, v. 47, no. 6, p. 1241-1254, http://dx.doi.org/10.1111/j.1752-1688.2011.00571.x

Skidmore, P.B., Thorne, C.R., Cluer, B.L., Pess, G.R., Castro, J.M., Beechie, T.J., and Shea, C.C., 2011, Science base and tools for evaluating stream engineering, management and restoration proposals: NOAA Technical Memorandum NMFS-NWFSC-112, National Technical Information Service, Springfield, Virginia, 253 p.

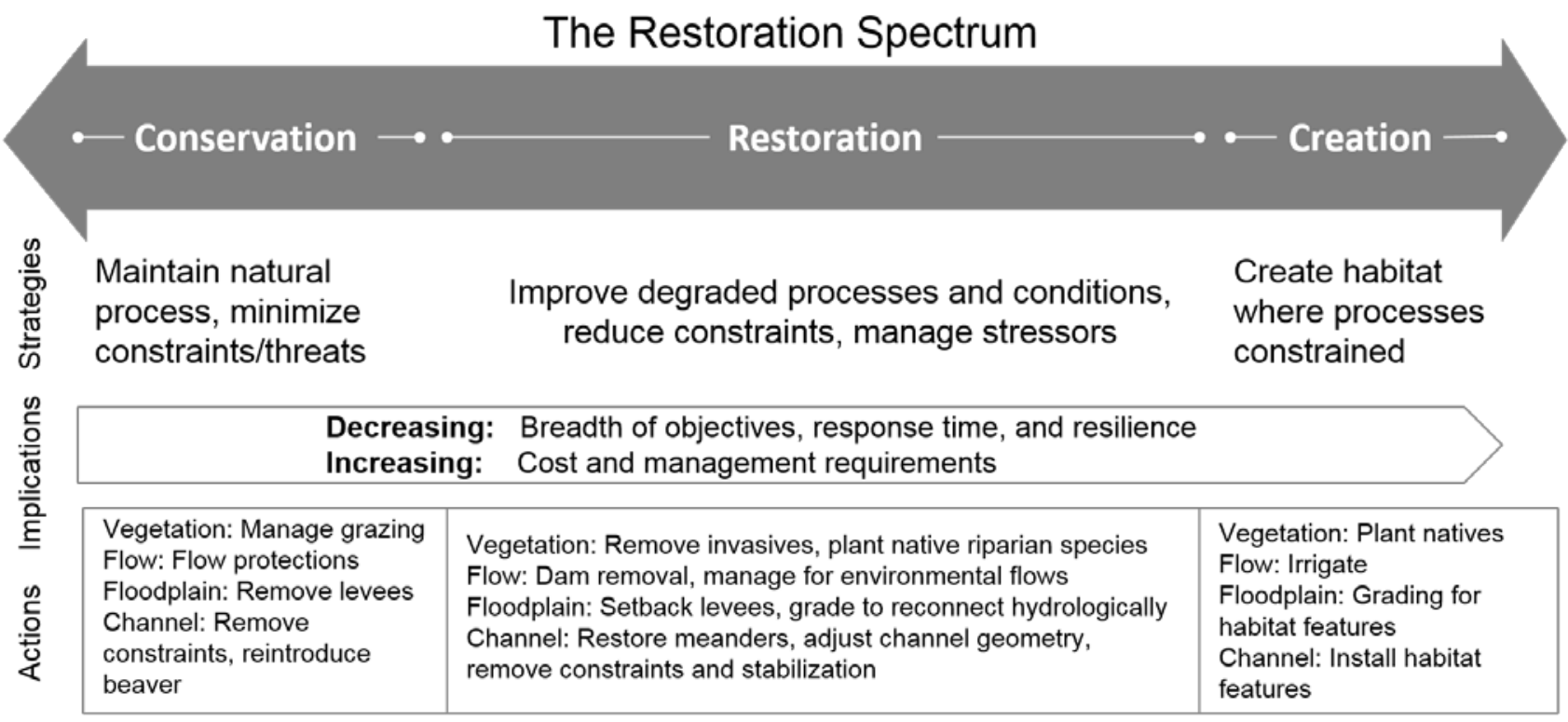

Figure 1. The restoration spectrum for riparian ecosystems (after Gillilan 2005 and Skidmore 2011). 


\section{Section IV. Watershed Scale Perspectives}

\section{Multi-scale Riparian Restoration Planning and Implementation on the Virgin and Gila Rivers}

By Bruce Orr ${ }^{1}$, Matthew Johnson ${ }^{2}$, Glen Leverich ${ }^{1}$, Tom Dudley ${ }^{3}$, Jim Hatten ${ }^{4}$, Zooey Diggory ${ }^{1}$, Kevin Hultine ${ }^{5}$, Devyn Orr ${ }^{3}$, and Shawn Stone ${ }^{6}$

\section{Introduction}

With the upsurge of river restoration and floodplain management projects being implemented across North America and elsewhere, it is valuable to incorporate informed, science-based project designs during the planning phases to ensure long-term success of these much-needed efforts (Palmer and others, 2014). This is especially true in highly dynamic systems, such as the large, flashy rivers in the arid Southwest that do not fit the "classic" textbook river model and, thus, demand consideration of regionally specific conditions. We have developed a riparian restoration planning approach for systems in the arid and semi-arid regions of the Western United States that links the key physical attributes of a river and its watershed — such as climate, hydrology, and geomorphology—with the ecological responses of vegetation, birds, and other wildlife to those conditions (see fig. 1 in Rasmussen and Orr, and in Orr and others, both in this volume). This integrative approach provides a functional framework for increasing our ability to implement successful restoration by using our understanding of key ecosystem linkages to identify appropriate and feasible restoration approaches, including both passive and active revegetation, and suitable locations for river-floodplain conservation and riparian restoration actions. We applied this approach in two ongoing restoration efforts in the Southwest that were initiated primarily to enhance and restore habitat for the endangered southwestern willow flycatcher (Empidonax traillii extimus) ('flycatcher') and other native species of interest, including the threatened western yellow-billed cuckoo (Coccyzus americanus) ('cuckoo'). The overarching goals of the restoration planning and implementation projects on the Virgin River (UT, AZ, NV) and the upper Gila River (AZ) were to: (1) prepare for observed (Virgin) and anticipated (Gila) alterations to the existing riparian system following colonization by the tamarisk beetle (Diorhabda elongata complex) introduced for the biological control of tamarisk (Tamarix spp.); (2) support recovery of native riparian habitat through active and passive revegetation to promote local increases in flycatcher population size; (3) facilitate implementation of a comprehensive approach toward riparian restoration by a collaborative group of stakeholders, resource managers, and scientists; and (4) provide recommendations to be incorporated into the restoration plans developed by local stakeholders, such as the Clark County Desert

\footnotetext{
${ }^{1}$ Stillwater Sciences, Berkeley, California

${ }^{2}$ Northern Arizona University

${ }^{3}$ University of California, Santa Barbara, California

${ }^{4}$ U.S. Geological Survey

${ }^{5}$ Desert Botanical Garden, Phoenix, Arizona

${ }^{6}$ Gila Watershed Partnership, Safford, Arizona
} 
Conservation Program (Virgin) and Gila Watershed Partnership (Gila). Much of the funding for this work was provided by the Walton Family Foundation-Freshwater Initiative Program.

\section{Southwestern Willow Flycatcher, Tamarisk, \& Tamarisk Beetle Background}

The Virgin and Gila rivers, like many rivers in the arid west, now support large, dense, nearly monotypic stands of invasive, non-native tamarisk or saltcedar (Tamarix spp.) (Bloodworth and others, 2016). These rivers also provide critical riparian and aquatic habitat for the endangered flycatcher, threatened cuckoo, and various other fish and wildlife species. Tamarisk and other invasive plants, such as Russian olive (Elaeagnus angustifolia) and giant reed (Arundo donax), are generally recognized as a threat to many migratory bird populations in the Southwest. However, in the absence of native riparian vegetation, tamarisk now serves as the primary nesting habitat for flycatcher in many areas. Tamarisk beetles were released in 2001 by the Tamarix Biocontrol Consortium at 10 sites in six states to suppress invasive tamarisk (Tracy and Robbins, 2009; Bean and others, 2013). These initial release sites were selected to avoid critical habitat for flycatcher. After release, however, non-regulated introductions to new sites within Utah led to the establishment of the beetle along the Virgin River near St. George, UT where flycatcher nest in both native riparian and non-native tamarisk habitats (Bateman and others, 2010; Dobbs and others, 2012). Within a few years the beetle expanded its range downstream to Lake Mead (Bean and others, 2013), and along the lower Colorado River (Bloodworth and others, 2016). Rapid defoliation may be one factor leading to low nest productivity in parts of the Virgin River, and subsequent dieback can have an influence on other riparian-obligate wildlife species, particularly where tamarisk forms the dominant vegetation type (Dobbs and others, 2012; Bateman and Johnson, 2015). The effects of biocontrol elsewhere will depend on the particular response of the ecosystem and its capacity for native plant recovery, management prescriptions implemented to mitigate tamarisk decline, and the particular wildlife taxa being considered (Bean and others, 2013). These impacts may be temporary, while in the long run tamarisk biocontrol is anticipated to yield increased water supplies and a reduction in wildfires, along with new food resources for wildlife (Dudley and Bean, 2012).

\section{Ecohydrological Assessment}

The "ecohydrological assessment," which provides an integrative restoration framework, considers a suite of hydrological, edaphic and ecological factors to identify suitable areas for active restoration. This framework can be applied at the river-corridor scale relying largely on remote-sensing data and GIS-based analyses to identify and prioritize potential restoration sites, and then at the more local reach- and site-scales using a combination of GIS and field-collected data to refine site prioritization and restoration plan development (Orr and others, 2014). The main components of the ecohydrological assessment conducted on the Virgin and Gila rivers included:

- Flood-scour risk - determined by assessing reach-scale river hydrology and geomorphology and reviewing historical aerial photographs to examine historical flood scour patterns and define the area of the river corridor most likely to be scoured in future floods (i.e., the "flood reset zone').

- Relative elevation (height above water surface in the low flow channel) - determined from high resolution topography generated from LiDAR (collected by the Utah State Remote Sensing Laboratory) to serve as a proxy for depth to groundwater (where possible shallow groundwater monitoring wells are used to provide calibration data on actual depth to groundwater at selected sites, especially at high priority sites), and identify key fluvial geomorphic surfaces (e.g., active channel, bars, floodplain, terraces).

- Soil salinity and texture - Natural Resources Conservation Service soils maps are used to assess soil texture and salinity at the river-corridor scale, supplemented at the site-scale by field 
sampling and laboratory analysis to characterize key soil conditions (e.g., salinity, texture, nutrients).

- Vegetation type and canopy height - Remote sensing data (multispectral imagery and LiDAR) were used to classify vegetation into dominant types (e.g., tamarisk, cottonwood-willow, mesquite). LiDAR data were used to measure vegetation canopy height, which served as an index of potential site productivity for woody riparian plants. More detailed field surveys of vegetation at specific sites were used to ground-check the vegetation mapping and to calibrate literature-based assessments of physical habitat requirements (e.g., depth to groundwater/relative elevation, soil salinity) of key native plant species being considered for active planting at restoration sites.

- Wildlife habitat suitability - review of available records of recent and historical occurrence of focal species (such as flycatcher and cuckoo) and conceptual models of habitat requirements were used to assess habitat suitability under current or potential restored conditions. An additional component of the ecohydrological assessment added for the Gila River was the application of a GIS-based model (Hatten and Paradzick, 2003, as cited in Orr and others, 2014) that identifies flycatcher breeding habitat suitability using Landsat Thematic Mapper imagery and 30-m resolution digital elevation models.

These data layers were then overlaid using GIS to identify sites that appeared to have the greatest ecological potential for success via active restoration actions (such as horticultural revegetation or earthmoving to create swales), as indicated by factors such as low relative elevations (shallow groundwater) and tall canopy heights (based on the hypothesis that tall healthy tamarisk indicates that native woody species would likely do well if tamarisk is actively removed, or reduced in abundance and vigor by biocontrol). This assessment can also be used to identify areas that are good candidates for more passive restoration (e.g., sites within the flood reset zone that have patches of native vegetation that could serve as sources of seeds or vegetative propagules for natural revegetation following high flow events, especially if tamarisk abundance and vigor is reduced by the tamarisk beetle) or for conservation (e.g., sites with healthy native riparian vegetation and high habitat suitability for flycatcher and other wildlife). After the ecological suitability areas were delineated, socioeconomic factors (e.g., cost, logistics, and willing landowners) were used to determine the highest priority sites for implementation. Additional field data were then collected at high priority sites to facilitate restoration planning design and permitting.

The ecohydrological assessments included the following key recommendations:

1. Conduct intensive active riparian restoration using a phased, patch-work approach to remove tamarisk in lower quality habitat patches and then plant appropriate native plants suited to site conditions, thereby expanding existing patches of suitable habitat and establishing new sources of native plant propagules (i.e., creating "propagule islands”), while at the same time preserving much of the existing taller tamarisk structure that currently provides suitable flycatcher-nesting habitat in areas such as the upper Gila where the tamarisk beetle is not yet present (i.e., include actions to minimize near-term disturbances to existing viable flycatcher-nesting habitat, as required for permitting). As native vegetation matures in the initial treated patches, additional tamarisk removal and revegetation can be implemented in adjacent patches. The goal is not to actively treat the whole riparian-floodplain corridor, rather it is to do enough active restoration to put the system on a trajectory that is likely to create a more resilient, self-sustaining, and diverse riparian ecosystem into the future in the context of climate change and tamarisk biocontrol. 
2. Carefully locate tamarisk removal and revegetation actions to avoid inducing any undesirable channel instabilities (such as those that might erode important infrastructure or existing high quality native vegetation).

3. Consider lower effort strategies in other areas where practical, including "disturbance contingency plans" such as spraying herbicide on re-sprouting tamarisk to promote natural recruitment process for willows and other native plants in areas disturbed by fires or floods, especially where much of the tamarisk biomass has been removed by the disturbance.

\section{Restoration Implementation Status}

Following completion of the Virgin River restoration framework, the project team was contracted by Clark County (Nevada) Desert Conservation Program (DCP) to develop plans for a demonstration project in the lower Virgin River on a county-owned parcel. The DCP and its contractors cleared several patches of tamarisk in Oct 2013 (fig. 1) and began revegetation planting in February 2014 (fig. 2 shows one site in October 2014, approximately 8 months after planting). One logistical challenge was exclusion of trespass cattle from the revegetation site without spending too much on installing and maintaining exclusion fencing. Building walls of cut tamarisk around the perimeter of each revegetation site (fig. 1), coupled with selective fencing in the surrounding area proved effective in excluding cattle. Another challenge was inability to conduct post-planting monitoring as planned because of the armed militia and BLM standoff in Spring 2014 (Urquhart and Turner, 2014). This delayed recognition that plantings in some areas were failing because crews planted many cuttings that did not meet the minimum specified size and planting depth requirements, resulting in high mortality during the dry season (with peak mortality probably occurring in June 2014). The DCP has recently been able to re-initiate site monitoring and has begun planning subsequent implementation phases to test new planting methods, enhance the diversity of native plant species, and add new restoration sites along the lower river corridor.

After completion of the Upper Gila restoration framework, the Gila Watershed Partnership (GWP) and the project team initiated an agency coordination and permitting process leading to selection of the Clean Water Act Section 404 Nationwide Permit \#27 from the U.S. Army Corps of Engineers as the preferred approach to allow for a range of restoration strategies capable of achieving successful long-term revegetation with minimal short-term impacts to existing riparian and aquatic habitats. This process also supported U.S. Fish and Wildlife Service's preparation of their Intra-Service Biological Opinion. Five sites on private land (totaling to 54 acres) were selected as the initial demonstration sites. All five restoration sites include or are adjacent to currently occupied flycatcher breeding sites. Restoration (tamarisk removal and revegetation) actions began in February 2015 (fig. 3). Additional planning and permitting efforts by the GWP and the project team are currently underway to expand the restoration effort and add more sites to help set the stage for improved natural revegetation by native species and increased biodiversity once the tamarisk beetle arrives in the area. Recent observations indicate that numerous flycatchers are using habitat near the treatment sites, indicating that measures taken to avoid or minimize short-term displacement of the birds (including use of buffer areas around nest sites that were documented in the nesting season prior to treatment) appear to be working. In addition, a good deal of fine sediment deposition and natural recruitment of native plants have been observed in the treatment areas.

Observed variation in beetle-induced impact on habitat conditions and flycatcher productivity in the Virgin River suggests the value of multiple-year studies to better understand post-beetle vegetation trajectories with and without active restoration, and the associated habitat changes affecting bird populations. Upon arrival of the beetle along the Gila River, we anticipate observing a similar yearly 
variation in both habitat conditions and flycatcher productivity, although the greater relative abundance of native woody species compared to the lower Virgin suggests high recovery potential. It will therefore be essential to continue assessing both habitat conditions and flycatcher (and ideally other riparianobligate focal species) populations to attribute the direct and indirect effects of both the beetles and our current restoration efforts on riparian habitat and on the flycatcher and other riparian obligates.

\section{Lessons Learned}

- Focused monitoring and adaptive management will be critical in designing and implementing effective riparian management to conserve habitat for listed wildlife species, reduce risk of secondary invasion by non-native plants, maintain native biodiversity, and maximize the longterm benefits associated with tamarisk biocontrol provided by the tamarisk beetle.

- Assessing ecological restoration potential is essential for identifying areas most likely to benefit from active restoration, and greatly reduce the risk of failure. Restoration feasibility is also strongly driven by practical considerations such as funding, landowner cooperation, site logistics, and need to limit grazing impacts by livestock in many areas.

- In designing adaptive management and monitoring programs, we typically focus on measures to increase resiliency to natural disturbances. However, unexpected human actions in or near the restoration area can also create substantial challenges and surprises.

- Careful oversight during implementation is critical - the best laid plans can go astray if the plan is not properly implemented.

\section{Reference Cited}

Bateman, H.L., and Johnson, M.J., 2015, Effects of biocontrol and restoration on wildlife in southwestern riparian habitats: Report submitted to Southern Rockies and Desert Landscape Conservation Cooperative, 79 p.

Bean, D., Dudley, T.L., and Hultine, K.R., 2013, Bring on the beetles! The biology of tamarisk biocontrol, in Sher, A., and Quigley, M., eds., Tamarix-A case study of ecological change in the American West: Oxford University Press, p. 377-403.

Bloodworth, B.R., Shafroth, P.B., Sher, A.A., Manners, R.B., Bean, D.W., Johnson, M.J., and HinojosaHerta, O., 2016, Tamarisk beetle (Diorhabda spp.) in the Colorado River basin-Synthesis of an expert panel forum: Colorado Mesa University, Ruth Powell Hutchins Water Center, Scientific and Technical Report No. 1, 11 p.

Dobbs, R.C., Huizinga, M., Edwards, C.N., and Fridell, R.A, 2012, Status, reproductive success, and habitat use of Southwestern Willow Flycatchers on the Virgin River, Utah, 2008-2011: Utah Division of Wildlife Resources Publication Number 12-36.

Dudley, T.L, and Bean, D.W., 2012, Tamarisk biocontrol, endangered species risk and resolution of conflict through riparian restoration: BioControl, v. 57, no. 2, p. 331-347.

Hultine, K.R., Dudley, T.L., Koepke, D.F., Bean, D.W., Glenn, E.P., and Lambert, A.M., 2014, Patterns of herbivory-induced mortality of a dominant non-native tree/shrub (Tamarix spp.) in a southwestern US watershed: Biological Invasions, v. 17, p. 1729-1742.

Orr, B.K., Leverich, G.T., Diggory, Z.E., Dudley, T.L., Hatten, J.R., Hultine, K.R., Johnson, M.P., and Orr, D.A., 2014, Riparian restoration framework for the upper Gila River in Arizona: Compiled by Stillwater Sciences, Prepared for the Gila Watershed Partnership of Arizona, 145 p. 
Palmer, M.A., Hondula, K.L., and Kock, B.J., 2014, Ecological restoration of streams and riversShifting strategies and shifting goals: Annual Review of Ecology, Evolution, and Systematics, v. 45, p. 247-269.

Urquhart, J., and Turner, C., 2014, Photos of a standoff-Armed militia members join Nevada cattle rancher to protest a cattle roundup from public lands: High Country News, 14 April, https://www.hcn.org/articles/bundy-tresspass-cattle-stand-off-with-blm-feds.

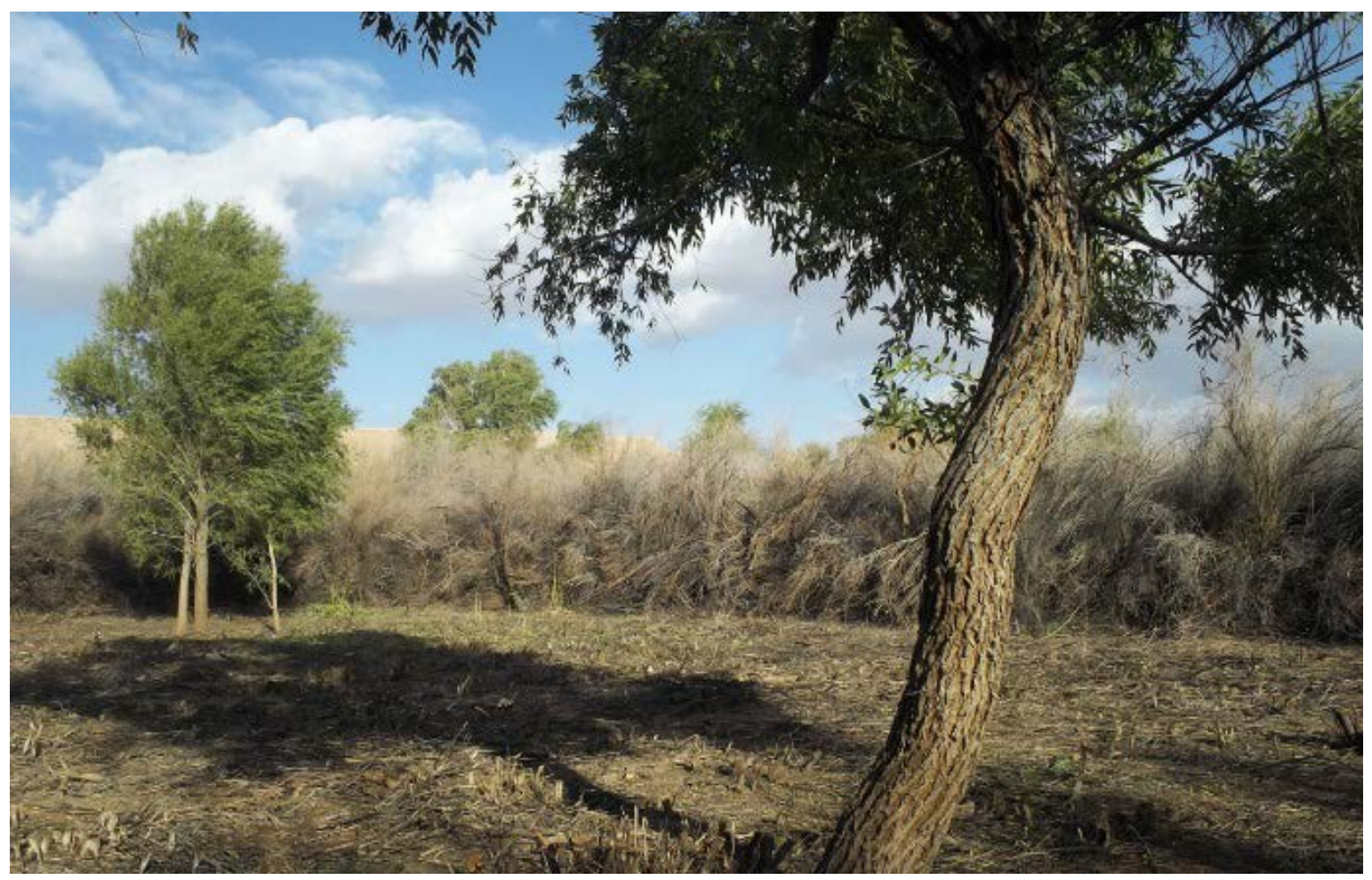

Figure 1. Mormon Mesa restoration site on lower Virgin River, Nevada showing a patch of recently cleared vegetation ready for replanting with native species located within the surrounding matrix of dense tamarisk (which appreas brown because it has been defoliated by the tamarisk beetle) with scattered emergent willows (Salix gooddingii). Cut tamarisk was stacked around the edges of the clearing to create a barrier to help exclude cattle. Photo taken October 2013 (source: Clark County Desert Conservation Program). 


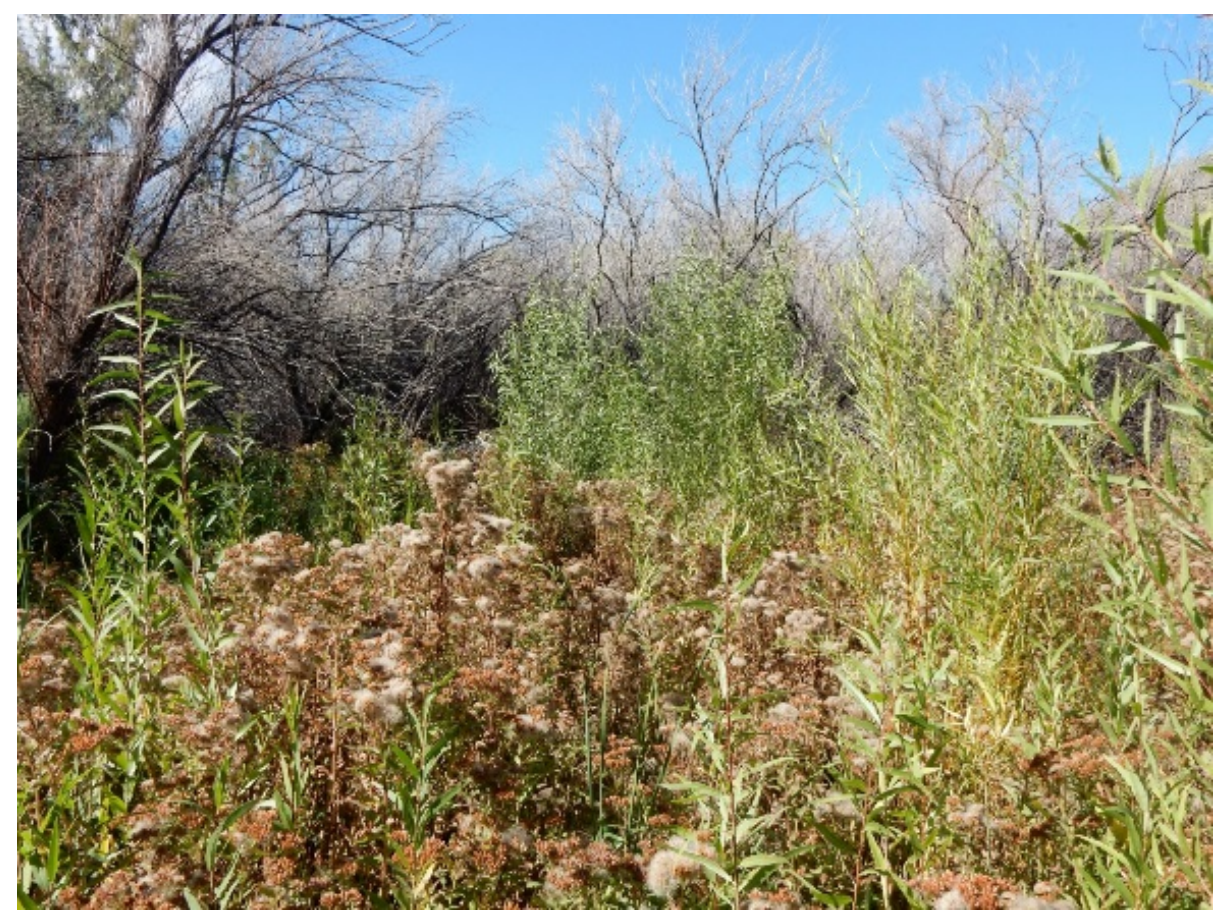

Figure 2. Mormon Mesa restoration site on lower Virgin River, Nevada showing surviving planted wilows (Salix gooddingii) and naturally recruited Pluchea odorata less than 1 year after restoration. Photo taken October 2014 (source: Stillwater Sciences).

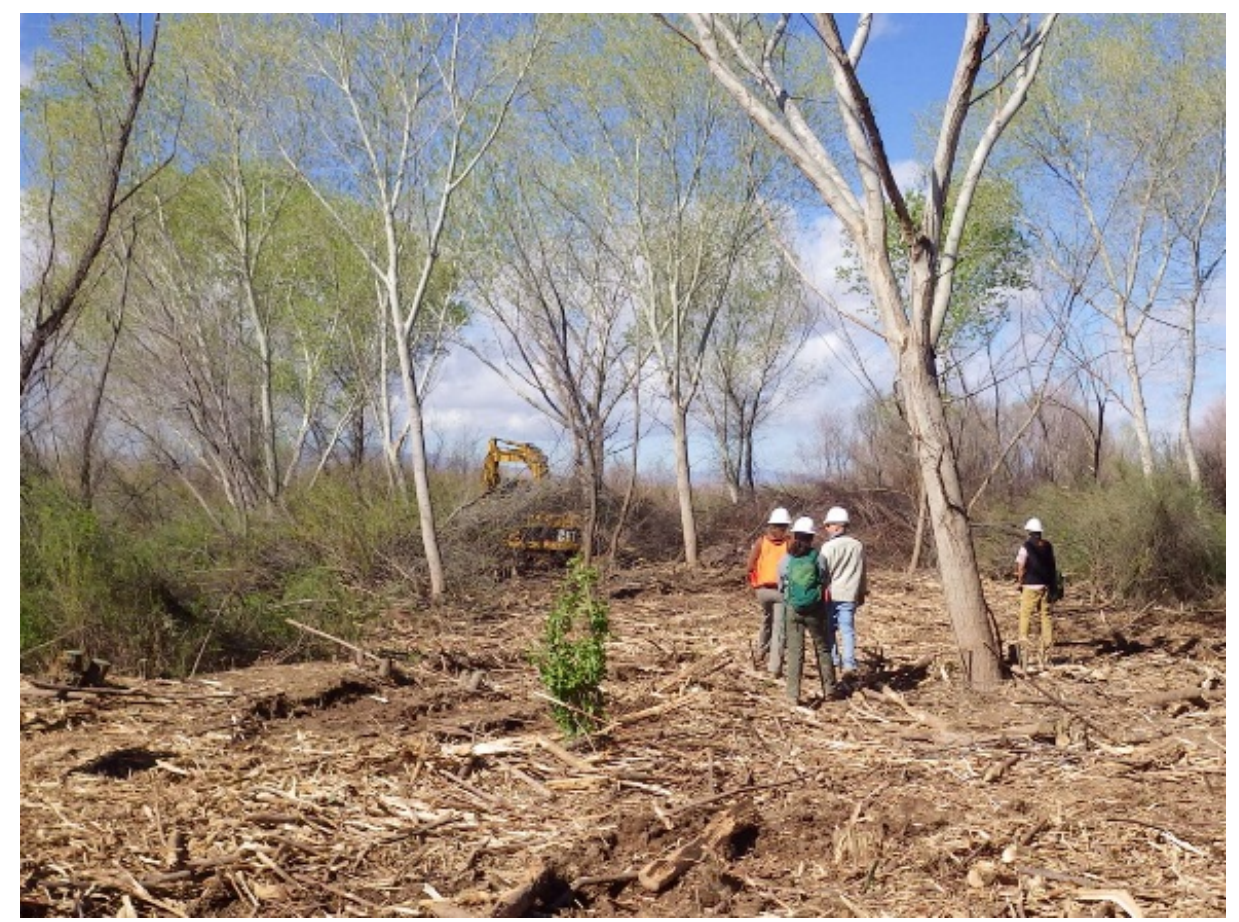

Figure 3. Example of using a mulcher to remove tamarisk while leaving native cottonwoods and willows intact at restoration site on the Upper Gila River, Arizona. Photo taken 23 February 2015 (source: Stillwater Sciences). 


\title{
Linking Forest Landscape Management and Climate Change to the Conservation of Riparian Habitat in the Grand Canyon
}

\author{
By Frances C. O'Donnell1ㄴ William T. Flatley², Abraham E. Springer ${ }^{1}$, and Peter Z. Fulé2
}

\section{Introduction}

The conservation of biologically significant riparian and springs ecosystems in lower elevations of the Grand Canyon is inextricably linked to the high elevation forest on the Kaibab Plateau. Roaring Springs, which contributes the sole source supply of water to Grand Canyon National Park, is connected to a cave and karst system on the Kaibab Plateau. The large, springs-fed tributaries of the Colorado River sourced on the Kaibab Plateau also provide critical habitat for such endangered species as the humpback chub (Gila cypha). Climate change is predicted to drive substantial vegetation change in these forests, with consequences for the water balance. Forest managers are attempting to improve forest resilience to change through fuel treatments and wildfire management. In the short term, forest treatments have an immediate impact on runoff and groundwater recharge (Wyatt and others, 2014; Robles and others, 2014). Forest management may also alter the rate and extent of climate-induced vegetation change, which will have consequences for future watershed output. The objectives of this applied research project are to 1) assess the response of forested systems to climate change and management, 2) assess the response of hydrologic systems to projected climate and management induced forest change and 3) examine the implications of hydrologic changes for the management of riparian and aquatic habitats. The project is ongoing and preliminary results are presented here.

\section{Methods}

Vegetation Modeling: We developed a landscape simulation model to assess future vegetation change under multiple climate and fire disturbance scenarios on the Kaibab Plateau, Arizona. We employed a multi-model approach linking the empirically based forest growth model Climate-FVS (CFVS) (Crookston and others, 2010) with the process based landscape simulation model LANDIS-II v6.0 (Scheller and others, 2007). We used C-FVS to model individual species establishment probability and growth rates according to different environmental site conditions and climate scenarios. We used LANDIS-II to simulate spatial patterns of fire disturbance and corresponding patterns of forest growth, regeneration, succession, and dispersal. The future climate scenarios were no climate change, a moderate climate change scenario based on outcomes from the representative concentration pathway (RCP) 4.5, and a more extreme climate change scenario based on RCP 8.5. For each of the climate scenarios we also tested a no fire scenario and a fire restoration scenario which incorporated restoration thinning and re-establishment of the historical fire regime.

Hydrologic Modeling: To assess hydrologic response to forest change, we are developing hydrologic models relating watershed output to forest composition and structure based data from paired watershed experiments that were performed in a range of vegetation types in Arizona in the 1950s-80s. Additionally, several of the sites were reinstrumented with stream gauges after wildfire, providing information on the effects of fire. For each vegetation type on the Kaibab Plateau, we are developing a

\footnotetext{
${ }^{1}$ Northern Arizona University, School of Earth Sciences and Environmental Sustainability

${ }^{2}$ Northern Arizona University, School of Forestry
} 
regression model for annual runoff and recharge based on precipitation and other variables, including temperature, vegetation biomass, and physical characteristics of the watershed, that we find to have a significant effect and can reasonably be included in the model application. We are also developing separate models that predict the change in runoff caused by treatment or fire in each vegetation type.

For each raster cell in the vegetation model output, we will identify and apply the appropriate model for runoff and recharge based on the predicted dominant vegetation type and apply a model for runoff and recharge change if the cell is fire- or treatment-affected. We will use the method developed by Wyatt and others (2014) to simulate the effect of disturbance on recharge, and extend the Northern Arizona Regional Groundwater Flow Model (Pool and others, 2011) to include the portion of the Redwall-Muav aquifer underlying the Kaibab Plateau and use it to translate runoff and recharge estimates to streamflow and spring discharge projections for Grand Canyon National Park.

\section{Results and Discussion}

Under the future change scenarios, forest biomass and composition responded strongly to the changes in climate and fire disturbance. Both climate change scenarios resulted in a decline in mean forest biomass and a compositional shift to forest species typical of the ecoregion directly lower in elevation. The restoration fire scenario generally resulted in more rapid biomass declines and compositional change followed by an earlier recovery and stabilization of biomass and composition. However, in the lower-mid elevation zone a continuation of the historical fire regime (a fire rotation of approximately 9 years) under either climate change scenario resulted in a conversion from ponderosa pine to non-forest vegetation. Landscape maps project that under either climate change scenario, the Kaibab Plateau will eventually be dominated by pinyon-juniper and ponderosa pine forest types, with a complete loss of the mesic conifers that currently dominate the upper two elevation zones (fig. 1).

Using data from the Beaver Creek and Castle Creek experimental watersheds, we determined that there is a linear relationship between winter precipitation (Oct.-Apr.) and annual runoff (water year) in ponderosa forest (fig. 2a). Using data from the Thomas Creek and Workman Creek experimental watersheds, we determined that there is a quadratic relationship between winter precipitation and annual runoff for mesic conifer forest (fig. 2b), which includes 10-20 percent aspen by basal area. Adding other climate and watershed characteristics did not significantly improve the models. Seven watersheds at the two sites were treated with some type of logging, and the increase in runoff in the years following treatment was determined through comparison with a control watershed. We used these data to develop a regression model that predicts the change in runoff following a restoration thinning treatment (fig. 2c). The increase in runoff in a given year depended on winter precipitation, time since treatment, and the reduction in basal area caused by the treatment.

\section{Lessons Learned}

Vegetation model results suggest that vegetation types will shift substantially over the next two centuries due to climate change, fire, and forest management. The preliminary hydrologic model results show that the relationship between precipitation and water yield is affected by both vegetation type and management history. Therefore, managers should expect changes in runoff and baseflow to rivers due to upland vegetation change and disturbance. Future work on this project will provide specific projections for flow in springs and streams in the Grand Canyon. 


\section{References Cited}

Crookston, N.L., Rehfeldt, G.E., Dixon, G.E., and Weiskittel, A.R., 2010, Addressing climate change in the forest vegetation simulator to assess impacts on landscape forest dynamics: Forest Ecology and Management, v. 260, no. 7, p. 1198-1211, http://www.sciencedirect.com/science/article/pii/S0378112710003853.

Robles, M.D., Marshall, R.M., O’Donnell, F., Smith, E.B., Haney, J.A., and Gori, D.F., 2014, Effects of climate variability and accelerated forest thinning on watershed-scale runoff in Southwestern USA ponderosa pine forests: PLoS ONE, v. 9, no. 10, p. e111092, https://doi.org/10.1371/journal.pone.0111092.

Pool, D.R., Blasch, K.W., Callegary, J.B., Leake, S.A., and Graser, L.F., 2011, Regional groundwaterflow model of the Redwall-Muav, Coconino, and alluvial basin aquifer systems of northern and central Arizona: U.S. Geological Survey Scientific Investigations Report 2010-5180, 101 p., http://pubs.er.usgs.gov/publication/sir20105180.

Scheller, R.M., Domingo, J.B., Sturtevant, B.R., Williams, J.S., Rudy, A., Gustafson, E.J., and Mladenoff, D.J., 2007, Design, development, and application of LANDIS-II, a spatial landscape simulation model with flexible temporal and spatial resolution: Ecological Modelling, v. 201, no. 3-4, p. 409-419, http://www.sciencedirect.com/science/article/pii/S0304380006004893.

Wyatt, C.J.W., O'Donnell, F.C., and Springer, A.E., 2015, Semi-arid aquifer responses to forest restoration treatments and climate change: Groundwater, v. 53, no. 2, p. 207-216, http://dx.doi.org/10.1111/gwat.12184. 


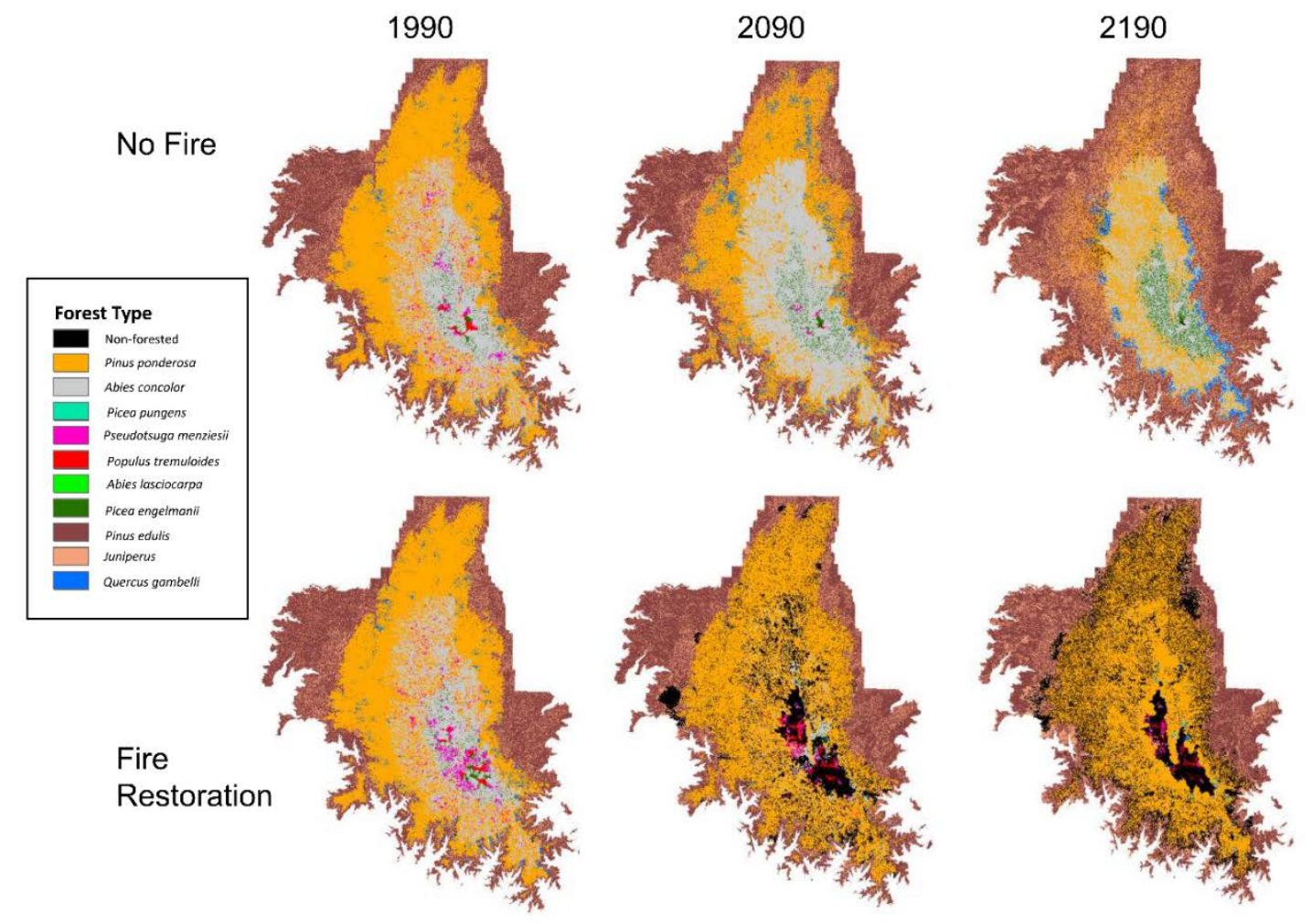

Figure 1. Maps of forest composition in the simulated Kaibab Plateau landscape under the RCP 4.5 climate change scenario. The maps are grouped according to the no fire scenario (top row) and the fire restoration scenario (bottom row). Pixels are classified according to dominant species biomass. 

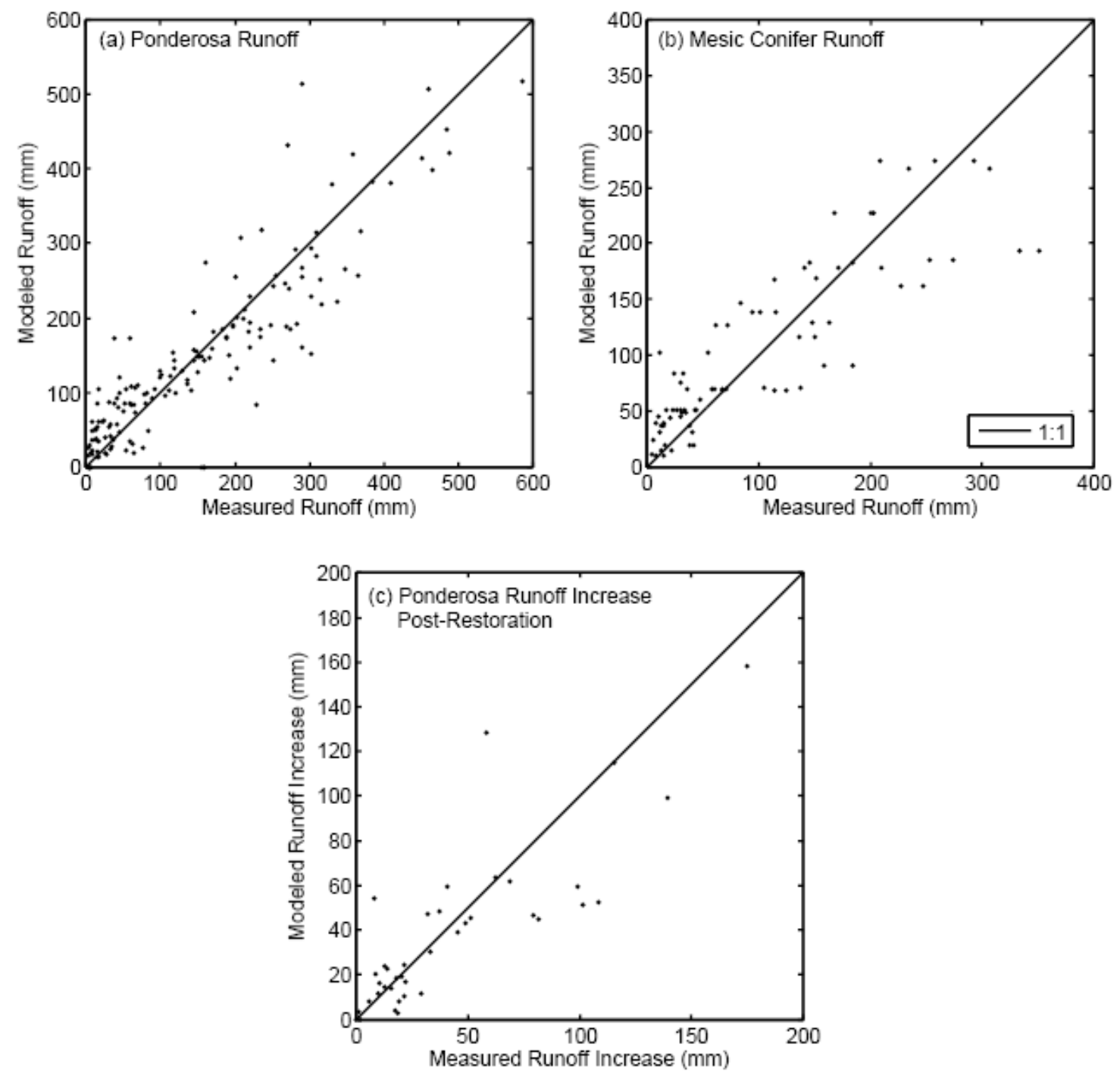

Figure 2. Measurements historic experimental watersheds compared to the outputs of regression models for (a) baseline runoff in undisturbed ponderosa forest, (b) baseline runoff in undisturbed mesic conifer forest, and (c) the increase in runoff following restoration in ponderosa forest. The regression equations used to produce model data are given, where $R O$ is annual (water year) runoff, $\triangle R O$ is increase in runoff, WP is winter (Oct.-Apr.) precipitation, $Y$ is years since restoration treatment, and $B A$ is a logistic term describing the reduction in basal area following restoration. 


\section{Conducting Monitoring for a Public-Private Collaborative: Lessons from the Dolores River Restoration Partnership}

By J. Daniel Oppenheimer ${ }^{1}$, Julie A. Knudson', Amanda Clements², Madeline Grant-Hoffman², and Anna A. Sher ${ }^{3}$

\section{Introduction}

The Dolores River flows from the San Juan Mountains of southwestern Colorado over 200 miles to its confluence with the Colorado River in eastern Utah. Much of the river's riparian corridor is infested with woody and herbaceous weeds, such as tamarisk (Tamarix spp.) and Russian knapweed (Acroptilon repens). Recognizing the extent of infestations as well as associated degradation to wildlife habitat, livestock forage, and recreational opportunities, several organizations seeking to make a landscape-scale impact developed the Dolores River Restoration Partnership (DRRP) in 2009. Today, the DRRP includes more than fifty partnering public agencies, landowners, non-profit organizations, schools, foundations, and businesses.

For six years, the DRRP has worked effectively across two states, five counties, four Bureau of Land Management (BLM) field offices, more than twenty participating private lands, and over 200 miles of the Dolores River and its tributaries to improve the health and plant diversity of the riparian corridor. Restoration work includes: controlling invasive plants; planting native flora; improving grazing management; and monitoring. One of the greatest components for collaborative success has been the DRRP's shared mindset for building on documented lessons learned (Oppenheimer and others, 2014). Lessons learned inform nearly all DRRP work, from how partnership meetings are designed to how cottonwood (Populus fremontii) poles are planted. Ecological monitoring, in particular, has provided an important way for the DRRP to document and build on restoration lessons learned.

The DRRP's Science and Monitoring Subcommittee (SMS) collects, assesses, and disseminates results from monitoring field data to inform project planning, track progress towards ecological goals, and evaluate the effectiveness of different restoration treatments. Since 2010, the SMS has developed several complementary monitoring protocols towards these purposes.

One of these monitoring efforts, pilot-project monitoring, is conducted to compare the effectiveness of multiple unique restoration treatment combinations across four sites all within a single watershed reach. The impetus for this monitoring is to learn, through small-scale trials, the most promising techniques for restoration along an arid, largely dewatered and highly saline portion of the river heavily infested with tamarisk before large-scale commitment of resources. This monitoring effort also explores the effects of the tamarisk beetle (Diorhabda spp.) — a biological control agent introduced into the system in 2007—on restoration efforts.

Our objectives here are to (1) highlight the SMS's collaborative lessons learned, and (2) share preliminary findings from the DRRP pilot-project monitoring effort, which may be potentially relevant for restoration programs in other watersheds in the arid West.

\footnotetext{
${ }^{1}$ Tamarisk Coalition, Grand Junction, Colorado

${ }^{2}$ Bureau of Land Management

${ }^{3}$ University of Denver
} 


\section{Methods - Building on Collaborative Lessons}

To summarize lessons learned by the SMS for conducting monitoring for a partnership, a review was conducted of subcommittee meeting minutes and presentations from past partnership meetings. Additionally, the authors, all SMS members, provided insight based on experience with DRRP monitoring efforts. Collectively, the authors have expertise in riparian ecology, invasive plant management, and conservation biology; they have played varying roles in designing, coordinating, conducting, and integrating information from the pilot-project monitoring into restoration decisions.

Sharing Pilot-Project Monitoring Findings

To share preliminary findings from the pilot-project effort, we drew on the most recent DRRP pilot project monitoring report developed by the University of Denver (Sher and Henry, 2015). This pilot project and its associated monitoring effort was originally designed and implemented in 2010. At that time, four 2-acre sites were selected along a 20-mile reach of the Dolores River, and four 0.5-acre plots were initially established at each site. Within a site, each plot was randomly assigned one of four tamarisk treatments: (1) tamarisk beetle only, (2) mechanical mulching, (3) hand cutting and removal, or (4) controlled burning. With the tamarisk beetle established throughout the system, there was no option for a set of completely 'untreated' plots.

All treatments were implemented in 2011, except for the controlled burning; this treatment was never completed due to perceived risks associated with fire. The remaining three plots (within each of the four sites) were then subdivided in half, resulting in 6 subplots. Russian knapweed was chemically treated within all subplots; tamarisk resprouts were chemically treated in half of the subplots; several species of containerized native riparian shrubs and trees (e.g. three-leaf sumac [Rhus trilobata] and New Mexico privet [Forestiera neomexicana]) were planted in half of the subplots; and native grasses and shrubs were seeded in half of the subplots.

The following insights from the pilot-project effort stem (1) from the originally devised monitoring effort, which involves the University of Denver collecting vegetation data (line-point intercept method [Caratti, 2006], adapted by Sher [2013]) and conducting statistical analysis on posttreatment data (e.g. how relative cover of native and exotic plants responded) from 2011, 2012, and 2014; and (2) from concurrent site inventories conducted by a BLM ecologist in 2011 and 2012 to assess and compare a variety of outcomes, including survival rate of plantings.

\section{Results and Discussion - Building on Collaborative Lessons}

When the DRRP was formed, there was early recognition that a coordinated monitoring program would be needed to cross state and field-office boundaries in order to adequately document and build on restoration lessons learned within the partnership and improve restoration approaches over successive years. However, DRRP discovered that developing an efficient, cohesive partnership framework for determining success and gleaning lessons learned to serve multiple vested interests across boundaries was a sizeable challenge.

The DRRP has managed to respond to emerging monitoring needs through flexibility established in the partnership's planning documents and a responsive governance structure (Oppenheimer and others, 2014), as well as trial and error, the driving force of enthusiastic and invested partners that continue to support and critically evaluate the partnership, and hands-on funders willing to be flexible and support the non-linear evolution of the partnership’s monitoring program.

In 2013, for example, after mixed successes with cottonwood plantings, the SMS began coordinating with a funder to develop a new, formal assessment of soil and water conditions (e.g. measuring soil salinity and water-table depth) to inform cottonwood plantings along the Dolores River. A monitoring crew conducted over 230 samples. At sites where soil and water conditions were 
considered suitable — based on the scientific literature — the crew worked with a contractor to plant 116 cottonwood poles in the winter of 2014. Following an assessment of cottonwood survival in the summer of 2014, these early findings were discussed in-depth at SMS and Project Implementation

Subcommittee meetings. Currently, these findings are being statistically analyzed by a university partner and will inform future plantings throughout the Dolores River riparian corridor, including in the pilotproject sites.

\section{Sharing Pilot-Project Monitoring Findings}

BLM's site inventories, which were conducted for two growing seasons post-treatment, indicate higher planting survival in the tamarisk-beetle only treatment (i.e. partial defoliation of tamarisk foliage, but woody structure remains intact). For example, across all sites the best performing species (three-leaf sumac and New Mexico privet) demonstrated the following combined survival rates: 95 percent survival in the leaf-beetle only treatments; 23 percent survival in mechanical mulching treatments; and 56 percent survival in hand-cut treatments. This finding is consistent with DeWine and Cooper (2010), who found tamarisk facilitates box elder (Acer negundo) seedling survival by providing shade and a cooler microclimate.

These findings, shared at partnership meetings, have informed restoration along the Dolores River on several sites similarly characterized with saline soils, disconnected floodplains, heavy tamarisk infestation, and presence of the tamarisk beetle. Specifically, a mosaic tamarisk removal method has now been implemented on other public as well as private lands to create accessible pathways through dense tamarisk stands (fig. 1); the pathways provide access for treating secondary weeds and later revegetation work, while the remaining tamarisk structure provides shade to the soil and groundcover. Follow up plantings will use three-leaf sumac and New Mexico privet, which had the highest survival rates of plantings across all the plots, with 42 percent and 49 percent overall survival rates, respectively.

In plots where tamarisk was actively removed and re-growth treated, University of Denver found relative cover of native plant species to be 57 percent higher than exotic species; it is likely that this can be attributed to the substantial reduction of tamarisk, which dominated the composition of the plots. Of note, high levels of native cover did not always occur where broadcast seeding of native grasses and shrubs occurred. While a number of factors may have been at play, anecdotal support from several restoration practitioners visiting the pilot-project sites suggest that the thickness of tamarisk mulch following removal methods may have impeded suitable seed contact with organic soil. As such, seeding methods have since been refined to use hand-tools and machinery to incorporate seed into the soil on sites where tamarisk has been removed.

The University of Denver also found cover of non-native plants other than tamarisk lowest on the tamarisk beetle only plots. This result is not surprising, as the invasion of herbaceous weeds such as Russian knapweed can be common on sites experiencing more disturbances - in this case, active treatment and removal of tamarisk. Anecdotally, this trend has been observed across many stretches of the Dolores River, underscoring the importance of assessing understory health before removing tamarisk and planning appropriately to respond to potentially rapid invasions of herbaceous weeds. In summary, these collaborative monitoring efforts, in concert with collaborative planning and resource sharing over the past six years, have yielded a variety of lessons learned and enabled the DRRP to successfully restore over 1,140 acres of the riparian corridor to a dominant mix of native grasses, shrubs, and trees. 


\section{Lessons Learned}

- Conducting long-term monitoring for a public-private partnership may inherently yield complexity and challenges stemming from different perspectives and values.

- Navigating these nuances requires partnership flexibility, which can be institutionalized in planning documents and governance structure (e.g. design of the Science and Monitoring Subcommittee), as well as a shared value in learning.

- Shared partnership value in learning allows for constant tinkering and modifying. Efficiency of this approach is enhanced with systematic monitoring, and regular opportunities and expectations among partners that the information will be interpreted and shared.

- Pilot projects and timely monitoring can inform large scale project implementation, even though they are often too brief to identify long-term outcomes.

- A mosaic treatment of tamarisk, in certain site conditions, can increase access for conducting other restoration treatments and provide beneficial shading for native plants in riparian ecosystems in the arid West.

\section{References Cited}

Caratti, J.F., 2006, Point Intercept (PO)—FIREMON—Fire effects monitoring and inventory system, in, Lutes, D.C., Keane, R.E., Caratti, J.F., Key, C.H., Benson, N.C., Sutherland, S., and Gangi, L.J., eds., General Technical Report: US Department of Agriculture, Rocky Mountain Research Station, Fort Collins, Colorado, 400 p.

DeWine, J.M., and Cooper, D.J., 2010, Habitat overlap and facilitation in Tamarisk and Box Elder stands-Implications for Tamarisk control using native plants: Restoration Ecology, v. 18, no. 3, p. 349-358, http://dx.doi.org/10.1111/j.1526-100X.2008.00494.x.

Oppenheimer, J.D., Beaugh, S.K., Knudson, J.A., Mueller, P., Grant-Hoffman, N., Clements, A., and Wight, M., 2015, A collaborative model for large-scale riparian restoration in the western United States: Restoration Ecology, v. 23, no. 2, p. 143-148, http://dx.doi.org/10.1111/rec.12166.

Sher, A.A., 2013, 2012 Watershed wide monitoring annual report: Submitted to the Tamarisk Coalition for the Dolores River Restoration Partnership (DRRP).

Sher, A., and Henry, A., 2015, 2014 Vegetation monitoring on uncompahgre pilot project sites associated with the Dolores River Restoration Partnership: University of Denver, Denver, Colorado. 


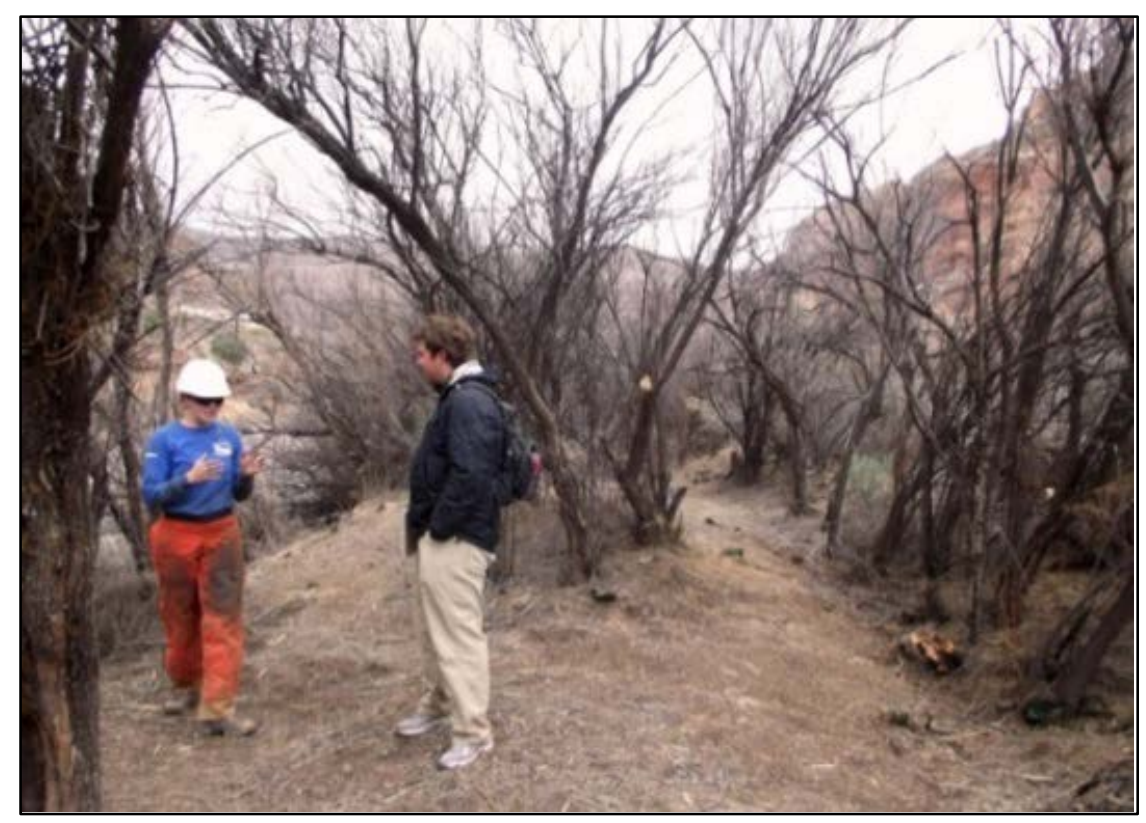

Figure 1. DRRP partners standing in a mosaic treatment, where pathways have been cleared through tamarisk by crews using chainsaws (photo, J. D. Oppenheimer, Tamarisk Coalition). 


\title{
Developing a Monitoring Plan for the Verde River Cooperative Invasive Plant Management Plan
}

\author{
By Anna V. Schrenk ${ }^{1}$, Sara Van Marel' ${ }^{1}$, and Robert Bryson ${ }^{1}$
}

\section{Introduction}

The Verde River, the main river snaking through the Verde Watershed, is treasured for its wildlife habitat, water supply, recreational opportunities, and natural beauty. It is one of the most substantial relatively free-flowing rivers in Arizona. Although the river corridor primarily supports native riparian vegetation, invasive species - particularly tamarisk (Tamarix spp.), Russian olive (Elaeagnus angustifolia), tree of heaven (Ailanthus altissima) and giant reed (Arundo donax) threaten the health and sustainability of these communities.

To address these resource concerns, the Verde Watershed Restoration Coalition (VWRC) was created in 2010. VWRC is a diverse public-private partnership working collaboratively in a coordinated effort to improve habitat on a watershed scale towards a shared vision: the Verde River and its tributaries comprise a diverse, self-sustaining and resilient riparian ecosystem in which invasive plants are controlled through cooperative stakeholder participation.

The Verde River Cooperative Invasive Plant Management Plan (CIPMP) is a five-year management plan, which was developed (in 2011) as a resource to guide land managers. CIPMP outlines goals, incorporates a holistic approach to invasive plant control on a watershed scale, and addresses ecological, social, economic, and management issues. The goals account for system stressors, use site and species prioritization approaches, and advance the VWRC's shared vision.

The project area extends along the Verde River from its headwaters near Paulden downstream to Sheep's Bridge and includes all perennial tributaries to the Verde River, a total of 459 miles of riparian cooridor covering almost 30,000 acres. The lateral extent of the project area encompasses the area within the riparian zone ${ }^{2}$, to determine the lateral extent of the project area, the Federal Emergency Management Agency (FEMA) 100 year flood hazard area maps for Yavapai and Coconino Counties are being used as a base then using ArcGIS all agricultural and developed areas were removed ${ }^{3}$. The project area is further limited to only those parcels where VWRC has secured agreements with the landowner or land managers.

The management objectives outlined in the plan are to reduce tamarisk and tree of heaven to less than 10 percent cover of the existing canopy cover on each site and remove all occurrence of Russian olive and giant reed from the project area by 2018.

To ensure that management objectives are met, a VWRC Monitoring Subcommittee was formed in 2012 to develop to oversee all monitoring and research efforts related to the project. The committee is co-chaired by representatives from Salt River Project and the Prescott National Forest and has five participating members from a diverse representation of stakeholders, including private landowners and several non-profit organizations.

\footnotetext{
${ }^{1}$ Friends of Verde River Greenway, Cottonwood, Arizona

${ }^{2}$ Riparian Zone - The biologically distinctive area between land and stream that is dominated by hydrophilic plants.

${ }^{3} \mathrm{~A}$ developed area is defined as any area with buildings, pavement and infrastructure.
} 
The main task of this subcommittee has been to develop a monitoring plan that utilizes a tiered approach, which includes both quantitative and qualitative elements. The various approaches cover: (1) short-term evaluation to determine whether actions are meeting management objectives and will indicate if changes need to be made during implementation (adaptive management) and, (2) the need for long-term monitoring of changes within the riparian zone. In the long term, data from various sites within the watershed can be compared to provide further insight into the cause and effect of observed changes. For example, it could be determined that treatment is more successful in December as opposed to February based on changes that are identified and tracked during long term monitoring.

\section{Methods}

The methods developed in this plan can be separated into our need for both short- and long-term monitoring information. There are both qualitative and quantitative elements in both approaches. The short-term monitoring focuses on the collection of information that will provide data for planning and implementation, measure treatment effectiveness and guide future management of a site. VWRCs monitoring plan includes photo point monitoring (repeat photography), pre- and post-treatment rapid assessments, and an inventory of target invasive plants recorded using GPS.

The photo point monitoring will provide a landscape scale view of changes over time. Photo point locations are established in a manner that allows the picture to be taken from the same location, filling the same frame, so that differences between and among years can be identified and compared.

Rapid assessments are preformed prior to invasive plant treatment on each site, the information collected is both qualitative and quantitative in nature. Information is recorded on invasive and native plant presence/absence, vegetation type, land-use, erosion potential, human disturbance and native plant recruitment. Similar post-treatment data are collected to inform adaptive management and evaluate the need for future maintenance and/or restoration activities.

Pre-treatment mapping is conducted at each site ${ }^{4}$ using established protocols and methods to determine locations, canopy cover, extent and species type for each target invasive plant species. After removal and treatment are complete, field crews collect treatment data for each species that includes site information and required treatment information. Post-treatment mapping and post-treatment rapid assessment are conducted within 18 months of treatment.

Monitoring will determine whether management objectives are being met through the implementation of invasive plant management activities. The quantitative elements of the plan include pre-treatment mapping, treatment information and post-treatment mapping, all of which can be spatially analyzed using ArcGIS to determine treatment effectiveness.

The partnership understands that research-based monitoring may be required to answer specific questions about restoration efforts or other ecological questions that may arise. VWRC will partner with research entities (Northern Arizona University, U.S. Geological Survey, and others) to frame research questions and develop appropriate means to address questions as they arise. All post-treatment mapping, photo-point monitoring, and post-treatment assessments are conducted during the growing season, which is from March to October. Private lands are monitored annually and public lands are monitored every other year. Other types of monitoring that are occurring on project sites prior to implementation of fieldwork include Southwest Willow Flycatcher (Empidonax trailii extimus) and Yellow Billed Cuckoo (Coccyzus americanus) surveys and consultation regarding listed Mexican Garter Snake (Thamnophis eques).

\footnotetext{
4“Site” is defined as any discrete geographic area as specified by the Project Manager.
} 


\section{Results and Discussion}

VWRC started implementation of CIPMP in September 2012 and has conducted invasive plant removal and treatment on over 5,000 acres during the last three field-seasons ${ }^{5}$. Monitoring has been conducted on treatment sites from the 2012/2013 and a portion of the 2013/2014 field seasons, monitoring of treatment sites from 2014/2015 season will be conducted during the summer and fall of 2015. Early data analysis indicates that populations of target invasive plants are being reduced and thus management objectives are being accomplished. A second season of monitoring data will provide VWRC with a current Southwest Willow Flycatcher survey. Preliminary analysis of these survey data suggest that birds are using sites that have been previously treated, where large stands of tamarisk were removed.

While there are only two years of data to compare thus far, preliminary data show that target invasive plants are being reduced and/or eliminated in the project area. Anecdotal results also show that natural recruitment of herbaceous and woody native plants is occurring.

\section{Lessons Learned}

VWRC was tasked with developing a monitoring plan that fit all the requirements of our federal, state and local agency partners, while at the same time answering management objectives and funder requests. This process entailed collecting monitoring requirements from all VWRC stakeholders and combining them into a comprehensive plan that includes methods and protocol. The biggest takeaway from this process was to keep the plan simple, yet robost enough to answer management objectives. For VWRC it was key they we develop monitoring protocols that could be implemented by field crews and citizen science volunteers.

One of the challenges the partnership was faced with early on was who would manage the data, where it would be stored, and how information transfer to stakeholders would occur. Friends of Verde River Greenway (FVRG), the lead non-profit in VWRC, created a geodatabase and is the database manager. FVRG disseminates information to stakeholders upon request and is currently working on developing a streamlined method for easier data sharing between partners. The partnership decided to house all inventory (mapping) and treatment data in the Forest Service Natural Resource Information System (NRIS) and Forest Activity Tracking System (FACTS) databases, respectively, for longevity as they are the largest land management agency in the watershed.

Another challenge the partnership was faced with was how to incorporate the data requests of funders without losing sight of the goals of CIPMP and developing or adopting protocols that the partnership has the capacity to implement. VWRC is partially funded by the Walton Family Foundation's Freshwater Initiative, as are several other partnerships in the Colorado River basin. VWRC is working closely with the Walton Family Foundation and other watershed partnerships in the Colorado River Basin, such as the Gila and Dolores Watershed Partnerships, to incorporate similar methods and protocols into monitoring plans so that data can be compared between watersheds throughout the basin.

\footnotetext{
${ }^{5}$ VWRC field season is approximately 22 weeks and takes place in the months that are not the growing season; October through February.
} 


\title{
Section V. Monitoring following revegetation
}

\section{Monitoring Wetland Restoration Projects in Arizona within the Arizona Game and Fish Department's In-Lieu Fee Restoration and NRDAR Programs}

\author{
By Michael F. Ingraldi ${ }^{1}$, Nora D. Clark ${ }^{1}$, and Shawn F. Lowery ${ }^{1}$
}

\section{Introduction}

The Arizona Game and Fish Department (Department) in collaboration with the Army Corps of Engineers is implementing an In-lieu Fee Wetland Restoration Program (ILF) within the state of Arizona. This program is designed to offset injures to jurisdictional waters across Arizona. We are designing and implementing a management and monitoring program using an adaptive management framework to create, enhance and protect wetland systems throughout Arizona in perpetuity. In addition, the Department oversees habitat restoration activities associated with the Natural Resource Damage Assessment and Restoration (NRDAR) program which includes a long-term monitoring component.

In order to evaluate and make predictions on future management needs within our restoration project areas, we employ a monitoring regime that improves our understanding of the ecological systems using an adaptive management framework. Monitoring data are used to establish measurable objectives (desired conditions) for restoration efforts and track the progress of these efforts. This robust program consists of a three phase monitoring regime: (1) baseline, (2) five year post-restoration, and (3) long-term effectiveness.

Baseline monitoring allows managers to assess pre-existing ecological conditions (abiotic and biotic) at the project site prior to implementing restoration activities. This information is ultimately used to compare pre- and post-restoration conditions in order to evaluate the effects of restoration efforts at the project site. In addition, data collected from baseline monitoring efforts help define logistical constraints of specific monitoring protocols, identify sample sizes required to survey populations in both a cost-effective and statistically rigorous manner, and help focus efforts on species habitats or communities unique to a given restoration site.

Baseline monitoring involves conducting pre-restoration surveys and inventories on both biotic (faunal and floral) and abiotic (weather, water, soil, and geomorphology) indicators. We use standardized survey and inventory protocols to measure pre-restoration conditions. We stratify monitoring based on vegetation community type pre-restoration (e.g., nonnative invasive vegetation communities) and post-restoration (e.g., native vegetation communities). The following parameters are measured for fauna and flora, where appropriate: species richness, species diversity, and occupancy (i.e., area occupied, detection probabilities, colonization, and extinction rates).

Monitoring protocols are largely based on an occupancy framework. This type of framework allows for tracking of trends in detection probabilities and area occupied over time, pre- and postmanagement. For example, when the detection probability falls below the set threshold for a given

\footnotetext{
${ }^{1}$ Arizona Game and Fish Department
} 
species or community (e.g., a guild's species richness), this may be an indication that restoration efforts need to be modified, which may include repatriation of species. In this manner, adaptive management techniques are employed, and we can modify our restoration activities to meet pre-defined performance standards for a given indicator. These pre-defined performance standards are unique to each restoration site. Using an occupancy framework to monitor indicators allows us to assess general population and distribution trends. In addition, when trends show that indicator thresholds are not met, then more discerning or stressor specific detection techniques (e.g., PVA, density and abundance indices) can be employed to evaluate potential reasons for declining trends. Occupancy is a cost effective, efficient, and less intrusive means of tracking indicator trends and associated environmental stressors in comparison to many other techniques (PVA, density and abundance indices, etc.). Abiotic parameters collected are co-variates that help identify and characterize annual variability and trends.

Biotic and abiotic indicators include the following:

- Faunal monitoring includes inventorying and collecting ecological parameters on the following taxonomic groups: mammals (small, mesocarnivores, elusive large carnivores, ungulates and/or bats), birds, fish, aquatic and terrestrial amphibians and reptiles, and invertebrates (tamarisk beetle and aquatic macroinvertebrates). In addition, all federal candidate, threatened, and endangered faunal species expected to occur within the project area (pre- or post-restoration) are monitored.

- Floral monitoring involve inventorying and classifying pre-existing vegetation conditions. Prerestoration floralistic conditions across the site are delineated by documenting dominant vegetation communities within the project site, and the vegetation composition and structure within each dominate vegetation community type. In addition, permanent photo points are established to further assess pre-restoration conditions of vegetation composition and structure. Also, survival and health of planted vegetation post-restoration is monitored. In addition, all federal candidate, threatened, and endangered floral species expected to occur within the project area (pre- or post-restoration) are monitored.

- Abiotic monitoring entails collecting environmental measurements on water quality, soil composition, geomorphology, and weather. Water quality sampling involves measuring temperature, $\mathrm{pH}$, turbidity, and total dissolved solids. Also, point source and non-point source pollutants are measured if the surrounding landscape indicates that collecting information on this parameter is deemed necessary. Soil composition (salinity, nitrogen, and organic levels), temperature and moisture are measured. Geomorphology measurements provide information on the bank aspect and longitudinal profile on the lotic system (i.e., rates of sedimentation and scouring). Onsite weather stations collect real-time, local climatological parameters such as daily precipitation, percent humidity, and wind speed.

Baseline monitoring is conducted on all indicators for at least one year, and two years when possible, immediately prior to implementing restoration activities. Ideally pre-restoration monitoring should be conducted for five consecutive years to evaluate a more robust measure of annual variability for indicators. However, time constraints are imposed by the date that restoration funds are received and subsequently the ILF ruling that requires restoration activities to start within one to two years of the injury; we are therefore restricted in collecting only one to two years of data before restoration activities commence.

The five year post-restoration monitoring period follows the completion of the restoration action. The purpose of intensely monitoring for five consecutive years is to capture annual variability 
associated with each biotic and abiotic indicator immediately post-management. Indicator trends collected during the five year monitoring period are evaluated to determine the specific temporal scale for which we monitor each biotic and abiotic indicator for the long-term (starting at the sixth year postmanagement and beyond).

This five year monitoring program begins within the first year after restoration activities are completed. The specific timeframe for monitoring each indicator involves the same calendar dates as described previously (see baseline monitoring section), but monitoring will occur every year for five consecutive years. Also, data are collected on the same abiotic and biotic indicators previously mentioned (see baseline monitoring section) using the same standardized protocols that were used to document baseline conditions during the pre-restoration period in an effort to document post-restoration conditions.

Long-term effectiveness monitoring data are collected starting the sixth year post-management and continue indefinitely for the life of the restoration project. During this monitoring period, we continue to document indicator trends and track restoration success. Restoration activities are strategically implemented using an adaptive management framework. Pre-defined performance standards (mentioned briefly in baseline monitoring section) are evaluated. For example, threshold values (e.g., algae should not create anoxic or nuisance conditions 6 years post-restoration, native amphibian diversity should be within 70 percent of reference sites 10 years post-restoration) are used as gauges for determining restoration success. When performance standards are not met, restoration activities are modified accordingly in an effort to reach those thresholds. Therefore, we monitor indicator trends, evaluate thresholds, identify stressors, and subsequently adjust restoration activities when deemed necessary in order to meet our restoration objectives (desired habitat conditions).

Long-term monitoring of biotic and abiotic indicators are conducted on a 1-, 3-, or 5-year interval. The monitoring timeframe for each indicator is delineated based on the annual variability exhibited by each indicator in response to post-restoration conditions as determined from the five year post-monitoring. The timeframe for monitoring each indicator involves the same calendar dates, the same standardized protocols, and the same parameters that were used to document pre- and postrestoration period conditions (see baseline monitoring section).

- Most biotic indicators are monitored on a 3- and 5-year interval. Most federal candidate, threatened, and endangered species expected to occur within the project areas are monitored annually because of their level of sensitivity. In the latter case, we defer to species-specific monitoring timelines specified in USFWS monitoring protocols.

- Monitoring abiotic indicators, such as soil properties, geomorphology and water quality, are conducted on a 5-year interval, while weather is monitored on an annual basis. 


\title{
Citizen Science along the Middle Rio Grande - Collecting Data on Ecosystem Change
}

\author{
By Jennifer F. Schuetz ${ }^{1}$, and Kim D. Eichhorst ${ }^{1}$
}

\section{Introduction}

Citizen science, or community-based monitoring, has become more accepted as a way of collecting scientific data in the 21st century (Silvertown, 2009) as budgets shrink but the need for highquality, reliable scientific data remains (Whitelaw and others, 2003; U.S. EPA, 2002; Gardiner, 2012). Not only do citizen science programs fulfill a need for large-scale and low-cost data that inform natural resource management decisions (Conrad and Hilchey, 2011), they also connect the public to local ecosystems and educate people about the natural world, fulfilling the need for increased outreach of upper-level science to the general public (Gardiner and others, 2012).

Although it is debatable whether citizen scientists can produce data comparable to professional scientists (Gollan and others, 2012; Gardiner and others, 2012), methods to improve the accuracy of citizen science data have been identified. Such methods include increasing familiarity with the subject and training volunteers (Brandon and others, 2003), matching volunteer interests with data collected, employing simple and repeatable methods (Whitelaw and others, 2003), using experts to guide and oversee volunteers, and adopting standardized protocols (U.S. EPA, 2002). When well-designed and well-implemented, citizen science programs can yield tremendous benefits.

A partnership between the University of New Mexico (UNM) and Bosque School (a private 6-12 grade school in Albuquerque, New Mexico [NM]) Ecosystem Monitoring Program (BEMP) is a longterm citizen science program in which K-12 students and their teachers collect data to track ecosystem change in the forest along the Rio Grande in NM, USA. Since 1997, BEMP participants have collected data that provide a broad picture of ecosystem health, including depth to groundwater, rainfall levels, vegetation, water quality, fire potential, and surface-active arthropods. Although K-12 students and their teachers collect most of the data, BEMP staff oversee collections along with UNM student interns enrolled in a 400/500-level UNM Department of Biology class taught by BEMP staff. In addition, professional scientists collect specialized data within their area of expertise, such as vegetation cover, water quality, and identification of arthropods. After passing through quality-control measures, data are made available to land managers, scientists, policy makers, and the public upon request, on UNM web site, and at meetings.

Here we discuss BEMP structure, long-term trends in select data, and program operations. We conclude with a discussion of the benefits of this citizen science program and recommendations on how to run similar programs.

\section{Methods}

BEMP consists of 32 study sites that span 250 kilometers ( 155 miles) from the pueblo of Ohkay Owingeh, NM, in the north to Lemitar, NM, in the south, plus one site $246 \mathrm{~km}$ (153 miles) south of Lemitar, at Mesilla Valley Bosque State Park, NM (http://bemp.org/site-maps/). Each site is 200 meters (m) long and $100 \mathrm{~m}$ wide except for a few sites located in narrow stretches between the river and levee.

\footnotetext{
${ }^{1}$ University of New Mexico
} 
Each site contains five groundwater wells, ten vegetation plots, ten litterfall tubs, 20 pitfall traps, and two rain gauges (fig. 1).

Each month, K-12 students and their teachers, with oversight by BEMP staff and UNM interns, collect basic data on ecosystem health, including precipitation, depth to groundwater, ditch water levels, and litterfall (leaves, wood, and reproductive parts). Supplemental datasets are collected at different intervals depending on funding availability. These datasets include surface and air temperature; surfaceactive arthropods; plant cover and species; fuel load/woody debris; tamarisk leaf beetle populations; cottonwood density, size, and gender; and water quality $(\mathrm{pH}$, conductivity, temperature, dissolved oxygen, turbidity, anions, E. coli, pharmaceuticals and personal care products, polychlorinated biphenyls, and pesticides).

Methodology for BEMP data collections are intentionally simple, low cost, and easy to replicate, which helps keep operational costs down and allows for consistency across sites and years. This also makes BEMP a good model citizen science program.

Although most data are collected by citizen scientists, BEMP incurs costs for transportation, coordination, oversight/quality control, and supplemental education. With transportation as one of the biggest hurdles for teachers to get their classes onsite, BEMP includes costs for buses in grant proposals to provide transportation to participating schools. Coordination and oversight of the 32 study sites, 30 schools collecting data, field maintenance, data entry and management, sample processing, and so on, are time consuming and critical to the program's success. To supplement field experiences, BEMP educators provide additional instruction to students and teachers in the classroom, focusing on ecosystem studies, how to form hypotheses and use real data, counting and identifying surface-active arthropods, and plant identification. BEMP staff also teach a 400/500-level Biology class at UNM where students learn about the changes to the Rio Grande through the years and gain hands-on experience in field protocols.

BEMP receives funding for data collections and community outreach from grants, foundations, businesses, private donations, and federal, state and local government agencies. One key element of BEMP's success is that funders request and use BEMP data (e.g., for post-restoration monitoring) and/or want to support environmental education and community outreach.

\section{Results and Discussion}

BEMP data collected by citizen scientists show long-term trends in ecosystem change. For instance, at the Alameda BEMP site located in north Albuquerque, NM, the shallow aquifer has been declining for the most part since 1997, with some recovery in 2005 and 2008 during high river flows (fig. 2). Vegetation cover data indicate that exotic forb and grass cover increases after mechanical clearing events that are not followed by flooding (fig. 3). Many native plants are dependent on floods and high groundwater levels, underlining the importance of overbank flooding as opposed to the more prevalent anthropogenic drivers that currently dominate this ecosystem.

BEMP provides benefits to 1) K-graduate students who gain hands-on experience in scientific data collections and learn about their local ecosystem, 2) teachers who get their students outside to learn and develop a sense of place in their community, 3) scientists who learn from long-term ecosystem data, and 4) funders and partners who obtain important data collected at a low cost while supporting community outreach.

\section{Lessons Learned}

Through the years, BEMP has learned a few important lessons that may be of value to others designing citizen science monitoring programs. These lessons are: 
- Establish protocols and ensure that they are easily accessible.

- Provide oversight to data collectors (teachers, interns, and site representatives) by trained professionals or staff until volunteers are competent and confident.

- Educate K-12 students on post field collection operations such as sample processing and data entry, thereby connecting field work to follow-up lab and office work.

- Produce data that can be used by natural resource managers to make land use decisions.

- Secure multiple-year funding rather than annual funding where possible.

- Obtain funding for base operations rather than adding new data sets and changing the program in order to secure funding.

- Engage a mix of citizen volunteers and professional scientists to collect both general data and specialized data.

- Create partnerships that are advantageous to the program. For example, in BEMP, UNM connections help ensure scientific integrity, and private school connections allow for greater ease in applying for certain funding and provide support of key personnel.

\section{References Cited}

Brandon, A., Spyreas, G., Molano-Flores, B., Carroll, C., and Ellis, K., 2003, Can volunteers provide reliable data for forest vegetation surveys?: Natural Areas Journal, v. 23, p. 254-262.

Conrad, C.C., and Hilchey, K.G., 2011, A review of citizen science and community-based environmental monitoring-Issues and opportunities: Environmental Monitoring and Assessment, v. 176, no. 1, p. 273-291, http://dx.doi.org/10.1007/s10661-010-1582-5.

Gardiner, M.M., Allee, L.L., Brown, P.M.J., Losey, J.E., Roy, H.E., and Smyth, R.R., 2012, Lessons from lady beetles-Accuracy of monitoring data from US and UK citizen-science programs: Frontiers in Ecology and the Environment, v. 10, no. 9, p. 471-476, http://dx.doi.org/10.1890/110185.

Gollan, J., de Bruyn, L.L., Reid, N., and Wilkie, L., 2012, Can volunteers collect data that are comparable to professional scientists? - A study of variables used in monitoring the outcomes of ecosystem rehabilitation: Environmental Management, v. 50, no. 5, p. 969-978, http://dx.doi.org/10.1007/s00267-012-9924-4.

Silvertown, J., 2009, A new dawn for citizen science: Trends in Ecology \& Evolution, v. 24, no. 9, p. 467-471, http://www.sciencedirect.com/science/article/pii/S016953470900175X.

U.S. Environmental Protection Agencey, 2002, Methods for evaluating wetland condition-Volunteers and wetland biomonitoring: U.S. Environmental Protection Agency, Washington, DC, 26 p.

Whitelaw, G., Vaughan, H., Craig, B., and Atkinson, D., 2003, Establishing the Canadian community monitoring network: Environmental Monitoring and Assessment, v. 88, no. 1, p. 409-418, http://dx.doi.org/10.1023/A:1025545813057. 


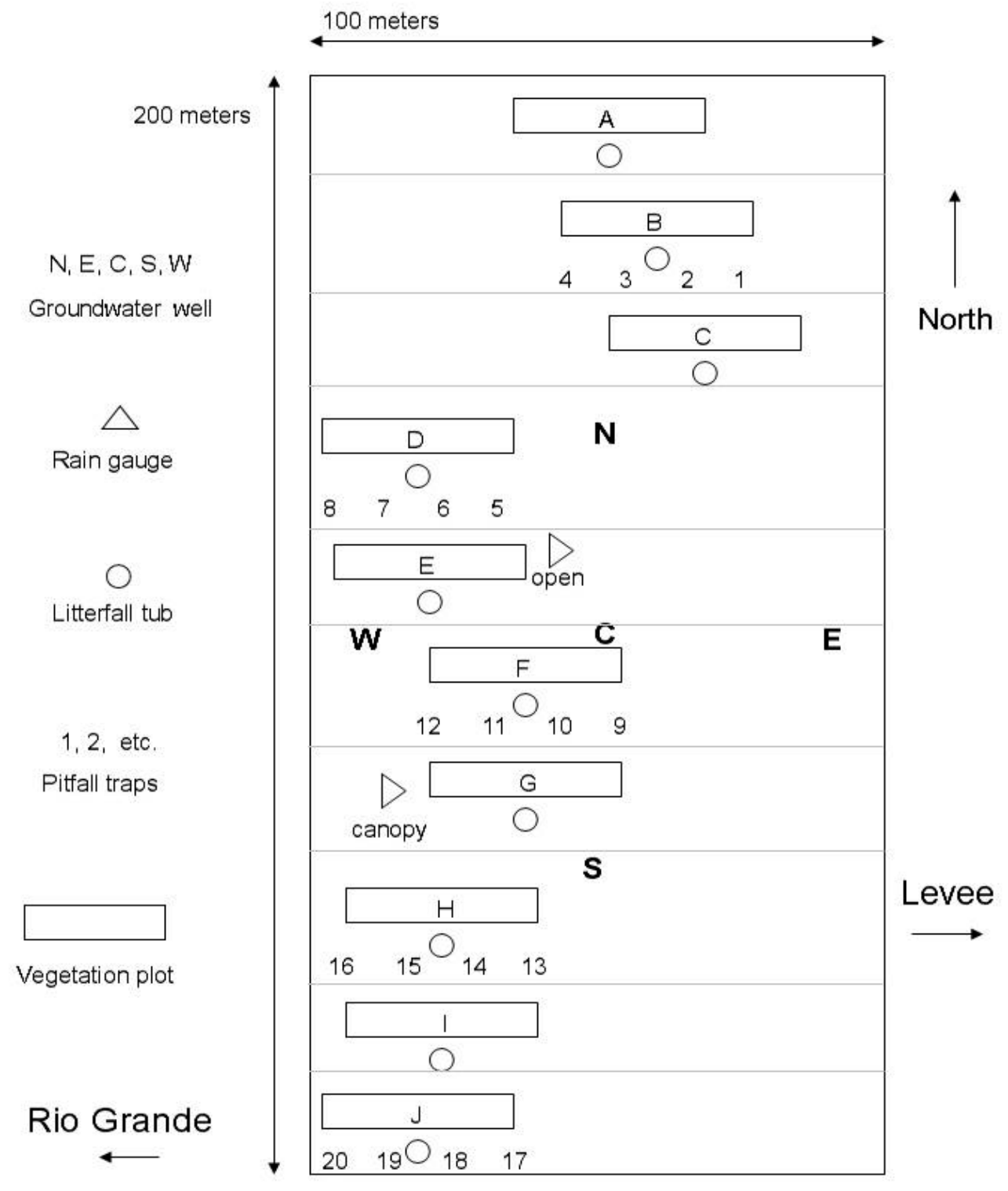

Figure 1. Example site layout in $100 \mathrm{~m} \times 200 \mathrm{~m}$ dimensions with the long edge oriented North to South. Sites include vegetation plots (rectangles), numbered pitfall traps, rain gauges (triangle), litter tubs (circles) and groundwater wells (capital letters). 


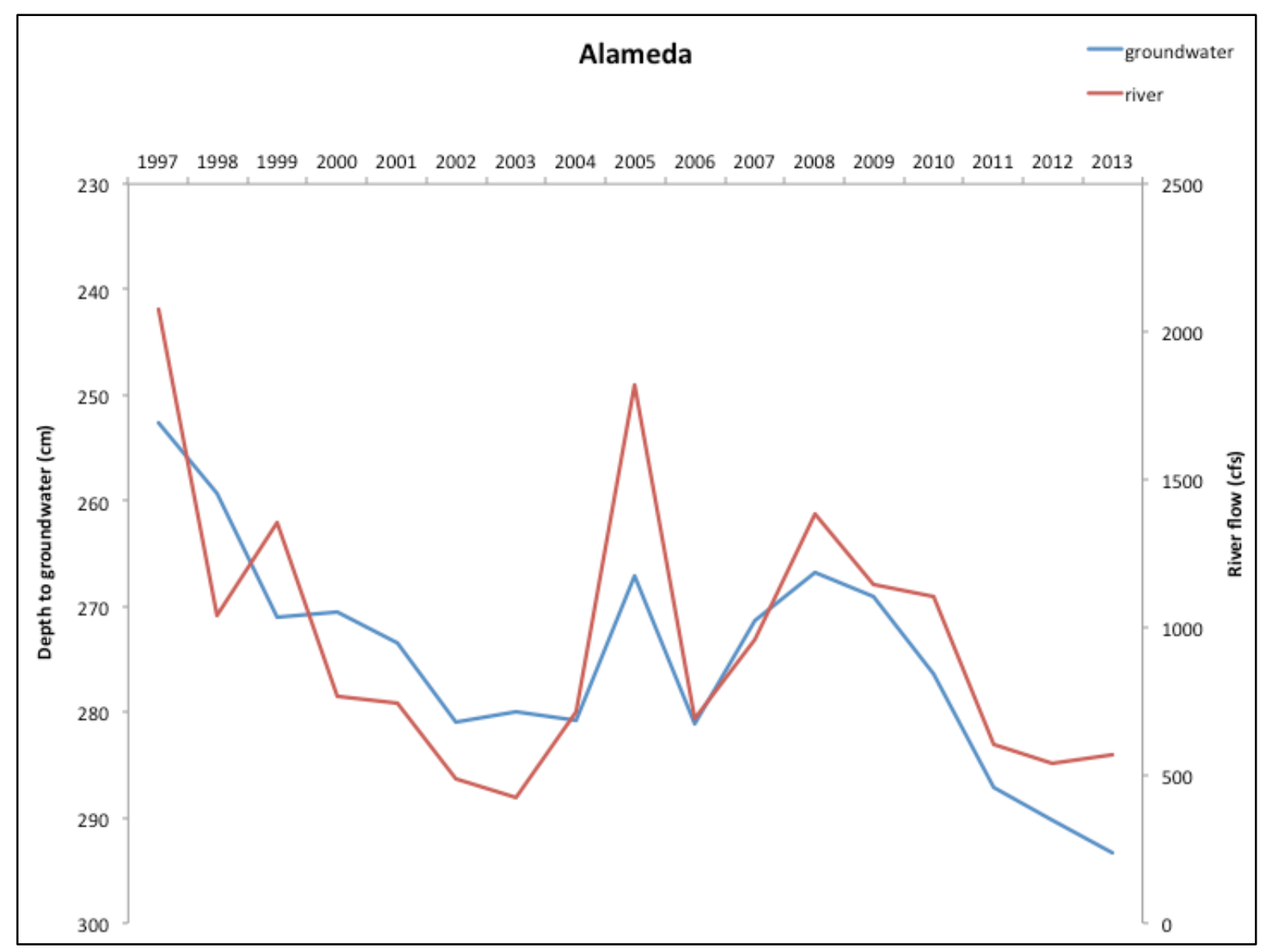

Figure 2. Trends in depth to groundwater at the Bosque Ecosystem Monitoring Program Alameda site in northern Albuquerque, NM. Depth to groundwater (cm) values (blue line) for the years 1997 to 2013 are compared with river discharge (cfs) values (red line) for the same period of time. 


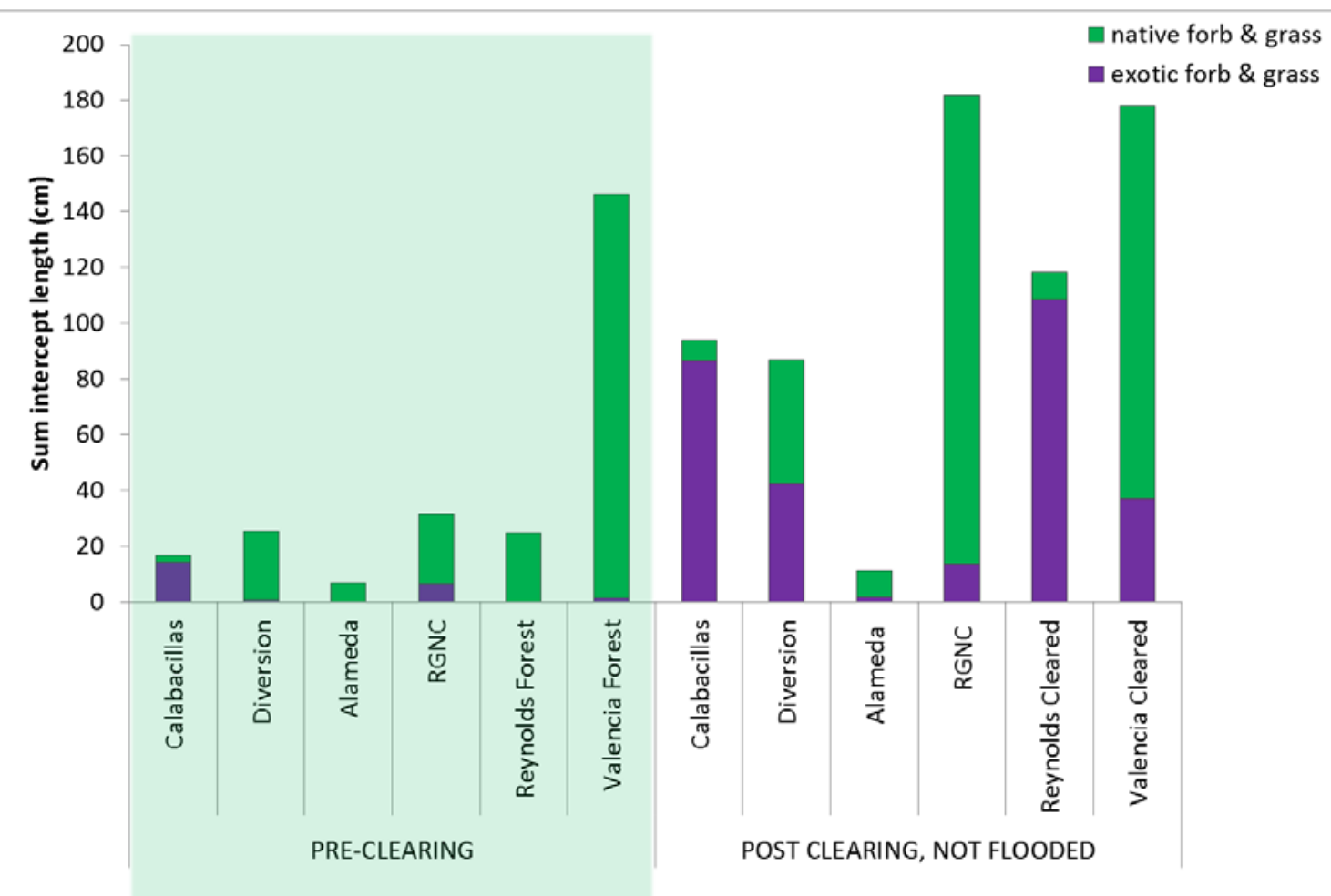

Figure 3. Comparison of two vegetation cover types in the absence of flooding (native forb and grasses (green bars) and exotic forb and grasses (purple bars)) at pre-clearing (green shaded part of graph) and post-cleaing sites. Clearing without flooding results in increased exotic forbs and grasses. Data are from six of 32 Ecosystem Monitoring Program study sites. 


\section{Lessons Learned from Revegetation of Aggregate-Mined Areas along a Large Western River}

By Robert J. Pabst ${ }^{1}$, Jeff Shatford ${ }^{2}$, and Daniel A. Sarr ${ }^{3}$

\section{Introduction}

The Willamette River in Oregon, like many large rivers in agricultural landscapes of the West, has had dramatic reductions in wetland and channel area since settlement (Christy and Alverson, 2011), with flow regulation by dams, disconnection from its floodplain (Sedell and Frogatt, 1984), and consequent changes in biodiversity. In a community restoration effort, volunteers planted and monitored a variety of native tree and shrub species at Endicott and Harrisburg ponds, two former gravel mine sites adjacent to the Willamette River. The goal was to restore native riparian habitat on formerly denuded and compacted gravel sites that had high biodiversity potential, including human-made lake habitat and restored connections to the main stem river. The project was part of a larger research effort done in collaboration with Oregon State University (Bayley and Baker, 2004) and funded by the Oregon Watershed Enhancement Board. The larger research objective was to examine how reconnecting the main stem Willamette with off-channel habitats affected migrating salmonids, other fish populations and local hydrology.

\section{Methods}

Seventeen woody species native to the Willamette Valley were selected for planting (table 1), based on site evaluations, assessments of intact riparian woodlands, and background research. Types of planting stock included bare root, container, dormant cutting, rooted cutting, and seed. Plant materials of local and regional provenance were purchased from a native plant nursery or collected from nearby locations (e.g., Salix spp. cuttings, Fraxinus latifolia saplings, Quercus garryanna acorns). The Endicott site was planted in 2000 and 2001; the Harrisburg site in 2001. Rooted and container stock were planted with shovels or pick-axes, and small earthen wells were formed around each plant to collect water. Dormant cuttings were simply pushed into the soil at Harrisburg, where soils were generally finer textured silt and sandy loams. In contrast, compact, gravelly soils at Endicott necessitated a laborintensive approach in which holes for cuttings were pounded into the soil using an iron bar driven with a fence-post driver. Trench-planting was also attempted at Endicott. In 2000 (Endicott only), planting stock on the day of planting was kept in plastic bags with moist sawdust. In 2001 (both sites), we dipped roots into a mixture of water and a starch-like substance (SoilMoist), then rolled up the plants in a wetted, reusable synthetic fabric called Kimtex. Cuttings were kept moist by carrying them in buckets of water.

Protecting plantings and some natural regeneration from browse became a high priority after finding that some new plants were simply pulled out of the ground or chewed to the soil surface within days of planting by nutria, beaver, deer, rabbits, and geese. Browse protection was accomplished by installing 2-4 foot tall chicken-wire cages or plastic tubes (solid and mesh) around plants. Some small-

\footnotetext{
${ }^{1}$ Oregon State University

${ }^{2}$ British Columbia Ministry of Forests, Lands, and Natural Resource Operations

${ }^{3}$ U.S. Geological Survey
} 
scale irrigation was conducted during the summer of 2000 with buckets. A biweekly irrigation program was employed in 2001, using a gas-powered water pump with garden hoses to water plants at each site.

A citizen science monitoring program was started in winter 2000 at Endicott and winter 2001 at Harrisburg to track plant survival and growth, as well as extent of browsing. A subset of plantings (144 at Endicott, 201 at Harrisburg) across the range of species was tagged, mapped and surveyed for elevation relative to staff gauges in the ponds. Subsequent data were collected monthly from spring through early fall in 2000 (Endicott only) and 2001(both sites) to record plant vigor and height, with the goal of comparing protected versus unprotected, and irrigated versus non-irrigated plants. Follow-up site visits were also made in November 2002 and 2004. Additionally, as a measure of drought stress, we measured pre-dawn stem water potential (plant moisture stress) with a pressure chamber on a subsample of irrigated and non-irrigated plants at Harrisburg during the 2001 growing season. Species tested were Oregon ash (Fraxinus latifolia) (7 irrigated, 6 not), ponderosa pine (Pinus ponderosa) (6 irrigated, 2 not) and black cottonwood (Populus balsamifera v. trichocarpa) (4 irrigated, 4 not, plus 7 naturally regenerated and not irrigated). These three species differ in their tolerance to drought and inundation (Burns and Honkala 1990), with Oregon ash, a facultative wetland species, having the broadest tolerance.

\section{Results and Discussion}

The Endicott site presented numerous challenges to establishing native plants: compacted, droughty soils and substrates compounded by summer drought, heavy predation by nutria and beaver, and competition from invasive non-native plant species (especially Himalayan blackberry (Rubus armeniacus) and reed canarygrass (Phalaris arundinacea)). As a result, first-year (2000) survival of plantings was only 20 percent. Sources of mortality varied by location at Endicott and across the growing season. Early in the season, when drought stress was minimal, greatest mortality among cottonwoods and willows occurred near the water's edge, where browsing by beaver and nutria was greatest. Even protected plantings succumbed to browsing when high water allowed the animals to swim above the browse cages and tubes. Unprotected ponderosa pine appeared to be defoliated by geese. In early summer, with water levels receding, mortality of willow and cottonwood shifted to higher elevations; by the end of summer, desiccation-related mortality of these species extended across all elevations in the absence of irrigation. Mortality was extremely high in areas with compacted gravelly soils. Survival was higher, regardless of species, at planting locations with more finely textured soils. Based on these observations, we improved our methods of planting, browse protection and irrigation, leading to substantially better survival of 2001 plantings at Endicott.

Endicott is an "old-style" gravel pit built near the river channel and surrounded by steep berms, limiting the amount and diversity of floodplain topography and soils. The gravel road bordering the pond further limited planting opportunities, while abundant dust generated by truck traffic coated plant leaves and probably reduced photosynthetic capacity. The results from Endicott provide a useful, extreme case scenario, in which any successes have a high probability of being repeatable in other gravel-mined areas.

At Harrisburg, we applied lessons learned at Endicott and were aided by considerably better soil conditions. Overall first-year (2001) survival was 86 percent among the monitored plants (table 1). In addition, the vigor of plants was better at Harrisburg than at Endicott, suggesting that the improved planting, irrigation, and protection techniques developed at Endicott, a particularly challenging site, were potentially effective and transferable across gravel mine sites.

Collecting data on plant moisture stress proved insightful. For example, despite better soils at Harrisburg, moisture stress of non-irrigated Oregon ash and ponderosa pine saplings still reached high 
levels (fig. 1), whereas irrigated ash and pine fared much better. Black cottonwood, generally planted near the water, seemed mostly immune to summer drought, as non-irrigated and irrigated plants alike experienced low levels of moisture stress on a par with healthy, naturally regenerated cottonwood saplings and sprouts.

\section{Summary}

Revegetating two former gravel mine sites met with mixed success. Overall survival of planted woody species was 46 percent at Endicott after four years and 57 percent at Harrisburg after three years, although survival rates varied widely among species. Oregon ash, ponderosa pine and snowberry (Symphoricarpos albus) were winners at both sites (table 1), although this may be confounded with less browsing pressure. Other species such as white alder (Alnus rhombifolia) and blue elderberry (Sambucus cerulea) performed well at one site but not the other. We expect plant desiccation and browsing to continue taking a toll on the plantings at these sites, delaying the long-term recovery of native vegetation.

Restoration efforts were successful from the perspective of community involvement, with more than 80 students, community members, Boy Scouts and others contributing over 700 hours of time on the project. In addition, through educational efforts the project reached some rural landowners and citizens.

The citizen-science monitoring component was implemented successfully but could not be sustained beyond a few years. Students formed the bulk of the monitoring team, but many of them moved out of the area within two years. After 2001, monitoring was limited to periodic site visits by the senior author, also a volunteer. The reliance on volunteers underscores the importance of a built-in mechanism or institutional support for longer-term monitoring and follow-up work. Such a mechanism, as might be found via high school or university ecology classes or through project adoption by a local environmental group, should be in place at the start of citizen-driven restoration and monitoring efforts to ensure ongoing participation.

\section{Lessons Learned}

- Irrigation is critical to ensuring survival through the first growth year in dry summer climates.

- Plants show important variation in drought tolerance, suggesting that a diversity of species will better guarantee at least partial success.

- Antecedent site conditions can result in varied outcomes even with similar methods.

- Measuring or anticipating future stressors (drought, herbivory, infertility, competing vegetation) are essential for longer term success.

- Monitoring for several years post planting is invaluable for learning about the effects of stressors on mortality and growth.

- Severely compacted substrates might benefit from soil amendments and tilling.

- Citizen science efforts can produce valuable and adaptive science, but can be short-lived without institutional structures to facilitate longer term monitoring and maintenance.

\section{References Cited}

Bayley, P. B., and Baker, C.F. 2004, Long-term monitoring results at Harrisburg, Endicott, and Truax aggregate-mined floodplain areas (Willamette River Basin, Oregon) under restoration: Oregon State University, Corvallis, Oregon. 
Burns, R.M., and Honkala, B.H., 1990, Silvics of North America-Vol. 2 Hardwoods: U.S. Department of Agriculture Handbook 654, Forest Service, Washington, DC, 877 p.

Christy, J.A., and Alverson, E. R., 2011, Historical vegetation of the Willamette Valley, Oregon, circa 1850: Northwest Science v. 85, no. 2, p. 93-107.

Sedell, J. R., and Frogatt, J. L., 1984, The importance of streamside forests to large rivers-The isolation of the Willamette River, Oregon USA from its floodplain by snagging and streamside forest removal: Internationale Vereinigung für Theoretische und Angewandte Limnologie Verhandlungen, vol. 22, p. 1828-1834. 
Table 1. Percent of monitored plants alive at the end of each growing season (irrigated and non-irrigated plants combined). ${ }^{*} N P=$ not planted.

\begin{tabular}{|c|c|c|c|c|c|c|c|c|}
\hline \multirow[t]{2}{*}{ Species } & \multirow{2}{*}{$\begin{array}{l}\text { \# of plants } \\
\text { monitored }\end{array}$} & \multicolumn{3}{|c|}{ Endicott } & \multirow{2}{*}{$\begin{array}{l}\text { \# of plants } \\
\text { monitored }\end{array}$} & \multicolumn{3}{|c|}{$\begin{array}{l}\text { Harrisburg } \\
\% \text { alive at end of season }\end{array}$} \\
\hline & & 2001 & 2002 & 2004 & & 2001 & 2002 & 2004 \\
\hline \multicolumn{9}{|l|}{ Trees } \\
\hline $\begin{array}{l}\text { Abies grandis } \\
\text { (grand fir) }\end{array}$ & 3 & 100 & 100 & 0 & 4 & 100 & 50 & 0 \\
\hline $\begin{array}{l}\text { Acer macrophyllum } \\
\text { (bigleaf maple) }\end{array}$ & 3 & 100 & 100 & 67 & 21 & 71 & 38 & 24 \\
\hline $\begin{array}{l}\text { Alnus rhombifolia } \\
\text { (white alder) }\end{array}$ & 10 & 20 & 10 & 0 & 14 & 86 & 64 & 64 \\
\hline $\begin{array}{l}\text { Fraxinus latifolia } \\
\text { (Oregon ash) }\end{array}$ & 15 & 100 & 100 & 60 & 36 & 97 & 94 & 92 \\
\hline $\begin{array}{l}\text { Pinus ponderosa } \\
\text { (ponderosa pine) }\end{array}$ & 8 & 100 & 100 & 88 & 8 & 100 & 88 & 63 \\
\hline $\begin{array}{l}\text { Populus balsamifera v. } \\
\text { tricho. (black cottonwood) }\end{array}$ & 34 & 100 & 91 & 44 & 34 & 79 & 68 & 41 \\
\hline $\begin{array}{l}\text { Quercus garryanna } \\
\text { (Oregon white oak) }\end{array}$ & $* \mathrm{NP}$ & & & & 3 & 100 & 100 & 67 \\
\hline \multicolumn{9}{|l|}{ Shrubs } \\
\hline $\begin{array}{l}\text { Cornus sericea } \\
\text { (creek dogwood) }\end{array}$ & 10 & 80 & 50 & 50 & 17 & 82 & 47 & 47 \\
\hline $\begin{array}{l}\text { Crataegus douglasii } \\
\text { (black hawthorn) }\end{array}$ & 16 & 94 & 75 & 50 & 7 & 100 & 100 & 86 \\
\hline $\begin{array}{l}\text { Oemleria cerasiformis } \\
\text { (Indian plum) }\end{array}$ & 10 & 100 & 80 & 40 & 4 & 75 & 50 & 25 \\
\hline $\begin{array}{l}\text { Physocarpus capitatus } \\
\text { (Pacific ninebark) }\end{array}$ & 10 & 70 & 0 & 0 & 11 & 64 & 27 & 27 \\
\hline $\begin{array}{l}\text { Roso pisocarpa } \\
\text { ( wild rose) }\end{array}$ & 2 & 100 & 50 & 0 & $* \mathrm{NP}$ & & & \\
\hline $\begin{array}{l}\text { Sambucus cerulea } \\
\text { (blue elderberry) }\end{array}$ & 9 & 89 & 56 & 78 & 11 & 82 & 9 & 9 \\
\hline $\begin{array}{l}\text { Salix spp. (3 species) } \\
\text { (willow) }\end{array}$ & 4 & 100 & 100 & 25 & 21 & 90 & 86 & 86 \\
\hline $\begin{array}{l}\text { Symphoricarpus albus } \\
\text { (snowberry) }\end{array}$ & 10 & 100 & 80 & 80 & 10 & 100 & 90 & 90 \\
\hline Overall & 144 & 88 & 73 & 46 & 201 & 86 & 67 & 57 \\
\hline
\end{tabular}



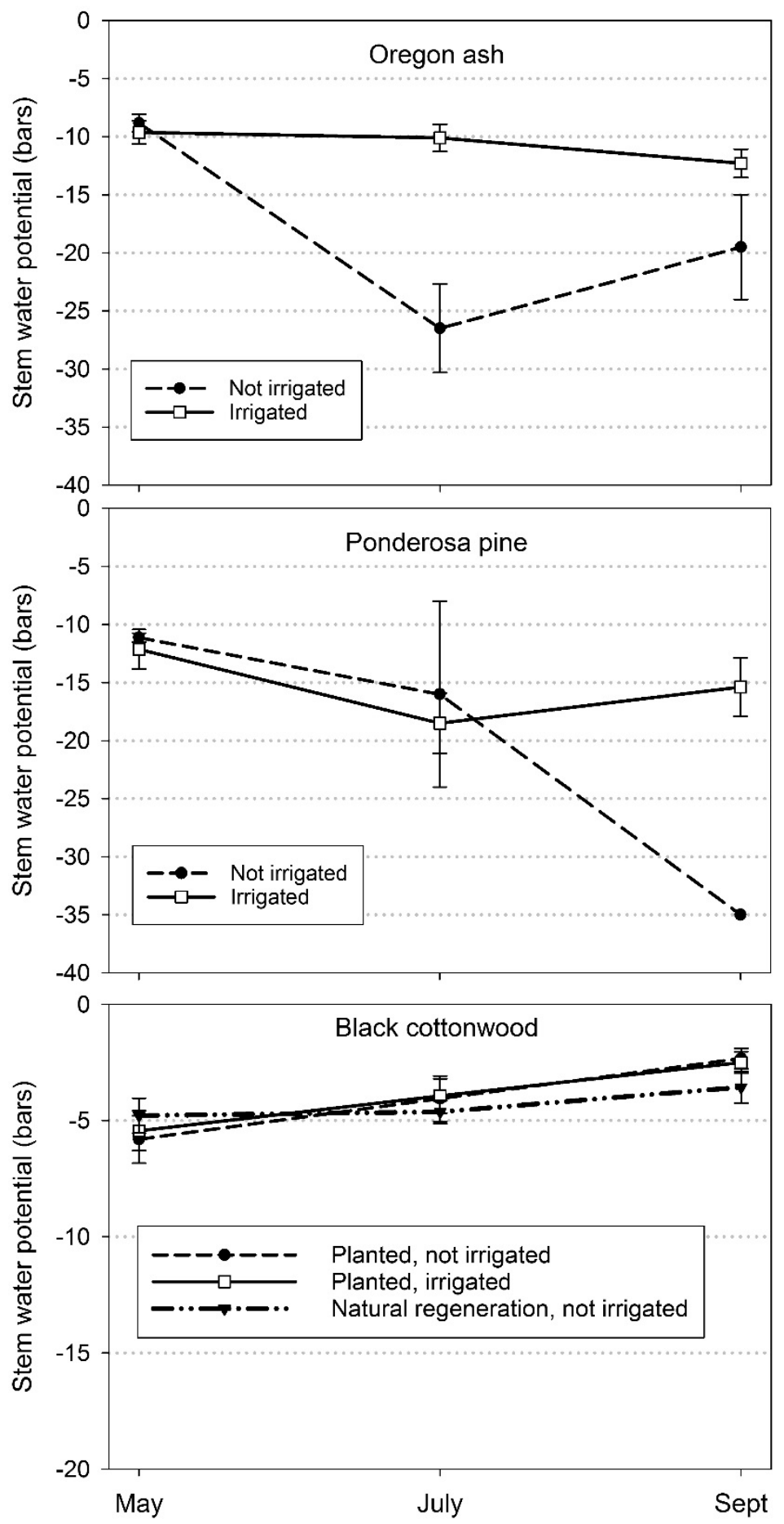

Figure 1. Mean and standard errors of pre-dawn plant moisture stress in three species during 2001 growing season at Harrisburg Pond. The severity of stress is indicated by the degree of tension in plant xylem, measured in negative atmosphere. Permanent wilting point for herbaceous plants is approximately - 15 bars. 


\section{Section VI. Results of break out group discussion and research needs ranking by workshop participants}

The results of break out group discussions and rankings of research needs by workshop participants are summarized in tables 1 and 2 respectively. Table 1 contains bulleted comments from break out groups intended to briefly highlight challenges, metrics for success, collaborative tools, and research needs related to restoration science. The ranking of research needs (table 2) represents the average values assigned to research categories (appearing on the left column of table 2) based on an assigned value from 1 (low priority) to 5 (high priority) by 21 participants who filled out the assessment. Prominent research needs for restoration site information included creating networks for storing and sharing information and identifying common metrics among sites that allow comparisons across sites. Biophysical, ecological, and life history research was also identified as a need, which would benefit all efforts associated with restoration. These included: interactions between hydrology, geomorphology, and vegetation; seed germination and early life history information for both native and nonnative species; and, physiological information regarding plant-soil-moisture relationships. A list of the workshop participants is included (table 3). 
Table 1. Compilation of break out group bulleted ideas and comments about restoration challenges, research needs and collaborative data sharing opportunities.

\begin{tabular}{|c|c|}
\hline Restoration Challenges & Measures of Success \\
\hline Finding out what differentiates success from failure & Having explicit outcomes is critical \\
\hline Specific seasonal treatments - need to be considered & $\begin{array}{l}\text { Identify a common goal(s) within an uncertain } \\
\text { frame work of climate change }\end{array}$ \\
\hline $\begin{array}{l}\text { Poor site maintenance over time (weed control, irrigation, etc.) } \\
\rightarrow 30 \text { yrs }\end{array}$ & $\begin{array}{l}\text { Define restoration within the context of } \\
\text { project limitations and the site or system }\end{array}$ \\
\hline $\begin{array}{l}\text { Fiscal year funding -- funding cycles can result in rush jobs. } \\
\text { Need to anticipate and be able to plan for longer term } \\
\text { funding/investment rather than year-to-year funding } \\
\text { uncertainty }\end{array}$ & $\begin{array}{l}\text { Putting the project in context of restoration } \\
\text { spectrum may help define expectations and } \\
\text { measurable success criteria (for example } \\
\text { lower Colorado River) }\end{array}$ \\
\hline Challenge to find time and funding for interactions and sharing & $\begin{array}{l}\text { Speak with a statistician at the beginning of a } \\
\text { project for monitoring and experimental set } \\
\text { up to enhance learning }\end{array}$ \\
\hline Continuity of resource managers and associated commitment & $\begin{array}{l}\text { Consider features versus function and process } \\
\text { when planning }\end{array}$ \\
\hline Failure to assess site & Reconciling success in "novel” systems \\
\hline Objects and restoration site are incompatible & $\begin{array}{l}\text { Social/community response, involvement, } \\
\text { usage, youth education, job creation }\end{array}$ \\
\hline Failure to pay attention to assessment & Solidifying long-term funding, endowments \\
\hline $\begin{array}{l}\text { Dollar spent in the absence of thoughtful planning and goes } \\
\text { straight to implementation (river cane and Rio Grande } \\
\text { example) }\end{array}$ & Publishing results \\
\hline $\begin{array}{l}\text { No monitoring before or after implementation to measure } \\
\text { effectiveness }\end{array}$ & $\begin{array}{l}\text { Development of team approaches increases } \\
\text { the likelihood of clear goals and objectives }\end{array}$ \\
\hline $\begin{array}{l}\text { Using plant associations that exist on a site to infer likely plants } \\
\text { for success when other species may be successful in long- } \\
\text { term }\end{array}$ & $\begin{array}{l}\text { Direct measures of habitat improvement or } \\
\text { population increase of target species }\end{array}$ \\
\hline Lack of oversight during implementation can lead to failure & \multirow{8}{*}{ This block intentionally left empty. } \\
\hline Natural variation not considered and affects outcomes & \\
\hline $\begin{array}{l}\text { Engineered solutions in natural systems may not be compatible } \\
\text { with long-term environmental changes }\end{array}$ & \\
\hline Understand long-term flow regime with respect to restoration & \\
\hline Planning for resilience - how is this done? & \\
\hline $\begin{array}{l}\text { Failure to account for sociopolitical drivers - seeking to strike a } \\
\text { balance }\end{array}$ & \\
\hline Competing or unclear/undefined goals despite future conditions & \\
\hline $\begin{array}{l}\text { Environmental flows defined for all resources in an altered } \\
\text { river system is a challenge. }\end{array}$ & \\
\hline Collaboration Tools and Data Sharing & Research Needs \\
\hline Beaver can create wetlands. Work with them! & $\begin{array}{l}\text { Proxy measure or easier test to characterize } \\
\text { soils }\end{array}$ \\
\hline Regional workshops to shape best practices & $\begin{array}{l}\text { Basic metrics that are collected universally } \\
\text { and shared }\end{array}$ \\
\hline LCC Landscape Conservation Planner Design & Vector control \& constructs \\
\hline $\begin{array}{l}\text { Experimental approaches can make science a collaborative } \\
\text { effort }\end{array}$ & $\begin{array}{l}\text { Herbivore/plant interaction studies on } \\
\text { restoration sites }\end{array}$ \\
\hline $\begin{array}{l}\text { Restoration in watersheds w/ more nature flow regimes (low } \\
\text { maintenance, regenerative, needs processes intact) }\end{array}$ & $\begin{array}{l}\text { Beaver-more information - complex support } \\
\text { in uplands are overlooked in their effect. }\end{array}$ \\
\hline Embrace novel ecosystems & Light detection and ranging (Lidar) data \\
\hline $\begin{array}{l}\text { University partners/ collaborations (for example, NAU/SEGA, } \\
\text { Springs Stewardship Institute) - }\end{array}$ & $\begin{array}{l}\text { Lack of knowledge about PSM (Plant Soil } \\
\text { Moisture) relationships for SW riparian } \\
\text { species }\end{array}$ \\
\hline
\end{tabular}




\begin{tabular}{|c|c|}
\hline Collaboration Tools and Data Sharing (continued) & Research Needs (continued) \\
\hline $\begin{array}{l}\text { Common garden long-term studies integrated with restoration } \\
\text { design }\end{array}$ & $\begin{array}{l}\text { Early life history information for non-native } \\
\text { and native species }\end{array}$ \\
\hline $\begin{array}{l}\text { Build support for monitoring approaches w/in universities, } \\
\text { municipalities, governments, local businesses }\end{array}$ & Germination requirements and processes \\
\hline $\begin{array}{l}\text { Use NEPA process and FWS Habitat Conservation Planning to } \\
\text { identify collaborators. }\end{array}$ & $\begin{array}{l}\text { Trait matrix - common association of } \\
\text { information }\end{array}$ \\
\hline Collaborate with water-rights holders & Wetland trade-off research \\
\hline $\begin{array}{l}\text { Web platform (webinars, YouTube) for information provides } \\
\text { continuity among workers in the field }\end{array}$ & $\begin{array}{l}\text { Synthetic articles (for example, } \\
\text { successes/failures \& status or restoration in } \\
\text { SW ; Sher article - measures of success \& } \\
\text { monitoring as a critical part of restoration) }\end{array}$ \\
\hline Publications & $\begin{array}{l}\text { Consideration needed in potential negative } \\
\text { impacts of restoration as part of project } \\
\text { development }\end{array}$ \\
\hline Create bilingual opportunities for exchange of ideas & $\begin{array}{l}\text { Incorporation of cost/benefit analysis for } \\
\text { reasons of success/failure }\end{array}$ \\
\hline $\begin{array}{l}\text { NGO, Foundations, Watershed network - regional technical } \\
\text { learning (Landscape Conservation Cooperatives: Tamarisk } \\
\text { Coalition; Society for Ecological Restoration; XWN (Cross } \\
\text { Watershed Network)learning (Landscape Conservation } \\
\text { Cooperatives; Tamarisk Coalition; Society for Ecological } \\
\text { Restoration; XWN (Cross Watershed Network) }\end{array}$ & $\begin{array}{l}\text { Community engagement is a strong lever of } \\
\text { success (for example, Minute 319) }\end{array}$ \\
\hline
\end{tabular}


Table 2. Average ranking of research needs for restoration at the local, river and watershed scale as identified by workshop participants ( $\mathrm{n}=21$ ) who assigned a rank of 1 (low) to 5 (high) priority research need.

\begin{tabular}{|c|c|}
\hline Revegetation/Site Restoration & Ranking \\
\hline Site Monitoring Design / Approaches & 4.3 \\
\hline Hydrological influences on vegetation & 4.2 \\
\hline Geomorphic influences on restoration & 4.1 \\
\hline Genetics of target plants & 3.9 \\
\hline Before After Control Impact Designs & 3.9 \\
\hline GIS and Remote Sensing approaches to monitoring and assessment & 3.7 \\
\hline Soil chemistry & 3.7 \\
\hline Soil biology (soil crusts, earthworms, arthropods, etc.) & 3.6 \\
\hline Regulated river flow management & 3.6 \\
\hline Riparian habitat influences on wildlife & 3.6 \\
\hline Sediment modeling & 3.5 \\
\hline Land use / riparian interactions (livestock, forestry, etc.) & 3.2 \\
\hline Nonnative vegetation removal techniques & 2.7 \\
\hline Vegetation propagation and planting techniques & 2.7 \\
\hline Basic studies of best planting techniques & 2.3 \\
\hline River Restoration & Ranking \\
\hline Climate influence on riparian restoration & 4.5 \\
\hline Flow / Habitat models for riparian plants & 4.3 \\
\hline Passive restoration approaches & 4.2 \\
\hline Effects of riparian restoration on fisheries and other aquatic life & 4.0 \\
\hline Minimum flows for riparian restoration & 4.0 \\
\hline Riparian flow guilds (groups of species with similar hydrologic response) & 4.0 \\
\hline Ecological functions of riparian plant species & 3.9 \\
\hline River Scale Monitoring & 3.9 \\
\hline Riparian / Fisheries interactions & 3.9 \\
\hline Hydrological influences on geomorphology & 3.5 \\
\hline Studies of riparian wildlife needs & 3.5 \\
\hline Restoration of Water Quality & 3.4 \\
\hline Hydrological Modeling & 3.2 \\
\hline Geomorphic mapping & 3.1 \\
\hline Fish passage, Culvert removal, etc. & 2.5 \\
\hline Watershed Restoration & Ranking \\
\hline Means for storing and displaying information & 4.3 \\
\hline Measuring ecological functions across multiple sites & 4.3 \\
\hline Restoration of sediment flows through watersheds & 4.1 \\
\hline Paired watershed studies & 3.9 \\
\hline Landscape ecology / remote sensing & 3.9 \\
\hline Collaborative approaches to watershed restoration & 3.8 \\
\hline Restoration of hydrological flows through watersheds & 3.8 \\
\hline Metapopulation dynamics & 3.6 \\
\hline Citizen Science & 3.4 \\
\hline
\end{tabular}


Table 3. List of workshop attendees and their affiliations. Name and affiliation Name and affiliation Name and affiliation

\begin{tabular}{|c|c|c|}
\hline Jan Balsom, National Park Service & Bennett Jackson, Haulapai Tribe & $\begin{array}{l}\text { Aimee Roberson, U.S. Fish and } \\
\text { Wildlife Service, Desert LCC }\end{array}$ \\
\hline $\begin{array}{l}\text { Mary Barger, Bureau of } \\
\text { Reclamation }\end{array}$ & $\begin{array}{l}\text { Vineetha Kartha, Arizona } \\
\text { Department of Water Resources }\end{array}$ & $\begin{array}{l}\text { Lavina Sanchez, Yavapai-Apache } \\
\text { Nation }\end{array}$ \\
\hline Jeff Bennett, National Park Service & $\begin{array}{l}\text { David Larson, National Park } \\
\text { Service }\end{array}$ & $\begin{array}{l}\text { Daniel Sarr, U.S. Geological } \\
\text { Survey }\end{array}$ \\
\hline $\begin{array}{l}\text { Daniel Boughter, National Park } \\
\text { Service }\end{array}$ & $\begin{array}{l}\text { Dave Lewis, Yavapai-Apache } \\
\text { Nation }\end{array}$ & Ed Schenk, National Park Service \\
\hline Peter Bungart, Haulapai Tribe & $\begin{array}{l}\text { Daniel Martinez, Northern Arizona } \\
\text { University }\end{array}$ & $\begin{array}{l}\text { Jack Schmidt, Utah State } \\
\text { University }\end{array}$ \\
\hline $\begin{array}{l}\text { Todd Chaudhry, National Park } \\
\text { Service }\end{array}$ & $\begin{array}{l}\text { Melissa McMaster, Mariposa } \\
\text { Consulting }\end{array}$ & $\begin{array}{l}\text { Anna Schrenk, Friends of Verde } \\
\text { River Greenway }\end{array}$ \\
\hline $\begin{array}{l}\text { Marianne Crawford, Bureau of } \\
\text { Reclamation }\end{array}$ & $\begin{array}{l}\text { Clay Nelson, U.S. Geological } \\
\text { Survey }\end{array}$ & $\begin{array}{l}\text { Jen Schuetz, Bosque Ecosystem } \\
\text { Monitoring Program }\end{array}$ \\
\hline $\begin{array}{l}\text { David Dean, U.S. Geological } \\
\text { Survey }\end{array}$ & $\begin{array}{l}\text { David M. Newlin, Little Colorado } \\
\text { River Plateau RCDA }\end{array}$ & $\begin{array}{l}\text { Peter Skidmore, Walton Family } \\
\text { Foundation }\end{array}$ \\
\hline $\begin{array}{l}\text { Jason Eckberg, Southern Nevada } \\
\text { Water Authority }\end{array}$ & $\begin{array}{l}\text { Frances O’Donnell, Northern } \\
\text { Arizona University }\end{array}$ & $\begin{array}{l}\text { Abe Springer, Northern Arizona } \\
\text { University }\end{array}$ \\
\hline $\begin{array}{l}\text { Helen Fairley, U.S. Geological } \\
\text { Survey }\end{array}$ & $\begin{array}{l}\text { Olvera, Andrew, Yavapai-Apache } \\
\text { Nation }\end{array}$ & $\begin{array}{l}\text { Vivian Stevens, Yavapai-Apache } \\
\text { Nation }\end{array}$ \\
\hline $\begin{array}{l}\text { Sue Fearon, Escalante River } \\
\text { Watershed Partnership }\end{array}$ & $\begin{array}{l}\text { Emily Omana Smith, National Park } \\
\text { Service }\end{array}$ & $\begin{array}{l}\text { Shaun Stone, Gila Watershed } \\
\text { Partnership of Arizona }\end{array}$ \\
\hline $\begin{array}{l}\text { Will Flatly, Northern Arizona } \\
\text { University }\end{array}$ & $\begin{array}{l}\text { Daniel Oppenheimer, Tamarisk } \\
\text { Coalition }\end{array}$ & Nita Tallent, National Park Service \\
\hline $\begin{array}{l}\text { Jason Fullmer, Yavapai-Apache } \\
\text { Nation }\end{array}$ & Bruce Orr, Stillwater Science & $\begin{array}{l}\text { Heidi Trathnigg, Fred Phillips } \\
\text { Consulting }\end{array}$ \\
\hline Matt Grabau, GeoSystems & $\begin{array}{l}\text { Emily Palmquist, U.S. Geological } \\
\text { Survey }\end{array}$ & $\begin{array}{l}\text { Scott Vanderkooi, U.S. Geological } \\
\text { Survey }\end{array}$ \\
\hline $\begin{array}{l}\text { Paul Grams, U.S. Geological } \\
\text { Survey }\end{array}$ & $\begin{array}{l}\text { Barbara Ralston, U.S. Geological } \\
\text { Survey }\end{array}$ & $\begin{array}{l}\text { Tom Whitham, Northern Arizona } \\
\text { University }\end{array}$ \\
\hline $\begin{array}{l}\text { Eric Head, Northern Arizona } \\
\text { University }\end{array}$ & $\begin{array}{l}\text { Chris Rasmussen, EcoMainstem } \\
\text { Contracting }\end{array}$ & - \\
\hline $\begin{array}{l}\text { Michael Ingraldi, Arizona Game } \\
\text { and Fish Department }\end{array}$ & $\begin{array}{l}\text { Lindsay Reynolds, Colorado State } \\
\text { University }\end{array}$ & - \\
\hline
\end{tabular}


https://doi.org/10.3133/20171091 